

\section{More Civil Justice? The impact of the Woolf reforms on pre-action behaviour Research Study 43}

Tamara Goriely, Institute of Advanced Legal Studies

Richard Moorhead, Cardiff Law School

Pamela Abrams, University of Westminster

Commissioned by The Law Society and Civil Justice Council 2002 


\section{Acknowledgements}

The authors would like to acknowledge the tremendous help of our colleague Susan Guilfoyle with this research. We are very grateful to her for her hard work and support and for her boundless energy and enthusiasm for the project. We wish her well in her new career as a solicitor. We would also like to extend our gratitude to Morag Russell for her help and energy in collecting information from files.

Thanks are due to the many people who provided us with advice, assistance and information, including: Suzanne Burn, Clinical Disputes Forum; Margaret Dangoor, ALARM; Alistair Kinley, Association of British Insurers; Neil Mackay, Legal Services Commission; Annette Morris, APIL; Claire Morgan, Law Society; David Ormondy, University of Warwick; Andrew Parker, FOIL; Pascoe Pleasence, Legal Services Research Centre; Arnold Simanowitz, AVMA; Steve Walker, NHSLA; and Tim Willcock, Lloyd's Underwriters' Non-Marine Association

The Steering Group provided much needed advice and support through the various stages of the research.

Finally, we would also like to express our gratitude to the practitioners, insurers and claims managers who took part in the study and who gave up their valuable time and office space to assist us with interviews and file reviews.

All rights reserved. No part of this publication may be reproduced in any material form, whether by photocopying, scanning, downloading onto computer or otherwise without the written permission of the Law Society and the Civil Justice Council except in accordance with the provisions of the Copyright, Designs and Patents Act 1988. Applications should be addressed in the first instance, in writing, to the Publications Department of the Law Society. Any unauthorised or restricted act in relation to this publication may result in civil proceedings and/or criminal prosecution.

(C) The Law Society and Civil Justice Council 2002

ISBN 1853288365

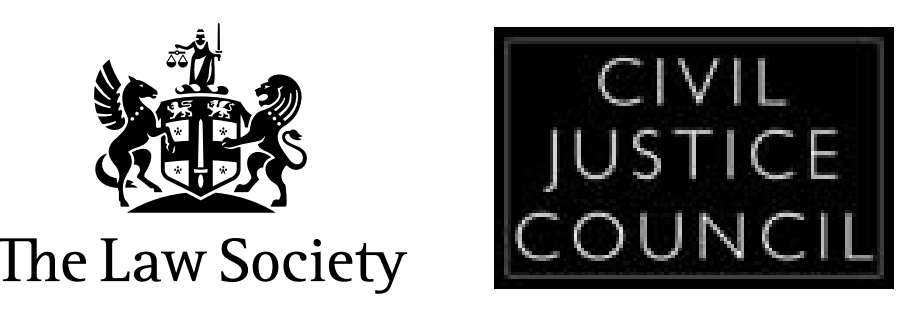




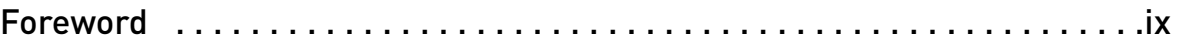

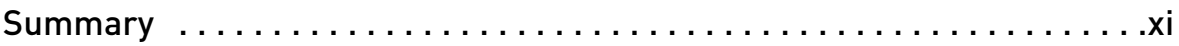

Section 1. Background $\ldots \ldots \ldots \ldots \ldots \ldots \ldots \ldots \ldots$

Chapter 1.1 Background $\ldots \ldots \ldots \ldots \ldots \ldots \ldots \ldots \ldots \ldots \ldots$

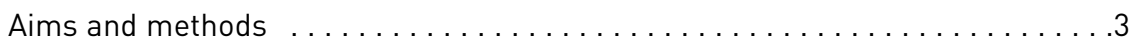

Pre-action protocols $\ldots \ldots \ldots \ldots \ldots \ldots \ldots \ldots \ldots \ldots \ldots \ldots \ldots \ldots \ldots \ldots \ldots \ldots$

Other changes in the litigation market $\ldots \ldots \ldots \ldots \ldots \ldots \ldots \ldots \ldots \ldots \ldots \ldots \ldots$

Previous research evaluating the Woolf reforms $\ldots \ldots \ldots \ldots \ldots \ldots \ldots . \ldots$

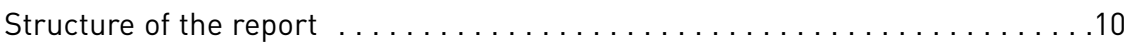

Section 2. Personal Injury Work $\ldots \ldots \ldots \ldots \ldots \ldots \ldots \ldots$

Chapter 2.1 Personal injury work: introduction $\ldots \ldots \ldots \ldots \ldots \ldots \ldots$

Other relevant literature . . . . . . . . . . . . . . . . . . . . . . . 14

Methods .............................................. 14

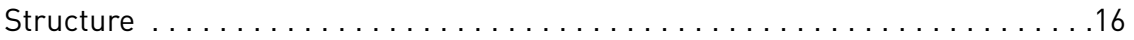

Chapter 2.2 The context for personal injury work $\ldots \ldots \ldots \ldots \ldots \ldots 17$

Developments affecting claimants: replacing legal aid with CFAs $\ldots \ldots \ldots 18$

The rise of claims intermediaries . . . . . . . . . . . . . . . . 21

Adapting to CFAs . . . . . . . . . . . . . . . . . . . . . . . .23

Making success fees recoverable . . . . . . . . . . . . . . . . . 29

Developments within the insurance industry $\ldots \ldots \ldots \ldots \ldots \ldots \ldots \ldots$

Summary . . . . . . . . . . . . . . . . . . . . . . . . 37

Chapter 2.3 The Woolf reforms: overall views and their impact on

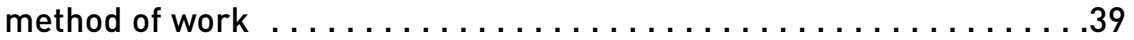

Overall views ......................................

The impact on claimant solicitors' methods of work . . . . . . . . . . . . 47

The impact on insurers' methods of work ..................... 58

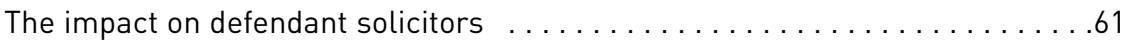

Summary .........................................62

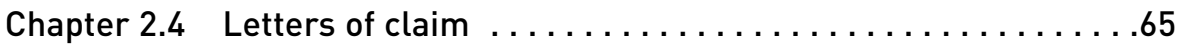

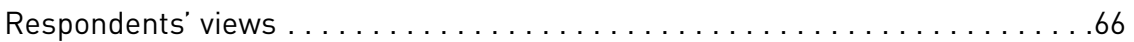

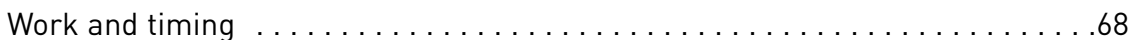

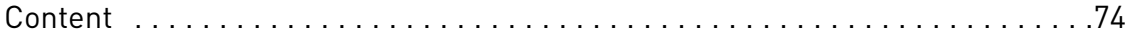

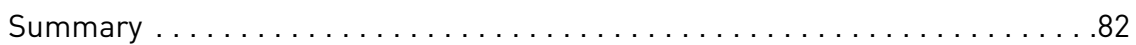


Chapter 2.5 Responding to the claim: acknowledgement,

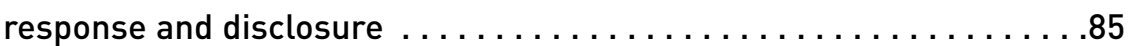

Acknowledgement ...................................... . . . . . . .

The response on liability: meeting the time limit $\ldots \ldots \ldots \ldots \ldots \ldots \ldots .88$

The response on liability: content . . . . . . . . . . . . . . . . . .94

Disclosure ..........................................99

A presumption of liability? . . . . . . . . . . . . . . . . . . . 102

Summary ..............................................104

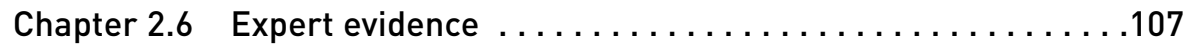

Medical evidence under the pre-action protocol .................108

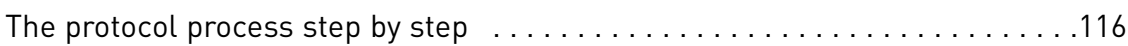

Delay and cost .............................................

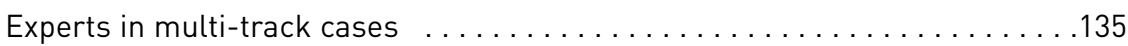

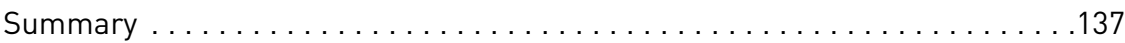

Chapter 2.7 Settlement . . . . . . . . . . . . . . . . . . . . . . . 141

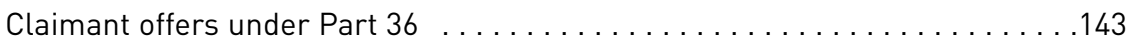

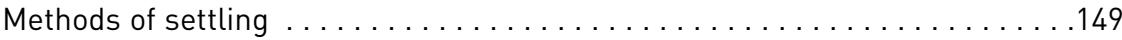

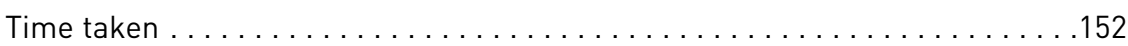

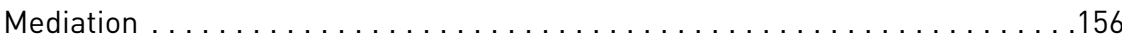

More settlements? . . . . . . . . . . . . . . . . . . . . . . 158

If the case fails to settle: supporting subsequent litigation ............160

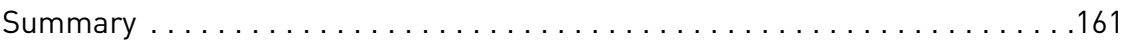

Chapter 2.8 Meeting the aims: is the process less adversarial, quicker or cheapter? . . . . . . . . . . . . . . . . . . 165

Is the culture less adversarial? .......................... 165

Speed ............................................. 170

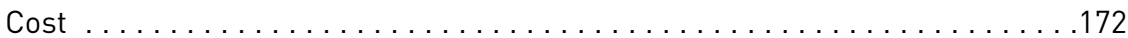

Summary ....................................... 182

Section 3. Clincial Negligence Work .............185

Chapter 3.1 Clinical negligence work: introduction and context . . . . 187

Reforming the NHS . . . . . . . . . . . . . . . . . . . . . . .

Defending clinical negligence litigation ......................189

Developments affecting claimants ........................... 191

Methods ................................................193

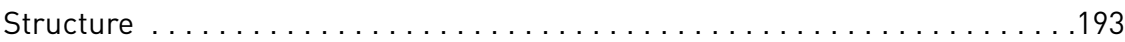


Chapter 3.2 The Woolf reforms: overall views and their impact on method of work ................................ 195

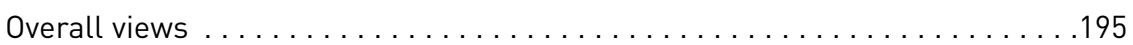

Views on cost ...................................... 198

The impact on methods of work .........................203

Pro-active claims management within trusts $\ldots \ldots \ldots \ldots \ldots \ldots \ldots \ldots . \ldots \ldots$

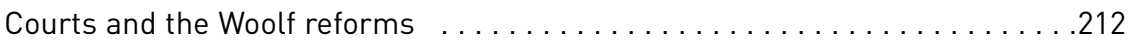

Summary ...........................................214

Chapter 3.3 General aims of the clinical disputes protocol $\ldots \ldots \ldots .217$

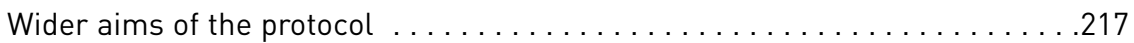

Interaction with the complaints system ......................218

Relationships between claimant solicitors and trusts ..............222

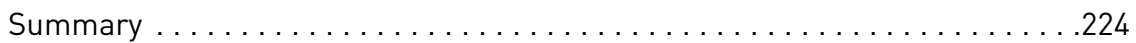

Chapter 3.4 Formulating and responding to the claim $\ldots \ldots \ldots \ldots 225$

Requests for medical records . . . . . . . . . . . . . . . . . . . 225

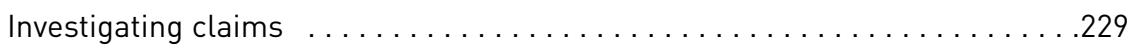

Letters of claim .....................................231

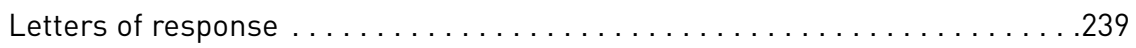

Summary ........................................247

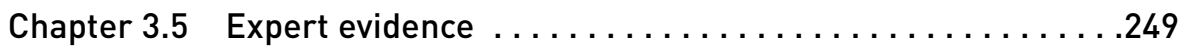

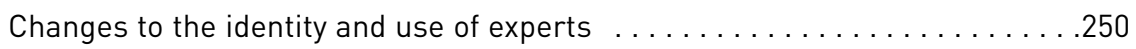

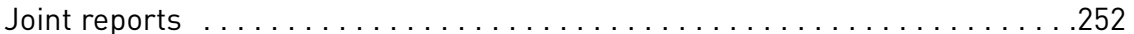

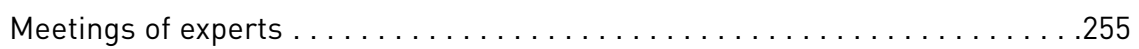

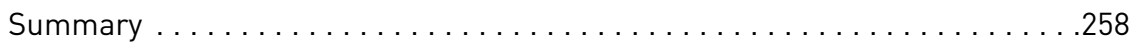

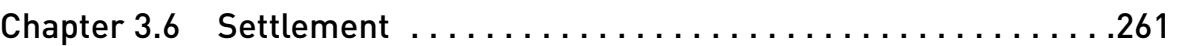

A shift to a settlement culture? . . . . . . . . . . . . . . . . . . . . . 261

Claimant Part 36 offers ....................................... 265

Defendant Part 36 offers and payments .....................269

Mediation . . . . . . . . . . . . . . . . . . . . . . . . . . . . . . . . . . . . . 272

Summary .............................................

Chapter 3.7 Clinical negligence work: do the reforms

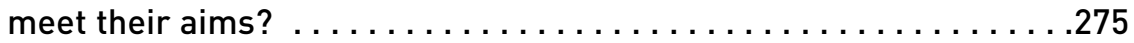

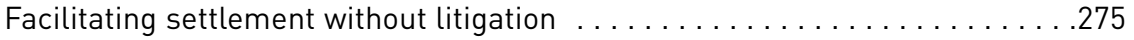

Is the culture more open? . . . . . . . . . . . . . . . . . . . . 276

Exchange of early and full information ......................... 277 
If the case fails to settle: supporting subsequent litigation $\ldots \ldots \ldots \ldots \ldots 278$

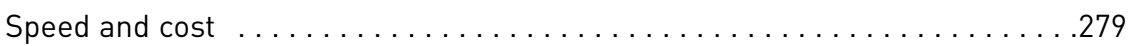

Overall . . . . . . . . . . . . . . . . . . . . . . . . . . . . . 279

\section{Section 4. Housing Disrepair Work $\ldots \ldots \ldots \ldots \ldots \ldots .281$}

Chapter 4.1 Housing disrepair work: introduction . . . . . . . . . 283

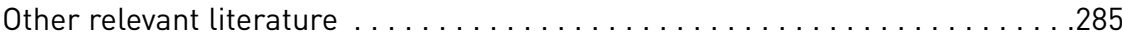

Methods . . . . . . . . . . . . . . . . . . . . . . . . .

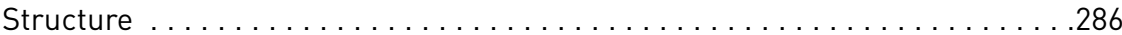

Chapter 4.2 The context for housing disrepair . . . . . . . . . . . 287

Fast track or multi-track? . . . . . . . . . . . . . . . . . . . 287

The funding context $\ldots \ldots \ldots \ldots \ldots \ldots \ldots \ldots \ldots \ldots \ldots \ldots \ldots \ldots$. 288

Landlords' scepticism of tenants and their lawyers . . . . . . . . . . 293

Towards a protocol . . . . . . . . . . . . . . . . . . . . . . . . . . 296

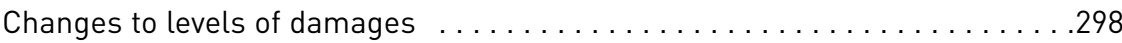

Other changes . . . . . . . . . . . . . . . . . . . . . . . . . . . . . 300

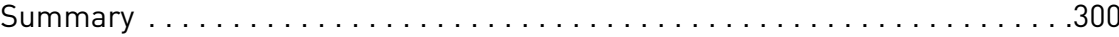

Chapter 4.3 The Woolf reforms: overall views and their impact on

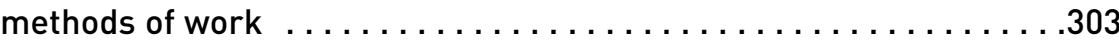

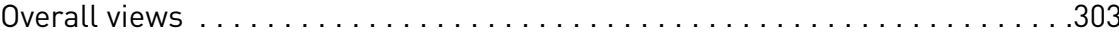

Speed ... . . . . . . . . . . . . . . . . . . . . . . . . . . . . . . . . .

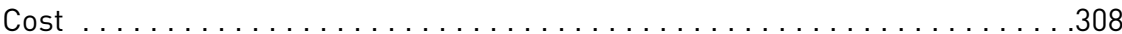

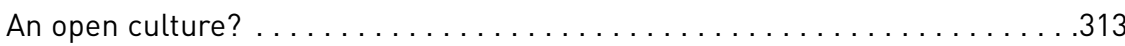

The impact on methods of work . . . . . . . . . . . . . . . . . . . 317

Negatives . . . . . . . . . . . . . . . . . . . . . . . . . 321

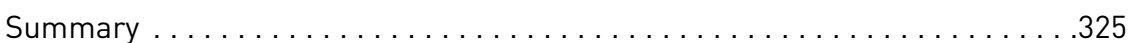

Chapter 4.4 Formulating and responding to the claim $\ldots \ldots \ldots \ldots . \ldots 327$

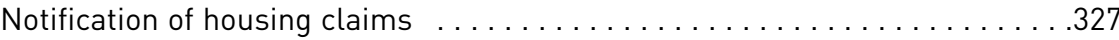

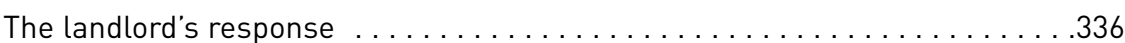

Seeking the housing file $\ldots \ldots \ldots \ldots \ldots \ldots \ldots \ldots \ldots \ldots \ldots \ldots \ldots \ldots \ldots \ldots$

Summary . . . . . . . . . . . . . . . . . . . . . . . . . . 345

Chapter 4.5 Expert evidence $\ldots \ldots \ldots \ldots \ldots \ldots \ldots \ldots \ldots \ldots$. . . . . . . . . . . .

Single joint experts? . . . . . . . . . . . . . . . . . . . . . . .

Changes in the quality of reports . . . . . . . . . . . . . . . . . . 354

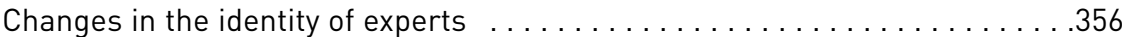

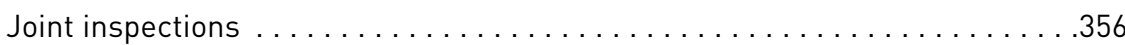

Summary . . . . . . . . . . . . . . . . . . . . . . . . . . . . . . . . 357 


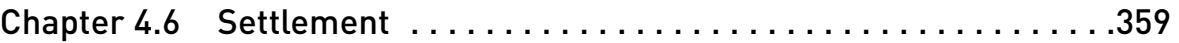

Attitude to settlement and the economics of settlement . . . . . . . . 360

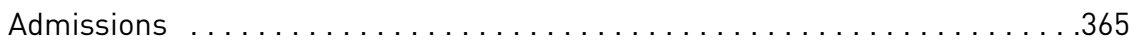

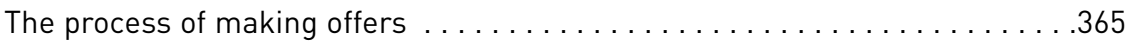

Part 36 offers . . . . . . . . . . . . . . . . . . . . . . 367

Mediation . . . . . . . . . . . . . . . . . . . . . . . . . . . . . . . . . . . . . 369

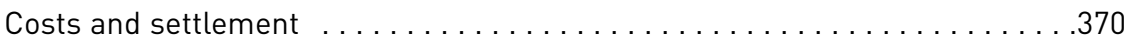

Summary . . . . . . . . . . . . . . . . . . . . . . . . . . . . . . . . . . . . 371

Chapter 4.7 Housing disrepair work: do the reforms

meet their aims? . . . . . . . . . . . . . . . . . . . . . . . . . 373

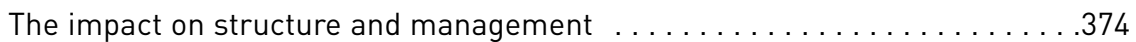

Costs: reasonable, predictable and proportionate? . . . . . . . . . . 374

Changes in information and culture . . . . . . . . . . . . . . . . 375

Problems with the courts . . . . . . . . . . . . . . . . . . . . . . . . 375

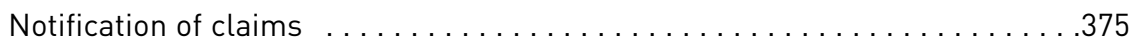

Disclosure . . . . . . . . . . . . . . . . . . . . . . . . . . . . . . . . . . . . . . 375

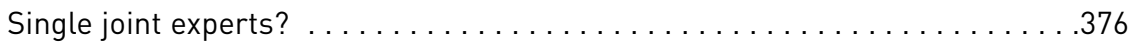

Speed . . . . . . . . . . . . . . . . . . . . . . . . . . . . . . . . . . . . . . 377

Problems with the draft protocol $\ldots \ldots \ldots \ldots \ldots \ldots \ldots \ldots \ldots \ldots \ldots \ldots \ldots$

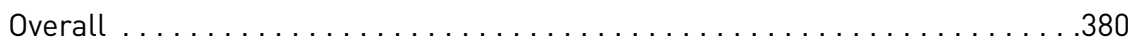

Section 5. Conclusion ......................383

Chapter 5.1 Conclusion: areas for review $\ldots \ldots \ldots \ldots \ldots \ldots \ldots \ldots$

Reviewing Part 36: penalties attached to claimant offers . . . . . . . . . . 385

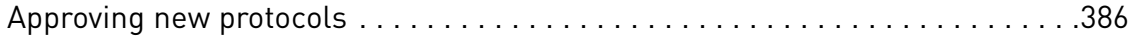

The Personal Injury Pre-action Protocol . . . . . . . . . . . . . . . 386

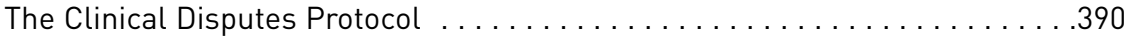

Housing Disrepair Pre-Action Protocol . . . . . . . . . . . . . . . . . . . 392

Costs . . . . . . . . . . . . . . . . . . . . . . . . . . . . . . . . . . 394

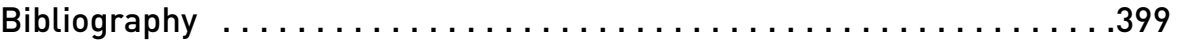

Appendix 1 Personal injury: methodology $\ldots \ldots \ldots \ldots \ldots \ldots \ldots .403$

Appendix 2 Clinical negligence: methodology . . . . . . . . . . . . . .409

Appendix 3 Housing disrepair: methodology $\ldots \ldots \ldots \ldots \ldots \ldots$

Footnotes . . . . . . . . . . . . . . . . . . . . . . . . . . . . .417 
Research Study 43 More Civil Justice? The impact of the Woolf reforms on pre-action behaviour 


\section{Foreword}

This research was commissioned jointly by the Law Society and the Civil Justice Council and is the first substantive research to be carried out on the effect of the Woolf reforms, implemented on 26th April 1999. The study is intended to assess the impact of the Woolf reforms on parties' pre-action behaviour in civil cases. It concentrates on three areas of work; personal injury, clinical negligence and housing claims. Two of these areas (personal injury and clinical negligence) have a pre-action protocol in place while the third area (housing) has no pre-action protocol at the present time, although one is in the process of being developed.

The research was conducted by:

Tamara Goriely, a Senior Research Fellow at the Institute of Advanced Legal Studies (IALS) and a qualified barrister. She has over 15 years experience of research into legal services and the courts, using both qualitative and quantitative techniques.

Pamela Abrams, a Principal Lecturer at the University of Westminster School of Law, a member of the Bar and a qualified solicitor. She has substantial experience as a qualitative researcher. She teaches personal injury and clinical negligence litigation on the Legal Practice Course.

Richard Moorhead, Senior Research Fellow at Cardiff Law School and a qualified solicitor. He has over ten years experience as a socio-legal researcher specialising in work on legal services and legal aid.

The project was overseen by a project steering group made up of the following members:

Robert Musgrove, Private Secretary to the Master of the Rolls and joint project manager

Anna Rowland, Policy Adviser to the Law Society on Civil Litigation and joint project manager

District Judge Dabezies, Civil Justice Council

Vicki Chapman, Civil Justice Council

Judith Sidaway, Head of Strategic Planning Unit, the Law Society

The project steering group and research team would like to thank all those who cooperated with the research project, by providing information and generously committing their time for interviews with the researchers, and for their help with producing this research. 
Research Study 43 More Civil Justice? The impact of the Woolf reforms on pre-action behaviour 


\section{Summary}

\section{Introduction}

In April 1999, wide-ranging reforms were introduced into the civil courts of England and Wales. New Civil Procedure Rules (CPR) were designed to cure the ills identified by Lord Woolf in his review of the civil justice system particularly the problems of cost, delay and complexity brought about by a culture of excessive adversarialism. At the same time, interest groups were encouraged to negotiate among themselves to produce 'pre-action protocols' on how lawyers should exchange information before starting formal litigation through the courts.

This study, conducted two years after the reforms were introduced, focuses on the way that representatives behave before they litigate. It does so in three specific areas of work: personal injury, clinical negligence and housing disrepair. We were keen to assess the effect of the personal injury and clinical negligence pre-action protocols and to consider the 'shadow' that the new court rules cast over inter-party bargaining.

The research is mainly qualitative. We spoke in depth to 54 lawyers, insurers and claims managers, of whom 30 specialised in personal injury work, 12 specialised in clinical negligence, and 12 specialised in housing disrepair. We asked them what they thought of the reforms, what impact the reforms had had on their practices, and how they responded to the various rules. We were particularly interested to see whether they thought that the reforms had resulted in a less adversarial 'culture of litigation', which put greater emphasis on settlement and co-operation. In the case of personal injury work, we were able to supplement the interviews with a study of files which compared around 150 claimant solicitor files concluded before April 1999 ('pre-Woolf') with around 150 opened by the same firms after April 1999 ('post-Woolf') and closed by the time of our study. Given that fieldwork took place within two years of implementation, the study inevitably focused on small, quickly resolved cases. 


\section{Themes}

Several general themes emerge from the study. The first relates to greater specialisation. In all three markets, claimant work was now concentrated in fewer, more specialist solicitor firms. For housing and clinical negligence work, this was mainly the result of Legal Services Commission policy, which has restricted legal aid funding to those firms which are able to demonstrate specialist expertise. For personal injury work, 'dabblers' were being discouraged by the pressures of the market. Defendant work was also more concentrated as insurers merged and as they and the National Health Service Litigation Authority reduced their own panels of solicitors.

Greater specialisation has been accompanied by greater particularisation, with different areas of work following different procedures. Personal injury and clinical negligence now effectively have their own pre-action 'codes', as set out in separate protocols, and the same is envisaged for housing disrepair. There are also considerable variations in the use of experts. Part 35 of the Civil Procedure Rules allows for both individual and joint experts, but the personal injury protocol effectively adds a third possibility, 'agreed experts', who exist only for personal injury work.

The next theme is the importance of context. Procedural rules rarely change cultures on their own. The possibilities for cultural change are greatest when reforms work with other structural and economic transformations. The court reforms have been most successful where they have worked alongside legal aid and managerial changes which also emphasise early focus and a pragmatic approach to settlement. We have therefore attempted to place the Woolf reforms in the context of these other developments.

A general finding from this study is that litigators like clear structures. They want timetables and example letters, provided that both can be adapted where necessary. Thus, in general, the protocols have been well received. Personal injury litigators appreciated the new-style letter before action and liked having a deadline for the response. Clinical negligence specialists spoke well of the standard form for pre-action discovery and thought the 40-day compliance period worked well. That said, in all three areas there was an undertow of criticism: opponents failed to comply, or replied late. It is also crucial that deadlines are realistic. For example, interviewees raised doubts about the feasibility of the proposed deadlines contained in the draft housing disrepair protocol. 
Finally, the study shows how intractable is the problem of cost. Although the reforms are well liked, and may have led to perceived 'soft' improvements in, for example, the level of co-operation and settlement, it is much more difficult to make litigation cheaper.

Here we summarise the main findings. We start by looking at overall views, and then attempt to place these in the context of other changes. We ask, in particular, whether the reforms have contributed to alterations in organisational structures and methods of work. We then look at the main impact of the protocols in formulating and responding to claims (through, for example, letters of claim and disclosure); at expert evidence; and at settlement. We conclude with an indication of views on speed and cost.

\section{Overall views}

Most practitioners regarded the Woolf reforms as a success. The reforms were liked for providing a clearer structure, greater openness and making settlements easier to achieve. Claimant offers under Part 36 of the Civil Procedure Rules were singled out for praise; claimants saw them as a useful way of obtaining a response from the defendant, while defendants appreciated them for setting an upper limit to the bargaining range. Those involved in personal injury and clinical negligence work also felt positive about the protocols. By establishing clear ground rules on how claims should be formulated and responded to, protocols were thought to focus minds on the key issues at an early stage and encourage greater openness. This smoothed the way to settlement. Interestingly, housing practitioners reported similar changes even though there was no protocol.

Most people thought that the dispute culture was now more open, with improvements in the relationship between, for example, personal injury claimant solicitors and insurers, and between clinical negligence claimant solicitors and claims managers working for NHS trusts. Housing practitioners reported sometimes quite dramatic changes in approach to disrepair claims. However, the picture was qualified. Often old antagonism proved difficult to cast off, with respondents frequently criticising their counterparts for failing to adapt to the new culture. Many respondents reported that change had been patchy. Some litigants, especially specialists, had adapted. Others maintained pre-Woolf attitudes and approaches. 
There were four main areas of criticism. The first was the lack of sanctions on those who failed to act reasonably in their pre-action negotiations. Personal injury claimant solicitors were particularly concerned about the perceived lack of sanctions when defendant solicitors failed to comply with the preaction protocol. Other groups also wanted clear sanctions on opponents' (but not their own) poor practice.

Secondly, expert evidence is a subject that continues to provoke controversy. Many solicitors continue to believe that they should 'own' their experts and they resented moves towards joint experts. This gave rise to disputes over, for example, the status of agreed experts under the personal injury protocol and joint reports on quantum in clinical negligence work. Local authority landlords were particularly critical of single joint surveyor reports, wanting to maintain control of the repair process (and, to a degree, the litigation) through their own in-house surveyors.

Thirdly, although case management was not explored in any depth, interviewees frequently highlighted perceived failings within the courts. This was particularly true of those involved in clinical negligence litigation, which is heavily court based, but similar points were repeated by those involved in housing disrepair and, to a lesser extent, personal injury litigation. Respondents criticised the courts for inefficiency and delay, suggesting that some courts were unable to list applications quickly enough for procedural timetables to have much bite. Case management was far more positively received in London than outside, where there were problems with providing experienced judges and apparently inconsistent decisions.

Finally, defendants complained that the Woolf reforms had failed to reduce the cost of litigation. This criticism was made most frequently by personal injury liability insurers, though landlord lawyers also complained that the costs of housing claims had not reduced sufficiently and remained disproportionate to the scale of disrepair.

\section{Housing disrepair and the lack of a protocol}

Disrepair litigation is characterised by considerable mistrust and some hostility. As local authority staff struggle to maintain their housing stock in the face of scarce resources, they perceived much disrepair litigation as illegitimate. Many blamed 'sharp' lawyers for stirring up litigation, often encouraging 'feckless' tenants to jump the queue, through the help of 'biased' courts. This mistrust has hampered efforts at reform. Although Lord Woolf saw a particular need for a pre-action protocol for disrepair claims land made 
specific suggestions for what it should contain), landlord and tenant representatives found it difficult to reach agreement on its contents. At the time of this study (2001), no such protocol had been introduced, although a draft had been subject to consultation and a final version is expected in $2002 .{ }^{1}$

Given the lack of an agreed protocol, and the apparent culture of mistrust, it is encouraging that most respondents thought the Woolf reforms had improved pre-action negotiations in housing disrepair cases. Many interviewees described how, before 1999, disrepair litigation was characterised by neglect and delay. The parties could sleep-walk through the procedural steps until just before trial, without focusing on the substantive issues. The fast-track timetable means they can no longer do this. Cases need to be readied for issue and progress to trial. Some landlord lawyers had responded by proposing their own protocols to tenant firms, promising to respond within three or four months if the tenant agreed to postpone litigation.

Thus, as with personal injury and clinical negligence, the overall picture was positive. Most housing lawyers thought that cases were settling more quickly, often without litigation, and at lower cost. This was matched by a perceived improvement in the way the parties exchanged information and engaged in resolving claims. It should be stressed, however, that improvements were not uniform: tenant lawyers complained that some landlord representatives continued to ignore correspondence, failed to disclose housing files and forced them into making unnecessary applications. The introduction of a proper protocol may improve practice.

\section{More protocols?}

Despite the overwhelming support for protocols, solicitors and insurers can only handle so many. When we asked personal injury practitioners whether they supported new, specialist protocols they were extremely wary. It was felt that the existing personal injury protocol was easy to adapt, and additional protocols would bring unwarranted complexity. There was little awareness of the Motor Accident Solicitors Society's attempt to introduce a road traffic accident protocol. 


\section{Woolf within a context of funding and organisational change}

The reforms need to be understood in the context of the funding and organisational developments affecting different forms of litigation. The research suggests that court reforms work best when they work with other changes, to produce transformations in culture and approach that reach beyond the details of the specific rule. Here, we look at the three areas of work studied to ask how the Woolf reforms have tied in with other changes in organisational structures and methods of work. We consider each of the main groups in turn before discussing the implications for barristers.

\section{Personal injury: changes within the insurance industry}

The last five years have seen the insurance industry go through several high profile mergers and take overs, out of which eight or so giant insurers have emerged to dominate the market. This has led to the development of fewer, larger, claims centres. Increasingly, centres specialise in an area of work and cover the whole of England and Wales from a single office. The telephone has increasingly been used to replace post (too slow) and meetings (too expensive). Meanwhile, insurers have invested heavily in information technology. Sophisticated computer systems prompt action and monitor staff performance.

Insurers said they had also changed their philosophy. A study from the 1980s argued that the insurance industry used delay as a negotiating weapon, to discourage claimants and induce lower settlements (Genn 1987). Insurance managers stressed that this was no longer the case. Instead, they emphasised the importance of settling cases quickly, pointing out that the cost of claims increased faster than their return on investment. A quick claim was believed to be a cheap claim, saving both solicitor costs and increases in damages. Claims handling staff felt under increasing pressure to 'get claims sorted'. Instead of waiting for the claimant to make the next move, they would chase on progress.

These developments were felt to have both positive and negative elements. Claimant solicitors agreed that settlements could be easier to obtain, but they also accused insurers of taking cost cuts too far, by reducing both the number and level of staff to an unacceptable extent. Meanwhile, claims handlers appreciated the greater efficiency, while expressing concern about stress, the heavy level of monitoring, and loss of discretion. 
These changes preceded the 1999 reforms, but insurers felt that the reforms had consolidated and focused the process in three ways. First, several insurers reported undertaking major reviews of their processes in the run-up to the implementation of Woolf's reforms. Although reviews might have taken place in any event, Woolf ensured that they attracted greater resources. Secondly, the most immediate effect was that firms added more dates to their computer systems. This has led to greater standardisation: systems now include more occasions on which the claims handler is prompted to consider the file and the prompts are set in a more structured way. There is also greater supervision to see whether deadlines are met. Thirdly, the reforms made it easier for insurers to insist that policyholders and brokers complied with protocol deadlines. Claims handlers reported that after some initial teething problems they had adapted to the new systems fairly easily. They fitted closely with existing trends.

\section{Personal injury claimant solicitors}

For solicitors acting for accident victims, the main change has been the withdrawal of legal aid from personal injury work and its replacement by conditional fees agreements (CFAs). CFAs work most smoothly and profitably for bulk work - that is, small, quick, easy cases that are handled in bulk. These provide a regular cash flow with little risk. Indeed, insurers suggested that since the Court of Appeal decision in Callery v. Gray, ${ }^{2}$ solicitors were over-remunerated for this type of work. Meanwhile, firms have had to be extremely cautious about taking on large, riskier cases.

Most firms were keen to expand their bulk casework, taking large numbers of small, simple cases. However, the market for such work has been changed by the rise of claims intermediaries, who advertise heavily for claims which they then pass on to solicitors for a fee. Solicitors were highly critical of such organisations, but few felt able to ignore them. Four firms had joined such schemes, and two other 'bespoke' practices (with national reputations for work on difficult claims) were about the join such schemes. Other firms were keeping the matter under review.

Claimant firms were less standardised than insurers, but many were proceeding down the same path. Several large claimant solicitor firms were developing standardised ways of handling fast track cases, by which work was delegated to lower-level staff supported by sophisticated computer systems. These systems combined a diary function (telling staff when to undertake 
tasks) with a bank of standard letters. Interestingly, the firm displaying the greatest level of standardisation said they preferred to recruit insurance staff rather than solicitors because they were more used to their methods of work.

The Woolf reforms have not caused standardisation among solicitors, but they have dovetailed with the process. First, they provide a useful conceptual distinction between fast track (suited to standardisation) and multi-track (not suited). Lord Woolf's report can be taken as an ideological justification for dealing with fast track cases in a cheap and cheerful way. Secondly, the preaction protocol provided a clear structure to negotiations. At its most basic, it gave firms more dates to programme into their computer systems. Thirdly, it meant that the deadlines would be more likely to be understood and adhered to by others. Finally, the reform process triggered solicitors to undertake wide-ranging reviews of their systems.

At the time of our study, few firms had much practical experience of recovering success fees and insurance premiums from defendants. However, the issue provoked strong feelings. Insurers complained that success fees led to unacceptable increases in costs and predicted more years of 'messy litigation'. Several respondents (on both sides) felt that the ill-will generated by the issue had soured relationships between claimant solicitors and insurers and undone much of the improvement brought about by the reforms.

\section{Personal injury defendant solicitors}

Defendant solicitors acting for insurance companies were the group most immediately affected by the introduction of the Civil Procedure Rules (CPR). As of April 1999, they experienced substantial reductions in workloads as litigation decreased. Although some of the reduction was short-term land work has since picked up a little), most of the reduction is long-term. Insurers are now settling more claims in-house, before issue. Some companies have also established in-house legal teams to deal with fast track litigation. At the same time, insurers have reduced the rates they pay their solicitors. Whether or not as result, defendant solicitors seemed less positive in their views of Woolf than either claimant solicitors or insurers.

\section{Clinical negligence claimant solicitors}

The main change affecting claimant solicitors undertaking clinical negligence work has been the concentration of the market brought about by the Legal Services Commission. Now that legal aid funding is restricted to those who 
can demonstrate expertise in this area, practitioners are more specialist. Claimant and defendant solicitors have more dealings with each other and know each other better. This ties in with moves under the Woolf reforms towards less adversarial relationships. However, unlike the personal injury market, there are no discernible moves towards standardisation. Clinical negligence remains a highly complex, individualised form of litigation, which makes considerable use of the courts.

Generally, solicitors said they had not made major changes to their practices or ways of working to deal with the new regime. For High Court cases, Practice Direction 49 already required active case management and specialised systems to deal with these claims. However, the protocol timetable and greater emphasis on case management under the CPR had resulted in increased workloads and the need to pursue clearer and more immediate case strategies.

\section{Clinical negligence defendants}

Clinical negligence claims represent a considerable cost to the National Health Service and have therefore been the subject of much government attention. New organisations have been established to improve the quality of care, including the Commission for Health Improvement and the National Institute for Clinical Excellence. Claims handling has become more centralised. A central authority, the National Health Service Litigation Authority (NHSLA), was established in 1995 and presently deals with larger claims, above the excess for which the individual NHS trust is liable. At the time of our study, trusts also employed claims managers who played a central role, liasing between clinicians, complaints departments and patients and managing and negotiating smaller claims below the trust's excess. After April 2002, however, the NHSLA will deal with all new claims, requiring changes to the role of claims managers working within trusts.

Unlike the personal injury protocol, the clinical negligence protocol contains 'good practice commitments', which reach beyond the legal process and summarise best practice for dealing with adverse outcome reporting, patient dissatisfaction, and complaints. For example, healthcare providers should 'ensure that patients receive clear and comprehensible information in an accessible form about how to raise their concerns or complaints'. It was felt that the culture of openness had not yet permeated the complaints procedure. 
Some claimant solicitors were highly critical of the process, whilst defendants thought that claimant solicitors themselves were less than open in pursuing complaints.

The many initiatives for improved quality, adverse outcome reporting, complaints and claims mean that it is particularly important to establish good channels of communication between the different departments within trusts dealing with these areas. At the time of our study, communication between complaints and claims departments within trusts seemed to work well, but claims managers expressed uncertainty over the extent of their duty in advising patients on the steps open to them following an adverse incident. They remain reluctant to admit liability unprompted by a claim or to advise patients to seek legal advice. This appears to be sanctioned by Department of Health policy.

For defendants, the main effect of the Woolf reforms has been to increase workloads as they need to investigate a greater number of cases at an earlier stage. Claims managers also reported increased workloads due in part to greater input into individual claims. One noticeable trend was that claims managers were electing to manage a greater number of 'below excess' claims in-house rather than sending them to solicitors. Some were beginning to use their solicitors as an arms-length resource, to provide occasional advice rather than necessarily taking control of the case. Nevertheless, claims managers had not taken on the task of instructing experts, but instead passed cases to solicitors for this purpose. Defendant solicitors had mixed views on this more pro-active method of claims management, but claimant solicitors thought that it had resulted in improved relationships and better administrative procedures in some trusts. It remains to be seen what effect the changes to the management of claims by the NHSLA will have on these developments.

\section{Housing disrepair: the context of other developments}

Housing disrepair work has also been affected by other economic and managerial pressures. On the tenant side, the vast majority of claims are legally aided. The Legal Service Commission Funding Code requires that solicitors focus on substantive issues at an early stage, and address their minds to whether costs are proportionate to the issues at stake. Meanwhile, the Commission's contracting requirements have led to greater specialisation and require firms to adopt more efficient office systems. The economic pressures within local authorities have also put a premium on the quick 
investigation and resolution of claims. Some local authorities have reorganised their departments to enable centralised, specialist teams of building surveyors and environmental health officers to deal with claims. Such teams are designed to respond to solicitors' letters quickly by arranging inspections and collating documents.

By and large, these developments have complemented and enhanced the reforms by encouraging a more focused approach to resolving disputes earlier in the process.

\section{The implications for barristers}

Solicitors in all three areas reported a reduction in their use of barristers. This was thought to be a general trend, which would have occurred independently of the reforms. However, Woolf made solicitors more conscious of the need to keep control of proceedings, to respond quickly and to show that costs were proportionate. All these pressures contributed to a more selective use of counsel. Solicitors were undertaking more drafting inhouse, retaining more fee-earning work, and maintaining control over a case and its timetable. Solicitors saw continuing roles for the Bar, including some new roles, such as drafting agendas for experts' meetings. However, they thought barristers would need to change by developing stronger specialisations, responding more quickly, working in partnership with solicitors and - in the personal injury field - considering acting under CFAs.

\section{Formulating and responding to the claim}

The claimant's central task in pre-action activities is to formulate a claim. The onus then passes to the defendant to respond, in preparation either for settlement or litigation. The pre-action protocols share a central concern. They each spell out what information claimant and defendant must exchange and they establish a timetable for doing so.

That said, there are important differences between the three subject areas, particularly in what the claimant must do to establish a prima facie claim. For personal injury, the requirements are modest. In many cases, the claimant is only required to send a summary of the facts of an accident, together with an indication of injuries suffered. This is often enough to raise a presumption of liability that the defendant must rebut. For clinical negligence, however, the requirements are onerous in all but the most straightforward of cases. In order to write a letter of claim, the claimant's solicitor must first obtain and 
then consider the medical records and commission expert evidence - a costly and time-consuming process. In housing disrepair, landlords expected to be liable for some disrepair but establishing the nature and extent of that liability was more contentious. Although claimant solicitors were often keen to found their claims on the basis of the landlord's file, many landlords were reluctant to disclose files in such circumstances. Thus, in discussing the details of how claims are formulated and responded to, we look at each of the three areas in turn.

\section{Personal injury claims: the letter of claim}

The first obligation under the personal injury protocol is that the claimant's solicitor should send the defendant a detailed letter 'immediately sufficient information is available to substantiate a realistic claim'. This should contain, inter alia, 'a clear summary of the facts' of the accident, together with 'an indication of the nature of any injuries suffered' and 'any financial loss incurred'.

Both insurers and claimant solicitors felt positive about the new approach to letters of claim. Insurers thought they now received a better level of information early in the case, without having to write a series of letters requesting further details. Meanwhile, claimant solicitors were increasingly focused on gathering information at the outset of the case. This was thought to be vital to assess risk. Having gathered the information, it was no hardship to disclose it to the other side.

The new approach, however, did lead to some 'front-loading', in which more work was carried out in the early stages of a case. Claimant solicitors said they were now more likely to interview their client before writing the first letter to the defendant, and that such interviews tended to be longer. One potential problem is that it now takes longer to write the initial letter to the defendant. Whereas before the reforms, half of all first letters were sent within a fortnight; now half of letters took over a month, with around one in five taking over three months. In general, neither insurers nor claimant solicitors were too concerned about these delays. On the other hand, the requirement under the protocol that the claimant solicitor should establish contact with the insurer before instructing a medical expert (see below) meant that delays in sending the first letter added to the overall time required to complete a case. 
The protocol suggests that, in some circumstances, the claimant solicitor may wish to provide an insurer with an 'early notification' that a letter of claim would be submitted in due course. There were considerable differences in how solicitors used this provision: one firm sent an early notification in almost every case, while others never sent them at all. For their part, insurers saw little point in early notifications unless the letter of claim would be delayed to such an extent that it would arrive over a year after the accident.

Insurers said that the level of the information they received was better than before, but was still 'hit and miss', with some solicitors providing considerably more detail than others. The file survey showed this to be the case. Since April 1999, there has been a clear improvement in the amount of detail provided: for example, the proportion of letters including at least a broad indication of the facts has increased from two in five to over four in five. However, gaps remain: for example, around a quarter of files failed to specify the place of the accident.

One problem is that, at the time of the letter of claim, insurers and claimant solicitors have opposite concerns. The insurer's priority is to put a valuation on the case, both for the purposes of their own reserves and to decide how the case should be investigated. Claimant solicitors are more worried about liability, and often postpone valuations until after the medical report has been received. Insurers were particularly critical about the level of information solicitors provided about the injury and special damages. The file survey confirmed that many letters contained significant omissions. One-quarter of letters failed to indicate the nature of the injury, two-thirds failed to provide any indication of the amount of lost earnings, while three-quarters failed to specify any other expenses incurred.

A final problem lies in the transmission of information required by the Compensation Recovery Unit to investigate whether social security or health payments should be repaid to the state. Although the protocol requires letters of claim in road traffic cases to provide the name and address of the treating hospital, very few do. We found no road traffic letters at all that contained the claimant's hospital reference number. 


\section{Personal injury: the defendant's obligations}

The personal injury protocol imposes three main obligations on defendants: to acknowledge the letter of claim within 21 days; to respond within three months thereafter, stating whether liability is denied; and, thirdly, if liability is denied, to disclose any documents in their possession which 'are material to the issues between the parties'.

Insurers clearly found it difficult to meet the 21-day time limit for an acknowledgement. They exceeded it in around one-third of cases. Letters of claim are usually sent to the actual defendant - the driver, employer or other organisation - and may be passed around several departments before reaching the insurer. Insurers expressed mixed views on whether the time limit should be altered. While some argued that it should be extended to 28 or 35 days, others expressed concern that this might send the wrong signals to their policyholders. For their part, claimant solicitors seemed resigned to late acknowledgements and the issue did not worry them greatly.

The time limit for a substantive response created more difficulties. The file survey showed that it was exceeded in around one-third of cases. Whilst this represented an improvement on previous practice, claimant solicitors complained that the number of late responses was too high. Claimant solicitors' main criticism of the protocol was that it contained too few sanctions to enforce compliance. Although in theory they could react to a later response by issuing proceedings, this was not a practical possibility without a medical report and witness statements.

Insurers thought that in standard fast track road traffic cases, the threemonth deadline was reasonably easy to meet. They would have been notified of the accident when it happened and would have already started their investigations. Work accidents, however, caused more problems. Insurers thought that the present three-month period should be retained as a target to aspire to, but should be applied flexibly.

When one considers the content of responses, the file study shows that insurers are now more likely to make outright admissions of liability and less likely simply to indicate a willingness to negotiate. However, most insurers were still cautious about applying words such as 'admit' or 'accept' to liability. Over half of protocol responses involved some form of equivocation, such as 'liability is not in issue' or 'liability is not in dispute'. Some claimant solicitors accepted these forms of wording. Others, however, felt that their clients would be prejudiced if they failed to investigate liability only to find that 
liability was later denied. Nevertheless, there was general agreement that denials were now more reasoned, and that this represented an improvement on previous practice.

Since the protocol was introduced, claimant solicitors are much more likely to ask for documents to be disclosed during pre-action negotiations. In work accidents, such requests are now made in the great majority of all cases. Documents are provided much less frequently than they are requested, though there does seem to be more pre-action disclosure than before the reforms. Insurers queried whether similar obligations should rest on claimants to disclose their own documents.

The new procedure raises questions about where the burden of proof now lies in personal injury claims. Insurers felt that letters of claim raised a presumption of liability, which it was up to them to either accept or rebut during the investigation period. They therefore felt that they should not be expected to meet any liability investigation costs that a claimant solicitor incurred between sending a letter of claim and receiving a response. Any discussion of cost reform would need to clarify what steps a claimant solicitor should take themselves to investigate liability during this period, and what an insurer might be liable to pay for. At the same time, it would be helpful to define what counts as late or equivocal insurers' responses, and to spell out their cost consequences.

\section{The requirements in clinical negligence claims}

In clinical negligence claims, the claimant is required to carry out more work to establish a claim. The first step is for the claimant solicitor to obtain their client's health records. The protocol requires the request to be made on the Law Society/Department of Health approved standard form, adapted as necessary'. The healthcare provider should send a copy of the records within 40 days, or explain why not. At this stage the healthcare provider will decide whether to investigate the case. The protocol states that it will not be practicable... to investigate in detail each case when records are requested'. However, healthcare providers 'should adopt a policy on which cases will be investigated'. Where there are grounds for a claim, the claimant solicitor should then send the potential defendant a letter of claim as soon as practicable'. This should contain 'a clear summary of the facts on which the claim is based, including the alleged adverse outcome, and the main allegations of negligence'. It should also describe the patient's injuries and, 
'unless impracticable', outline their financial loss. Finally, the healthcare provider has three months from the letter of claim, to provide a reasoned answer', either admitting the claim or giving a detailed denial.

\section{Clinical negligence: requests for records}

Generally, there were positive comments about the use of the Law Society/ Department of Health request for records form, although its use was still not universal. Claims managers were not always confident of their ability to release the notes on time. However, there was a clear feeling among claimant solicitors that the provisions were working well: records were generally dispatched within 40 days or clear reasons given for the delay. Court applications for pre-action disclosure are now rare.

\section{Clinical negligence: the decision to investigate}

Claims managers are faced with difficult decisions about which claims to investigate following a request for records. There is a tension between investigating claims as soon as possible and keeping costs down. In the light of tighter timetables and the need to respond substantively to letters of claim, claims managers were careful to screen requests for records and to maintain good communication with medical records departments to ensure that likely claims were investigated. There was some evidence that a greater number of potential claims are now being investigated. Where trusts investigate requests for records that fail to materialise as claims, this clearly adds to costs.

\section{Clinical negligence: letters of claim}

There were mixed views on the effectiveness of the letter of claim. On the positive side, they clearly provide more detailed information than old style letters before action and there was a strong sense that this opened up the potential to settle claims at an earlier stage. On the negative side, doubts were cast over whether the letter of claim served much purpose in larger claims, where the complexity of the issues and difficulties in quantifying the case at this stage made settlement far less likely. Contrary to the intention of the protocol, letters of claim are being regarded as a trial run at the particulars of claim: here again there were implications for increasing the costs of the claim. Like their personal injury counterparts, claims managers and defendant solicitors appreciated the greater level of information, but 
complained that not all the protocol requirements were complied with. There were also differences of opinion about how much supporting evidence should accompany the letter.

\section{Clinical negligence: the response}

Letters of response frequently took longer than three months. Most defendant solicitors and claims managers criticised the three-month period as insufficient in all but the most straightforward cases. However, they said that requests for extensions were generally acceded to. Whilst defendant solicitors reported that they were providing full letters of response, claimant solicitors had mixed views on their effectiveness. This stage appears to be of most benefit in lower value, less complex claims, where it was most likely to lead to settlement. As might have been expected, there were few complete admissions in letters of response: defendants tended to admit breach but deny causation, and then usually only in lower value claims. In some cases, admissions continued to be delayed until a very advanced stage of the claim.

\section{Housing disrepair: establishing a claim}

Establishing the facts necessary to found a disrepair claim involves establishing details of the defect itself; the repairs necessary to put it right; when the defect was first notified to the local authority; the effect of the disrepair on the tenant(s); and any special damage caused by it. The interviews revealed considerable disagreement about whether the onus is on the tenant to establish a prima facie claim, and how far fact finding should be seen as a co-operative exercise between the parties. The issue of prior notification caused particular difficulties. Although a landlord's liability for the consequences of disrepair depends crucially on when the tenant first complained, a combination of tenants' poor memories and landlords' inadequate record keeping makes the facts difficult to establish.

Much of the dispute centred on whether landlords should be required to disclose their whole housing file. Many landlords resented blanket requests for disclosure, arguing that disclosure should be confined to specified documents or specified times. They did not think that tenants should be allowed to build their case on the basis of the landlord's file, even when the file indicated that disrepair was more extensive or had been notified earlier than the tenant alleged. They were particularly concerned about disclosing inadequate files which failed to include any previous complaints. This, they 
thought, could too easily allow unscrupulous tenants to come back with allegations of very early notifications, which the landlord would then be unable to rebut.

Landlords' practice on disclosure varied. Those with centralised disrepair teams would often copy files as a matter of routine. Others would resist strongly, and were reported to sometimes try and settle a case immediately rather than risk disclosing the whole file. This saved cost and prevented claimant lawyers building a stronger claim.

\section{Expert evidence}

In Access to Justice, Lord Woolf identified expert evidence as a major generator of unnecessary costs. The Civil Procedure Rules therefore included a variety of reforms designed to emphasise the expert's duty to help the court impartially and to encourage a more focused use of experts. For the purposes of this study, the changes fall into three groups:

- First, Part 35.10 contains requirements about the contents of reports. The expert's first duty is to court, and the report must state that the expert understands this. The report must also 'state the substance of all material instructions' (Part 35.10(3)).

- Secondly, the court has power to direct that evidence "is given by one expert only' (Part 35.7(1)). Although there is no presumption in favour of joint experts, solicitors felt that judges were encouraging their use.

- Thirdly, the personal injury protocol adds a further layer of procedural rules specifically for medical evidence in fast track cases. It sets out a procedure whereby one party should provide the other side with the names of one or more medical experts. If at least one expert is acceptable, the other side would not normally obtain their own report. This is in contradistinction to the clinical negligence protocol, which recognises that "the parties and their advisers will require flexibility in their approach to expert evidence'.

The first group of changes (to the contents of reports) were generally felt to have a positive effect. Respondents in all three areas of work welcomed the fact that experts are now less partisan and are instructed in a more neutral way. They felt that different experts were now being used: those traditionally known to have a claimant or defendant bias were no longer instructed - and many solicitors were clearly relieved to have 'seen them off'. There was a 
downside, however. Clinical negligence solicitors, in particular, worried that the pool of available experts had been reduced. Furthermore, the additional administration and obligations that the CPR placed upon experts were thought to deter some from undertaking medico-legal work. The new Part 35 Rules also made solicitors more cautious about sending enclosures, especially client statements. In some complex clinical negligence cases, this was felt to compromise the free flow of information between solicitor and expert.

The other changes are more controversial. Lord Woolf pointed out that the issue of experts has considerable potential to generate conflict. Although most solicitors manage on a day-to-day level to instruct and exchange expert reports, conflict is never far below the surface. We look first at the expert procedure set out in the personal injury protocol and then at the use of experts in multi-track cases, including clinical negligence claims and larger personal injury claims. As the Court of Appeal has pointed out, ${ }^{3}$ the two procedures are quite different. Each has their own rules and consequences. We conclude by outlining the specific criticisms of joint experts made by local authority landlords.

\section{Agreed medical experts under the personal injury protocol}

On a day to day level, the protocol procedure appears to work as intended. Most claimant solicitors nominate one, two or three doctors, and insurers almost always agree to at least one of the names submitted. It is extremely rare for a doctor to be instructed to whom the defendants have objected. Our data suggest that the number of medical experts used per case has fallen slightly.

However, the study revealed considerable confusion over the status of 'agreed' medical reports. All insurers and some claimant solicitors had started by assuming that such reports would be jointly instructed by both parties. Insurers also thought that in some cases they might be the ones to nominate experts. On the other hand, there is a strong current of thought among claimant lawyers that the claimant should 'own' their medical report. The first two years of the protocol have seen a battle between claimant lawyers and insurers over ownership of protocol reports.

It is a battle that claimant solicitors have won. Despite insurers' attempts to commission the only medical evidence, this takes place very rarely. In most cases the claimant instructs the doctor without showing their instructions to the opponent. Claimant solicitors retain the right to question their expert and 
ask for amendments without notifying the opponent. Claimants also retain the right not to disclose reports they dislike. The sample of post-Woolf cases contained five cases where the first medical reports had been changed at the behest of the claimant solicitor without the defendant's knowledge, and six cases where medical reports had been obtained and not disclosed.

A major problem with the protocol procedure is that it has slowed the process of obtaining medical reports. Instead of instructing a doctor soon after the first meeting, solicitors must now contact the other side and wait for an acknowledgement. Defendants then have a further 14 days to agree to names. Thus the median time taken to issue instructions has increased by 46 days from just over two months to well over three months. This, coupled with increasing delays in writing reports, means that, post-Woolf, half of first medical reports take well over six months to obtain. As responses on liability are produced more quickly, there is an increasing problem of 'dead time' after liability has been accepted, while the parties wait for medical evidence. In half of cases, over four months was spent in 'dead time' of this sort. Insurers complained vigorously about the delay in producing medical evidence, and asked for the protocol to provide a target timetable to disclose the first medical report.

There is a case for reviewing the protocol procedure to examine whether the process of submitting and agreeing names justifies the delay involved. The initial effect appears to have been positive, as part of a cultural shift towards less partisan experts. However, its benefits are diminishing as time goes on. On a practical level, insurers rarely have access to the information they would need to make reasoned decisions about which experts to agree. Given that claimants can ask for amendments without the defendant's knowledge and fail to disclose reports they disagree with, it has only a limited effect in ensuring unbiased reports.

Insurers complained that too many medical experts wrote reports without access to medical records, such as GP notes. Our survey suggested that around one-quarter of reports were written without such access. A review of the protocol might also consider whether the absence of GP notes should trigger any particular sanction (such as giving defendants the right to obtain their own evidence if they wish). 


\section{Evidence in multi-track cases}

In large multi-track cases, expert evidence is subject to a different regime, as set out in the Civil Procedure Rules rather than the protocol. The common practice is for each side to commission their own key experts. In clinical negligence cases, separate experts were almost always used for liability issues. For large claims - both clinical negligence and personal injury - it is also common to use separate experts for the most controversial quantum reports, such as the overall care regime. However, secondary quantum specialists may be commissioned on a joint basis (with joint instructions, and the report disclosed to both sides simultaneously).

Solicitors felt that judges were driving them to make greater use of joint experts. Some admitted that they used joint reports to 'play to the gallery' and impress the judge. Many solicitors found joint experts to be a positive move. However, formulating joint instructions could be difficult, with the claimant seeking to maximise the claim and the defendant to minimise it. So too was arranging to obtain follow-up information from a jointly instructed expert. It was also alleged that some experts found joint instructions difficult, particularly where they were asked to attend conferences with one side and then the other.

All but one of the clinical negligence solicitors interviewed had had experience of meetings of experts. Here too the courts were driving this approach. Claimant solicitors had many criticisms of such meetings, though defendants were more positive. The first complaint concerned the time, effort and difficulty in arranging the meetings and drafting the agenda. Secondly, disputes arose about whether solicitors should be present. Broadly speaking, claimant solicitors were more in favour of attendance than defendants. Thirdly, respondents felt that experts' meetings increased the cost of claims. Where the experts had entirely opposing views, the meeting was unlikely to provide a means of resolving the claim or issues within it.

\section{Local authorities and joint reports}

Local authorities expressed strong resistance to the notion of single joint experts, saying they would much prefer to use their own in-house surveyors to negotiate with tenants' own experts. This provided them with an expert they could trust, and enabled them to exert greater control over the resolution of the claim, particularly in scheduling the work to be carried out. Tenant lawyers saw sense in this approach. Even where a joint expert was used, local authorities would in any event ask their in-house surveyor to scrutinise the 
report or meet the joint expert. This would not only negate some of the possible cost savings of joint experts, but might disadvantage the tenant by weighing the balance of expertise in favour of the landlord. Many landlords also saw advantages in tenants instructing their own expert early in the process, providing a clear indication of the nature of the claim they needed to respond to.

By and large, tenant solicitors agreed that separate experts was the best approach, perceiving that local authorities were more willing to settle cases when they had their own experts. The main support for joint reports came from housing associations or private landlords that lacked in-house expertise, though even local authorities were happy to use joint experts for specialist knowledge they did not possess in-house. Interviewees also suggested that, rather than emphasising joint experts, it was joint inspections by both parties' experts that were crucial to early settlement. Such inspections were now more common and often worked well to resolve issues.

\section{Settlement}

The reforms have affected the settlement process in at least four ways. First, the court is under a duty to encourage the use of alternative dispute resolution procedures, such as mediation (Part 1.4(2)(e)). Secondly, Part 36 contains new provisions for claimants to make offers that carry formal penalties if unreasonably rejected. Thirdly, the reforms attempt to preserve litigation as a last resort. Claims should be issued in court only when preaction attempts at settlement have failed. Finally, taken overall, the reforms are intended to encourage a less adversarial, more settlement-minded culture. Below we consider the effect of each of these changes.

\section{Alternative dispute resolution}

Alternative dispute resolution techniques such as mediation have made almost no impact on the three areas studied. The research confirmed the conclusion reached by the evaluation of the Central London County Court scheme that the demand for mediation in personal injury work was 'virtually non-existent' (Genn 1998 p.v). Mediation was slightly better established in clinical negligence claims, but even here interviewees had very limited experience of it. They found it difficult to identify any real advantages, beyond suggesting that it might be suited to some low value/high emotion claims. 
Similarly, housing solicitors had almost no experience on which to draw. Landlords expressed some interest in mediation or arbitration, but only if it would minimise the role of tenant solicitors.

\section{Part 36 claimant offers}

The introduction of claimant offers under Part 36 of the Civil Procedure Rules was seen as an important change. For the first time, claimants have the opportunity to make formal written offers to settle a case that carry penalties if they are refused. Rule 36.21 states that where at trial 'a judgment against a defendant is more advantageous to the claimant' than the proposals contained in the offer, the court may award extra interest lup to $10 \%$ above the normal base rate) and may grant the claimant costs on an indemnity basis.

Claimant offers were received positively by all the groups in our study. Claimant solicitors liked them because they provide a way of eliciting a response. Defendants liked them because they set an upper limit to the bargaining range. However, in all three areas of work, claimant and defendant solicitors varied in how they perceived their use. Claimant solicitors commonly suggested they made first offers early in the process, with, for example, the letter of claim. Most defendants thought this was rare. Landlords felt that tenant lawyers were particularly reluctant to make initial offers. They thought that the main effect of Part 36 has been to encourage counter-offers after the landlord has named the first figure.

The personal injury file survey shed some light on these differences of perception. It confirmed that the change in the use of claimant offers is evolutionary rather than revolutionary. The proportion of personal injury cases in the study containing a claimant offer of some sort had increased from $48 \%$ pre-Woolf to $58 \%$ post-Woolf. Before the reforms, it was extremely rare for claimant solicitors to make the first offer. It is now less rare, but still unusual: $15 \%$ of post-Woolf personal injury cases contained a first offer by the claimant. When pressed, around half of personal injury claimant lawyers said that they almost never made first offers. They thought it was better to wait to see what the defendant was offering rather than take the risk of undervaluing a claim. There was also thought to be client resistance to the idea.

The penalties for rejecting a claimant offer apply only to cases that go to trial. Few interviewees, therefore, had any experience of penalties being imposed. The issue revealed considerable confusion, especially over the effect of receiving indemnity costs in cases fought under a CFA or collective CFA. Claimant solicitors criticised the penalties for only biting on early offers in 
large cases. They felt that there was little sanction that a claimant could apply in small cases or in the run-up to trial. The study suggests that the penalties contained within Rule 36.21 should be reviewed, to make them more appropriate to a wider variety of cases.

\section{Fewer cases issued before the courts}

One effect of the reforms is that the court is now involved at a later stage in the process. There are two reasons for this. First, the pre-action protocols set out a clear structure for formulating and responding to the claim, which means that claimant solicitors do not have the same need to use the court to secure a response. Most accept that they should wait for protocol deadlines to elapse before the issuing (though some queried the value of this in difficult multi-track clinical negligence cases that would issue in any event). Secondly, the fast-track timetable was perceived as very short. Claimant solicitors said that fast track cases now needed to be fully prepared before issue.

Later issue means less issue. Almost all the respondents in the study thought that more cases were now resolved without court involvement. The effect was clearest in personal injury cases, where a couple of insurers estimated the reduction at 'around a third'. Clinical negligence cases are more difficult to resolve and are therefore more likely to still involve the court. However, respondents thought that some small, straightforward cases were more likely to be resolved before court proceedings started. Housing disrepair cases were also felt to be considerably more likely to settle without proceedings being issued. This fall in issued cases is confirmed by court figures. A report by the Lord Chancellor's Department concluded that, following a substantial drop in claims issued immediately after the reforms, the 'overall trend remains at a lower level than before' (LCD 2001 p.8).

The perceived effect of less court involvement depends on one's point of view. Personal injury insurers saw it as a major improvement, as they were able to settle more cases through in-house claims handlers and made less use of solicitors. Defendant solicitors were less positive. From the claimant solicitor point of view, the change was in tactics rather than strategy. They felt that much the same work was still needed to prepare and settle claims, but it was done without formal court involvement. 
A less adversarial, more settlement-minded culture?

Respondents shared a strong perception that claims were now easier to settle. It is difficult to pin down exactly what they meant by this. Before the reforms, very few cases went to trial. Studies suggest, for example, that among personal injury claims, the proportion of trials may be less than one per cent (Pleasence 1998). Any change in this proportion would be difficult to discern, and would make little difference to most cases.

The perception that settlement was 'easier' related to matters other than the trial rate. This was partly because more cases were settled before issue, and partly because it was felt that settlement was more likely to be through discussion of the issues rather than attrition. For example, many housing lawyers felt that the parties now took a more pragmatic approach to resolving matters, and tended to focus on the real issues earlier. In clinical negligence, it may also be that cases are weeded out sooner. Those that survive to the letter of claim stage may have more merit and therefore be more likely to settle. It was also felt that the parties put forward more realistic sums, and were less likely to offer inflated (claimant) or reduced (defendant) values.

That said, most respondents thought that the journey away from adversarialism still had some way to go. There were widespread complaints that the changes were 'marginal' rather than 'fundamental', and that some opponents had adapted better than others. Personal injury claimant solicitors complained that some insurers lacked resources and used inexperienced staff. Insurers complained that a few claimant solicitors were still unacceptably rude. In clinical negligence work, claimants reproached defendants for not being as open as they were, while defendants said that claimant solicitors sought to prolong cases for financial gain. In housing disrepair cases, the culture remains one of 'non-admission'. Although settlement was perceived as occurring earlier, most negotiations were conducted on a 'without-prejudice' basis, and actual admissions were extremely rare.

\section{Evidence from the personal injury file study}

The personal injury file study allowed us to test out these perceptions by considering, first, whether the settlement process had become quicker, and secondly, whether files contained fewer 'wasted' letters. 
The file survey suggested that, once a medical report had been obtained, the remaining stages of personal injury cases were concluded more quickly. The median time from medical report to settlement had fallen from 170 days preWoolf to 123 days post-Woolf. This was partly because first offers are made sooner and partly because it took less time after the first offer to reach a settlement. This provides support for the assertions made by insurance companies that they are now more focused on achieving settlements quickly. Claimant offers were also thought to have speeded the process.

One objective of the protocol was that there should be 'more pre-action contact between the parties'. This needs to be interpreted in terms of quality rather than quantity. One criticism of the old system was that it produced large numbers of wasted letters, including demands for: more information about the accident; chasing letters; repeated requests for decisions on liability; and futile threats to issue proceedings. The file study suggested that the overall number of pre-action contacts remained much the same. The median standard fast track case now involves around 15 contacts: eight letters from the claimant to the defendant, six letters from the defendant to the claimant, and a phone call to finalise settlement. However, we found some evidence that the quality had improved. The new system provoked fewer requests for more information about the accident and fewer threats of litigation.

Nevertheless, chasing letters have not disappeared. They were present on half of all files. The protocol also provides a whole new area for procedural disputes. Over one-quarter of post-Woolf cases contained allegations that the other side had failed to comply with the protocol in some way. Given that the survey was conducted at a time when the protocol was 'bedding down', the level of dispute might have been greater. That said, procedural arguments have clearly not been eliminated.

\section{Is the process quicker?}

It was difficult to gauge the effect of the reforms on the duration of cases. Several respondents reported that cases were now resolved more quickly. This was especially true for housing lawyers. One landlord representative, for example, suggested that cases now took five to six months, where previously they could take up to two years. These assertions, however, need to be treated with care. The personal injury study found that solicitors routinely underestimated the time cases took. 
Among clinical negligence cases, the results were inconclusive. Some solicitors thought that smaller cases were dealt with more quickly. The protocol steps allowed cases to settle earlier, and, if they did not settle, the work carried out under the protocol meant that that was less to do after issue. Court timetables on the fast track were now much quicker. Large cases, however, were subject to the less stringent multi-track timetable. Here additional delays may be caused by waiting for a pre-issue response and by the need to hold meetings of experts.

In personal injury cases, many respondents thought that cases were resolved more quickly. The file study, however, suggests that the issue is far from straightforward. As discussed above, the early stages of a case have become slower. It now takes longer for claimant solicitors to make their first contact with defendants and to instruct a medical expert. However, after a medical report has been received, the process of settling a case has become quicker. Our own file survey was only able to gather data on small, quickly resolved cases. Within this sector, the two changes largely cancelled each other out, with mean and median times remaining much the same. The minimum time for concluding a case has become longer: very few settlements were now secured in less than six months.

\section{Is the process cheaper?}

Reducing costs was a major objective of the reform process. Although the evidence on this issue is far from conclusive, initial indications do not suggest that case costs have decreased. Each potential saving in the reform is offset by other changes that require more work, or bring forward work to an early stage, so that it is required in a greater proportion of cases.

For clinical negligence and housing disrepair case, our data was limited to respondents' perceptions. In personal injury, we collected some quantitative data on small, quickly resolved cases.

\section{Clinical negligence}

Those we talked to about clinical negligence work painted a mixed picture. It was thought that some elements of the protocol may have resulted in a reduction in pre-issue costs. For example, streamlined procedures for the release of medical records have minimised the need for applications for preaction disclosure, while the earlier exchange of information could lead to earlier settlement. On the other hand, the need to obtain medical records and 
an expert's report meant that costs were front-loaded. For claimant solicitors this was nothing new. However, for defendants, the necessity to front-load the investigation of claims may well have increased costs. This would counteract costs savings due to earlier settlements.

Broadly speaking, clinical negligence interviewees reported that post-issue, the cost of claims had not decreased and in some cases were rising. This was attributed to increased court attendance and the need to produce interim schedules of costs. Much of the overall costs in clinical negligence claims is taken up with experts' fees. The protocol is not prescriptive about the use of joint experts and, whilst they may be used on quantum issues, joint experts on liability are rare. Given the pivotal role of the expert in these claims, it is difficult to see how this aspect of overall costs can be addressed.

\section{Housing disrepair}

In housing disrepair claims, views were more positive. Tenant lawyers reported that the cost of disrepair claims had dropped - a view supported by enough landlord representatives to suggest that the drop was real rather than imaginary. Some landlord solicitors, however, pointed out that although earlier settlements led to some cost savings for them, these were often counteracted by front-loading. The same work needed to be done; it just needed to be done earlier in the proceedings. They also complained that tenant solicitors bills remained disproportionate to the damages obtained.

\section{Personal injury}

There was little evidence that the cost of personal injury claims had decreased since 1999. Instead, insurers' own figures point to substantial increases in the average case costs they have paid to claimant solicitors since the reforms. Further analyses are needed that include the cost of issued cases. Our own data, limited to relatively quickly resolved, small cases, suggest that the cost of resolving a simple personal injury claim has risen slightly faster than the rate of inflation. This occurred before the introduction of recoverable success fees, which will lead to further increases.

There are two possible explanations for an increase in costs since 1999. One relates to front-loading. More work is now required before the initial letter of claim. The other explanation is that there is general inflation within the personal injury industry, at a rate that is higher than the Retail Price Index. As 
damages creep up, so do costs. The possible increase in costs needs to be investigated further, through a deeper analysis of data from a wider range of insurers.

Lord Woolf was particularly concerned that, in lower-value cases, costs may be disproportionate to the damages involved. Although many claimant solicitors rejected the notion that the costs should reflect damages, a statistical analysis suggests that the two are linked. In our own data, both costs and damages had increased. This meant that, when expressed as a proportion of damages, costs had remained constant. In both the pre- and post-Woolf samples, the cost of small cases amounted to $68 \%$ of damages.

A final criticism made by all those involved with personal injury litigation was that far too much time is now spent arguing about costs. The problem has been exacerbated by the introduction of recoverable success fees and insurance premiums in CFA cases. The use of cost negotiators has increased over the last two years, so as to become another 'cottage industry' in the claims-handling process. Insurers complained that without a fixed fee regime, the Woolf proposals had been only partially implemented.

\section{Issues requiring review}

Although many of the findings reflect well on the reforms, it is clear that achieving Lord Woolf's objectives will require ongoing review and reform. Section 5 of the report highlights the following issues:

1. The Civil Justice Council should review the penalties attached to claimant offers under Rule 36.21, to make them more appropriate for a wider variety of cases.

2. The Head of Civil Justice should approve new protocols only if there is a clearly demonstrated need for them.

3. The Personal Injury Pre-Action Protocol Working Party (The PI Working Partyl could usefully provide claimant solicitors with clearer guidelines about when early notifications should be used.

4. The PI Working Party should attempt to promote greater understanding among claimant solicitors about the importance of including financial information in letters of claim.

5. The PI Working Party should review the protocol requirements to exchange information relevant to compensation recovery. 
6. The PI Working Party should review the consequences if defendants fail to meet the three-month deadline for submitting a response on liability and should provide clearer guidance on what amounts to an admission.

7. The PI Working Party should consider whether the benefits derived from the process of submitting and agreeing expert names justify the delay involved.

8. The PI Working Party should consider the status of medical reports obtained in the absence of General Practitioner records.

9. The Clinical Disputes Forum (CDF) should review the provisions within the protocol concerning the release of medical records. Consideration should be given to the need to inform the healthcare provider whether the claimant has received treatment elsewhere and the practicability of allowing requests for records to be dealt with more speedily in special circumstances.

10. The CDF should review whether the protocol should emphasise the importance of setting out the claimant's case on causation.

11. The CDF should consider whether the protocol might provide further guidance as to when schedules of loss and other supporting evidence should be provided with the letter of claim.

12. The CDF should consider formulating specific guidance to experts on their role as single joint experts.

13. Consideration should be given to amending Rule 35 to include a time limit by which an expert should respond to written questions asked by the other party.

14. The Housing Disrepair Protocol should provide clearer guidance on the overlap between disrepair and personal injury claims.

15. The Housing Disrepair Protocol should be reviewed after a year to see how it is operating particularly in relation to: the way defects are detailed in letters of claim; the way that information about notice is exchanged; the landlord's obligation to disclose records of prior notice; and the role of joint experts. 
16. Further research should be done on the cost of personal injury claims, looking in more depth at data gathered from a wide range of insurers. This should include cases issued before the courts as well as those settled in-house. Further studies of the cost of clinical negligence and housing disrepair claims would serve to clarify whether costs savings are actually being made.

\section{Footnotes}

For details of the current position see Section 4. p.58

2 [2001] 3 All ER 833.

3 Carlson v. Townsend [2001] EWCA Civ 511. 
Research Study 43 More Civil Justice? The impact of the Woolf reforms on pre-action behaviour 
Section 1. Background 
Research Study 43 More Civil Justice? The impact of the Woolf reforms on pre-action behaviour 


\section{Chapter 1.1 Background}

In April 1999, major reforms were introduced into the civil courts of England and Wales. They were designed to remedy the shortcomings identified by Lord Woolf in his report, Access to Justice (Woolf 1996). These shortcomings included excessive and unpredictable cost, delay and complexity. With cases run by the parties rather than managed by the courts, litigation was perceived as being too adversarial.

Lord Woolf identified principles that should underpin the civil justice system. The system should be just, fair, proportionate, understandable and responsive to those who use it. It should deal with cases with reasonable speed. The system should also provide as much certainty as the nature of the case allows and be effective, adequately resourced and organised.

Reforms were aimed at each stage of the litigation process. For the pre-action stage, Lord Woolf proposed protocols to 'enable parties to obtain information earlier and promote settlement' (Woolf 1996, p.5). Other key features of the new system included a unified set of Civil Procedure Rules (CPR), claimant offers to settle and the use of single joint experts. Cases would be allocated to one of three tracks - small claims, 'fast track' and 'multi-track' according to their value and complexity. They would be managed by the courts to ensure they were dealt with justly and proportionately.

\section{Aims and methods}

This research was commissioned jointly by the Law Society and the Civil Justice Council to provide an initial evaluation of the reforms. It concentrates on the pre-action stages of litigation, particularly protocols and offers to settle. Another study has been commissioned to consider case management after litigation has started ${ }^{1}$ - though inevitably the pre- and post-action stages impact on each other.

We look at three areas identified by Lord Woolf as being in particular need of protocols: personal injury, clinical negligence and housing. This study was designed to find out what solicitors and claims managers thought of the reforms, how the reforms impacted on their practice, and whether they have led to a more 'settlement-oriented' culture. On a more detailed level, we wanted to see how the parties exchanged information, whether they had 
changed the way they used experts and the effect of claimant offers under Part 36 of the CPR. We also wished to explore initial perceptions of changes in speed and cost.

The research takes a primarily qualitative approach. It is based on 54 in-depth semi-structured interviews with practitioners and claims managers, carried out between January and August 2001. These interviews were supplemented by a quantitative study of around 300 personal injury files, comparing files opened since April 1999 with those closed before the reforms. The methodology is discussed further in the individual sections and set out in Appendices 1 to 3 .

\section{Pre-action protocols}

Pre-action protocols are designed to govern pre-action behaviour in different areas of litigation. We study two areas where protocols were quickly set up: personal injury and clinical disputes. These were introduced into the main body of the CPR in April 1999. We also under scrutiny is one area of law housing disrepair - where an agreed protocol is not yet in operation, although at the time of writing a draft has been formulated for approval.

The Protocol Practice Direction sets three objectives for protocols:

- to encourage the exchange of early and full information about the prospective legal claim;

- to enable the parties to avoid litigation by agreeing to a settlement of the claim before the commencement of proceedings; and,

- to support the efficient management of proceedings where litigation cannot be avoided (Practice Direction - Pre-action Protocols para. 1.4).

The Practice Direction also states that the courts will expect all parties to have complied in substance with the terms of an approved protocol. The CPR enable the court to take compliance into account when giving directions for management of the case and when making orders for costs (para. 2.1).

\section{Personal injury protocol}

This protocol is primarily designed for fast track cases (road traffic, tripping and slipping, and accident at work cases) with a value of less than $£ 15,000$. However, it suggests that its 'cards on the table' approach is equally 
applicable to some higher value claims. Thus the spirit if not the letter of the protocol should still be followed for multi-track claims (worth more than $£(5,000)$. The protocol sets out a series of steps for the parties to follow within a clearly formulated timetable. These include the sending of a letter of claim, a reply on liability, and rules on early disclosure of documents. The protocol also encourages the agreement and use of single experts.

Discussion prior to the protocol's introduction was generally favourable, but stressed that it would require a fundamental change in culture (LCD 1998; Goriely et al 1998; Blundell 1998; Peysner et al 1998). Concerns were expressed that, for example:

- fears of making a mistake might induce claimants' solicitors to delay writing letters of claim;

- defendants might be reluctant to admit liability in clear terms lor may later attempt to resile from admissions);

- the attempt to agree experts might lead to unproductive disputes over the way experts were instructed;

- lawyers might obfuscate the issues by taking refuge in stock legal phrases;

- front-loading costs might increase costs in cases that would settle in any event.

\section{Clinical disputes protocol}

The Clinical Disputes Forum, a multi-disciplinary body formed following Lord Woolf's inquiry, developed the Pre-action Protocol for the Resolution of Clinical Disputes. The protocol is designed to encourage a climate of openness when something has 'gone wrong' with a patient's treatment or the patient is dissatisfied with that treatment. It provides general guidance on how this climate of openness might be achieved when disputes arise and provides a timed sequence of steps for patients, healthcare providers and their advisers to follow when a dispute arises. These include the release of medical records and the provision of a letter of claim and response.

Unlike its personal injury counterpart, this protocol is intended for all clinical negligence disputes irrespective of their value or track. It applies equally to all aspects of the health service: primary and secondary; public and private sectors. It does not seek to be prescriptive about the way in which expert evidence should be commissioned. 


\section{The draft housing disrepair protocol}

Prior to Lord Woolf's Final Report, the Housing Law Practitioners Association and public sector landlords bodies had drawn up their own potential protocols (Woolf 1996, para. 59). In spite of this, a draft pre-action protocol has only very recently been produced and is unlikely to be agreed until sometime this year (2002). ${ }^{2}$ It does not cover some of Lord Woolf's suggestions, such as the proposal that each local authority keep a list of proposed experts (para. 61).

The draft pre-action protocol confines itself to civil claims. It does not cover Environmental Protection Act (EPA) claims in the magistrates' court, nor does it include counter claims. As a large portion of housing work arises in the context of possession proceedings, where the tenant counterclaims for disrepair, this is an important limitation. Similarly a significant amount of disrepair work is conducted through EPA proceedings in the magistrates' court. The draft protocol does seek to include disrepair cases with a claim for personal injuries but perhaps confusingly adds a rider. It says: 'If there is a personal injury case which is serious enough to be dealt with separately, on behalf of any claimant, the personal injury protocol should be followed, as appropriate, with necessary modifications'.

\section{Other changes in the litigation market}

The Woolf reforms have been implemented alongside other major organisational and funding changes. Section 2, for example, discusses the concentration of the market for liability insurance to deal with personal injury claims, leading to larger, more specialist claims centres. There have also been important developments in the way that the National Health Service and local authorities organise their claims handling.

Meanwhile, claimant solicitors have needed to adapt to significant changes to legal aid. The Access to Justice Act 1999 removed most personal injury claims from the scope of public funding, on the basis that claimants can use conditional fees to meet their legal costs. The Act also made provision for part of the success fee and the after-the-event insurance premium to be recoverable from the unsuccessful defendant.

At present, public funding remains available for clinical negligence claims. However, since August 1999, the Legal Services Commission (LSC) has only provided funding for these claims where the firm instructed has a specialist level quality mark (formerly a franchise) in clinical negligence. Fee earners 
must be panel members of the specialist panels maintained by the Law Society or Action for Victims of Medical Accidents. As at August 2000, 253 solicitors' offices had full franchises for clinical negligence (National Audit Office 2001). Despite the availability of public funding, in practical terms it is of little value to those with claims under $€ 10,000$ because such cases are unlikely to meet the LSC's cost-benefit test.

Most housing work for tenants is also publicly funded. The provision of legal help (broadly similar to what used to be known as 'green form') can only be provided if a firm has a contract. This means that housing practitioners carrying out publicly funded work are subject to the Commission's quality criteria. It also appears to have led to a contraction in suppliers. In 1995/96 over 7,000 solicitors did at least some housing work, though few handled cases in bulk: only 295 firms received more than 25 housing legal aid certificates per year (Sherr and Goriely 1997). Since January 2000, the LSC has encouraged greater specialisation by letting 804 subject specific contracts in housing. ${ }^{3}$ However, outside the major connurbations, many cases may continue to be conducted by matrimonial solicitors through 'tolerances' in family franchises. ${ }^{4}$ All publicly funded court representation is also subject to the LSC's Funding Code, which requires solicitors to focus on the costs and benefits of the action at an early stage.

All of these changes impact on the way that cases are run. Some, such as the legal aid developments, have similar aims to the Woolf reforms: greater emphasis on proportionality and efficiency. Others may cut against aspects of the Woolf reforms: for example arguments about the recoverability of success fees and insurance premiums in CFA cases may be recreating adversarialism in personal injury litigation. The concentration of the market is also likely to have a profound effect on how solicitors conduct cases. Previous research suggests that specialist solicitors may be more litigation minded. Specialists waste less time in hesitation and delay, but tend to drive cases further down the litigation path (Genn 1987; Dingwall et al 2000). We discuss the context of the reforms in personal injury, clinical negligence and housing disrepair in each relevant section.

\section{Previous research evaluating the Woolf reforms}

Since the introduction of the Woolf reforms, there have been several surveys of practitioners to obtain feedback on how they are working in practice. These include a MORI/CEDR audit of the reforms (CEDR 2000) and a postal study of APIL members. ${ }^{5}$ The general consensus was that the reforms were a 
qualified success. Practitioners thought that the pre-action protocols and Part 36 offers had succeeded in changing the culture of negotiations for the better. However, costs were not thought to have decreased and some hostility was expressed towards summary costs orders. The reforms have also had their critics, with complaints about too much form filling, increased costs and arbitrary judicial decisions (Mears 2000a, 2000b).

In March 2001, the Lord Chancellor's Department published an early evaluation of the Civil Justice Reforms (LCD 2001). This suggested that an overall drop in the number of claims issued was an indicator of the success of the Woolf reforms. It pointed to anecdotal evidence that the protocols were working well to promote pre-issue settlement and reduce the number of illfounded claims. There was also evidence to suggest that settlements 'at the court door' had decreased. The use of single joint experts and case management were said to be successful. It reported that the time between issue and hearing for cases going to trial had fallen lalthough not for small claims). However, it was too early to provide a definitive view on costs.

\section{Clinical Negligence}

Two studies have been carried out evaluating the effect of the Woolf reforms on clinical negligence litigation. The first focused on the effect of the protocol on the claims management environment within NHS trusts (Dangoor 2001). ${ }^{6}$ It indicated that the protocol was speeding up the pre-action process and that a variety of measures had been taken to comply with its good practice commitments. It suggested there was a more open approach to communications between claims handlers and claimant solicitors.

A follow-up study compared answers to some of the questions raised by the earlier research. ${ }^{7}$ In this study, the great majority of claims managers (84\%) said that they now had a system in place for selecting out possible adverse incidents requiring more detailed investigation. There were consistent reports that letters of claim did not meet the requirements of the protocol and there was great difficulty in meeting the three-month deadline for responding to the letter of claim when dealing with more complex cases. Most claims managers $(83 \%)$ had received at least one letter of claim containing an offer to settle. They all reported that the protocol had speeded up the management of claims.

More recently, the Clinical Disputes Forum (CDF) has conducted its own evaluation of the protocol. Approximately 100 replies were received to a structured questionnaire, which was sent to a wide range of consultees, 
including claimant and defendant solicitors, claims managers and defence organisation advisors. Generally, respondents were positive about the value and impact of the protocol. Negative comments included the need to frontload work and costs (comments from defendants) and that the protocol would carry more weight if the court imposed sanctions for non-compliance. Specific questions were answered in relation to costs, workload, court compliance, health records, letters of claim and response and experts, settlement and mediation. We refer to the CDF research, where appropriate, in Section 3.

\section{Housing}

Research on housing disrepair litigation relevant to the Woolf reforms is very limited. The main study of relevance concerns itself with criminal proceedings under the Environmental Protection Act 1990 (Ormandy et al 1995). It evidences a dominant local authority attitude, which sees disrepair litigation as a diversion of resources from planned repairs and improvement programmes. It also shows that local authorities were particularly resentful of the level of costs claimed by tenant advisers and their alleged methods of raising business through leafleting la process now largely prohibited by the LSC). Local authorities also complained that tenants tended to exaggerate complaints in making claims. However, the research itself points out that, whether or not tenant lawyers encourage or simply provide the ability to litigate disrepair, the existence of disrepair and tenants willing to bring claims are preconditions for a disrepair claim. The recommendations for guidance and advice for local authority legal departments make clear that there was variability in the quality and speed with which local authorities responded to disrepair complaints. The DETR have commissioned a further study to provide good practice guidance on avoiding and dealing with housing disrepair litigation for local authorities and social landlords. It is due to report shortly. The Local Government Association has also conducted a survey of local authorities in relation to housing disrepair litigation (LGA 1997). This makes similar points to the DETR study. Landlords alleged that the cost of disrepair litigation was disproportionate to the cost of repair work and that disrepair work is based on solicitors targeting estates where tenants are in receipt of income support and therefore eligible for legal aid. 


\section{Structure of the report}

The differences between subject areas justify looking separately at each type of litigation. The report is therefore divided into four further sections. Section 2 deals with personal injury litigation (presenting findings from both the qualitative and quantitative data). Section 3 deals with clinical negligence litigation, and Section 4 deals with housing disrepair litigation. Within each section, we place the reforms within the context of other organisation and funding changes; look at overall views; and consider the effect of the reforms on methods of work. We then look at specific changes: in formulating and responding to the claim; in expert evidence; and in reaching settlements. Each section ends with a discussion of how far the reforms could be said to meet their aims.

Finally, Section 5 concludes by highlighting issues for action. Three appendices contain further details of the methodology. 
Section 2. Personal Injury Work 
Research Study 43 More Civil Justice? The impact of the Woolf reforms on pre-action behaviour 


\section{Chapter 2.1 Personal injury work: introduction}

Compensation for accident victims under the tort system is a major source of dispute and litigation. Indeed, it is often regarded as an archetype of standardised, mass litigation. Each year, many thousands of accident victims, often with little previous experience of the legal system, seek compensation for their injuries. Although cases are nominally brought against a variety of defendants - drivers, employers and property owners - the great majority are defended by insurance companies, who have developed highly systematised methods of dealing with such claims.

Lord Woolf regarded clinical negligence and housing disputes as important 'special cases'. Personal injury, however, was considered as almost the 'standard' case. It is therefore an important test-bed for the reforms. It is highly unlikely that the Woolf reforms will be deemed a success unless they are found to have succeeded for personal injury work.

Although it is common to talk of this area of work as personal injury litigation, the phrase can be misleading. Even prior to the reforms, Pleasence (1998, p.51) found that court proceedings were issued in around only one-third of cases - a figure that has declined since 1999. The focus of this study is on what takes place before the court becomes involved, as information and offers are exchanged between the parties. Much of the study is concerned with the personal injury pre-action protocol - which represents a major innovation, both in how it came about and in what it attempts to do. As Tomkins (2001) points out, it was one of the first attempts to bring the warring factions together and ask them what the framework should be:

The pre-action Personal Injury Protocol came directly out of the civil justice review process. The pre-action protocols working party included people who had usually been directly opposed to each other in disputes. They very often had little good to say about each other. They certainly did not start out trusting each other. Trust grew and the 'culture' changed. (Tomkins 2001, p. 324)

The protocol is a direct attempt to reach beyond the court to regulate the private behaviour of potential litigants. However, it is by no means the only element of the new Civil Procedure Rules (CPR) that impacts on pre-action negotiations. It has become common to talk of the shadow cast by formal 
rules of law and court procedure over what comes before. ${ }^{8}$ We were therefore interested in the shadow cast by the CPR as a whole over personal injury negotiations.

\section{Other relevant literature}

Since the late 1970s, personal injury litigation has attracted considerable socio-legal attention. ${ }^{9}$ The Oxford National Compensation Study (Harris 1984) provided the first firm quantitative framework for the discussions, while Genn (1987) provides a crucial qualitative study of how negotiations take place. We were also able to draw on Pleasence (1998) for more recent quantitative information about personal injury litigation in a legal aid context. Thus, although this is the first empirical study of personal injury litigation since the Woolf reforms, we were also able to draw on a rich seam of other studies to consider how the process has changed.

\section{Methods}

This is largely a qualitative study. This section is based on 30 interviews with personal injury practitioners. We talked in depth to 18 claimant solicitors (in 17 firms), eight insurers (in five companies) and four defendant solicitors (in four separate firms). We also thought it important to include a small element of quantitative research, based on our own reviews of files. This formed an important 'reality check' on what interviewees told us. We therefore asked the claimant solicitors we spoke to supply us with equal numbers of files closed before April 1999 (the 'pre-Woolf' files) and files opened after May 1999 (the 'post-Woolf' files). We avoided 'transitional' files, opened before 1999 but closed afterwards, as these would not allow us to evaluate the reform process. In the end, we were able to look at just over 300 files, gathered from 18 firms.

Supplying files in this way proved to be a major operation, and we are extremely grateful to the firms who helped us in this way. Many claimant solicitors found it difficult to comply with our request: some did not have sufficient volumes of files opened and closed since May 1999; others lacked the database from which to identify closed files; some had neither the staff nor the space to accommodate us. An initial concern was that those firms unable to help may be subtly different from those who could help. Perhaps, for example, they felt under greater strain and were more negative about the Woolf reforms? We therefore supplemented the 18 face-to-face interviews 
with seven telephone interviews among claimant solicitors who had refused our initial request. Most solicitors were very happy to spend 20 minutes talking about the reforms over the telephone, and their views appeared similar to those who were interviewed face-to-face.

The most obvious difficulty was that firms were being asked to give us access to files that had been opened and closed within some two years following the reforms. The first firm was visited 20 months after the introduction of the reforms: the last firm was visited 28 months after introduction. This is not long, given the average duration of personal injury claims. Pleasence (1998) found that, among legal aid files, the mean time from legal aid certificate to payment of the final bill was just over two years. Since the Woolf reforms, the process may have become somewhat quicker, but it soon became apparent that it was not vastly quicker. One large firm with a sophisticated database calculated that out of 5,700 cases opened between 1 May and 31 December 1999, 35 per cent had finished by 31 January 2001. The equivalent figure for pre-Woolf cases lopened from 1 May to 21 December 1997 and closed by 31 January 1999) was 30 per cent.

In practical terms, this means that the quantitative sample of post-Woolf cases concentrates on the third representing the quickest, simplest claims. It is largely a sample of small cases where the protocol works: 90 per cent were settled for less than $€ 7,000$ and 85 per cent did not involve proceedings being issued. In the discussion that follows, we often focus on the 'standard fast track claim', defined as a case involving minor to moderate injuries and a settlement of less than $€ 7,000$ arrived at in under two years. Such cases account for an increasing volume of work and are, by and large, the sort of cases for which the protocol was designed. This study provides an important insight into how the Woolf reforms have affected the standard, simple case. However, it is still too early to gain any quantitative understanding of personal injury litigation as a whole. In order to conduct such an overall study one would have to wait until at least 90 per cent of cases opened from May 1999 to April 2000 have been completed - which ljudging from previous studies of personal injury litigation) may well take until mid-2003. ${ }^{10}$

Details of both the qualitative and quantitative methodologies are given in Appendix 1. 


\section{Structure}

This section is divided into a further seven chapters. The next chapter puts the Woolf changes into the context of other changes affecting personal injury litigation, and asks how far they work with or against other trends in the culture of personal injury negotiations. Chapter 2.3 sets out interviewees' overall views of the Woolf reforms, and considers their impact on methods of work. The next four chapters analyse the various steps of running a case: the letter of claim (Chapter 2.4); the defendant's acknowledgement, response and disclosure (Chapter 2.5); obtaining medical evidence (Chapter 2.6) and settlement (Chapter 2.7). The final chapter (2.8) returns to the problems the reforms were designed to address. It asks how far it has made the system less adversarial, quicker and cheaper. 


\section{Chapter 2.2 The context for personal injury work}

The Woolf reforms represent only one change among several that have affected personal injury litigation over the last few years. Both claimant lawyers and insurers spoke of the rapidity with which events were moving:

I can't see six months into the future... it's changing so radically. (Claimant Solicitor)

I've seen more changes in the last four or five years than perhaps all the rest of my career put together... Not only the way things have developed but the speed. (Insurer)

On the claimant side, the major change occurred in April 2000, when legal aid was abolished for most personal injury litigation. It was expected that most types of case that had been legally aided would be brought under conditional fee arrangements (CFAs). At the same time, CFAs were transformed. Previously, claimants had been expected to pay the premium for after-theevent insurance, to cover themselves against their potential liability to meet the insurers costs should they lose. Successful claimants were also expected to pay their solicitors' success fees out of their winnings. From April 2000, however, both the success fee and insurance premiums could be recovered from the losing insurer. Another important change has been the rise of claims intermediaries, who advertise heavily and then pass claims to solicitors for a referral fee. The first and best know such intermediary, Claims Direct, was established in 1995. In the last few years, however, many other firms have entered the market and have become a familiar feature of daytime TV advertising. ${ }^{11}$

On the insurers' side, the main feature has been the number of mergers taking place and the rise of eight or so 'giant' insurers who now dominate the market for both motor and employers' liability insurance. These firms have developed highly systematised approaches to claims handling, supported by heavy investment in Information Technology. Increasingly, claims handling is conducted through large national and regional claims centres rather than through local branch offices. At the same time, the ethos of claims handling has changed. All the insurers in the study spoke of the importance of resolving claims quickly. They stressed time and time again that speed reduced both costs and damages. 
This chapter sets the context for the Woolf reforms by describing these other changes. It begins by looking at what claimant lawyers thought of CFAs and the rise of claims intermediaries, before discussing how firms had adapted to the reforms. We then consider the main changes within the insurance industry, looking first at the insurance perspective and then at how developments were perceived by claimant and defendant solicitors.

\section{Developments affecting claimants: replacing legal aid with CFAs}

The 17 claimant firms we spoke to relied on a variety of funding sources.

- Five firms had developed as predominantly trade union firms. Two were still dependent on their links with trade unions for the great majority of their business. The other three were developing other sources of business, which they conducted alongside their trade union work. Two had contracts with legal expenses insurers (LEI) and one received considerable business from a claims intermediary.

- Three firms received most of their work from their links with legal expenses insurers. They dealt with large numbers of small motor claims in a highly systematised way.

- This left nine firms that, before April 2000, had been dependent on legal aid and private clients for the majority of their work. We were interested to find out how the legal aid firms had adapted to CFAs.

\section{Advantages of CFAs over legal aid}

Legal aid was not greatly loved by personal injury lawyers. Several solicitors expressed their relief to be free of the administrative hassles associated with the legal aid scheme:

In some ways, it's a welcome relief, because public funding has become such a... bureaucratic thing. And it ties you so closely to cost limits and to reporting back to the Legal Services Commission and so forth. It's a blessed relief in a sense. (Claimant solicitor - medium firm)

Legal aid is hopeless anyway... I think it's absolutely atrocious... just a horrible part of your working life... So the nice thing about conditional fees is that it's your risk, your insurance - insurance companies are much easier to deal with. It's you, the client, the money comes in... and everyone knows what they're going to get. And you don't have to fill in a 12-page form... and all kinds of rubbish like that. (Claimant solicitor - small firm) 
I hate to think what my life would be like if legal aid had remained in PI work, because my wife heads up our matrimonial department and she is getting very fed up with the whole business of public funding. We've got a franchise in matrimonial, housing and crime and we keep having partners meetings at which we keep saying we're going to give it up - and then we say, well, dare we? (Claimant solicitor - small firm)

Solicitors also pointed out that CFAs were more profitable:

I'd rather do a good PI case on a CFA than on legal aid, because I'll be able to get on with it more quickly and I'll make more money out if it. IClaimant solicitor - medium firm)

\section{Problems with CFAs}

Despite the advantages, solicitors made three main criticisms of CFAs: complexity, cash flow and risk. As far as complexity is concerned, several firms mentioned how difficult the arrangements were to understand, both for the firm and the client. The difficulties clients had in understanding the oldstyle (pre-recovery) CFAs have already been chronicled through detailed research with clients (Yarrow and Abrams 2001). Some firms suggested that, since April 2000, the arrangements were even more complex:

You can't give your clients any advice whatsoever at the moment on conditional fees and what's going to be recoverable in the success fee and your insurance premium... You have to spend 40 minutes to an hour going through all the potential scenarios, probably only one or two will apply to that case. All of which is unpaid. (Claimant solicitor - large firm)

The client care provisions - totally unworkable. The stuff you have to explain to clients - the clients don't understand it... The recoverability provisions certainly weren't thought through... The rules were drafted by people who had no conception of how it was actually going to work in practice and wouldn't listen to those who did. (Claimant solicitor - large firm)

Cash flow was a particular problem for small firms:

Cash flow is obviously a problem, because with [legal aid] certificates we were getting $£ 250$ on account... We're not getting that now. And you've got to pay for the disbursements. (Claimant solicitor - small firm) 
Cash flow was also a difficulty for specialist 'niche practices' that dealt with serious land therefore lengthyl claims:

The issue is cash flow, when you suddenly realise that you've got 200 on the go and you're paying disbursements up-front. And you realise you've got people who aren't going to bill for a year or two. (Claimant solicitor - medium firm specialising in catastrophic injuries)

The answer to cash flow difficulties was to have a regular stream of small, quick cases. As a solicitor in a small firm put it:

I'm concentrating on getting a reasonable number of smallish ones, because they're going to pay sooner and better. (Claimant solicitor - small firm)

As we discuss below, several firms were actively seeking to expand their 'bulk work'. Cash flow was one impetus behind the move.

The most serious criticism that claimant solicitors made of the move to CFAs was the difficulty in taking riskier cases:

The down-side on CFAs are those cases which are very borderline... and l'd like to progress it further but a bit reluctant to do it... You do get the 50/50, to 51 per cent sort of case which... I don't think anyone can take on. (Claimant solicitor - small firm

You've got at 51 per cent to 70 per cent a huge raft of cases and usually cutting edge-cases, a sporting case, an accident in a nursing home... asbestos cases. We've got a number of them, where we apply for insurance cover and they say 'forget it'. (Claimant solicitor, specialising in cutting-edge cases)

This was a particular problem for firms that specialised in serious or difficult cases, and lacked the 'critical mass' of small cases. These firms were particularly cautious in their use of CFAs. They took only a limited number of large, high-risk cases that had received the approval of risk evaluation committees. They were aware of their vulnerability:

You're probably talking to other firms that'll be amazed by how few CFAs we're doing. And you may say, 'Why aren't they catching up?' We're just very cautious because our cases tend to be high cost. We just can't afford the risk... Unfortunately... the statistics are that you only have to lose one to wipe out vast numbers of victories. (Claimant solicitor, specialising in catastrophic injuries)

We get specialist stuff [because] people feel that we are risk-takers... Which is an image that is two-sided really, in terms of benefits. The disadvantage is that the insurers... look at us and wonder if we are taking too many risks. (Claimant solicitor, specialising in catastrophic injuries) 
Specialist solicitors were aware that many cases were not receiving funding:

No-one's taking them on. [I'm in] a group of top lawyers, and we're actually asking each other, 'can you take this one?'... But we can't. None of us can. We're all in that situation where nobody has, if you like, a funding chest, which legal aid had, to take those cutting edge cases on. (Claimant solicitor, specialising in catastrophic injuries)

This particular solicitor was especially angry at the abolition of legal aid:

The bottom line is with legal aid going for Pl, there's huge numbers of people that are disenfranchised from getting access to justice. It hasn't accessed justice, it's removed it. (Claimant solicitor - specialising in catastrophic injuries)

\section{The rise of claims intermediaries}

Solicitors told us that the way to make money out of CFAs was to have a regular throughput of small, easy cases. These concluded quickly, providing a steady cash flow. They offered good returns for little risk. Furthermore, they lent themselves to standardised arrangements, avoiding the complexity of individually negotiated insurance premiums. The importance of small, lowrisk cases to any successful adaptation to CFAs meant that the conversation led directly from CFAs to claims intermediaries, whom solicitors felt had impacted directly on the market for such work. Most solicitors had something to say about claims intermediaries, and their comments were usually negative:

They're absolutely abysmal. I mean, I just think [named claims intermediary] are absolutely an appalling organisation... I am just so frustrated with them. (Claimant solicitor - small firm)

A horrible impact. We hate them. (Claimant solicitor - small firm)

The first criticism solicitors made was that advertising by claims intermediaries brought the profession into disrepute:

PI lawyers have always had a worrying reputation, sort of ambulance chasers. But that's just highlighted and enhanced that really. IClaimant solicitor - large firml

Lawyers are now really seen in a hugely bad light and if you introduce yourself as... a personal injury solicitor - oh! (Claimant solicitor - small firm) 
Secondly, solicitors complained about the high referral fees that claims intermediaries charged:

They charged the solicitor an absolute fortune for the case. I don't know what it is at the moment but I went to one panel to see what they were trying to sell, and it was about $£ 500$ a case. (Claimant solicitor - small firm)

The fees would make the thing dreadfully unattractive... We spoke to a number of solicitors who were working in that type of environment and... the answer we were hearing time and time again was it's great if you look at work in progress, but in fact the arithmetic never really comes out right. (Claimant solicitor small firm]

Thirdly, solicitors complained about the controls that claims intermediaries placed on cases. Some intermediaries, for example, required solicitors to report back to a claims manager, to seek counsel's advice on quantum and to use a specified medical agency:

We've looked at them, yes. And we haven't been impressed by what we've seen, for two reasons... One, the cost element. But secondly, and I think more importantly, the kind of controls and restrictions that are placed on your handling of the client matter. I think that you can compromise your position. So we don't rule it out because it's obviously a changing playing field, but so far we've not been tempted down that path. (Claimant solicitor - large firm)

One small firm that had entered into an arrangement with a well-known claims intermediary was particularly frustrated at the controls. He described the claims managers as 'incredibly inefficient', had made several complaints about the medical agency he was compelled to use and disliked having to go to counsel for advice on quantum: 'We can work out quantum... a lot more accurately and quicker than a junior barrister.'

Finally, solicitors worried about whether claims intermediaries acted ethically in providing clients with a good deal. One particular concern was the amount of the insurance premium and whether it would be recovered from the defendant insurer:

This business of the insurance premium - they've now re-insured the insurance premium and it's incredibly confusing what they've done. And they've written to all the clients... Oh, it's just absolutely a nightmare at the moment. (Claimant solicitor - small firm) 
Despite all the problems, however, the importance of achieving a regular flow of bulk work meant that claims intermediaries were difficult to ignore. Several (though by no means all) firms mentioned that, as a result of TV advertising and other marketing activities by claims intermediaries, they had seen a drop in new cases:

I feel a bit like one of those Red Indians on the plain saying: 'There don't seem to be many buffalo this year.' Because we have a feeling that, you know, the herds are getting away from us. So we've got concerns about our market share. (Claimant solicitor - medium firm)

Out of the 17 firms visited, only four had already entered into an arrangement with a claims intermediary. However, as discussed below, another two were about to start such arrangements and others were keeping the issue under review.

Despite the problems, most people thought that claims intermediaries in some form were here to stay. The only alternative would be for solicitors to carry out their own advertising. Although several firms mentioned this as a possibility, they acknowledged that it would be expensive:

A couple of months ago, we did some television advertising - just as a pilot really and that was actually quite successful... But all advertising along those sorts of lines is expensive, so actually getting the balance between advertising cost and return in terms of cases is more difficult. (Claimant solicitor - large firml

One large firm that undertook commercial work was also worried about the effect advertising might have on their image:

We, as a commercial firm, don't particularly want our names splashed across the back of buses, saying 'come to us if you have injured yourself'. So by using a marketing company we can take advantage of a regular flow of work without sullying our commercial name. (Claimant solicitor - large firm)

Claimant lawyers were aware that they would need to watch developments closely.

\section{Adapting to CFAs}

The forgoing discussion has highlighted both the advantages and the problematic nature of CFAs. For firms that had been dependant on legal aid, CFAs represented a major change. We were interested to see how they had adapted. Some developments, such as the increasing move to standardisation, 
work with the Woolf reforms; while others, such as disputes over the recoverability of success fees, have the potential to undermine the co-operative culture encouraged by Woolf.

\section{Is the number of firms conducting PI decreasing?}

One issue that cannot be addressed by qualitative research is whether there has been an overall reduction in the number of firms conducting personal injury work on behalf of claimants. By definition, we only spoke to firms who continued to carry out the work. Even where firms told us that they were giving up, it is difficult to distinguish between normal turnover and an overall reduction. In contacting firms, however, we did come across quite a few who had recently abandoned personal injury work. For example, out of 25 medium-sized firms contacted, five had stopped conducting PI claims. Many small firms listed as carrying out personal injury work had taken on very few cases since $1999 .^{12}$

There is surprisingly little information about the overall structure of the claimant PI market. The most reliable information comes from the Law Society's regular panel surveys, which ask firms for details of the fee income they received. The results of the last three surveys are given in Table 2.2.1. It shows the proportion of firms receiving some income from personal injury work in the year in question, together with the proportion receiving at least one-quarter of their income from personal injury work.

Table 2.2.1 Percentage of firms doing personal injury negligence work

$\begin{array}{lccc} & \text { Business survey } 2001 & \text { Panel survey } 1999 & \text { Panel survey } 1998 \\ \text { Financial year: } & 1999-00 & 1998-99 & 1997-98 \\ \text { Base: } & 585 \text { firms } & 318 \mathrm{firms} & 339 \mathrm{firms} \\ & \% & \% & \%\end{array}$

\section{Sole practices}

$\%$ of all doing $\mathrm{PI}$

2-4 partners

$\%$ of all doing $\mathrm{Pl}$

5-10 partners 


\begin{tabular}{|c|c|c|c|}
\hline \multicolumn{4}{|l|}{ Continued } \\
\hline & Business survey 2001 & Panel survey 1999 & Panel survey 1998 \\
\hline Financial year: & 1999-00 & $1998-99$ & 1997-98 \\
\hline \multirow[t]{2}{*}{ Base: } & 585 firms & 318 firms & 339 firms \\
\hline & $\%$ & $\%$ & $\%$ \\
\hline \multicolumn{4}{|l|}{ 11-25 partners } \\
\hline$\%$ of all doing $\mathrm{PI}$ & 76 & 87 & 88 \\
\hline$\%$ with $25 \%+\mathrm{PI}$ & 20 & 23 & 19 \\
\hline \multicolumn{4}{|l|}{ 26-80 partners } \\
\hline$\%$ of all doing $\mathrm{PI}$ & 65 & 72 & 68 \\
\hline$\%$ with $25 \%+\mathrm{PI}$ & 18 & 19 & 13 \\
\hline \multicolumn{4}{|l|}{ North } \\
\hline$\%$ of all doing $\mathrm{PI}$ & 77 & 83 & 85 \\
\hline$\%$ with $25 \%+\mathrm{PI}$ & 25 & 24 & 19 \\
\hline \multicolumn{4}{|l|}{ South } \\
\hline$\%$ of all doing $\mathrm{PI}$ & 64 & 77 & 79 \\
\hline$\%$ with $25 \%+\mathrm{PI}$ & 10 & 6 & 4 \\
\hline \multicolumn{4}{|l|}{ Midlands/Wales } \\
\hline$\%$ of all doing PI & 73 & 79 & 79 \\
\hline$\%$ with $25 \%+\mathrm{PI}$ & 7 & 13 & 14 \\
\hline \multicolumn{4}{|l|}{ London } \\
\hline$\%$ of all doing PI & 39 & 41 & 52 \\
\hline$\%$ with $25 \%+\mathrm{PI}$ & 9 & 10 & 10 \\
\hline
\end{tabular}

Source: Research and Policy Planning Unit, Law Society

There are a couple of caveats to make about this table. First and most obviously, it only looks at the position up until April 2000. As the surveys ask about income, they show cases closing, rather than new cases being taken on. It is too early to tell what has happened since legal aid was withdrawn. Secondly, the sample sizes were quite small. One cannot place too much reliance on changes of only a few percentage points.

Despite these problems, however, Table 2.2.1 does seem to show that even before the abolition of legal aid, the market in PI work was consolidating. Fewer firms were dabbling and more were specialising (with one-quarter or more of their business devoted to personal injury). This tendency was particularly marked among sole practitioners and medium-sized firms 
(5-25 partners). It also appeared stronger in London and the South. We need more information about how far the legal aid and CFA changes have increased this trend.

Interviews conducted for this study suggested that firms had adapted to CFAs in a variety of ways. Below we look at four separate approaches: embracing CFAs; withdrawing from personal injury work; keeping small and flexible; and attempting to develop the mass market.

\section{Bulk providers: embracing CFAs}

The most enthusiastic proponents of CFAs were two large firms who also had trade union contracts. This meant that they were not wholly dependent on CFAs and had been able to adapt gradually over time:

We found it good... We started using them as soon as they came out in July 1995. We broke ourselves in gently at that point because most of our work was union and legal aid and legal expense insurance, so it was only the remaining ones that we did [under] CFA. And we learnt how to use them with those... Since then we have gradually built up our conditional fee caseload. Over the last year it has really taken off. (Large PI claimant solicitor)

This firm said that its workload had almost doubled in the last couple of years - mainly through an increase in small and medium-sized claims.

Both firms put their success down do the fact that they are large, specialist firms with 'critical mass'. This gave them the edge in an increasingly competitive market place:

We've got 'critical mass', to use the jargon. We have been doing this sort of work for decades, in bulk... We know how to risk assess - we're often doing that. If you do union work in bulk, you always have to assess risk and you always have to bear dispersals. (Claimant solicitor - large firm)

\section{Unable to cope}

At the other extreme, one medium-sized firm described CFAs as 'a disaster'. They found it difficult to cope with the complexity, cash flow and risk involved with CFAs, and were thinking of giving up on personal injury work altogether:

I think at the moment we are probably approaching a crossroads with personal injury... I don't think I'm prepared to nail my colours to the mast and say in two years time we will still be doing personal injury work. (Claimant solicitor - medium firm] 
Although this was the only firm in the study which talked of giving up personal injury work, several other firms refused an interview on the grounds that they had withdrawn from the work.

\section{Small firms}

Four of the firms interviewed were surviving in the personal injury market by being small and flexible. In two firms, personal injury work was handled by only one person. In one firm, a partner and an assistant handled the work; in the fourth firm, it was handled by a partner, assistant and trainee. As discussed above, it is likely that many small firms have recently discontinued personal injury work. Others, however, survived, and were able to offer a local, personal service at a time when larger firms were increasingly offering a remote service by phone and post:

The worst part of modern personal injury is that you've got people in Manchester dealing with people a hundred or two hundred miles [away], never see the client... So it's got to be rough and ready, and it's got to be an inferior service. (Small PI claimant solicitor)

Small firms readily admitted that they had found the adaptation to CFAs difficult. They were not necessarily 'sophisticated' in their use:

We're starting to use CFAs more and more. I wouldn't say we were like some of the big Pl practices that have whole departments dedicated to CFAs. Candidly, I wouldn't say that we're the most sophisticated practice in the country operating CFAs... [But] obviously, all the PI work that comes in now, if we're going to do it, we have to do it on some form of alternative funding arrangement. (Claimant solicitor - small firm)

Life was from far easy for these small firms. Without backup, any untoward event could cause problems:

I had a virus for about two months from before Christmas... That was difficult, because I wasn't up to it. But I suppose that's exceptional isn't it? (Claimant solicitor - only person in practice conducting litigation]

One had felt compelled to enter into an arrangement with claims intermediaries and was depressed at the nature of work:

I do feel it is a bit depressing. I think the Claims Direct/Accident Group stuff is incredibly depressing... It almost seems like it isn't what I want to be doing. (Small PI claimant solicitor) 


\section{'Bespoke' practices}

Finally, the sample contained three firms with national reputations as 'bespoke' personal injury practices. They specialised in large, difficult cases, usually involving catastrophic injuries. Despite their high profile and exceptional reputations, these firms had found the change to CFAs particularly difficult. They found themselves turning away work on the grounds that it carried too much risk. They were also concerned that their caseloads were unbalanced: too many large, high-risk cases and insufficient bulk work. This made cash flow a problem, exposed them to the risk of a few catastrophic failures, and could cause difficulties with after-the-event insurers. One firm also worried that, under Woolf, their larger cases were settling more quickly, for less cost:

If you're having a lower caseload and you're doing less costs, you do need that turnover... So we're quite ravenous for new work. IClaimant solicitor 'bespoke' practicel

Another highlighted a worrying decrease in new cases:

We have found to our increasing concern that, with the increase in television advertising, a lot of our traditional referral sources are drying up... Our billing is very good and looks to be very good for another couple of years - but we've noticed a drop-off in the work coming in. So we have concerns about the future. (Claimant solicitor - 'bespoke' practice)

Out of the three firms, one was now concentrating heavily on clinical negligence cases, which are still legally-aided. Two, however, felt that they had no choice but to expand their bulk work. They had both recently decided to join claims intermediary schemes. After researching the market carefully, they had found schemes which they thought were ethical and acceptable. Although they expressed some qualms about developing a mass-market approach, they felt impelled to move in that direction:

It's not a market we really want to get into... Ideally, we'd continue with our traditional market here, which is a small number of heavy-weight cases. We don't really want to be having 300 trippers... But it's a very uncertain time. It may be that we have to go that way... to function as a practice. (Claimant solicitor - 'bespoke' practicel

That is an intense debate at partner level... I have to say that those of us in the PI field feel that, subject to the ethics of any particular provider, we should be moving in that direction. (Claimant solicitor - 'bespoke' practice) 


\section{Making success fees recoverable}

Recoverability is a relatively recent issue. Success fees and insurance premiums only became recoverable for agreements entered into since April 2000. At the time these interviews took place (January to September 2001) many firms had no experience of concluding cases under recoverable agreements. Others reported that negotiations over the amount of the success fee had been delayed pending the Court of Appeal decision in Callery v. Gray in July 2001. ${ }^{13}$ This lack of practical experience, however, did not stop respondents discussing the topic. It was clearly a live issue, with ramifications for the culture of negotiations between claimant solicitor and insurer.

Insurers and defendant solicitors were particularly critical of the provisions, arguing that they would lead to a massive and unwarranted increase in costs. They argued that the cost would be much greater than the legal aid it replaced:

The biggest problem is the massive expense, out of all proportion to the replacement of legal aid... Every single consumer [will pay] because of increased insurance premiums on a household, on a motor, every time they go into Marks \& Spencer, they're going to have to pay extra for it. And that cost is vastly growing. (Defendant solicitor)

It depends on who you speak to, but the belief is that the implementation of CFAs will cost something between $£ 300$ and $£ 500$ million per annum, to replace legal aid that cost $€ 50$ million per annum. There is something fundamentally wrong there... I don't think many insurers in the market have taken that very well. (Insurer)

Insurers also condemned the Court of Appeal decision in Callery v. Gray, on the grounds that it had over-estimated the risks involved:

Callery is a very poorly thought-out judgment. I don't know how the Court of Appeal can say an innocent passenger sat in a stationary vehicle that is hit from the rear presents a risk. There is a technical risk on Part 36, but it is a technical argument... In the Liability Insurers group we tried to find... a passenger claim on a rear impact where we hadn't made a payment. We didn't get one. So to say there is a $20 \%$ risk in a situation like that... it's just beyond belief. (Insurer) 
A defendant solicitor suggested that the sense of outrage had been exacerbated by the fact that the insurance industry had failed to prepare adequately for the cost increase:

Liability insurers are nowhere near ready for this... [In Summer 2000] when the rules were out, I got together with the top 10 insurers. There wasn't a single one of these people who could tell me that they had any reserves or any guidance given to... their staff... We've had two years of huge increases in motor premiums... and frankly those increases... have not included anything to cover [success fees]. That's just damages. (Defendant solicitor)

We return to the issue of costs in Chapter 2.8. For the moment, we are more concerned with the effect recoverable success fees have had on the relationship between claimant solicitors and insurers. Several respondents suggested that recoverable success fees had led to more disputes, undermining much of the goodwill engendered by the Woolf reforms. Although this was not a universal view, it was widespread - mentioned by insurers, defendant and claimant solicitors alike:

All the good work that Woolf has achieved in terms of the solicitors and insurers talking to each other, and all the good-will that has built up since April 1999, with the introduction of CFAs, I'm afraid that all went out the window... We are... as adversarial as we were pre-Woolf. (Insurer)

I think the Woolf reforms have been excellent... Where things have gone wrong is because the government decided to change the funding situation at the same time. The government simply did not think that through at all. (PI defendant solicitor)

Recoverability against the defendant is just dreadful. It's the worst thing that has happened and it's in danger of bringing the whole system into disrepute. (Claimant solicitor - leading firm)

The problems caused by success fees may represent teething problems, which will disappear once the industry has discussed its problems and the courts have given appropriate guidelines. However, several respondents suggested that disputes and litigation were likely to continue for years to come:

CFAs will go one of three ways: there will be some form of mediated agreement; there will be agreements on individual bits and pieces; or there will be one hell of a messy litigation that will go on for years and years, a bit like credit-hire... I think we will be talking about CFAs in five years time and still be saying: 'Oh that case is still in the Court of Appeal - I wish they would hurry up because I have got a hundred cases stacked up behind me, depending on the outcome of it.' (Insurer) 


\section{Developments within the insurance industry}

Insurers have also experienced change - in organisational structure, in methods of work, and in the culture of claims handling. These are explored below, looking first at what insurers have said and then at solicitors' perceptions.

\section{Changes in organisation and methods of work}

Insurance companies are becoming larger. For one firm visited, this was through organic growth. For the others, it was through merger. Mergers have resulted in fewer, larger offices, which increasingly specialise in particular areas of work. Insurers were now more likely to employ specialist staff, within specialist units:

We have to specialise people far more these days... Three years ago... we used to have claims handlers who handled every type of claim but, as insurance claims became more technical or fast moving, more and more legal arguments, we had to specialise people. It was not just the Woolf reforms but things like credit hire. (Insurer)

As far as methods of work are concerned, all the companies we spoke to stressed the increasing importance of communicating by telephone. Direct Line, founded in 1985, was one of the first insurers to offer a predominantly telephone-based service, and it inspired a culture change within the industry. The telephone is now the preferred way of receiving notifications from policyholders, investigating claims, and negotiating with claimant solicitors. Phone calls were thought to be quick, provided more information than letters and cost less than face-to-face meetings:

We are very much trying to get away from letter writing to telephone as a medium, we just pick up the phone... Our personal injury claims handling philosophy: as soon as we get a letter of claim we ask the handler to phone the solicitor, just to establish telephone contact... We feel the telephone is a better way of doing business. (Insurer)

We return to this subject in Chapter 2.7, when we discuss methods of negotiating settlements.

Another change in working methods was the increasing investment in computerised systems. The flagship computer project was Colossus, a damages programme used by several insurers in the study. Claims handlers typed in details of the injury and Colossus provided the range of damages 
figures they could offer in negotiations. Advocates of Colossus saw it as an important way of 'holding the line' on settlement values. Some claims handlers, however, regretted their loss of discretion:

It's not so enjoyable... I personally feel that you're in a little box and you can't really move too far each side of that... There is less discretion over damages than there used to be when we did our own valuation... Our hands are tied more... It's what Colossus says, and I sometimes think that's a bit on the low side. But then, if we are getting the claims settled, perhaps it is correct after all. (Claims handler)

Colossus is a subject that provokes controversy within the industry, with a couple of organisations stating that they would not use it:

People cheat with Colossus... A lot of their staff... know how to work it now, so they just put in the information that they need to get an answer out. And also... Colossus produces a lot of litigation, far more than we have. Our audits show that we are settling in at a little bit more than Colossus, but we are probably saving at the other end. (Insurer)

Although Colossus represents the industry's most advanced computer project, information technology has also allowed other developments. Case handlers were able to track the work required through a computerised diary system, rather than responding to the incoming post.

That is probably one of the major changes... We deal with things on a diary system rather than waiting for the post to come in and responding to it. (Claims handler)

Computerised systems also allowed claims handlers to be monitored through an array of performance targets and audits:

We're monitored on costs; we're monitored on life cycles of claims; monitored on telephone calls, quality and quantity. Almost everything under the sun is monitored... It has really been coming in over the last couple of years, and I suppose for the last 12 months it has been at its peak. (Claims handler)

We return to these issues in Chapter 2.3, when we discuss the implication of Woolf on working methods. 


\section{A change in approach?}

Insurers claimed that changes in organisation and methods of working have been accompanied by a change in philosophy. Their emphasis now is on resolving claims quickly. Hazel Genn, in her seminal work on personal injury negotiations, Hard Bargaining, suggested that insurers used delay as a powerful negotiating weapon:

Despite protestations to the contrary, it is clear that insurance companies do use delay as a potent threat against their opponent while creating or contributing to it and remaining relatively insulated from its effects themselves. (Genn 1987, p.103-4)

Genn argues that delay favoured insurers for several reasons. It discouraged and worried accident victims, causing them either to go away or settle for less. It also allowed insurers to 'retain their money while the case takes its course, and earn interest at a greater rate than that which they would have to pay to a successful plaintiff', (Genn 1987, p.104).

Genn's research was conducted in the 1980s. Insurers claimed that this was true then, but over the last five to 10 years, their approach had changed. They all stressed that delay cost money: the cheap claim was a quick claim:

It's a total change of focus. Years ago, when I first came into the industry, it was just leave it till it goes away... That type of attitude - ignore it and it might go away. Sometimes it did, but sometimes it turned into a massive claim... If [now] we exposed our clients to increase costs because we'd played around the file, we would have a major rap on our hands. (Loss adjuster)

If you look back at the way we handled claims, it was fairly laid back. The claims didn't move forward very swiftly, just everything was relaxed... I don't suppose costs really mattered quite so much in those days either. If you look at... the pace of claims handling over... the last 10 years, even... the last two years, it just gets faster and faster and faster and more efficient. (Insurer)

Insurers were acutely aware that it was they who ended up paying claimant's legal costs. The main reason for speed was to resist the build-up of claimant solicitors' costs:

The savings for us are in costs. If someone has been injured they're entitled to $x$ amount of pounds and it doesn't matter whether we pay that now, or whether we pay it out later, we're still going to have to pay it out. I think that the savings - the thing that increases the longer a case comes out - is solicitors' costs. (Claims handler) 
However, some insurers argued that damages also increased with delay:

Primarily [it's] legal costs but, of course, in the last few years if it's a large claim we've also been hit by all the other changes as well. If you've had a claim sitting in the cabinet for, say, eight years, a large claim, you'll have been hit by NHS charges, changes in the CRU, the Ogden changes... with the multiplier. So the cost of the claim is going up rapidly, interest is building up... all the time. So the pressure now is to get the claim sorted out practically and settled. (Insurer)

They specifically denied that they could earn more by hanging onto their money:

The $A B I$ audit says that claims costs are increasing by 13 per cent per annum. So if you've got a claim that's... worth about $£ 10,000$ and you delay settlement through bad handling... and it costs you six months in terms of time... you've made that claim... $E 650$ more expensive... At the moment, in terms of investment income... if were getting 6 per cent we would be doing well. So here we are. We've got a book of business that is haemorrhaging at 13 per cent per annum and we can only generate 6 per cent per annum in terms of costs to cover it. The maths is very simple. (Insurer)

As Dingwall and others (2000) have pointed out, one cannot necessarily take everything that respondents say at face value. However, the claims handlers we spoke to mirrored their managers concerns about the need for speed. They all felt under considerable pressure to conclude cases quickly and were conscious of being monitored by their employers:

The targets are put on a white board, and how you have reached your target is put on the white board, and you have a monthly one-to-one meeting... You obviously want to meet your target and ... yes, you are more prone to get on and get it done. I think everybody... has now got the view that they need to get the claim and do it as fairly and as quickly as possible... If the solicitor doesn't bug us then we will bug him until we get something going with it. (Claims handler)

This suggests that when insurers say that one of their first priorities is to conclude cases quickly, this is a priority that they have made some attempt to realise in practice.

Thus even before the Woolf reforms, there were perceived economic pressures to deal with claims more quickly, according to a timetable set and monitored by insurers themselves. A theme of the subsequent chapters is how far the reforms consolidate these existing changes. 


\section{Dumbing down? Solicitors' views}

Claimant solicitors were aware of the changes insurers were undergoing: The reality is the insurance market is vastly more competitive than it used to be. Insurers have amalgamated, taken over, there is more of an international flavour to the insurance world. And, by definition, their operations are going to change. (Claimant solicitor - medium-sized firm)

However, they did not necessarily see these changes in a favourable light. Claimant solicitors' main complaint was that insurers had 'dumbed down', laying off experienced staff and replacing them by more junior staff:

They've dumbed down... We used to deal with experienced insurance inspectors who would often get on the phone to you, speak to you about a case, and come around to see you at the office... We are [now] dealing with fairly junior people... who are not lawyers. Probably not even graduates, almost certainly not even graduates. (Claimant solicitor - TU firm)

Claimant solicitors also complained that insurers were short-staffed and suffered from undue staff turnover:

Insurers are getting more and more understaffed, and more and more pressured and they just don't have the time. (Claimant solicitor - large firm)

The trouble with insurance companies is that they've got their own problems... You can have a case going on for a year and a half, and find you're dealing with four different people. (Claimant solicitor - small firm)

Some solicitors also expressed frustration at the call-centre approach: You never really know who you are dealing with... When you speak to an insurance company, [it's] dial one for Kirsty, dial two for switchboard, and we'll put you on hold for the next half hour'. You never have a human being you can relate to anymore. (Claimant solicitor - TU firm)

Defendant solicitors echoed these concerns, accusing some insurers of 'paring costs' by employing too few staff, or staff with insufficient skill:

Generally, the insurance industry have de-skilled significantly... Some have retained significant levels. Some, through merger and other processes, have found it very difficult to get the right skill-levels in there, or to get the right resources in there. (Defendant solicitor) 
Defendant solicitors expressed concern that insurers saw claims handing as a cost, with extra resources spent on it providing little benefit to the company:

The insurance industry, generally, as most industries are, are run by accountants, bean-counters... [They] do not put much value into the claims process. They would tend to say, 'well, the claim is worth what it's worth, and whatever you do, you can't affect the value of the claim'. Now that's not something I would accept but that's... a commonly-held view within the insurance industry. And if you hold that view, you do not necessarily want to put a huge amount of resources into a claims department, because it's a cost, which doesn't necessarily see any benefit. (Defendant solicitor)

\section{Dumbing down? Insurers reply}

For their part, insurers denied that they now employed less experience people. Instead, they claimed that staff were now better trained and more specialist than before. One manager, while conceding that other firms may have 'dumbed down', was firmly of the opinion that the criticism could not be applied to his own organisation:

Instead of dumbing down, and getting rid of people, and making the claims process something where there isn't a human being involved, we've gone in the opposite direction. I would suggest that the unit that sits out there is probably one of the best on the market... They don't come cheap, because experience costs, but all in all it is a better way to approach it. (Insurer)

On the other hand, some insurers did admit that the drive for efficiency savings had increased the pressures claims handlers were under:

We've got good volumes of staff but... you've got to make life a little bit difficult because of the challenges that come with that. Of course it's high portfolios, more portfolios, more work, more deadlines to comply with, more offers to make, more medicals to read. It's difficult to get a Utopian department. (Insurer)

Two of the three claims handlers we spoke to felt that they were now under more stress than before. The following exchange provides an indication of how staff perceived the new pressures:

Interviewer: Are you under more pressure than you used to be?

Claims-handler: Oh, enormous amount, yes. I had a month off with stress earlier in the autumn... Head Office are very much looking at resources and methods of working, which are continually looked at anyway, but even more so. I had a discussion recently with our senior management about the needs of the 
personal injury department... We were finding that there were far more claims coming in that we can possibly deal with, expediently, with the existing resources. (Claims handler)

In the chapters that follow, we consider how these pressures affect the way that the Woolf reforms have been implemented.

\section{Summary}

The Woolf reforms have not taken place in a vacuum. In order to assess their effect, it is first necessary to place them in the context of other changes happening in the market place.

From the claimant solicitor point of view, the main change has been the withdrawal of legal aid from personal injury work and its replacement by conditional fees. CFAs work most smoothly and profitably for 'bulk work' that is small, quickly resolved, easy cases handled in bulk. They provide a regular cash flow with little risk. Indeed, insurers suggested that since the Court of Appeal decision in Callery v. Gray, solicitors were over-remunerated for this type of work. The market for bulk work has been changed, however, by the rise of claims intermediaries, who advertise heavily for claims which they pass on to solicitors for a fee. Solicitors were highly critical of such organisations, but few felt able to ignore them. Four out of the 17 firms we spoke to had joined such schemes and two other 'bespoke' practices (with national reputations for work on difficult claims) were about the join such schemes. Other firms were keeping the matter under review.

Few firms had much practical experience of recovering success fees and insurance premiums from defendants. However, the issue provoked strong feelings. Insurers complained that success fees led to unacceptable increases in costs and predicted several more years of 'messy litigation'. Respondents on both sides of the fence felt that the bad will generated by the issue had soured relationships between claimant solicitors and insurers and undone much of the good work achieved by Lord Woolf in improving relationships.

Insurers have also undergone changes. After a process of mergers, eight or so giant insurers now dominate the market. There are fewer, larger, claims centres. Increasingly, centres are specialising in areas of work, covering the whole of England and Wales from a single office. The telephone was increasingly used to replace post (too slow) and meetings (too expensive). 
Claims handling has also been affected by developments in information technology - particularly by Colossus la computer programme to assess damages), by computerised diary systems and by performance indicators. Staff felt that they had less discretion and were more heavily monitored than before. They also thought that stress levels had increased. These changes were not always welcomed by claimant solicitors, who bemoaned the loss of the 'personal touch' and criticised companies for 'dumbing down'.

Insurers said they had also changed their philosophy. All the firms we spoke to stressed the importance of handling claims quickly. A quick claim was believed to be a cheap claim, saving both solicitor costs and increases in damages. Claims-handling staff felt under increasing pressure to "get claims sorted'. Instead of waiting for the claimant to make the next move, they would chase on progress. 


\section{Chapter 2.3 The Woolf reforms: overall views and their impact on methods of work}

This chapter looks first at overall views of the reforms, and then considers their impact on the working methods of claimant solicitors, insurers and defendant solicitors. We were interested in the changes that these groups have made in, for example, their use of information technology and staffing. We particularly wished to explore whether the Woolf reforms have encouraged a more standardised approach towards handling personal injury work.

\section{Overall views}

For the most part, those involved in personal injury work liked the Woolf reforms. When respondents were asked an open question on what they thought of the reforms, their responses were overwhelmingly positive. Below we look at the overall views of claimant solicitors, insurers and defendant solicitors. We then consider whether there is a demand for additional specialist protocols, to cover specific areas of personal injury work, such as multi-track or disease claims.

\section{Claimant solicitors' views}

Among the 18 claimant solicitors we interviewed, 12 gave a reply that favoured the reforms, while the other six gave a more mixed answer, containing both positive and negative elements. No-one gave a generally negative reply. Initially, we had been concerned that the interviewees might have been atypical, with those opposing the reforms disproportionately likely to refuse an interview. Results from the telephone discussions, however, did not suggest widespread resentment of the reforms. Out of seven telephone discussions with solicitors unable to grant a full face-to-face interview, four were broadly positive, while three gave mixed replies that contained both favourable and unfavourable elements.

Only one solicitor refused an interview on the grounds that he was unhappy with the changes. He was especially critical about uncertain costs orders. He felt that there had been 'minimal consultation' prior to the reforms and felt that anything he said now 'would probably make no difference'. On further 
probing, however, it appeared that many of his concerns stemmed from the replacement of legal aid with CFAs and the competitive pressures introduced by claims intermediaries.

The following quotations give a flavour of the favourable reactions elicited by the Woolf reforms:

Fantastic... There's been an outbreak of common sense. (Claimant solicitor leading firm)

A very positive move in the right direction. (Claimant solicitor - leading firm)

Terrific, absolutely terrific. (Claimant solicitor - small firm)

I don't have a great deal of bad words to say about it really. (Claimant solicitor - medium firml

In fact, on closer probing, most claimant solicitors did have a few bad words to say about the new procedures. Their detailed concerns are discussed in the rest of the report. It is important, however, to place these criticisms within a framework that is essentially favourable to the changes.

The extent to which Woolf's principles of openness and co-operation have now become the new orthodoxy can be gauged by the fact that many respondents claimed to have taken a 'Woolf' approach long before April 1999:

Our philosophy has always been pro-active here, so there's no huge psychological or philosophical changes necessary. We've tended to believe in a cards-on-the-table approach. (Claimant solicitor - leading firm)

It is possible that adversarial hard-bargainers continue to exist, but respondents were reluctant to admit to such attitudes openly.

\section{Claimant solicitors: the most positive aspects}

When claimant solicitors were asked what they particularly liked about the Woolf reforms, their replies covered a wide span, including case management conferences, telephone conferencing and a more sensible approach to late claims. Most replies, however, could be grouped under three inter-related themes: a clearer structure, more openness and greater emphasis on settlement. 
Claimant solicitors appreciated the fact that the pre-action protocol gave a clearer structure to the negotiation process:

The whole thing's organised... There's a framework so everyone knows where they are a lot more. (Claimant solicitor - small firm)

You know where you are from day one, and you have a procedure which you follow. Provided you follow it, you shouldn't really come unstuck. IClaimant solicitor - small firm)

Where is was necessary to issue court proceedings, cases were better prepared than before:

When you go to court now you are ready... You've done all the work - frontloading has had that effect, so you're more organised when you get to court. (Claimant solicitor - small firm)

Solicitors also saw the benefits of greater openness and exchange of information:

When I did my legal training it was: give as little information out as possible, and issue as quickly as you can; and with defendants, it was: delay as long as possible. And that has all obviously changed a great deal. (Claimant solicitorsmall firm)

They were always holding their cards back just in case - maybe the case won't go ahead... maybe they'll make a mistake. You know those games. IClaimant solicitor - leading firml

However, the greatest benefit, mentioned by around half the sample, was that the Woolf reforms had made settlement easier:

[It] encourages early settlement... Insurance companies are now much, much more keen to settle claims... Things can be brought to a conclusion much more quickly, which suits us, suits the client - they get their money quickly, and you can move on and get the next case. (Claimant solicitor - small firm)

Several solicitors singled out claimant offers under Part 36 of the Civil Procedure Rules for praise. As we shall see, they were regarded as useful way of moving settlement negotiations to a conclusion.

\section{Claimant solicitors: criticisms}

The most common criticism - raised by one in three claimant solicitors was the perceived lack of sanctions where defendants failed to comply with the pre-action protocol: 
We'd like some sort of sanctions for not complying with the protocol. At the moment, there's very little we can do about it. (Claimant solicitor - medium firml

Where are the sanctions if you don't? Basically nothing. (Claimant solicitor medium firm]

Claimant solicitors felt frustrated that if defendants failed to respond to their letters of claim within the protocol period, all they could do was issue the claim. As this would require a medical report, they were rarely in a position to do this. They also thought that even if they did issue, judges were reluctant to apply sanctions:

Maybe I'm a bit biased, but I think often the courts are too lenient on defendants in terms of them complying with the time limits. (Claimant solicitor - leading firml

There's a natural reluctance from district judges to impose sanctions. (Claimant solicitor - small firm)

The request for sanctions, however, is problematic. Respondents wanted judges to be tougher on their opponents, but softer on them. The next most common criticism (made by four solicitors) was that judges were too interventionist. Judges were criticised for being overly anxious to apply time limits without a regard to practical reality:

\footnotetext{
Initially the courts were so hell-bent on grabbing the case by the scruff of its neck and pushing it through quickly that to an extent they lost the plot of what it was like to actually handle those cases in practice. (Claimant solicitor leading firml

If you keep getting such tight timetables on things that are unreasonable, you have to keep going back and trying to explain to the court, this is what the problems are... If you're dealing with a brain injury claim... you get a quite ludicrous four weeks to do this - and four weeks on a brain injury claim is just ridiculous. (Claimant solicitor - medium firm)
}

Although individuals raised a range of other issues, only one other criticism was made by three or more solicitors. It was that too much pressure was applied to agree to joint experts. As we shall see, claimant lawyers regarded experts as an essential part of their case construction, and they were keen to keep control of the process. We discuss this further in Chapter 2.6. 


\section{Insurers' views}

Insurance managers were remarkably consistent in their views. Again their response were predominantly positive. Like claimant solicitors, they liked the reforms for providing a clearer structure, improving openness and encouraging settlement. They were particularly pleased that there was less litigation than previously:

Increased settlements and less claims... being issued... The focus now is for what you're trying to achieve and there is obviously a time-scale to work to and try and... negotiate and reach a settlement. (Insurer)

We don't get as much litigation in terms of people just issuing willy nilly and certainly a lot more emphasis on talking and negotiation. (Insurer)

The reforms tied in with several of the changes described in Chapter 2.2. Crucially, the reforms were thought to lead to quicker, more focused claims handling. Insurers were keen to have deadlines to put into their computerised diary systems. The fact that the time limits were clearly set out in the protocol (rather than merely internally) meant that they carried credibility with policyholders as well as internal staff. They also welcomed the fact that, with fewer cases being issued in the courts, they were dealing with more of the work in-house, rather that putting matters out to external solicitors.

Insurers, however, made two criticisms. The first was that, despite the increased emphasis on settlement and tighter time-scales, there had been no saving in cost. Insurers felt that without the fixed costs recommended by Lord Woolf, the reforms had not been fully implemented. We return to this in Chapter 2.8.

The second criticism was that the scheme for medical reports under the protocol had 'not worked as well as it should have done':

When it works, fantastic... When it doesn't work it really can be a bit of a pain. (Insurer)

As discussed in Chapter 2.6, procedures for commissioning medical reports have proved a battle ground, with claimant solicitors and insurers fighting for control. 


\section{Defendant solicitors}

Only four defendant solicitors were spoken to, so it is difficult to make any definitive assessment of their views. The impression they gave however, was that they were less positive about the reforms than either claimant solicitors or insurers. They were the group most disadvantaged by the changes. With fewer claims issued, insurers were passing less work to defendant solicitors. Also, because defendant solicitors were only involved after issue, their experience was confined to claims where the protocol had failed in some way.

One defendant solicitor described himself as 'neutral':

I think my view is... neutral. My private view was that, whatever the rules do now, save for one or two bits and pieces, such as Part 36 offers, the situation was available under the old rules. It's just that they weren't policed by the courts. (Defendant solicitor)

Another said he was 'sceptical':

I was sceptical about whether it was ever necessary. I think the main reason for Lord Woolf's reforms was to exercise some control over the less competent firms of claimant solicitors who were letting cases run on and on. (Defendant solicitor)

One was positive:

I think the Woolf reforms have been excellent... I'm frankly surprised that they've gone as well as they have... Obviously the protocol has been enormously helpful. (Defendant solicitor)

He thought that most current difficulties were the result of recoverable success fees.

The final solicitor had mixed views: 'I think on the whole it has worked.' He was, however, concerned about 'unrealistic timetables and district judges being silly'.

\section{More protocols?}

As already seen, there was substantial support for the personal injury protocol, which was seen as providing a clearer structure to negotiations and encouraging openness. Respondents were asked whether they thought the 
personal injury protocol was suitable for all personal injury cases, or whether it should be supplemented by other protocols to cover, for example, multitrack cases, or specialist areas, such as industrial disease or motor claims.

Generally, claimant solicitors did not see any need for a separate multi-track protocol. Instead, they found it quite easy to adapt the existing protocol to give it the flexibility required for larger cases:

We use the pre-action protocol for multi-track cases. I don't know if it will improve it to have a different one. I suspect not. (Claimant solicitor - bespoke practicel

I have not made a distinction. It works both ways. Heaven forbid that we have a separate protocol. (Claimant solicitor - large firm)

Insurers were also generally happy to 'follow the spirit' of the existing protocol in multi-track cases. Two, however, thought that it might be worth looking at' some variation of the personal injury protocol for larger claims. One insurance manager, for example, thought that, although very expensive claims (over $€ 125,000$ ) needed their own individual handling, there was a 'middle ground' of cases worth $€ 15,000$ to $£ 125,000$ which might benefit from greater standardisation. Insurers suggested that a multi-track protocol might contain: a longer period for admission; provision for joint expert reports; and discussion of how the parties should approach quantifying future loss. A few claimant solicitors added that such a protocol might also include more comprehensive disclosure of documents.

When asked about specialist protocols for different types of case (such as industrial disease claims), insurers generally opposed the idea. They feared that additional protocols would add to complexity, without producing any great benefit:

I do think we are getting a bit protocolled out... It gets terribly onerous in terms of what protocol is this and what section have I got to look at, and how does that fit in with everything else. You can go a bit far with these things. (Insurer) 
Most solicitors agreed. They found the existing protocol easy to understand and adapt, and did not see a need for further technicalities:

There's a danger... of having too many protocols and too much of a prescribed way of doing things. The principles should be laid out and they should have a pretty universal application... If you start adding too many protocols, it's just going to get far to technical. (Claimant solicitor - large firm)

The only support for separate protocols came from highly specialist firms. Five solicitors (four acting for claimants and one for defendants) thought one or two specialist protocols might be useful, for example in disease cases, but some added that there should not be 'too many more'.

The Motor Accident Solicitors Society (MASS) has produced a charter for its members, which commits them to additional protocol requirements over and above those of the general personal injury protocol. The MASS charter has not received official approval, and it does not appear to be well known. Around half of those solicitors spoken to for this research had not heard of it at all, and most of the rest were vague about what it contained. For example, one solicitor, when asked what he thought about the MASS protocol, replied:

It was in a book that I got, a Road Traffic book... It slipped my mind what I thought about it. I did think it looked quite good. I can't remember what I was going to do, but actually it reminds me, I'm planning to do something about it, and I can't remember what it is. (Claimant solicitor - small firm)

Even members of the scheme felt it was not well understood. One claimant solicitor said that his firm were 'very much founder members of MASS' and that he was the protocol representative. However, he found it difficult to remember details of what the charter contained:

I read it once a year when I have a complaint or something. I have to go back into it and re-familiarise myself again. (Claimant solicitor - large firm)

Another firm, who took part in the pilot scheme, was concerned that the message did not filter down to claims handlers:

The trouble is it is not very well known within the insurance company... There will be one person within the company who deals with it. If that person moves, it takes months to get somebody to replace them, to get them trained up. (Claimant solicitor - medium-sized firm]

The low awareness of the MASS protocol illustrates the difficulty of introducing new specialist protocols into personal injury work. Solicitors and insurers have a limited capacity to absorb the complexities of new schemes. 
Under the Protocol Practice Direction, protocols require the approval of the Head of Civil Justice (para 1.1). Our findings suggest that the Head of Civil Justice should approve new protocols only if there is a clearly demonstrated need for them.

\section{The impact on claimant solicitors' methods of work}

One issue we particularly wished to explore was the impact the Woolf reforms had had on solicitors' methods of work (in terms, for example, of staffing, computer systems and use of counsel). We have already discussed how insurers were investing in computer systems and standardising their procedures. Below we examine changes within claimant solicitors firms. In particular, we were interested to see how far Woolf had encouraged lor discouraged) a standardised approach, in which work was delegated to lower level staff, supported by sophisticated IT systems. We start by describing firms' IT systems, staffing and use of counsel. we then look in more detail at the five firms within the study that took a standardised approach to fast track work. We consider the pressures firms felt to standardise and ask how the Woolf reforms affected this trend. Most firms denied that they had changed their methods of work as a direct result of Woolf. However, the Woolf reforms often encouraged (and tied in with) other changes that were taking place.

\section{IT systems}

Personal injury firms covered a wide span in their use of IT. At one end of the spectrum was the solicitor who boasted that he did not have a computer on his desk. In his firms computers were used only by secretaries, as enhanced typewriters.

Several firms gave their fee-earners computers and left it up to them how they used them. This provided internet and e-mail access, as well as standard software. A couple of solicitors mentioned that Microsoft Outlook was a useful way of diarising the many deadlines that Woolf generated:

We're now at the situation where there is a network... there's internal and external e-mailing... A number of my colleagues tend to manage their cases through some of this other standard software... Outlook and that kind of thing. But there is no specific case-management software. (Claimant solicitor medium-sized firm]

I use Outlook Express on my computer just as a diary to remind me of dates. (Claimant solicitor - small firm) 
This level of computerisation also allowed the use of firm-wide standard letters:

We standardise things like certain letters... more mundane things like standardised letters to engineers, doctors, police reports, obviously client care, letters... liability letters. All that has been standardised but I think, the actual working of the case, it's quite difficult... We try not to become too much of a factory here, because I think you can almost standardise too much. I think you take away the subtleties of the lawyer. IClaimant solicitor - medium-sized firml

Making standard letters available, however, did not necessarily ensure that solicitors used them:

I've got, for instance, precedents on disk and all that. But to be honest with you, it's quicker for me to... dictate it for my secretary to type it up... With a person of my experience, I can just dictate it out of my head anyway. IClaimant solicitor - small firml

The next level in terms of computerisation was to provide firm-wide software that combined a diary function with standard letters. At this level, one can start to talk about a standardised approach to case-management. The diary told fee-earners when they should address issues, while the standard letters told them how to. There was general agreement that such an approach was suited to fast track rather than multi-track:

We keep looking at it in terms of multi-track, but I just think the way you run a multi-track case is so diverse that it's actually difficult to have a structure. (Claimant solicitor - leading firm)

A further development of standardisation was when the computer system could be used to monitor and supervise more junior fee-earners in their work. One firm that used non-solicitors to deal with large numbers of minor road traffic cases had recently developed new software that allowed supervisors to set the deadlines:

We have introduced the facility so supervisors can set tasks on the computer system for people. So if a court date comes in, an allocation questionnaire comes in, and there's a deadline within which it's got to be returned, the teamleader will task that to the case-handler through the computer system... Before it was up to the case-handlers themselves to diarise it on their own personal diary, and then if they were sick or ill it would get overlooked... That's something we've introduced since Woolf, but I don't think because of Woolf. (Claimant solicitor - standardised firm) 
With supervisors able to set the tasks, claimant fee-earners were subject to the same sort of controls as claims handlers within the major insurers. It is telling that this particular firm referred to its staff as claims-handlers and said that it liked to recruit people with an insurance background. Like insurance staff, the claims handlers in this firm were subject to an array of performance targets, including case duration, billing targets and closure rates. The firm explained that the computer system offered a choice between 'blank precedents' and pre-written standardised letters, known as 'zippers'. To ensure maximum use of 'zippers', staff were monitored on the number they used.

A fifth level of computerisation would be to introduce systems that went beyond diaries and standard letters to structure decision making. Some firms used checklists to ensure that crucial decisions took relevant factors into account. Several showed an interest in computerised case management systems that included decision-making prompts. One solicitor said that his firm had already decided to install such a system:

We've relied on our IT quite heavily... over the years, but the new case management system is going to be even better, hopefully... I would like to hope that it was more of a back-up, certainly for junior people it will structure their decision making and... help the supervision process. (Claimant solicitor trade union firml

There is as yet, however, little practical experience of using such systems. Two firms had attempted to find case-management systems to structure higher-level decision making, but so far without success:

We've been looking... for three years... [for] a proper case-management system... We've seen some, we've tried them out, we've experimented and we've found them wanting... They're date-led. There's not enough qualitative information... The case-management systems that we've seen don't provide the right quality or analysis or information that we need. We do very detailed case reviews and that's very time consuming. (Claimant solicitor - 'bespoke' firm)

Finally, some solicitors mentioned that, in theory, it would be more efficient if solicitors' systems communicated directly with the court's systems. Despite the enthusiasm Lord Woolf showed for court-based IT, however, they felt that the courts had a long way to go:

We did send out support staff to an open evening at the court and they fell about laughing at the [court's] IT system, so there's a bit of a credibility gap. (Claimant solicitor - leading firm) 


\section{Staffing}

Standarised computerised systems are often linked with the greater use of paralegal staff. Those firms that had gone down the route of bulk, standardised, fast track work were using high levels of unqualified staff, and saw this as a developing trend:

We are skinning down, employing lots and lots of paralegals. We don't have so much room for qualified staff or high-powered legal executives. That's actually what's happening. (Claimant solicitor - standardised firm)

We are certainly developing our paralegal team, partly because of your low margins on fast track work. Also if you can get a good paralegal you're increasing your profitability. (Claimant solicitor - standardised firm)

One firm suggested that, as well as being cheaper, unqualified staff responded better to the constraints of bulk fast track work:

We find with solicitors that they've spent years and years training to be this very important person... And if we take them in and say: 'Right, here you are, sitting open-plan at a desk next to someone not qualified, but you do the same job, and you don't have your own secretary. 'It's not really what they wanted. So they tend not to be as happy... And we're not giving them probably the variety of cases that they want. (Claimant solicitor - standardised firm)

It was also pointed out that the shortage of training contracts meant that the applicants for paralegal jobs were often of a high calibre:

There are some very good candidates out there who are now looking for paralegal-type posts, notwithstanding the fact that they are very competent, good individuals... It's sad. There are a lot of good people out there that just aren't getting [training contracts]. (Claimant solicitor - standardised firm) 
Firms with predominantly multi-track workloads did not allow unqualified staff to take responsibility for cases, though some were increasing their use of legal assistants for specific tasks:

We have more legal assistants than we used to have, and we make use of our legal assistants and trainees more than perhaps we used to... [for] jobs within files... straightforward schedules of special damages, and not so straightforward ones; some witness statement-taking; cost schedules and collating trial bundles and so on. (Claimant solicitor - leading firm)

One firm linked the increasing use of legal assistants to the Woolf approach on proportionality:

I think it's proportionality... I mean, we're very careful about what we will do on a case. There's no point sending a solicitor off to... see witnesses, for example... - spending a day in Cambridge seeing witnesses on the case... That's not cost-effective, not proportionate. We're not going to cover it... So we either do a questionnaire, or we send out someone who's a paralegal. So we're doing that now, much more than we used to. (Claimant solicitor - leading firm)

Another, however, denied that their greater use of paralegal staff was Woolf related, and put it down to general commercial pressures:

Pre-Woolf we had three solicitors working on personal injury work. Post, or today, we have four solicitors working with a couple of paralegals... But [the changes] are not Woolf-driven, they are practice development driven. (Claimant solicitor - medium-sized firm)

Overall, around half the firms said that they were making greater use of unqualified staff, suggesting a general trend. The other half, however, denied that they had changed their mix of staff. A solicitor in a small legal aid practice pointed out that, compared with legally aided work, personal injury work was well paid:

On personal injury, there is a potential to earn at a rate of something approximating 1200 an hour, when you take into account the success fee. With the majority of legal aid in the office, that's charged at $£ 60$ to $£ 70$ an hour, a lot of it even less if it's... legal advice at court work. (Claimant solicitor - small firm) 
He therefore saw no reason not to continue to use qualified solicitors. A solicitor in a bespoke practice suggested that the risks posed by CFA agreements might mean that staff needed greater skills than previously. She described a firm-wide course on risk assessment that had shown up weaknesses in some fee-earners approach:

There are a couple of weaker fee-earners who did not last the week course. [They] went of their own volition when it became increasingly embarrassing... as to how they could not analyse a case... That's just our firm's experience, but these are people who worked in personal injury for six to seven years preWoolf. (Claimant solicitor - leading firm)

Finally, it was suggested that one of the effects of the reforms was to require more work within a shorter period. Five firms said that their staff now carried fewer cases at any one-time, though they turned cases over more quickly:

In the past you could probably have large caseloads, but I don't think that's possible now... They've all probably got a full caseload of 200 plus - we're endeavouring to get it considerably below that... We think 150 is probably a reasonable figure these days. (Claimant solicitor - medium-sized firm)

\section{Use of counsel}

Almost every claimant solicitor said that they were now making less use of barristers.

In fast track cases, firms claimed they rarely used counsel to draft pleadings or give advice on liability or quantum. Most solicitors said they would only use counsel for pre-trial issues for particularly 'awkward' clients, for cases that were likely to proceed to trial eventually or for 'something we can't be bothered to do'. However, some claims intermediaries required that counsel opinions were sought. Barristers would be used for trials, but as one firm put it 'we're not having that many trials anyway.' In our own survey of fast track files, ${ }^{14} 15$ per cent of pre-Woolf cases used counsel, compared with 13 per cent of post-Woolf cases. Where counsel was used, they were mostly asked for advice on quantum or liability, or to settle particulars of claim. The numbers are too small to show any real change in behaviour, but they do suggest that barristers were used in only a small minority of cases. 
Claimant solicitors said that they still used counsel for large, multi-track claims, but they now used them more selectively - usually to check that nothing had been missed:

On a catastrophic injury case, l'd still use counsel... but only at a stage when I think I've done everything and got everything ship-shape. Then l'd get counsel to have a look at it and make sure that you've not missed anything. (Claimant solicitor - leading firm)

More and more we steal away a lot of the work that the juniors would have done, because it's work that we can do, and we can make money out of it... For example, big schedules of damages in brain injury cases, which traditionally you'd give to barristers to do, we've now started to do in-house. IClaimant solicitor - leading firm)

Several respondents mentioned that counsel were now expected to work as part of a team, participating in joint decision making, rather than simply tell solicitors how the case should proceed:

[In a major case] I wouldn't get a written advice on quantum but l'd have a quantum conference and bring along the experts... and... as part of that we'd talk about what we consider to be the value of the case. But I definitely see it as a two-way process. It's very much... adding to and considering issues as a joint venture and moving forward, rather than handing over responsibility to counsel and saying 'we've brought it this far, now it's your job'. IClaimant solicitor - leading firm)

Several reasons were given for the trend away from counsel. The main one was that solicitors were now much more specialist: 'we see ourselves as the experts.' This was particularly true when it came to valuing claims: as one solicitor in a small firm put it: 'If a PI solicitor has got any skills, it has got to be [in] assessing quantum.' It was suggested that barristers had been slow to offer the highly specialist skills that solicitors wanted, though this was now changing:

The other problem the Bar had traditionally is that they didn't specialise enough, quickly enough. So it's pointless having specialist lawyers in solicitors' offices, then instructing a general barrister who knows far less about personal injury litigation than the solicitors instructing them. Fortunately, the Bar has taken that on board and they are now getting better at specialising. (Claimant solicitor - leading firml

The replacement of legal aid with CFAs was also thought to have had an effect. This was partly because legal aid had required opinions from counsel that solicitors now thought unnecessary. It was also more difficult to instruct 
counsel on a CFA basis because, as self-employed people, barristers found it difficult to spread the risk: "they should be spreading risk across the chambers.'

The other reasons given for using counsel less were linked to the Woolf reforms. These were a faster timetable, the perceived need to keep control of the case, and the pressure to ensure that costs were proportional to the claim. As one solicitor said, 'maybe the CPR has escalated that process'. Solicitors expressed concern about the delay barristers introduced into cases:

It's better that we work on the case, in terms of the profit share, but also in terms of our control and understanding of the case... Typically, the best juniors are very busy and it's frequently just another source of concern - when will the barrister get back to you? Much better to control the case yourself, do it yourself, and then at least... you know when it's going to be done. (Claimant solicitor - leading firml

By the time you've instructed counsel, sent the papers off and waited $X$ number of weeks to get it back, you could have done it yourself and moved it on. (Claimant solicitor - leading firm)

Solicitors were also aware of the need to keep control of case management conferences. One solicitor expressed concern about the idea that she might send counsel in her stead: 'it's dangerous.' Finally, it was suggested that the courts were now less likely to approve barristers' fees on assessment:

We find when it comes to... tax assessments, assessment officers are saying: 'Why do you need counsel? You don't need counsel. It's not proportionate.' (Claimant solicitor - leading firm)

Thus, although solicitors considered that there was a continued role for expert barristers in large claims, they felt that there was less work for younger barristers. This was part of a more general trend, of which the Woolf reforms were a small part. In order to adapt, barristers would need to develop greater specialist skills, respond more quickly, work in partnership with solicitors and consider acting under CFAs.

\section{A standardised approach}

Five firms within the study could be said to have developed a standardised system for dealing with fast track claims. They were all large firms, who received many similar fast track cases each year, usually through arrangements with trade unions or legal expenses insurers. They all 
measured their caseloads in thousands and often in tens of thousands. The characteristics of a standardised approach were heavy use of non-qualified staff, coupled with investment in IT. The computer systems prompted feeearners on the tasks that needed to be done, and provided them with banks of standard letters, so that the task could be completed with less effort. Senior solicitors saw themselves primarily as managers rather than feeearners.

The standardised approach tended to flow from arrangements with 'bulk' referrers - notably LEI insurers and trade unions:

It's mainly accredited to a [former partner] who thought: well, let's target the insurance companies - there's money to be made out of getting legal expenses work referred to us. And really, even since then, it's been very focused and streamlined, because we deal with about 10,000 claims a year which are to do with car accidents. So we've got that volume of car accidents and 95 per cent of them take a very similar course... so it's easier to be streamlined and focused, because of the similarity of the work. IClaimant solicitor - large firml

One firm did not yet have a sufficient turnover of fast track cases to justify a standardised approach, but it was attempting to build up both the number of cases and the systems to handle them:

Two solicitors... are really taking the bulk of the smaller PI and between them they're developing standardised structures to deal with it. Because the idea is that we'll build a... quick turnover section of the department, which will be as standardised as possible... In our dream scenario, those two people would take on more and more cases, and probably recruit legal execs to deal with them... and then they would supervise the whole thing. (Claimant solicitor - medium firm)

Firms cited a variety of pressures to standardise. One was the perceived need to deal with claims as quickly and cheaply as possible:

One day we're going to get fixed costs and we think you have to design your process with that in mind... You have... to do the work as cheaply and efficiently as you can. You can only do this through having a very sophisticated IT system. (Claimant solicitor - large firm)

We're certainly introducing more case management for fast track work. But I don't think that's the result of Woolf. I think it's the result of realising that the way to make fast track work profitable is to have it case managed, full stop. (Claimant solicitor - large firm] 
Another was the requirement under client care rules land, formerly, under legal aid franchisingl to provide the client with standard information. The computer systems contained many different standard reports, to send to clients on a regular basis:

You have to cope with client care in a different way. You have a system which deluges the client with information on a regular basis, so they don't have to phone up and say: 'What's going on?' (Claimant solicitor - large firm)

Also, legal expense insurers and trade unions increasingly wanted audit information, to show that case-handling met the targets they had set:

They look at... how much, how long you're taking to deal with cases. They do client satisfaction surveys. (Claimant solicitor - trade union firm)

A standardised approach both ensured consistency and provided the information that referrers asked for.

One firm had embraced the standardised approach more fully than others and provided a good illustration of both the strengths and weaknesses of the model. On the one hand, the firm dealt with cases quickly and cheaply. Both its completion times and costs were substantially below the average. It also provided its clients with regular updates. On the other hand, some communications with clients lacked the personal touch - as, for instance, when a mother and her two young sons (aged two and three) had each received identical letters on the same day. Although files were reviewed thoroughly before issue, initial offers could be rejected without the same degree of care. Fee-earners were meant to spend 50 minutes considering the medical report, but it was difficult to ensure that they did. The manager expressed concerned that some non-qualified staff did not give the medical report (and subsequent valuation) sufficient thought:

In my unit, there's one or two people... I don't get the feeling they've perhaps perused the medical report at the same length they used to... I think there's people who take a quick look at the medical report and think, looks alright... It's our risk. If we've given the wrong advice; if we haven't perused it properly, we will be the ones that get penalised. (Claimant solicitor - standardised firm)

In two of the files we looked at, the claimant had ended up settling for the same or less than the offer they had already rejected, and this could cause bad feeling. 


\section{A standardised approach and the Woolf reforms}

No firm suggested that the Woolf reforms had led them to adopt a standardised approach. Most stressed that they had already proceeded down that route before the reforms were introduced. Although they had needed to adapt their systems to Woolf, this was part of a constantly developing process:

It's constantly being evolved. It's one of those things that you are constantly developing and tweaking. (Claimant solicitor - large firm)

We were adapting anyway, so l'd like to think that whether the CPR had come in or not we would have adapted in the way we have. IClaimant solicitor - large firml

However, firms did feel that the Woolf reforms made the process of standardisation easier. As one solicitor put it, 'it's dovetailed'. The Woolf reforms consolidated existing trends in at least four ways.

First, they provided a helpful conceptual distinction between fast track which was suitable for standardisation - and multi-track, which was not. Woolf provided an ideological justification for dealing with smaller personal injury claims in a way that was quick, cheap and cheerful.

Secondly, as we have seen, they provided a clearer structure. The standardised approach relies crucially on computer-generated deadlines, and the Woolf reforms provided more deadlines to programme into the system:

It is easier to tag on the sort of Woolf pre-action stuff to computers now because you get, you know - check in 21 days, check in three months, so it does help. (Insurer)

Thirdly, under Woolf, deadlines were generally accepted rather than set unilaterally by the firm. There was therefore more chance that insurers and defendant solicitors would respond in the time-scale the computer had set:

There was a feeling that it would really help us, because we felt that we were pretty streamlined and there wasn't a lot we had to do to come into line with it. But we thought that, hopefully, the insurers would come more into line, and other solicitors would come more into line, so that our clients would get a quicker and more efficient service - because of the people we dealt with being quicker and more efficient. So there was quite a lot of excitement about it. (Claimant solicitor - large firm) 
Finally, the Woolf reforms had prompted firms to overhaul their systems. Although most firms said that they would have revised their systems in any event, the reviews carried out in the run-up to Woolf received greater attention and resources than would otherwise have been the case. Firms had needed not only to train staff but also to review their standard letters and procedures. Several solicitors described the process of 'gearing up for Woolf' as a major undertaking:

We had to redraft a lot of our standard letters and forms - that was a vast undertaking. We revamped our supervision systems so that in the short term we could ensure that people were actually writing the proper letter of claim and all that sort of thing. It was a vast amount of work. (Claimant solicitor (eading firm)

The process had encouraged partners to think hard about how they conducted their cases:

There was no transitional period... everything was being 'Woolf-ed' from day one. The positive thing is that it stopped me from getting bored as I reached... my 40th birthday - because it does make you think about litigation. IClaimant solicitor - leading firml

\section{The impact on insurers' methods of work}

The previous chapter discussed the major changes sweeping through the insurance industry. The last five years have seen an increasing emphasis on resolving claims quickly, in the belief that speed reduces both solicitors' costs and the level of damages. Claims-handling techniques are now more structured, with greater use of computer systems to prioritise work and monitor performance. These changes were not the result of the Woolf reforms: they started before 1999, and were inspired by more general commercial pressures within the industry. If there were a casual relationship, it was the other way around: the pre-action protocol partly reflects the industry's increasing emphasis on resolving cases quickly, according to a clear structure. However, the reforms have consolidated the process. As one insurer put it, Woolf 'focused' things:

It started coming in earlier, things had been hotting up, but then the Woolf reforms really focused it... You have got the Woolf reforms which have changed the mindset, but you have also got other commercial pressures also playing in the background. If you combine the two together, the pace of change is very swift. (Insurer) 
Woolf had a similar effect on insurers as on standardised firms. Although insurers carry out regular procedural reviews in any event, Woolf implementation had encouraged more resources to be devoted to the process. As one insurance manager put it:

Back end of October 1998, we formed a working party... We really did as a company say: 'Right, let's forget what we've done before. Let's look long and hard at what we are doing now.' (Insurer)

The result was a completely new office manual, covering all aspects of claims handling. Interestingly, though, Woolf was not the sole motivating factor behind this. At the time, the company was also undergoing a merger, which likewise encouraged a new, streamlined approach.

In preparing for April 1999, the first change insurers needed to make was to add more deadlines to their computer systems:

We had specific Woolf action bars inserted [to the computer system]... It has got all the deadlines that they have to adhere to... 'Have you received a letter of claim?' 'Yes' - and you put in the due dates so they know when the 21 days expire. 'Has an expert been nominated?' 'Yes,' - and again you put the due date in. (Insurer)

What we actually did was we changed our diary system... First, letter of claim comes in, they will do the [acknowledgement]. Then they go to the screen, they'll put a date in, which will be first letter of claim received... I think it is set about two months on, to pull the file, make sure that you've looked at it, and make sure your enquiries are done. (Insurer)

One insurer pointed out that there were now more dates in the system, each requiring the claims hander to review the file:

The feeling is that there's probably more review dates... If it's one where we're disputing liability, obviously they've got to be aware of the three-month deadline... so you're going to have file reviews for that. Also if you're waiting for medical reports they'll put file reviews in for that. And Part 36 offers when they come in, obviously there are 21 days to respond to those. (Insurer)

Not only were there more review dates, but they were imposed on a more structured basis:

[Before review dates] were more flexible, depending on the individual view of the case. So it would be almost be a judgement call, when do I need to look at this one again? It was more ad hoc, and inevitably became much more structured. (Insurer) 
Woolf also encouraged the industry to design systems that enabled supervisors to monitor compliance with the timescales:

If it goes two days past, [the new software] will elevate to their manager that they haven't complied. (Loss adjuster)

We do file auditing on a very regular basis. Every personal injury handler is audited... to look at Woolf compliance, making sure that they are meeting deadlines. (Insurer)

One particular advantage of the Woolf reforms was that they established the 21-day and three-month deadlines as industry norms. They could therefore be used to encourage a quicker response from those outside the company, especially policyholders and brokers.

We do a lot of work with our policyholders, educating them on Woolf, saying we've got to have these letters of claim quickly. The brokers know they've got to be sent to us quickly... People are far more focused. In the good old days, they'd probably sit on them for weeks. (Insurer)

Another respondent referred to the increase in 'policy power'. Some insurers had started to write Woolf deadlines into their policies, so that if policyholders refused to respond within an appropriate time period, they could threaten to invalidate the policy. As he put it: 'We've... got this big beating stick.'

Respondents stressed that the Woolf changes, although time-consuming, did not represent a radical change in direction:

We've had to be a bit more sophisticated in tracking our advisors... That was already underway in any event because of what we thought was an increasing need to be more proactive on things. (Loss adjuster)

As the new deadlines worked with an existing trend towards a more structured approach, they seem to have been well received. Staff found that the changes introduced as a result of the Woolf reforms fitted in with their existing methods of work. Thus, after an initial period, they were quite easy to adapt to:

Overall, I think it has certainly made claims easier to deal with. You know, an initial shock when it first came out, but it's not that difficult. It's just not that difficult to follow. (Claims handler) 


\section{The impact on defendant solicitors}

Defendant solicitors are usually only used once litigation has been issued in court. They were therefore more directly affected by the Woolf reforms than either claimant solicitors or insurers. The immediate impact of implementation in April 1999 was that defendant solicitors experienced a substantial reduction in their caseloads. As one insurer put it: they are not getting the same amount in terms of volume... they definitely aren't'. There were three reasons for this. The first was a temporary blip, as claimant solicitors reacted to the new procedure by postponing issuing cases until the reforms had settled down. The second, however, was long-term. Insurers report that they are settling more cases in-house, with fewer being issued in court. The final blow is that some insurers have now established their own inhouse legal departments to handle routine fast track litigation:

We have an in-house legal department which pretty much deals with all our small, fast track work... You're talking 90-95 per cent of the fast and small track litigation goes to them. (Insurer)

The result was a dramatic reduction in work for defendant solicitors, with some firms forced to make redundancies:

The immediate impact of Woolf which everyone noticed... was the amount of litigation declined quite rapidly. So that meant redundancies... I think we had at least two redundancies that could be attributed to that... Both were salaried partners. (Defendant solicitor)

By the time of our interviews in 2001, firms reported some improvement. The temporary downturn had been replaced by a temporary upturn as the delayed cases worked their way through the system. Insurers had reduced the size of their solicitor panels, which meant more work for those that remained. One firm had also succeeded in securing contracts for claims-handling work from companies beset by temporary 'merger mayhem'. However, it was clear that life would never be quite the same. Defendant solicitors would have fewer routine, fast-track cases and would have to concentrate on quality rather than quantity'.

Defendant solicitors' problems were compounded by the fact that insurers had taken the opportunity to reduce the rates they paid. As one insurer put it:

Lawyers' costs we've squeezed down to the bone, literally. It's incredible - the rate we've controlled our own lawyers... and we've got claimants' lawyers running up huge bills. (Insurer) 
Defendant solicitors were resigned to a continuing downwards trend:

I suspect that... because of the commercial pressures and the buying power of the insurance companies, [defendant solicitors are going to] find themselves at the raw end of these deals. (Defendant solicitor)

It was thought that insurers would increasingly require solicitors to charge on a fixed fee basis, or on a scale agreement that depended on the level of proceedings reached. Where hourly rates were used, these would either be pegged, or forced down in cash terms. The result was that defendant firms who, as commercial suppliers, had traditionally been more prestigious than claimant firms, were now receiving lower hourly rates. One defendant solicitor remarked that while claimant solicitor rates has risen to $€ 150-€ 160$ an hour plus success fees, defendant solicitor rates had fallen:

Perhaps 10 years ago we would have said our rate was $£ 120$ and now most of them would say it was $E 110$ or even $E 100$. (Defendant solicitor)

Given these immediate problems, defendant solicitors had had less chance to think strategically about the direction of their firms, and it was difficult to discern other trends. Nor could we see any overall trend in the amount of authority insurers gave to their solicitors. Some claimed they delegated more authority, to allow a quicker response within the timetable set. Others, however, wanted to keep tighter control of the litigation process.

\section{Summary}

In general, both claimant solicitors and insurers liked the Woolf reforms. The reforms were thought to have provided a clearer structure, introduced greater openness and led to easier settlements. The main criticism that claimant solicitors made was the perceived lack of sanctions when defendant solicitors failed to comply with the pre-action protocol. Insurers' main criticism was that the reforms had not reduced costs. Both sides also expressed some concerns about the arrangements for commissioning medical reports (discussed further in Chapter 2.6).

One reason why those involved in personal injury litigation liked the reforms was that they fitted in with existing trends. Several large claimant solicitor firms were developing standardised ways of handling fast track cases, by which work was delegated to lower-level staff supported by sophisticated computer systems. These systems combined a diary function (telling staff when to undertake tasks) with a bank of standard letters. 
The Woolf reforms did not cause standardisation, but they consolidated the process in four ways. First, they provided a useful conceptual distinction between fast track (suited to standardisation) and multi-track (not suited). Lord Woolf's report can be taken as an ideological justification for dealing with fast track cases in a cheap and cheerful way. Secondly, the pre-action protocol provided a clear structure for negotiations. At its most basic, it gave firms more dates to programme into their computer systems. Thirdly, it meant that the deadlines would be more likely to be understood and adhered to by others. Finally, the reform process triggered solicitors to undertake wide-ranging reviews of their systems.

By April 1999, insurers were already further down the path of standardisation. Yet, like claimant solicitors, they felt that the Woolf reforms had consolidated and 'focused' the process. Several insurers reported undertaking major reviews of their processes in the run-up to Woolf. Although reviews might have taken place in any event, Woolf ensured that they attracted greater resources. The most immediate effect was that firms added more dates to their computer systems. This has led to greater standardisation: systems now include more occasions on which the claims handler is prompted to consider the file and the prompts are set in a more structured way. There is also greater supervision to see whether deadlines are met. Finally, the reforms made it easier for insurers to insist that policyholders and brokers complied with protocol deadlines. Claims handlers reported that after some initial teething problems they had adapted to the new systems fairly easily. This is because they fitted closely with existing trends.

Defendant solicitors were the group most immediately affected by the introduction of the Civil Procedure Rules. As of April 1999, they experienced substantial reductions in workloads. Although some of the reduction was short-term (and work has since picked up a little), most of the reduction is long-term. Insurers are now settling more claims in-house before issue. A few companies are also establishing in-house legal teams to deal with fast track litigation. In addition insurers have used their bargaining position to reduce the rates they pay their own solicitors. Whether or not as result, defendant solicitors seemed less positive in their views of Woolf than either claimant solicitors or insurers.

Almost all the solicitors we spoke to reported a reduction in their use of barristers. This was thought to be a general trend, which would have occurred independently of the reforms. However, Woolf made solicitors more conscious of the need to keep control of proceedings, to respond quickly and 
to show that costs were proportionate. All these pressures contributed to a more selective use of counsel. Although solicitors still saw a role for the Bar, they would need to develop greater specialisms, respond more quickly, work in partnership with solicitors and consider acting under CFAs.

Finally, we asked solicitors and insurers whether they saw a need for new, specialist protocols to cover specific aspects of personal injury work, such as multi-track or disease claims. Most respondents were wary of introducing new protocols. They found the existing personal injury protocol easy to adapt, and feared new protocols would add unnecessary complexity. The Motor Accident Solicitors Society's private protocol was not well known.

The research findings suggest that the Head of Civil Justice should approve new protocols only if there is a clearly demonstrated need for them. 


\section{Chapter 2.4 Letters of claim}

The personal injury pre-action protocol requires the claimant's solicitor to send the defendant two copies of a letter of claim immediately sufficient information is available to substantiate a realistic claim and before issues of quantum are addressed in detail,' (para. 3.1). The letter of claim should contain:

a clear summary of the facts on which the claim is based together with an indication of the nature of any injuries suffered and of any financial loss incurred. In cases of road traffic accidents, the letter should provide the name and address of the hospital where treatment has been obtained and the claimant's hospital reference number. (Personal injury pre-action protocol para. 3.2: emphasis in originall

The information should be sufficient to enable the defendant to "commence investigations and at least put a broad valuation on the "risk" (para. 3.5). The protocol recommends that solicitors use a standard format, and provides an example.

This chapter is divided into three sections. It begins by exploring what respondents thought of letters of claim. The new approach was regarded as a major change from what had gone before: one solicitor called it the biggest sea-change'. Both insurers and claimant solicitors felt that it was an improvement.

Next we discuss the timing of letters. Letters of claim involve claimant solicitors in carrying out more preparatory work and were inevitably sent later than short, old-style letters. We were interested in how much work they involved, how much later they were sent, and whether this caused any problems. The protocol suggests that, in some circumstances, claimant solicitors may wish to send an 'early notification' that a letter of claim was on its way. We look at how often such early notifications were sent, and whether they were seen as a useful part of the process.

Thirdly, although insurers thought that new-style letters of claim gave more information than previously, they complained that compliance was patchy. We explore the extent to which letters met the standards set by the protocol and annexed letter. We start by considering the basic requirements, such as whether letters specified a date and place, and whether they contained a summary of the facts and an indication of the injuries. We then look at 
two areas that have caused particular problems: the indication of financial loss; and the details required by the Compensation Recovery Unit. Finally, we asked insurers how they reacted if letters of claim missed some or all of the information required.

\section{Respondents' views}

Both insurers and claimants described previous practice as giving minimal information. Now the first letter the insurer received would contain a much higher level of detail:

The old letter was: 'We are instructed by $x$, he was injured on $x$, give us the money, you bastards.' And we didn't see why we should tell an experienced insurance company what the claim was about, because we took the view they know. So there is a sudden culture leap to setting it all out it detail. (Claimant solicitor - leading firm)

It's far better than what you used to get which was, I'm instructed by Joe Bloggs to make a claim against you, full stop,' - end of story. (Insurer)

A couple of solicitors suggested that the change may be less than first appeared, because they would send letter of claim information eventually in a second or third letter rather than the first:

We had always done that letter - well not exactly the same - but we had always given the detailed allegations and more detail about what actually happened in our second letter. First letter was shot out early on, just to get the insurance company involved. (Claimant solicitor - leading firm)

Most insurers, however, felt that they were now getting more information, at an earlier stage: 'that's an area that's improved considerably.'

Both insurers and claimant solicitors liked the new approach to letters of claim. Insurers appreciated it because it helped them put a reserve (valuation) on the case, allocate it to an appropriate level of claims handler and follow up their investigations. They felt that there was less delay and unnecessary cost than the previous 'drip-feed' approach, where requests for more information led to prolonged correspondence:

Much more comprehensive in terms of the accident circumstances. That immediately then gives us an opportunity to investigate properly from day $1 . .$. We also get a good idea of the type of injury and whether there has been any grievous loss as a consequence. So you are also aware of a fairly good guestimate that you can put on the file. (Loss adjuster) 
You used to get [Firm X] who used to usually write in and say, 'we have a claim'. We had to write back and say, 'well what's the injury?' And that would generate another letter. It was just cost building. Solicitors would not put the detail in their letter. Now they do put the detail... which makes our job far easier and quicker. (Insurer)

Claimant solicitors were also overwhelmingly positive about the change: We've accepted it, accepted it with open arms, and we're getting good responses back. (Claimant solicitor - leading firm)

It makes a lot of sense, and Woolf sort of prompted us to do that. IClaimant solicitor - leading firm)

Solicitors stressed that writing a letter of claim was a useful part of their own case preparation. Funding changes meant that, at an early stage, they needed to gather the main facts of the claim and work out its chances of success. Having done this, it was no hardship to disclose their information to the other side:

By the time we do our letter of claim, we will have analysed things, so it's actually no hardship for us to draft the letter of claim. So we're not doing anything that is nice or helping the defendants. We're doing nothing more than setting out what we have done on our internal work product. And the disclosure of that, at that early stage, had to be right, and there's no resistance to that idea. (Claimant solicitor - leading firm)

The old days of 'let's run it for a bit and see what happens', those days have gone. Even with unions, they've gone. So you're doing a lot of work to vet the case anyway, and when you've done that work, you've usually got enough to write the letter. (Claimant solicitor - leading firm)

It was even useful to have the information set out in writing at the front of the file:

It's nice because it is also a point of reference in the file. If you want to see... what the claim is about, all you have to do is flick back to your letter of claim, and you see everything in one letter... So it is a good idea. (Claimant solicitor small firm) 


\section{Work and timing}

\section{The work required}

Claimant solicitors were asked what work they would normally undertake before writing a letter of claim. Most, but not all, said they would interview the client. One firm dealing with small road traffic cases in a standardised way said that they very rarely held face-to-face meetings with clients at any stage of the case:

It's all letters and phone and e-mails and faxes... We have a few local clients, but our client base is pretty much truly national. (Claimant solicitor - large firm]

Another firm said that the trade union would usually provide enough information to write the first letter:

The union work comes in a fairly standardised sort of format, so often there will be more than sufficient information there to actually start the claim immediately. (Claimant solicitor - medium-sized firm)

Other solicitors, however, said that they would start by interviewing the client. For a simple fast track road traffic claim, this usually provided sufficient information:

An RTA will take you at least 20 minutes to make sure you've got the right facts, the right allegations... If the client has told me the date of the accident and what happened, and is basically quite sure about it, then you don't need to check up on anything. I think your client is entitled to be believed: as long as they sign the letter, then that's fine. (Claimant solicitor - large firm)

Sometimes, however, clients were vague, and solicitors would need to check essential information:

If it's a client off the street, often they can't even remember when the accident was and we perhaps have to do a bit of searching around. GP records are normally a good source. (Claimant solicitor - medium-sized firm)

In a few cases, solicitors thought it might be worth checking essential facts with witnesses - though at this stage, witnesses would be contacted by telephone or questionnaire rather than seen personally. Solicitors were wary about incurring substantial costs in investigating liability before receiving the insurers' response in case the insurer admitted liability and argued that such costs were unnecessary: 
There are some cases where you would want to know more from the witnesses before the three months is over. And of course, the earlier you see the witnesses the better... But in general cases, we would probably do it by telephone and questionnaire at the outset, just to get a rough idea of what it is we are going to say... We don't want to be accused of incurring costs that are unnecessary. Witnesses, for instance, who are a long way away and need to be seen and need to travel, we would avoid that. (Claimant solicitor - large firm)

In work-related accidents, several solicitors felt that it was important to check relevant regulations and mention them in the letter of claim:

We've had a great debate here about what you should put in your protocol letter of claim in an employers' liability case. I always took the view that you didn't need to plead breaches of statutory duty. I've lost that battle to those who do a lot more employers' liability than I do, who say: 'No, no - it's much better if up-front you demonstrate to the opposition that you have done your homework and that there are 40 separate breaches of statutory duty regulations and you can quote them all.' So that is now what we do. IClaimant solicitor - leading firm।

The amount of work thought necessary to write a letter of claim was clearly influenced by how sure solicitors felt they needed to be of their facts. Views differed considerably on this. The protocol attempts to assuage concern by pointing out that this first letter is not a pleading. Paragraph 2.9 states that if matters subsequently come to light to suggest a different version of events, it would not be consistent with the spirit of the protocol for a party to "take a point" on this in the proceedings, provided that there was no obvious intention... to mislead'. One solicitor said that he was pleased to see the courts upholding this 'very sensible approach':

Today nobody says, 'oh, your letter of claim said so-and-so and so-and-so'. I think so long as we have that freedom where our [words are] not going to come back and haunt us, we will continue to be open... [Judges] have got their feet on the ground and I just hope that continues. (Claimant solicitor - leading firm)

Others, however, were not convinced:

We don't take any notice of the provision in the protocol that it won't be held against you if you get it wrong. We take the view that it bloody well will, and so we tell people they've got to make sure that they are as certain as they can be that they've got the facts right. (Claimant solicitor - leading firm) 
In the event it becomes subject to litigation, we wouldn't want insurance companies and their representatives saying that you led us down the garden path, and you didn't make this assertion at the outset. (Claimant solicitor leading firm)

As well as ascertaining the facts, claimant solicitors also needed to make funding arrangements. For CFA cases, this could be time-consuming. Most firms carried out a formal risk assessment that they put to a firm committee. It would therefore usually take a week or two to wait for the next meeting. If the firm gave it's own go-ahead, the timing of the letter of claim would then depend on the type of after-the-event insurance used. One leading after-theevent insurer required that the CFA was signed before the letter of claim was sent. This meant sending the agreement to the client and talking through the provisions with them before sending the letter of claim. Other insurers, however, were more flexible, which allowed the letter of claim to be sent to the insurer at the same time as the agreement document was sent to the client:

Standard run-of-the-mill would be: client in; take the statement. At the first meeting generally we would make some form of risk assessment, maybe to be clarified later at a meeting with the other fee-earners, because we have department meetings every week. And the letter of claim would be shot off pretty much soon after that. So when I write to the client with a copy of the statement with the conditional fee agreement - a copy of that and explanatory notes and all that sort of stuff, I'd probably at the same time be shooting a letter of claim off to the defendant. (Claimant solicitor - small firm)

\section{Time taken}

Our survey of around 300 claimant solicitor files showed that first letters to insurers are now being sent later. We measured the time from the claimant solicitor first being notified of the case, and the first communication with the defendant. The median number of days pre-Woolf was 13; post-Woolf it was 36. This difference is statistically significant. ${ }^{15}$ Figure 2.4 .1 shows that the initial letter is now less likely to be sent within the first week. Most are sent in less than two months, but one in five take more than three months. 
Figure 2.4.1 Time taken from when claimant solicitor first notified of claim to first communication with defendant: in days

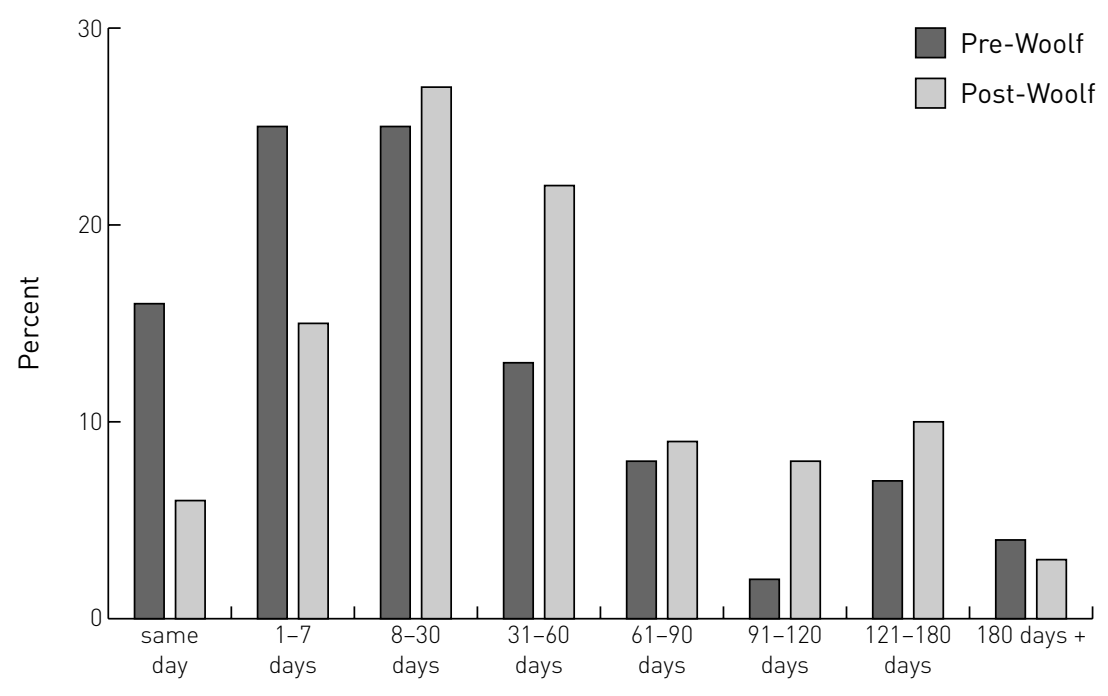

First notification to first communication with defendant

Pre-Woolf cases have been weighted to reflect the firms from which post-Woolf cases were drawn. Weighted base: pre-Woolf -150 ; post-Woolf -148

Unweighted base: pre-Woolf -156 ; post-Woolf -147

The data confirmed that, among post-Woolf cases, first letters are sent more quickly in road traffic cases (median 12 days) than in work-related accidents (median 48 days). ${ }^{16}$ The sample contained only 11 post-Woolf CFA cases, so it is difficult to provide reliable data on the length of time taken in these cases. On the small sample there is, the process of agreeing a CFA does appear to slow the process down considerably. Out of these 11 cases, over half took over 106 days or more, with a mean of 141 days.

We asked insurers whether they were concerned about delay in receiving the letter of claim. In general they were not concerned. Although they acknowledged that it might take 'a little bit longer', they did not feel this to be a worry unless the first notification was very late. One insurer, for example, remarked that it did not really matter to them whether the letter of claim was received three, four or five months after the accident: the policyholder can 'still remember it'. The problems came in notifications after two years:

Those ones are the problem - when you get those in, particularly if you've had no notification from the policyholder. The policyholder may not be insured with us anymore. You may not have contact details because they've moved and you're very much left with, 'what do you do with it?'. (Insurer) 
Although respondents did not generally perceive the length of time taken to send a letter of claim as a problem, delays at this stage do add to the overall time taken. As we shall see, settlement is often delayed in waiting for a medical report. A medical report cannot be obtained unless a doctor is instructed, and under the protocol provisions, claimants cannot instruct a doctor until they have made contact with the insurer. Thus the time taken to write the letter of claim is part of the critical path to settlement.

\section{Early notification?}

The protocol suggests that in some circumstances, the claimant's solicitor might wish to contact the insurer before the letter of claim to say that a claim would be made in the future. Paragraph 2.6 states that:

The claimant's legal representative may wish to notify the defendant and/or his insurer as soon as they know a claim is likely to be made, but before they are able to send a detailed letter of claim, particularly for instance, when defendant has no or limited knowledge of the incident giving rise to the claim or where the claimant is incurring significant expenditure as a result of the accident which he hopes the defendant might pay for, in whole or in part. If the claimant's representative chooses to do this, it will not start the timetable for responding.

Claimant solicitors were asked how often they sent an early notification of this sort. Some firms said that they would never send an early notification:

The first letter is always the letter of claim... I don't think you're going to get any benefit from doing a normal letter, so you might as well wait until you are ready to go. Certainly I don't think it would forearm or forewarn the other side. They probably wouldn't do anything. Theyd just say, 'bully for you'. (Claimant solicitor - large firm)

At the other extreme, one standardised firm always sent two letters. The firm tended to be notified of accidents within a day or two of them taking place. A first letter would be sent immediately on notification, with a second letter a few days later:

In the customer services, they are not trained lawyers, so they can't really do the nitty-gritty of what the claim involves really, and we don't really want them to. So they send a sort of pre-letter, just to say we are instructed... But then... after two or three days, it will go up into the operational unit, and then the case-handler's... first job is to write the sensible initial letter. IClaimant solicitor - large firm) 
This procedure was justified on the grounds that the client was reassured to know that a letter had been written immediately:

I would rather have a one-stage process, but it's just in terms of client care... The client is likely to be reassured that... we've already written to the other side's insurers. (Claimant solicitor - large firm)

In reading through this firm's files, it was not immediately apparent which letter was intended as the letter of claim. Although the second letter contained some more information than the first, neither complied fully with all the protocol requirements.

The remaining firms said that they would send an early notification in some circumstances. Three firms said they would send an early notification where a full letter of claim could not be sent for several months. They thought this was in keeping with general Woolf principles, and would allow them to retain the moral high-ground:

That's in keeping with the principles... It's not really in the principle of Woolf that six months after the event someone gets a storming letter saying... 'here it is, it's all your fault'. (Claimant solicitor - medium-sized firm)

You need to strike while the iron is still relatively hot and... put the other side on notice that there's something coming. The biggest moan insurers have is that we didn't know about this claim for a year... You've always got to keep the high moral ground and what you want to be able to say is, look, we told the other side it was coming'. (Claimant solicitor - large firm)

Other firms said they would send early notifications only in special circumstances, where, for example, there would be lengthy delays or evidence might be destroyed. The clearest example was in industrial disease claims going back many years where the solicitor wanted to ensure that a potential insurer existed before doing any more work on the case.

The file survey showed that out of 152 cases, 34 (22 per cent) had included an early notification, but practice differed substantially between firms. One firm accounted for 22 such letters, while a further two firms accounted for seven. The remaining 13 firms had sent only five early notifications between them. 
For their part, insurers rarely saw much point in early notifications, unless the full letter of claim would be seriously delayed (until, for example, a year after the accident): 'it defeats the purpose to be honest.' As we shall see, most insurers would have been told about the accident by their policyholder and would carry out an initial investigation immediately. They were reluctant to do more until they had received letter of claim details. Most claims handlers worked under fairly rigid computerised systems, and they disliked any correspondence requiring a response that did not fit into the system they had. They tended to see it as 'cost-building' by claimant solicitors.

Given the variety of practice, this is an area that might sensibly be revisited when the protocol is next reviewed. It would be useful to provide clearer guidance on when early notification should be used.

\section{Content}

\section{Primary requirements}

The pre-action protocol recommends that the letter of claim should follow a standard format similar to the one in Annex A. This letter suggests that solicitors should start by giving the broad nature of the accident le.g. work, road traffic, trippingl before stating a date and place. They should then provide a brief outline of the circumstances of the accident, the reason why the claimant was alleging fault and a description of the injuries.

During interviews, insurers complained that the level of information they received, while an improvement on previous practice, was 'a bit hit and miss', with some solicitors much better than others. Insurers felt that some solicitors did the bare minimum necessary to comply:

Some solicitors, they've got a pro forma type form. It depends on your solicitor

- some people will just do the bare minimum... You'll see a lot of bold paragraphs: 'You hit us in the rear, injuries - whiplash'. (Insurer)

We were interested to see how far the main letter of claim contained on the file met the standards set in the protocol and annexed letter. During the pilot we developed categories to record the level of detail, and provided data collectors with guidance about what these categories should contain. The results are given in Table 2.4.2. 
Table 2.4.2 Does the main letter of claim contain the type, date and place of accident, summary of the facts, reasons for fault and an indication of injury?

(weighted data)

Pre-Woolf

Post-Woolf

No

$\%$

No.

$\%$

Overall type of accident le.g. work, road, trippingl

No

Yes

$\begin{array}{rrrr}7 & 5 & 5 & 3 \\ 142 & 95 & 144 & 97 \\ 149 & 100 & 149 & 100\end{array}$

Total

Date of accident

No

More than one possible month

More than one possible day

Specific day

Not applicable (e.g. industrial disease)

Total

$\begin{array}{rrrr}3 & 2 & 6 & 4 \\ 0 & 0 & 1 & 1 \\ 1 & 1 & 3 & 2 \\ 141 & 94 & 133 & 89 \\ 5 & 3 & 6 & 4 \\ 150 & 100 & 149 & 100\end{array}$

Place of accident

No

Yes - in broad terms le.g. Y Road,

$X$ hospital, Heathrow Airport,

Arndale centrel

Yes - specific le.g. junction of X St.\&

Y Rd, Import Dispatch, Heathrow Airport, private house, shop)

$\begin{array}{rrrr}42 & 28 & 67 & 45 \\ 150 & 100 & 149 & 100\end{array}$

Total

Summary of the facts

None lother than overall type)

$\begin{array}{rrrr}90 & 60 & 18 & 12 \\ 12 & 8 & 11 & 7 \\ 25 & 17 & 55 & 37 \\ 24 & 16 & 66 & 44 \\ 151 & 100 & 150 & 100\end{array}$

Total 
Continued

Pre-Woolf Post-Woolf

No. $\%$ No. $\%$

Reason why claimant is alleging fault

None/simply states 'negligence'

or 'negligence and/or breach of

statutory duty'

113

75

45

30

Standard allegations le.g. failed to provide safe system of work, failed to brake, keep proper look out etc.)

Some detail le.g. floor wet, failed to repair trolleyl

More detail le.g. why floor wet, specifies what repairs, mentions specific warnings or regulations)

$\begin{array}{rrrr}16 & 11 & 55 & 37 \\ 151 & 100 & 149 & 100\end{array}$

'An indication of any injuries suffered'

\begin{tabular}{lcccc} 
None & 105 & 71 & 38 & 26 \\
$\begin{array}{l}\text { Broad indication (e.g. neck injury, bruising) } \\
\text { Some detail (e.g. broken arm, }\end{array}$ & 15 & 10 & 33 & 22 \\
bruised leg, whiplash) & 21 & 14 & 30 & 20 \\
More detail (e.g. compound fracture) & 6 & 4 & 48 & 32 \\
Total & 147 & 100 & 149 & 100 \\
\hline
\end{tabular}

Table 2.4.2 suggests that there is some substance to insurers' complaints. The new-style letters of claim clearly contain more information than previously. Before the Woolf reforms, most letters of claim gave the overall type of accident and the date, but over half did not state the place. Three in five did not provide any summary of the facts, over two-thirds did not provide an indication of the injury, while three-quarters failed to state why fault was alleged. This has improved significantly. Almost 90 per cent of letters now provide at least a broad indication of the facts and around three-quarters now provide at least a broad indication of the injuries.

However, compliance is patchy. Of particular note is that over one-quarter of letters failed to specify a place. Almost one in five gave no more than a broad indication of how the accident occurred. 
Almost half (44 per cent) did not progress beyond standard allegations of fault. Insurers did not however, seem to pick this up as a general concern. In Chapter 2.5 there is a discussion of how many standard fast track personal injury cases are now resolved on a presumption of liability. In many cases, the facts are taken to speak for themselves. Where, for example, a claimant suffers a rear-end shunt or (as in one case in the study) visits a DIY superstore to have a lawnmower fall on their head, they are not generally required to provide further allegations of why the defendant is at fault.

Insurers were concerned, however, that one-quarter of letters contained no details of the injury. Claims handlers expressed particular worries about this:

We'd like more on injuries. Sometimes you just get a letter through that says our client has been injured and when you contact the other side - well, we're taking instructions. (Claims handler)

'Our client has sustained a personal injury and'... What is the injury? We have no idea and that's not good enough. (Claims handler)

\section{Indications of financial loss}

The protocol also requires the claimant's solicitor to provide an indication of 'any financial loss incurred'. The annexed letter suggests that that this should include the claimant's occupation, the dates of absence from work, and the approximate weekly income (if known). Alternatively, if the claim is being brought against an employer, a solicitor may ask the employer to provide the 'usual earnings details'. The annexed letter does not contain a paragraph for other financial losses, although the wording of the protocol itself suggests that any financial loss should be indicated.

Insurers complained that claimant solicitors were particularly poor at providing information about financial loss (or 'special damages'). We were told this was 'one of the worst areas' and a 'main failing'. Part of the problem was lack of detail in the letter of claim itself:

You get a comment that frequently appears that 'the client has been off work for a period of six weeks - we are currently checking what their salary is'... The client... must be aware of what their weekly earnings, monthly earnings are in gross terms, so at least we can get a flavour of it. And they must also be aware [if] they actually got payment through while they were absent. (Loss adjuster)

Part of the problem was that further information about special damages was supplied too slowly, and only after requests from the defendant: 
They drip-feed. They are one of the biggest headaches, especially loss of earnings... Medical evidence done, 'oh, oh, he has got loss of earnings'. 'Fine, why didn't you tell us earlier.' (Insurer)

The protocol states that:

The claimant will send to the defendant as soon as practicable a Schedule of Special Damages with supporting documents, particularly where the defendant has admitted liability (para 3.13).

This was criticised as 'just too woolly', allowing claimants to argue that it was not practical to provide a schedule because they had not yet obtained medical evidence, even though the claimant must be aware of how long they had spent off work. Insurers accused claimant solicitors of a culture of delay when it came to special damages:

There is almost a culture which says, 'we'll get the medical evidence and then we'll deal with special damages...' Most specials damages aren't large sums of money. It would be useful to have them early, have them produced and let's get on and quantify the claim and get rid of it and pay it. Let the injured person have their money. (Insurer)

We were not able to consider all aspects of the way special damages information was provided, but we did look at how far letters of claim complied with the protocol. The results are shown in Table 2.4.3.

Compliance can only be described as poor. Less than half of letters contained any indication of whether the claimant took time off work, and even when an indication was given, it often did not contain dates. Less than one-quarter of letters gave earnings figures. It can be argued that in work related cases these are best provided by the defendants. However, compliance with this requirement was even worse in non-work accidents: out of 78 non-work related accidents, only nine (12 per cent) gave an indication of the amount of lost earnings. In the sample as a whole, only a quarter of post-Woolf cases gave an indication of other losses. 
Table 2.4.3 Does the main letter of claim contain indications of financial loss?

(weighted data)

\begin{tabular}{cccc}
\multicolumn{2}{c}{ Pre-Woolf } & \multicolumn{2}{c}{ Post-Woolf } \\
No. & $\%$ & No. & $\%$ \\
\hline
\end{tabular}

Whether the claimant took time off work?

$\begin{array}{lrrrr}\text { Yes } & 11 & 7 & 68 & 46 \\ \text { No } & 126 & 83 & 64 & 43 \\ \text { Not applicable } & 14 & 9 & 17 & 11 \\ \text { Total } & 151 & 100 & 149 & 100\end{array}$

Where an indication was given that the claimant took time off work, were dates provided?

Yes

No

Total lall where indication given that time taken]

An indication of the amount of lost earnings?

\begin{tabular}{lrrrr} 
Yes & 2 & 1 & 34 & 23 \\
No & 133 & 88 & 103 & 69 \\
Not applicable & 16 & 11 & 13 & 9 \\
Total & 151 & 100 & 150 & 100 \\
An indication of other expenses incurred? & & & & \\
Yes & 18 & 12 & 38 & 25 \\
No & 133 & 88 & 113 & 75 \\
Total & 151 & 100 & 151 & 100 \\
\hline
\end{tabular}

The problem illustrates the different standpoints of claimant and defendant at the time of the letter of claim. The first thing insurers did on receipt of a letter of claim was to put a reserve on the file, estimating the value of the claim. This was thought crucial for the company's own accounting. A claims handler described the emphasis that his company placed on having the correct reserve:

They do like to look at their reserves a hell of a lot. Some companies will put reserves on and not review them for the whole of the case. [X company] are completely different. They want the correct reserve on the case, so you would constantly be questioning your own reserve when you get further information... That's why we need better exchange of information - [for] trying to base 
premiums on our reserves. If the information we're getting in isn't accurate or not coming quick enough, then it's going to have an effect on our business.

(Claims handler)

Reserves not only indicated a company's future liability, but also governed the seniority of claims handler assigned to the claim, and the level of resources spent on its investigation:

Maybe claimants solicitors don't think like this, but... if we know it's a minor claim, and doesn't need any investigation, we can admit liability. We can give it to somebody who fits that criteria. If we know it's a multi-track claim, serious issues involved, there's a liability issue. Then we give it to someone who deals with that type of issue. So by telling us what it's about we'll get it to the right handler. (Insurer)

At this stage, however, claimant solicitors were much more concerned with liability than with quantum. Under CFAs - and also increasingly under trade union or LEI arrangements - the solicitor would only be paid for the case if liability was established and, as a defendant solicitor put it, "however confident the claimant solicitor is about liability, he's never that confident'. Thus in writing a letter of claim, the claimant solicitor's mind would be focused on issues of liability and risk assessment. Claimant solicitors did not spend time valuing claims at this stage, ${ }^{17}$ and would usually only think seriously about doing so once the medical evidence had been obtained. Thus, inevitably, during their first interview with the client, questions that insurers thought to be basic (such as 'how much do you earn?' and 'did you receive sick pay?') would not be top of their mind.

If the level of information exchange is to improve, there is a need for a greater level of understanding about what each side is looking for at this stage of the case.

\section{Compensation recovery Unit (CRU) details}

Insurers are required to submit certain information to the $\mathrm{CRU}$, so that the Unit can consider whether social security and health expenditure should be recovered. In road traffic claims, both the protocol and annexed letter require the solicitor to provide 'the name and address of the hospital where treatment has been obtained' and 'the claimant's hospital reference number'. 
Insurers complained that CRU information was frequently missing, particularly the name and address of the hospital:

Quite often they tend to forget to tell us whether they've attended a hospital, and also which hospital, for emergency treatment. We have to tell the Compensation Recovery Unit - we have to give each hospital a code and then they can tell us if the payment has been made, so that it is important. And that can hold up a lot of claims. (Claims handler)

Table 2.4.4 shows that little attempt was made to provide this information. Out of 62 road traffic cases, only five ( 8 per cent) provided the name and address of the hospital. We did not find any road traffic cases that included the claimant's hospital reference number. In the study as a whole, only two cases included a hospital reference number, and neither were road traffic cases.

Table 2.4.4 Road traffic cases: does the main letter of claim contain hospital information?

(weighted data)

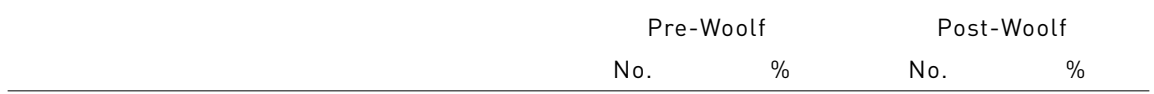

Name and address of hospital

Yes

No

Total (RTA cases)

Claimant's hospital reference number

\begin{tabular}{lrrrr} 
Yes & 0 & 0 & 0 & 0 \\
No & 57 & 100 & 62 & 100 \\
Total & 57 & 100 & 62 & 100 \\
\hline
\end{tabular}

The CRU also requires insurers to obtain and pass on the claimant's national insurance number. Originally it had been intended that that it should be included in the letter of claim. However, as most letters of claim are sent to lay defendants, this proved to be a security risk. The protocol now states that:

Details of the claimant's national insurance number and date of birth should be supplied to the defendant's insurer once the Defendant has responded to the letter of claim and confirmed the identity of the insurer. This information should not be supplied in the letter of claim. (para. 3.4) 
In fact, 64 post-Woolf letters of claim (43 per cent) did contain the national insurance number. Most of these had been sent to employers (45 letters) or insurers (8 letters). However, six letters containing national insurance numbers were sent to lay defendants.

Insurers complained that now that national insurance numbers were not automatically supplied in the letter of claim, they frequently had to chase for them. In the files we looked at, 30 files (20 per cent) included at least one request for the national insurance number, and two contained more than one.

The provision of CRU information is an area ripe for review. It would appear that further efforts need to be made to persuade solicitors of the importance of at least including the name and town of the hospital (though not necessarily the full postal address). Given the level of compliance, the review would need to consider whether it is in fact realistic to ask for the letter of claim to contain the hospital reference number, or whether this requirement should be omitted.

\section{Challenges}

We asked claims handlers how they would react if the letter of claim failed to comply with the protocol. At first insurers had challenged letters, rejecting them for non-compliance. As time progressed, however, they were more likely simply to ask for the information they needed, rather than provoke timeconsuming arguments about the protocol:

We used to have a standard letter saying: 'Your letter is not Woolf-compliant for the following reasons, blah, blah, blah.'... I tend not to use that letter that often... We've streamlined to ease congestion of work... I tend not to put that letters are not Woolf compliant unless someone was being particularly churlish. (Claims handler)

\section{Summary}

Both insurers and claimant solicitors felt positive about the new approach to letters of claim. Insurers thought that they now received a much better level of information early in the case, without having to write a series of letters requesting further details. Meanwhile, claimant solicitors were increasingly focused on gathering information at the outset of the case. This was thought to be vital to assess risk. Having gathered the information, it was no hardship to disclose it to the other side. 
The survey of files showed that claimant solicitors now took longer to send an initial letter to the defendant. Whereas, before the reforms, half of all first letters were sent within a fortnight, now half of letters took over a month, with around one in five taking over three months. Solicitors told us that it took much longer to write letters of claim for work accidents than for road accidents, and this proved to be the case. Among post-Woolf cases, the median time for work accident cases was 48 days, compared with only 12 days for road accidents. Solicitors also said that the need to enter into conditional fee agreements before the first letter was sent could add substantially to the time taken, and this was supported by our data. For the 11 post-Woolf CFA cases in the sample, the median time was over 100 days. In general, neither insurers nor claimant solicitors were too concerned about these delays, but they do add to the overall time required to complete a case.

The protocol suggests that, in some circumstances, the claimant solicitor may wish to provide an insurer with an 'early notification' that a letter of claim would be submitted in due course. There were considerable differences in how solicitors used this provision: one firm sent an early notification in almost every case, while others never sent them at all. For their part, insurers saw little point in early notifications unless the letter of claim would be delayed to such an extent that it would arrive over a year after the accident. Given the variety of practice, it would be useful to provide claimant solicitors with clearer guidance about when early notifications should be used.

Insurers said that the level of the information they received was better than before, but still hit and miss, with some solicitors providing considerably more detail than others. The file survey showed this to be the case. Since April 1999, there has been a clear improvement in the amount of detail provided: for example, the proportion of letters including at least a broad indication of the facts has increased from two in five to over four in five. However, gaps remain. Thus in the file study, around one-quarter of files failed to specify the place of the accident, and almost one in five failed to give more than a broad indication of the facts of the accident.

One problem is that, at the time of the letter of claim, insurers and claimant solicitors have opposite concerns. Insurers' first priority is to put a valuation on the case, both for the purposes of their own reserves and to decide how the case should be investigated. Claimant solicitors, on the other hand, are much more worried about liability, and generally postpone valuations until after the medical report has been received. Insurers were particularly critical about the level of information solicitors provided about the injury and special 
damages. The file survey confirmed that many letters contained significant omissions. Thus one-quarter of letters failed to indicate the nature of the injury, two-thirds failed to provide any indication of the amount of lost earnings, while three-quarters failed to specify any other expenses incurred. There is a need to promote greater understanding among claimant solicitors about the reliance insurers place in financial information at this stage of the case.

A final problem lies in the transmission of the information required by the CRU to investigate whether social security or health payments should be recovered. Although the protocol requires letters of claim in road traffic cases to provide the name and address of the treating hospital, very few letters do. Finally, we found no road traffic letters at all that contained the claimant's hospital reference number. The requirements to provide CRU information with letters of claim need review. 


\section{Chapter 2.5 Responding to the claim: acknowledgement, response and disclosure}

The protocol imposes three main obligations on defendants: to acknowledge the letter of claim within 21 days; to respond within three months thereafter, stating whether liability is denied; and, thirdly, if liability is denied, to disclose any documents in their possession which 'are material to the issues between the parties'. This chapter looks at each obligation in turn.

The first section considers some of the difficulties of acknowledging letters of claim within 21 days, and looks at how long the process took in practice. The next section discusses the time limit for the response - due three months after the acknowledgement. We explore the work that insurers carry out, views on the time limit, and the length of time taken. This is followed by a discussion of the content of responses on liability, examining whether admissions were clear and denials reasoned. The fifth section considers whether documents were in fact requested or disclosed. Finally, we reflect on the implications of the protocol for the burden of proof in personal injury cases, and ask how far it establishes a presumption of liability.

\section{Acknowledgement}

The protocol requires the defendant to reply to a letter of claim within 21 days, identifying their insurer (para. 3.6). The protocol envisages that the letter of claim will usually be sent to an individual defendant, who will pass it straight to their insurers, ${ }^{18}$ though where the claimant knows the name of the insurers, a copy should be sent directly to them (para. 3.4). The insurers we spoke to described the deadline as 'tight', 'hard' and 'very difficult' to meet.

If all went smoothly, 21 days was a reasonable period:

If everything works smooth and $\mathrm{OK}$, a letter of claim goes to the policyholder; he sends it on the next day; it comes into the claims department;... it gets sorted into reference numbers and it goes back out to the claims [handler]... On that basis, 21 days is fine. (Insurer) 
But there was much that could go wrong. The defendant might delay acting on the letter. Sometimes the letter would be passed around departments, as an organisation worked out what to do with it. One insurer specialising in commercial fleets suggested that hauliers would often pass the letter through three separate hands:

It goes to the driver, so the driver sits on it - says, 'Oh, I must do something about that,' and eventually passes it through to the manager, who passes it through up the chain via the broker to us. (Insurer)

Further problems arose if the identifying details were inadequate. Ideally, insurers would like a reference number or, for road accidents, at least the defendant's name and registration number. Without those it was 'like looking for a needle in a haystack'.

The file survey confirmed that letters of claim were sent to a wide variety of individuals and organisations. Table 2.5.1 shows that only one-fifth of letters were either sent direct to the insurer or copied to the insurer. In work accidents, most letters of claim were sent to the employer; in road traffic claims, most were sent to the driver.

Table 2.5.1 Post-Woolf cases: who was main letter of claim sent to?

(unweighted)

\begin{tabular}{lrc} 
& Number & $\%$ \\
\hline Employer & 64 & 42 \\
Local authority & 6 & 4 \\
Other larger organisation & 10 & 6 \\
Lay defendant & 40 & 27 \\
Insurance company & 23 & 15 \\
Both lay defendant and insurance company & 8 & 5 \\
Other/not known & 2 & 1 \\
Total & 151 & 100
\end{tabular}


Figure 2.5.1 shows the time between the main letter of claim and the acknowledgement. It suggests that since the introduction of the protocol there has been a small increase in the number of claims acknowledged within 21 days. The proportion meeting the 21-day deadline has increased from 61 per cent to 68 per cent. However, the difference was small land not statistically significant). One in five post-Woolf cases still took over 35 days to produce an acknowledgement.

Figure 2.5.1 Time from main letter of claim to acknowledgement

(weighted data)

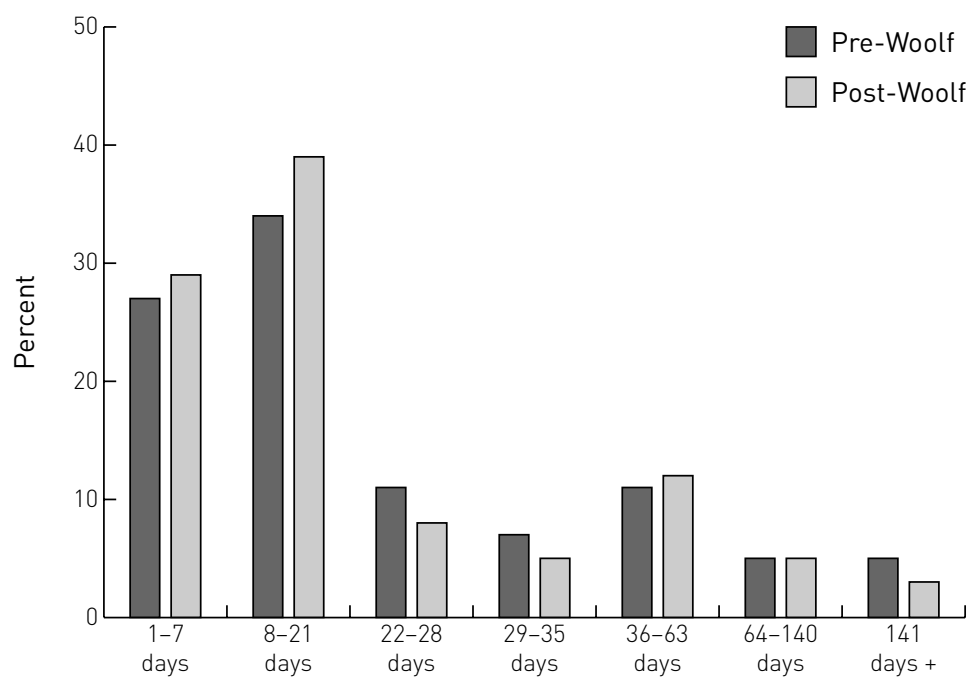

Time taken to acknowledge LOC

Base: all cases where information available.

Weighted base: pre-Woolf - 147; post-Woolf -148 .

Unweighted base: pre-Woolf - 153; post-Woolf -147

Despite the problems, a couple of insurers felt that the deadline should be left at 21 days. It provided the opportunity 'to really hammer home' to policyholders and brokers that letters should be sent in quickly. Two, however, argued that a 28-day period might be more realistic, and one suggested a 35-day period, which would allow lorry drivers with busy schedules' to be tracked down. They all agreed with the principle that the protocol should include a target for letters of claim to be acknowledged. 
For their part, claimant solicitors agreed that many acknowledgements failed to meet the deadline. Late acknowledgements did not, however, emerge as a great concern. As one claimant solicitor put it, 'you half expect' defendants to leave letters on the mantelpiece. Claimants rarely took any action at this stage except to send a chasing letter:

It doesn't worry me. I do chase them... but I don't lose sleep over the fact that I don't get replies from insurance companies for many weeks. (Claimant solicitor - large firml

\section{The response on liability: meeting the time limit}

The protocol gives insurers three months from the acknowledgement in which to investigate liability, and provide either an admission or denial. Paragraph 3.7 states that:

The defendant/'s insurers) will have a maximum of three months from the date of acknowledgement of the claim to investigate. No later than the end of that period the defendant (insurer) shall reply, stating whether liability is denied and, if so, giving reasons for their denial of liability. (Emphasis in original).

Below we start by looking at what insurers do to investigate claims. We discuss insurers' and claimant solicitors' views on time limits, before considering how long the process takes. The following section then looks at the content of responses.

\section{Work required}

Insurers were increasingly encouraging their policyholders to notify them as soon as an accident occurred, so that investigation could start before a letter of claim arrived. Private motorists were asked to report accidents by telephone, which they usually did:

Nine times out of ten... we get a telephone call from our policyholder... and as a consequence, we have details there and then. (Insurer)

Commercial fleet operators could be slower about notifying claims, but one insurer explained that the company was constantly trying to reduce such delays:

The claim will come through from a number of sources. It may come through from the insured direct... If may come through a broker; it may come through an accident management company, all of which builds in delay. You may have a truck that wasn't particularly damaged in the accident; the driver - it's not 
his lorry - slow to report it. We've had people who've taken pedestrians' legs off on pedestrian crossings and hadn't thought to report it to us. So there often is a delay which we're constantly working to try and reduce. (Insurer)

For work-related accidents, practice differed. One company explained that in factories you can get hundreds of incidents which cause injury every year, and only a small fraction turn into claims'. Therefore they usually waited for a letter of claim before investigating. Other companies, however, said that they were increasingly taking steps to go out and look for accidents:

Virtually all EL claims are investigated and not only because we like to do the investigation but also we think it is a good PR thing. It lets us see what our insureds are up to, making sure they are doing their health and safety right. (Insurer)

We've a number of plans that insist... [on] meeting with the insured on a regular basis... Asking for a copy of the accident book, running the entries on that and just seeing whether there's anything, even if it's not reportable... That is the big change. (Loss adjuster)

'Pro-active' checks were thought not only to encourage good safety practice but could also identify a company's IBNR (incurred but not reported) liabilities, allowing more accurate premium setting.

On notification, the first task would be to place a reserve on the file. This may well involve telephone calls to the policyholder, police or even the hospital:

The policyholder will be asked a question whether any injury was sustained. The answer is often 'Yes', but not much more information, so whenever an injury is reported, we make sure the advisors do get on the phone to the policyholder: 'You said there was an injury, can you give me some more information?'. They may phone the police officer in charge... They may phone the hospital, if we know the name of the person and we know the hospital. (Insurer)

Police officers were described as usually helpful. Hospitals would be more guarded, confirming only that the potential claimant was a patient and the name of the ward. Yet even this could provide a useful indication of the extent of the injury.

After placing a reserve on the case, claims handlers would then consider liability. Insurers stressed that in many road traffic accidents, liability was clear cut: 'It seems invariably we're to blame.' In straightforward claims, a 
couple of telephone calls to the policyholder would be sufficient to establish that an admission should be made. Insurers would frequently prepare an admission letter before the letter of claim arrived:

If it's a straightforward hit in the rear case, no dispute... we advise the claims advisor to admit liability... We've actually done a letter in the system for them to respond to the first letter of claim. (Insurer)

In less clear-cut cases, the investigation might include making a series of further telephone calls, asking for a police report, sending out witness questionnaires or asking a claims inspector to visit the scene or take statements from the insured and other witnesses. Claims inspectors were used much more frequently with employers' liability or public liability claims than with motor claims.

A difficult question was how far insurers should work with policyholders, asking for their agreement to any admissions made, and how far they could make admissions over the heads of the insured. One company said that they now no longer asked lay defendants for agreement to make admissions:

We had a problem when the Woolf reforms first came out... because we were a bit concerned about admitting liability on behalf of our policyholders and... we thought we should really get their permission. So we were writing out to the drivers saying: 'Look you've been negligent for the following reasons... please confirm that you admit liability.' And the letters we got! 'I haven't been negligent.'; 'I wasn't a negligent driver.' The lay person was construing negligence not in a legal sense... but wanting to take it personally. So we've just stopped that... We thought, well, if we get any complaints, we'll just deal with them, but I haven't had a single complaint since. (Insurer)

Other companies, however, felt the need to take their insured's denials of liability seriously, to the extent of listening carefully to what they had to say and investigating any leads they provided:

If you have a policyholder who says: 'No, the accident was not my fault,' unless you actually exercise the rights under the policy to settle against [them] you sometimes have to go with it... That's particularly the case where it's very much one word against the other. You may have doubts as to which way it's going to go, but it's a tough call... until you've gone down the track a bit. (Insurer) 


\section{The time limit: insurers views}

We asked insurers how easy they found it to comply with the three-month time limit set out in the protocol. Several said that for standard fast track road traffic claims, three months was 'fine' - 'more than ample'. However, most cited examples where difficulties arose: it might take more than three months to receive a police report, especially if a prosecution was contemplated.

Insurers thought that employers' liability cases could be 'trickier'. As one said of work accidents:

The three-month period in principle should be fine, if we have an accident that's reported at the time, have a well-pleaded case in the initial letter of claim and we've got a co-operative insured we're dealing with. Unfortunately, we don't always get those three constituents together. In fact it's very rare that you do. (Loss adjuster)

In work-related cases, much depended on the attitude of the employer:

Basically, the problems rest with our insured... Like anything, you get different types of insured... Some... we'll say, 'can we see your accident book?', and they'll say, 'What's an accident book?'. (Insurer)

Where an employer denied any liability, insurers said that they would send a claims inspector. This could sometimes involve patient negotiation, which took longer than three months. A couple of insurers mentioned cases in which the claimant had already left the employment 'under a cloud' as particularly problematic:

You can find that sometimes... it's difficult because our insured is just not interested. [They think]: 'Jimmy Smith is trying to pull a fast one... so why should we do anything to help with his EL claim?' (Insurer)

Insurers considered that the three-month time limit should be retained as 'something to aim at', but that it needed to be applied flexibly:

You should aim for that date at least, but there should be more leeway... If we can come up with a good enough reason why we haven't done it... then that should be allowed. (Insurer)

Three months is a reasonable objective... Maybe it could be softened in terms of language. (Insurer) 


\section{The time limit: claimant solicitors' views}

Claimant solicitors' main complaint about the pre-action protocol was that many insurers failed to respond within the three-month limit. Most said that they were sympathetic if the insurer told them of special circumstances:

Where there's a criminal prosecution on a road traffic accident, and the CPS have got the police report, I can perfectly understand that... the defendant is not going to [admit] without some police report. (Claimant solicitor - leading firml

However, claimant solicitors thought that many delays happened because claims departments were under-resourced. They expressed considerable frustration that there were so few sanctions to enforce the timetable, and suggested that insurers knew this when they fixed their staffing levels:

Because there's no sanctions... they think why should they? I think that's the attitude they have. (Claimant solicitor - leading firm)

Technically, after the three-month period has passed, the claimant may issue proceedings. Most solicitors pointed out, however, that this was rarely a practical possibility:

Technically after three months you can commence proceedings... But you do not commence proceedings until you have really got everything: you've got all your witnesses statements; you've got our disclosure list; you've got your medicals... After three months, you've actually got to do all that work, so the fact that they're delaying doesn't make any difference. (Claimant solicitor leading firm)

Many claimant solicitors felt that there were few options on the expiry of the deadline except to send chasing letters:

They know full well you can't issue proceedings until you've got the medical report. So what do you do? You just write stroppy letters. IClaimant solicitor (eading firm)

These might be accompanied by a threat to bring the matter to the attention of the court:

I point out that they're beyond their three months, and l'll draw this to the attention of the court. It's not a very good weapon, but it's a weapon. IClaimant solicitor - small firm] 
This threat, however, was usually felt to be hollow:

When you come to case management... one of the questions on the list is: 'Have the protocols been complied with?' Quite often it's: 'No.' And quite often it's: 'Well, who gives a damn really?' (Claimant solicitor - medium-sized firm)

It was suggested that there should be clearer cost sanctions - such as automatically increasing the amount of a success fee if the three-month deadline were missed, or accepting that claimants were automatically entitled to their issue costs. One solicitor even suggested that claimants should be entitled to enter judgment. It would be useful to review the consequences of defendants failing to meet the three-month deadline in fast track cases.

\section{Time taken}

In the file study, we defined a response as a letter or recorded telephone call in which the defendant set out their approach to liability, providing some form of acceptance or denial, or indicating a willingness to negotiate. We were able to identify some form of response in around 90 per cent of cases, a proportion that was similar for both pre and post-Woolf cases. The remaining cases were either abandoned or proceeded straight to settlement without the issue of liability being addressed directly.

The protocol requires a response within around 112 days from the letter of claim lallowing 21 days for the acknowledgement and another 91 for the response). Our data showed that the proportion of responses arriving within this time has increased. Looking at all cases with a response, before the reforms only 44 per cent arrived within 112 days, compared with 64 per cent after the reforms. It is probably fairer, however, to concentrate on 'standard' fast track cases. ${ }^{19}$ This is partly because it ensures that like are being compared with like, and partly because the response time limit is often regarded as inappropriate in multi-track claims.

Figure 2.5.2 shows the time taken between letter of claim and response for the standard fast track cases in our survey. The proportion meeting the time limit has increased - from 58 per cent to 69 per cent - but the difference is not significant. On the positive side, over one-quarter of responses arrive very quickly (within one month of the letter of claim) and the great majority (84 per cent) are now received within six months. But when claimant solicitors 
complain about missed deadlines, this has some basis. Even among standard fast track claims, around one-third fail to produce a response within the time limit set out in the protocol.

Figure 2.5.2 'Standard' fast track cases: time taken from main letter of claim to response

(weighted data)

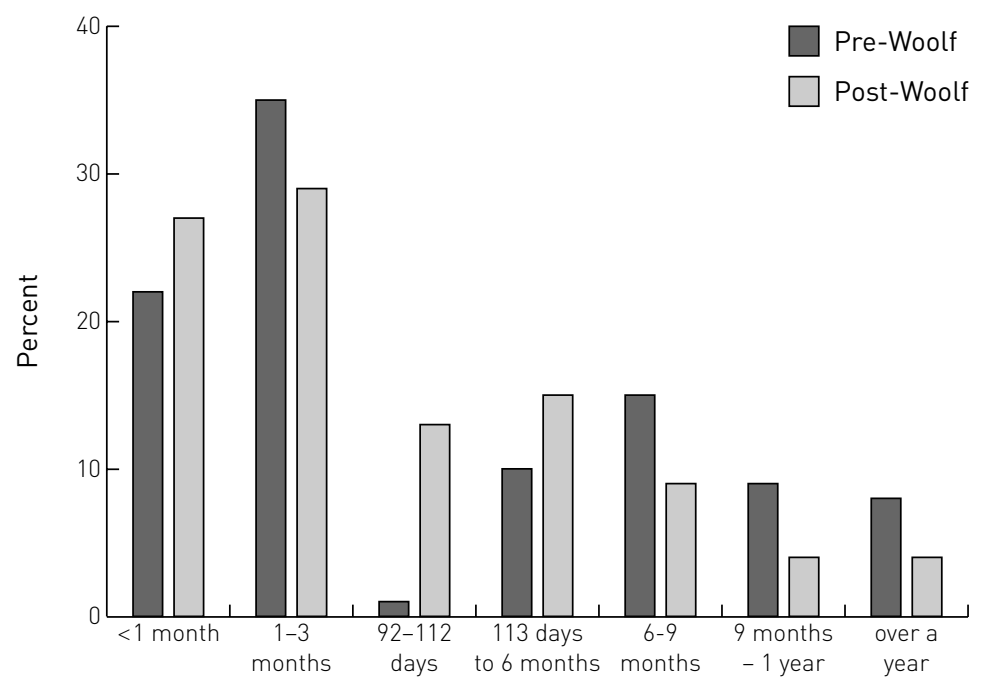

Days from LOC to response on liability

Standard fast track cases are defined as minor or moderate injuries, settled for less than $€ 7,000$

within less than two years.

Base: all cases with a response where information available.

Weighted base: pre-Woolf -81 ; post-Woolf -110 .

Unweighted base: pre-Woolf -81 ; post-Woolf -110 .

The data supported insurers' contentions that road traffic cases take less investigation than accidents at work. Among post-Woolf standard fast track road cases, the median time for a response was only 31 days. Among work cases, it was 94 days: in other words, half took longer than three months.

\section{The response on liability: content}

Tables 2.5.2 and 2.5.3 consider the content of the insurers' responses. The first table looks at all cases within the study in which a response could be identified. The second concentrates on standard fast track cases linvolving minor or moderate injury and settled for less than $€ 7,000$ in less than two years). 
The tables show that the content of responses has changed since the introduction of the protocol. The change has not been in the proportion of outright denials - which for standard fast-track cases remained at 8-9 per cent. The main difference lies in the number of responses that failed to address the issue of liability directly. Before the reforms, almost half (48 per cent) either simply stated a willingness to negotiate or gave an offer. Yet after the reforms, only one-quarter of standard fast track cases (24 per cent) did (a statistically significant difference). Far more letters included a full admission of liability: the proportion rose from 7 per cent to 29 per cent. One insurer highlighted this as a major change in culture:

[Before] it was just unheard of, writing to someone pre-litigation and actually telling them you were responsible for this accident. It just didn't leave you anywhere to run if you needed to get out of it at a later stage. (Insurer)

Table 2.5.2 All cases: indication on liability given in response

(weighted data)

\begin{tabular}{lcccc} 
& \multicolumn{2}{c}{ Pre-Woolf } & \multicolumn{2}{c}{ Post-Woolf } \\
& No. & $\%$ & No. & $\%$ \\
\hline Accept/admit 100 per cent liability & 7 & 5 & 35 & 26 \\
State that liability not in issue /not in dispute & 30 & 22 & 39 & 29 \\
State a willingness to negotiate & 46 & 34 & 23 & 17 \\
Simply give an offer with no indication & & & & \\
on liability & 19 & 14 & 15 & 11 \\
Deny all liability & 22 & 16 & 10 & 7 \\
Allege contributory negligence & 6 & 4 & 9 & 7 \\
Admit liability but deny causation & 3 & 2 & 1 & 1 \\
Other & 3 & 2 & 3 & 2 \\
Total & 136 & 100 & 135 & 100 \\
\hline
\end{tabular}


Table 2.5.3 Standard fast track cases only: indication on liability given in response (weighted data)

\begin{tabular}{lrrrr} 
& \multicolumn{2}{c}{ Pre-Woolf } & \multicolumn{2}{c}{ Post-Woolf } \\
& No. & $\%$ & No. & $\%$ \\
\hline & 6 & 7 & 33 & 29 \\
Accept 100 per cent liability & & & & \\
State that liability not in issue /not in dispute & 24 & 28 & 32 & 28 \\
State a willingness to negotiate & 26 & 30 & 15 & 13 \\
Simply give an offer with no indication & & & & \\
on liability & 16 & 18 & 12 & 11 \\
Deny all liability & 8 & 9 & 9 & 8 \\
Allege contributory negligence & 4 & 5 & 8 & 7 \\
Admit liability but deny causation & 0 & 0 & 1 & 1 \\
Other & 3 & 3 & 3 & 3 \\
Total & 87 & 100 & 113 & 100 \\
\hline
\end{tabular}

\section{Clear admissions?}

Despite the increase in admissions, it is still the case that only a minority of insurers were happy to use words such as 'accept' or 'admit'. Even after the reforms, over half of responses involved some form of equivocation: either stating that liability was 'not in issue' or 'not in dispute'; or indicating a willingness to negotiate; or simply putting forward an offer.

Claimant solicitors varied in their responses to these phrases. Several solicitors in small and medium-sized firms said that they were prepared to accept words such as 'not an issue' or 'prepared to negotiate' as well-known 'insurers' euphemisms' for admission:

If they say liability isn't an issue, to me that's an admission of liability. I think that's enough. (Claimant solicitor - small firm)

However, a vocal minority felt that these words did not amount to a sufficient admission. They were concerned that if negotiations broke down, the insurer could resile from their response. The claimant would be left with a fight on their hands without having undertaken the necessary preparations on liability. They said that they frequently pressed insurers for clearer indications, threatening to incur further investigation costs unless a full admission was made. One solicitor cited a case in which the response had initially stated 'we are prepared to discuss settlement with you': 
I wrote back and said: 'Sorry, refer to the protocol, please. I want to know what you're doing.' And they wrote back saying: 'Yes, alright then, we concede liability', which itself isn't really good enough. So then I had to write back again, saying: 'Look, can we be clear about this? I'm taking the letter to mean that for all purposes you are admitting liability'... and they wrote back and said: 'Yes.' Now it would have been a bloody sight easier if they'd said that in letter 1. (Claimant solicitor - leading firm)

Insurers themselves were often uncertain about both the actual words used in their standard letters and their legal effect. For example, one manager declared that his company's policy was to make full admissions:

People do write these funny letters... for the purposes of negotiation, liability isn't an issue'. I mean, what nonsense!... If you're admitting liability, just admit it. (Insurer)

A claims handler in the same company, however, said that the form of words used on their standard documentation ('it is not our intention to dispute liability') often led to further correspondence, in which solicitors asked for clearer admissions. He was unsure of whether this was justified: 'I don't know whether that's right or wrong, to be honest.'

The reason insurers gave for care in their choice of words was that they could admit primary liability only to find later that there was a question of causation or contribution. The classic case cited was a rear-end shunt where the claimant was not wearing a seat-belt:

We could have hit someone in the rear... Why should we deny liability, we are responsible for that accident. And you'll have a medical report saying, 'wasn't wearing a seat-belt'. Well, we can apply contributions to that. (Claims handler)

Defendant solicitors, however, went further and cited a range of cases in which admissions of liability turned out, on further reflection, to be illadvised. For example, in this case the company had agreed to accept only 15 per cent contribution, without taking statements from witnesses:

I had to say we wanted to resile from that, so now we're going to have a hearing... And who is going to pay the costs of that hearing?... It's all uncertain, and whether they've suffered any prejudice. (Defendant solicitor)

He felt that: "it would have been better to have adopted the pre-Woolf idea of saying: "we're not admitting liability but this is our offer". The claimant's solicitor would then have known that it was a good idea to go on investigating liability and not just simply take it for granted.' 
The hypothetical studies carried out before the protocol was introduced suggested that a major barrier for making admissions was insurers' fears that a case may turn out to be considerably more expensive than anticipated. The report therefore recommended that, in order to encourage insurers to make full admissions, such admissions should only be binding up to $€ 15,000$. If the case turned out to be worth more, insurers should be allowed to retract them without penalty (Goriely et al. 1998, p.47-8). This recommendation was introduced into the protocol, which states that where liability is admitted, the presumption is that the defendant will be bound by this admission for all claims with a total value of up to $€ 15,000$ ' (para. 3.9).

Views on this provision were mixed. Insurers liked it, describing it as 'a smart rule to put in'. Some claimant solicitors felt that the rule was fair, though sometimes 'a little bit frustrating'. But others objected strongly:

I think it's absolutely scandalous that you can still, in theory, make an admission under the protocol and then go back on it. (Claimant solicitor leading firm)

What's the reasoning behind that?... 'We've decided but we might want to wriggle out of it again?' It's a bit of a weak reasoning, isn't it? (Claimant solicitor - leading firm)

One problem appears to be that a rule intended to apply only to cases that started small and became bigger can be taken to apply to all multi-track claims.

The rules on admission need further clarification. Claimant solicitors want to feel secure that they are not prejudicing their clients by ending their investigations into liability. Conversely, insurers wish to keep some options open should the medical report include surprises: either that the injuries are much more serious than first thought, or that they were not wholly caused by the accident.

\section{More detailed denials?}

The protocol requires insurers to give 'reasons for their denial of liability' (para. 3.7). The great majority of claimant solicitors thought that insurers now gave more information in their responses, and that this helped them in their case preparation. Responses ranged from the enthusiastic to the grudging:

This is the great joy of the protocol, that suddenly you're not getting 'sod off and leave us alone' denials... You are getting a denial that you can evaluate. (Claimant solicitor - leading firm) 
It's definitely better than it was, but it's not something that would be at the top of my mind to say... that's a great change. I think the situation before was so bad, we didn't get any information. (Claimant solicitor - small firm)

Unfortunately, the file study yielded too few denials for this issue to be investigated in depth. In only 28 pre-Woolf and 19 post-Woof cases was liability denied or contributory negligence alleged. We were able to gather information about the level of detail in slightly fewer cases: 26 pre and 17 post. Therefore, the results, given in Table 2.5.4, are highly tentative. They do, however, lend some support to the strongly expressed view that denials are now more reasoned.

Table 2.5.4 Responses including a denial of liability or allegation of contributory negligence: level of detail given

(weighted data)

\begin{tabular}{lcccc} 
& \multicolumn{2}{c}{ Pre-Woolf } & \multicolumn{2}{c}{ Post-Woolf } \\
& No. & $\%$ & No. & $\%$ \\
No reason/simple denial & 10 & 38 & 2 & 12 \\
Some detail & 8 & 31 & 4 & 24 \\
More detail & 8 & 31 & 11 & 64 \\
Total & 26 & 100 & 17 & 100 \\
\hline
\end{tabular}

\section{Disclosure}

The protocol requires a denial to be accompanied by any documents material to the issues. It states:

If the defendant denies liability, he should enclose with the letter of reply, documents in his possession which are material to the issues between the parties, and which would be likely to be ordered to be disclosed by the court, either on an application for pre-action disclosure, or on disclosure during proceedings. (para. 3.10) (emphasis from original)

The notes explain that:

The aim of the early disclosure of documents by the defendant is not to encourage 'fishing expeditions' by the claimant, but to promote an early exchange of relevant information to help in clarifying or resolving issues in 
dispute. The claimant's solicitor can assist by identifying in the letter of claim or in a subsequent letter the particular categories of documents which they consider are relevant. (para. 3.10)

To assist the process, an annex to the protocol provides a non-exhaustive list of documents 'likely to be material to different types of claim' (para. 3.11).

These provisions have encouraged claimant solicitors to request documents. Table 2.5.5 shows that documents are requested in pre-issue negotiations much more frequently than before the reforms. The proportion of files including such a request has risen significantly, from 22 per cent to 51 per cent. Although documents are rarely relevant to road traffic cases, they are now requested in the great majority of all work-related accidents.

Table 2.5.5 Whether documents are requested - by type of case

(weighted data)

\begin{tabular}{ccccc}
\multicolumn{2}{c}{ Pre-Woolf } & \multicolumn{2}{c}{ Post-Woolf } \\
& No. & $\%$ & No. & $\%$ \\
\hline
\end{tabular}

Road traffic cases

Documents requested

Documents not requested

$\begin{array}{rrrr}1 & 2 & 7 & 11 \\ 56 & 98 & 55 & 89 \\ 57 & 100 & 62 & 100\end{array}$

Total

$\begin{array}{rrrr}28 & 38 & 63 & 88 \\ 45 & 62 & 9 & 12 \\ 73 & 100 & 72 & 100\end{array}$

Work cases

Documents requested

Documents not requested

Total

Other cases

Documents requested

Documents not requested

$\begin{array}{llll}4 & 19 & 8 & 44\end{array}$

Total

$\begin{array}{llll}17 & 81 & 10 & 56\end{array}$

$\begin{array}{llll}21 & 100 & 18 & 100\end{array}$

All

\begin{tabular}{lrrrr} 
Documents requested & 33 & 22 & 78 & 51 \\
Documents not requested & 118 & 78 & 74 & 49 \\
Total & 151 & 100 & 152 & 100 \\
\hline
\end{tabular}

Documents only need to be disclosed where the defendant is denying liability or alleging contributory negligence. As we have seen, this is relatively rare. Our file survey included only 27 work-related cases with such a denial or 
allegation: 15 pre-Woolf and 12 post-Woolf. Although this is insufficient to provide a quantitative analysis, Table 2.5.6 looks at these cases in more detail to give a general feel for the extent of disclosure in such cases. It suggests that documents are more commonly disclosed than before: in five out of 12 post-Woof cases at least some documents were disclosed, compared with only two out of 15 pre-Woolf. Yet it appears that, even now, substantially more documents are asked for than provided.

Table 2.5.6 Work-related cases where liability is denied or contributory negligence alleged: documents requested and disclosed

(unweighted data)

Pre-Woolf Post-Woolf

Requested Disclosed Requested Disclosed

Accident book/other internal records

of this accident

Records of other similar accidents

Accident report/HSE correspondence

Maintenance/checking records

Instructions to employees/manual

Training records

Risk assessment/internal discussions

of safety issues

Other

At least some documents

2

1

1

0

0

0

(n)

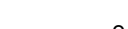

6

0

0

0

0

0

2

2

1

2

0

0

2

Base

$15 \quad 12$

Insurers felt that they did disclose documents more readily now, and that this was an improvement on previous practice: one called it 'a vast improvement' as, when faced with the evidence against them, claimants were less likely to litigate. Several insurers pointed out, however, that it could be extremely difficult to obtain documents from employers. Many smaller employers simply did not have the documents specified in the standard list. Others had them scattered over different sites, and it was a 'mad scramble' to locate them. They also criticised claimant solicitors for unthinkingly referring to the annex list without considering its relevance to the case in hand:

They will say... this is a standard EL, claim... we want all the documentation for the standard sections and all the manual handling documentation. And we actually look at it and realise that five bits of what they are asking for - just no way in the world that it even applies to the circumstances of what happened... 
COSHH regs on a lifting accident, and you immediately [say], 'COSHH is hazardous substances - it's got nothing to do with the fact he jarred his back'. (Insurers)

Insurers blamed claimant solicitors for 'not properly educating their staff' about the details of Health and Safety documentation.

Among claimant solicitors, many said that document disclosure had improved since the reforms. More documents were provided, though rarely within the time limit. A couple of solicitors specifically mentioned that it was now easier to obtain highway inspection reports in tripping cases. However, several felt that obtaining documents remained 'a battle' or 'a bit of a struggle'. They complained that they had to send a series of letters threatening applications for pre-issue disclosure. The overall verdict seemed to be some improvement: could do better'.

I don't think that... we get the discovery that we've asked for, but we tend to get more than we used to... It is very difficult for people to change habits of 20-odd years, but I think it is changing. (Claimant solicitor - medium-sized firm)

Finally, some insurers criticised the protocol for being uneven. It imposed obligations on defendants to provide documents, without any reciprocal obligations on claimants. They mentioned several documents within the claimants' control that might be relevant to the case - including employment records or, where a self-employed claimant was claiming for loss of earnings, tax records.

\section{A presumption of liability?}

The legal rules of tort place the burden of proof firmly on the claimant. The law requires that the claimant prove, on the balance of probabilities, that the defendant owes them a duty of care, that the defendant breached the duty of care, and that they suffered an injury caused by that breach. ${ }^{20}$ An important issue in the socio-legal literature is how far these requirements exist in practice as well as in theory. It is, of course, well established that very few personal injury cases actually go to trial. Pleasence (1998) puts the proportion of trials at less than one per cent. ${ }^{21}$ Genn (1987), however, argues strongly that the need to prove liability casts a long shadow over the bargaining process. Her study found that, except for some small road traffic cases, liability was very much a live issue in the minds of both parties: the overwhelming impression gained from interviews and on the basis of observation was the extraordinary amount of time spent debating the merits, 
in terms of both liability and quantum of damages,' (p.60). She argues that accident victims were rarely as well placed as defendants to establish the facts of the accident. Their inability to construct a case, so as to confidently predict a successful outcome at trial, provided scope for 'discounted, bargainbasement settlements' and led to claims being 'killed off by a forceful denial of liability from the defendants' (p.75).

Genn argued that the individualisation of English personal injury negotiations of the 1980s was 'in stark contrast' to the way that some insurance claims were settled in the USA (1987 p.59). For example, a classic US study by Ross (1980) found that claims adjustment was a highly bureaucratised process, in which legal rules were replaced by simple rules of thumb. As the system became routinised, cases were settled on an assumption of liability without the need for claimants to 'prove' their case in a legal sense.

We have already described the growing trend towards bureaucratisation and routinisation among both insurers and claimant solicitors. An important question is how far this has affected the basis of settlement. Does liability remain a live issue in most cases - so that claimants must either construct a case, or pay for any weaknesses in their claims construction by discounting damages? Or do most claims now proceed on a presumption of liability?

The impression we gained from this study is that there has been a major shift away from the individuated approach Genn described. Even before the Woolf reforms, standard files for small or moderate injuries contained remarkably little individual discussion of liability. Pleasence (1998) found that liability was denied in only just over one-third of cases; it was admitted in around one-third; and in the remaining third it appeared to be assumed. The issue became lost against the 'backdrop of assumptions shared between solicitors,' (p.52). This study contained even fewer denials - under 20 per cent. The only group committed to fighting liability issues were defendant solicitors. Their refrain was that insurers were now more interested in saving money through staffing cutbacks than through disputing claims; they "just throw money at it rather than fight the thing properly'. An example cited several times was that of customers suing fast-food chains because their coffee was hot. Insurers were blamed for assuming that it was 'cheaper to pay than to argue'.

Although the trend towards assuming liability started before the Woolf reforms, it has become institutionalised in the protocol. For fast track claims, there is now a presumption of liability. As we have seen, the letter of claim often contains little more than a basic description of the accident, based on an interview with the claimant. Almost half did not progress beyond standard 
allegations of fault, already programmed into standard letters. Although insurers made many complaints about letters of claim, this was not one of them. Insurers accepted that a recitation of the facts of an accident was enough to pass the onus of investigation to them. On a practical level, claims handlers felt that their job during the three-month investigation period was either to accept liability or to disprove it:

I appreciate someone has made an allegation against our insured but it seems that they can make an allegation and just sit back on that, and we've got to do all the work rummaging around and mostly trying to disprove why our insured is not responsible... That's quite difficult really. I understand why. It's now probably to keep costs down, stop them running off every single time and making loads of investigations, but it is a case of where you sort of find yourself trying to disprove something. (Claims handler)

This is very different from the position in clinical negligence claims (described in Section 3) where a claimant must go to considerable lengths to found a prima facie case on liability. It may also be different in multi-track cases, which we were unable to study in depth and where liability is reportedly much more commonly disputed. For most fast track claims, however, liability only becomes an issue where the defendant has produced a reasoned rebuttal. An insurer who wrote back to a claimant simply asking them to 'prove it' would be in breach of the protocol, and would not receive a sympathetic consideration from the courts.

If there is such a presumption, it would suggest that a claimant solicitor need not carry out any investigations into liability between the letter of claim and response. If they do, insurers would not be liable for the costs should they subsequently admit. It also has important implications for guidelines on success fees under CFAs, which need to distinguish between cases where liability is admitted and cases where it is denied.

\section{Summary}

The first obligation the protocol imposes on defendants is to acknowledge the letter of claim within 21 days. Letters of claim are usually sent to the actual defendant, such as the driver or employer, and may be passed around several departments before reaching the insurer. Insurers clearly found it difficult to meet the 21-day time limit. They exceeded it in around one-third of cases. Some argued that it should be extended (to 28 or 35 days). Others, however, 
expressed concern that this might send the wrong signals to their policyholders. For their part, claimant solicitors seemed resigned to late acknowledgements and the issue did not worry them greatly.

Secondly, the insurer must provide a response within three months of the acknowledgement (or around 112 days from the letter of claim) stating whether liability is denied, and if so, giving reasons. Insurers said that in fast track road traffic cases, the deadline was reasonably easy to meet. They would have been notified of the accident when it happened and would have already started their investigations. The file survey showed that half of responses to standard road traffic claims were provided within one month. Work accidents, however, caused more problems: for these, the median time was 94 days. Insurers thought that the present three-month period should be retained as a target to aspire to, but should be applied flexibly.

The file survey showed that, overall, the deadline was exceeded in around one-third of cases. Whilst this represented an improvement on previous practice, claimant solicitors complained that the number of late responses was too high. Although most declared themselves sympathetic to special cases, they felt that many late responses resulted from understaffing by insurers. Claimant solicitors' main criticism of the protocol was that it contained too few sanctions to enforce compliance. Although in theory they could react to a later response by issuing proceedings, this was not a practical possibility without a medical report and witnesses statements. It would be useful to review the consequences for defendants if they fail to meet the three-month deadline.

When one considers the content of responses, insurers are now more likely to make outright admissions of liability and less likely simply to indicate a willingness to negotiate. However, most insurers were still cautious about applying words such as 'admit' or 'accept' to liability. Over half of responses still involve some form or equivocation, such as 'liability is not in issue'. Some claimant solicitors accepted this. Others felt that their clients would be prejudiced if they failed to investigate liability only to find that liability was later denied. This appears to be an area requiring further clarification. 
There was general agreement that denials were no more reasoned, and that this represented an improvement on previous practice.

Since the protocol was introduced, claimant solicitors are much more likely to ask for documents to be disclosed during pre-action negotiations. In work accidents, such requests are now made in the great majority of all cases. Documents are requested much more frequently than they are provided, though there does seem to be slightly more pre-action disclosure than was the case before the reforms. Insurers raised the issue of whether similar obligations should rest on claimants to disclose their own documents.

The new procedure raises questions about where the burden of proof now lies in personal injury claims. Insurers felt that letters of claim raised a presumption of liability, which it was up to them to either accept or rebut during the investigation period. They therefore felt that they should not be expected to meet any investigation costs that a claimant solicitor incurred between sending a letter of claim and receiving a response. There is a case for clarifying further what steps a claimant solicitor should take themselves to investigate liability during this period, and what an insurer might be liable to pay for. At the same time, it would be helpful to define what counts as a late or equivocal insurers' responses, and to spell out their cost consequences. 


\section{Chapter 2.6 Expert evidence}

In Access to Justice, Lord Woolf identified expert evidence as a major generator of unnecessary costs (1996, p.137). He made a series of recommendations, designed to emphasise the expert's duty to help the court impartially and to encourage a more focused use of experts (p.139). The Civil Procedure Rules (CPR) include several major reforms. They state clearly that the expert has an overriding duty to the court rather than the parties ICPR Part 35.3), and the report must include a statement stating that the expert understands this duty (CPR Part 35.10(2)). All expert evidence put before the court requires leave from the court (CPR Part 35.4) and the court may direct that it is given by a single joint expert (CPR Part 35.7). A report must state the substance of all material instructions' and the court may in some circumstances order such instructions to be disclosed (CPR Part 35.10(3-4)).

It is not possible here to look at all the many aspects of expert evidence. Instead we focus primarily on the use of medical reports obtained under the protocol for use in pre-action negotiations. Medical reports account for the vast majority of expert reports in the survey: almost all cases lover 90 per cent) involved at least one medical report and very few (under 10 per cent) involved any other form of expert. The chapter is divided into four sections:

- The first looks generally at the protocol approach to instructing experts. It outlines the procedure, considers the status of an 'agreed expert' under the procedure and explores whether experts are now perceived as being less partisan. It then sets out data from the file study about the number and type of doctors used.

- The second section goes through the protocol procedures step by step. It asks a series of questions. How were names proposed and accepted? Did defendants propose names? How were doctors instructed? Did experts consider GP notes? What queries were raised on their reports? Were reports disclosed?

- The third section considers issues of delay and cost. It looks at how long it took to instruct an expert and receive the report. It also considers the cost of reports. 
- The chapter concludes with a brief look at the use of experts on the multi-track, which is governed to a much greater extent by court rules. The usual approach is for each side to commission their own expert on key issues such as injuries and care, but to agree joint reports for less important specialisms, such as physiotherapy or occupational therapy.

\section{Medical evidence under the pre-action protocol}

The protocol aims to discourage the use of partisan experts, and the consequent duplication of reports obtained by both the claimant and the defendant. Instead, the instructing party should provide the other side with one or more names, and attempt if possible to agree a mutually acceptable expert. If the expert is acceptable, the other side would not normally obtain their own report.

The protocol sets out the following procedure:

- Before any party instructs an expert he should give the other party a list of the name(s) of one or more experts in the relevant speciality whom he considers are suitable to instruct. (para. 3.14)

- Within 14 days the other party may indicate an objection to one or more of the named experts. The first party should then instruct a mutually acceptable expert (para. 3.16). If the expert is named in the letter of claim, the defendant has 14 days from the acknowledgement.

- If the second party objects to all the listed experts, the parties may then instruct experts of their own choice. It would be for the court to decide subsequently, if proceedings are issued, whether either party had acted unreasonably. (para. 3.17)

- If the second party does not object to an expert nominated, he shall not be entitled to rely on his own expert evidence within that particular speciality unless:

(a) the first party agrees;

(b) the court so directs; or

(c) the first party's expert report has been amended and the first party is not prepared to disclose the original report. (para. 3.18) 
Lord Woolf noted that proposed changes to expert evidence provoked particularly strong reactions. He described the idea of single experts as 'anathema to many members of the legal profession' who proved reluctant to give up their adversarial weapons (1996, p.140). The protocol procedure was the result of careful negotiations between claimant and defendant representatives. Either intentionally or unintentionally, it leaves several issues unresolved. The first issue, discussed below, is the status of any report obtained under the procedure: is it joint or does it belong to the instructing party? The second is whether it is for the claimant or defendant to be primarily responsible for the medical evidence. The notes suggest that the claimant should obtain the medical report:

The protocol promotes the practice of the claimant obtaining a medical report, disclosing it to the defendant who then asks questions and/or agrees it and does not obtain his own report. (para. 2.11)

On the other hand, the use of deliberately neutral words in the protocol itself ('first party' and 'second party') provides scope for defendants to nominate an expert. As shall be seen, both these issues have become bones of contention.

\section{The status of a 'agreed expert' report under the protocol}

The words of the protocol contain some ambiguity about the status of a report from an expert 'agreed' under the outlined procedure. Is it a joint report, or does it belong to the party initiating the procedure? The issue has several practical implications, most notably whether a claimant who does not like the report must disclose it to the other side. Although the notes to the protocol state that protocol is designed to encourage "joint selection of, and access to, experts' (para. 2.11), the document does not at any stage use the words 'joint instructions' or 'joint report'. Instead, para.3.16 (above) suggest that the expert will be instructed by the 'first party' alone. This later interpretation has now been upheld by the Court of Appeal in Carlson v. Townsend..$^{22}$ The court pointed out that the CPR regulated experts used in evidence but not those used pre-action. As Brooke LJ put it, the protocol did not aim to deprive a claimant of the opportunity to obtain confidential pre-action advice about the viability of his claim, which he would be at liberty to discard if he did not agree with it'. Thus reports obtained pre-action under the protocol procedure differ from joint reports obtained during the course of proceedings, and need not be disclosed to the other party. 
The issue remains controversial. Taylor (2001) has criticised the Carlson decision on the grounds that it allows claimants to 'cherry pick' their expert. As he puts it, claimants:

Can put forward as many names to the defendant as they wish, and, providing none of the named experts is objected to, could, in theory at least, keep going through that list until a report is produced that best suits their claim. The defendant would be none the wiser. For defendant solicitors, this decision merely confirms what, in their eyes is a case of 'heads you win, tails I lose'. (Taylor 2001, p.1036)

This study found considerable confusion over the status of 'agreed' experts. Claimant solicitors differed markedly over how they regarded such reports. Some felt that they were definitely joint reports, and a few even saw this as an advantage in handling difficult clients:

That's an advantage, because once you've got the report, you can say to the client... the other side have already seen a copy. So you don't get stuck with a client who says, 'He says I'm overweight - I want that taken out', or... 'I don't agree with what he says there'. (Claimant solicitor - medium-sized firm)

Others, however, felt that, in the light of Carlson, this was a misunderstanding of the protocol:

I didn't realise for a few months that in fact I was actually misreading the protocol... I think... I was largely misled by defendants' insurers telling me what was in the protocol. (Claimant solicitor - small firm)

Claimant solicitors interviewed at the end of the study tended to be more positive of their ownership of protocol reports:

We take quite a strong difference between an agreed protocol report and a joint report. So we are very much aware that if the client really doesn't like it, we don't have to disclose it. (Claimant solicitor - large firm)

Claimant solicitors emphasised how important it was to have control over the medical report:

The claimant has to have control over that. It's the claimant's injuries; it's the claimant's medical notes... it's the claimant's claim. It's for us to prove our case - and for us to be doing that with a report that's effectively owned by somebody else, it's not right. It's not in the interests of justice and it loses us control over a vital aspect of a personal injury claim. IClaimant solicitor large firml 
For their part, defendant insurers and solicitors were highly critical of Carlson. When the protocol was first introduced, several insurers had assumed that it would produce joint reports, and complained that current practice was against the spirit of openness they regarded as the touchstone of the current reforms. One claims handler put it in the following terms:

What we used to have, and did expect, was a joint instruction, in that instructions, although coming from a lawyer, were also effectively coming from us. So that when the expert prepared his report, we got a copy, the solicitor got a copy. That does not happen any more. I don't recall the rules being changed about joint instructions, but they do not send us a copy of the medical report simultaneously. What they do is send it to the client and ask whether it is correct, and whether there are any other amendments and changes that need to be made, to fine tune it. (Claims handler)

Almost all the insurers spoken to argued that the protocol should make provision for joint reports. One argument was that this would prevent the delay involved in waiting for the claimant to approve a medical report:

We prefer to do it on a joint basis, simply because if we get the medical report in at the same time as the claimant's solicitors, we want to be looking at it and thinking about making offers. (Insurer)

It would also stop one-sided changes:

I strongly suspect a lot of claimant solicitors... they're sort of changing it as they want it, and then disclosing it. (Insurer)

If is, of course, open to the parties to agree to instruct an expert jointly. Insurers said that they often suggested it, and offered the incentive that they would pay half the fee in advance. They reported, however, that claimant solicitors were rarely amenable to this. One claims handler suggested that only around 20 per cent of protocol reports were commissioned on a joint basis - the rest were from 'agreed' experts but belonged to the claimant. In the end it was easier to accept that the claimant commissioned the report than to spend time and money arguing the point:

Normally we would always ask for a joint one, but quite often the other side come back and don't want that... They would prefer an agreed specialist... We don't really want to argue too much backwards and forwards about the type of expert... because we want to get the claim in, the medical done and out again. (Claims handler) 
Another insurer conceded that despite the advantages of joint reports, the process of agreeing instructions would add to the workload and in the majority of cases that work isn't probably necessary'.

\section{Are medical experts less partisan?}

Most of those we spoke to agreed that the reforms had succeeded in producing less partisan reports. There were several reasons for this. Partly, the procedure for agreeing names had excluded the most notoriously biased experts:

Some people have disappeared off the scene altogether because they were so markedly one way or the other. And the people that were fairly middle of the road, and prepared to stand by their views and back them up, are doing very well out of it. (PI defendant solicitor)

I know the ones who used to have the bias, and most of those have been seen off. [X], he's the classic - he's the man who doesn't believe that there is such a thing as RSI... I think he has been seen off at last... Good riddance, dreadful man. (Claimant solicitor - small firm)

Experts were also thought to have a greater understanding of their duty to help the court, partly as a result of the statement now required under Rule 35.10 , and partly as a result of greater training. Both claimant and defendant solicitors felt that there was now a 'new breed' of medical experts, who were more factual and to-the-point:

A lot of the old school of medical experts have now retired... The new breed are slightly more direct... slightly briefer in their reports. They now do know what Part 35 says. They've had training in it. And they do address the issues rather better than some of the old school. Less partisan, maybe. (Claimant solicitor large firml

They're much more factual, and less likely to sit in judgement. Because some of the old lads tended to sit in judgement, rather than actually getting to grips with what the real issue is. (PI defendant solicitor)

The requirement under Rule 35.10(3) to state the substance of all material instructions was also felt to have reduced the amount of off-the-record correspondence:

[Before] perhaps there might have been a conversation from the consultant... saying: 'Look, I've given you this report, but I really don't believe the client.' So we would disclose the report without the other side knowing that there was a 
doubt in the consultant's mind... Whereas now... everything has got to be in writing, since Woolf. So telephone calls are out, side letters are out. You know, just give us your honest opinion. (Claimant solicitor - large firm)

To our surprise, almost everyone we spoke to thought that the reduction in partisan reports was an improvement:

Both sides have stopped using the extreme experts, which is brilliant.

(PI defendant solicitor)

It's certainly much fairer... There's no pet consultant any more. (Insurer)

Claimant solicitors, in particular, felt relieved that they could now rely on a medical report without fearing that it might contain an exaggeration: 'There is nothing more frustrating than running a case and then finding out there is more to this client's injuries than meets the eye.'

\section{Medical experts used}

We found a few cases (five pre-Woolf and ten post-Woolf) without a medical report. Three of the post-Woolf cases had been abandoned early in the proceedings, before medical evidence had been commissioned. In the remaining cases, the defendant insurers had been willing to settle without a formal report. But these are very much the exception. The great majority of personal injury claims require a medical report, though only a few involve more than one.

Tables 2.6.1 and 2.6.2 show the number of medical experts used per case, first for all cases in the survey and then for standard fast track cases only. Note that this is the number of experts - not the number of reports. Some experts provided more than one report, especially where symptoms took a while to resolve. 
Table 2.6.1 All cases: number of medical experts used

(weighted data)

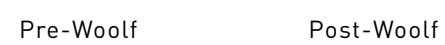

No. of medical experts primarily instructed by claimant

$\begin{array}{rrrrr}0 & 5 & 3 & 11 & 7 \\ 1 & 127 & 84 & 136 & 90 \\ 2 & 14 & 9 & 3 & 2 \\ 3 & 4 & 3 & 2 & 1 \\ 4 & 2 & 1 & 0 & 0\end{array}$

No. of medical experts primarily instructed by defendant

$\begin{array}{rrrrr}0 & 137 & 90 & 146 & 96 \\ 1 & 15 & 10 & 6 & 4\end{array}$

Total no. of medical experts instructed in case

\begin{tabular}{lrrrr}
0 & 5 & 3 & 10 & 7 \\
1 & 117 & 77 & 134 & 88 \\
2 & 21 & 14 & 6 & 4 \\
3 & 7 & 5 & 2 & 1 \\
4 & 2 & 1 & 0 & 0 \\
Total & 152 & 100 & 152 & 100 \\
\hline
\end{tabular}

Table 2.6.2 Standard fast track cases only: number of medical experts used

(weighted data)

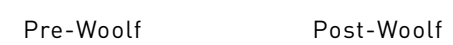

No. of medical experts primarily instructed by claimant

2

3

No. of medical experts primarily instructed by defendant

$\begin{array}{rrrrr}0 & 93 & 95 & 124 & 98 \\ 1 & 5 & 5 & 3 & 2\end{array}$




\begin{tabular}{|c|c|c|c|c|}
\hline \multirow{2}{*}{ Contin } & \multicolumn{2}{|c|}{ Pre-Woolf } & \multicolumn{2}{|c|}{ Post-Woolf } \\
\hline & No. & $\%$ & No. & $\%$ \\
\hline \multicolumn{5}{|c|}{ Total no. of medical experts instructed in case } \\
\hline 0 & 5 & 5 & 8 & 6 \\
\hline 1 & 83 & 85 & 116 & 91 \\
\hline 2 & 7 & 7 & 3 & 2 \\
\hline 3 & 3 & 3 & 0 & 0 \\
\hline Total & 98 & 100 & 127 & 100 \\
\hline
\end{tabular}

The tables show a slight reduction in the number of experts used. Among all cases, the pre-Woolf mean of 1.24 reports per case has now fallen to 1.01 reports. The fairer comparison is for standard fast track cases, where the mean has fallen from 1.08 to 0.96 . The reduction is statistically significant, ${ }^{23}$ though far from dramatic. It is worth noting that even before the Woolf reforms, defendants obtained separate reports in only a small minority (5 per cent) of standard fast track cases.

Most reports (79 per cent) continue to be commissioned from consultants. General practitioners were used in less than one in five cases. One firm that regularly used GPs for small whiplash claims argued that they had many advantages. They were quicker, cheaper and more convenient for the claimant. They were also thought to produce clearer reports:

GPs take a much more pragmatic view... much more in the client's own language. And they're looking at how the accident has affected the client, rather than which particular muscle has been affected, and how all the research points towards various obscure things. (Claimant solicitor - large firml

Nevertheless, this was a minority view. Other claimant solicitors worried that even an apparently minor injury could 'turn nasty', and it was better to have the protection of a consultants' report. 


\section{The protocol process step by step}

This section considers each step of the process of obtaining and disclosing medical reports under the protocol. It starts with the procedure for submitting and agreeing names. It then considers instructions, obtaining GP reports and queries to the report (first by claimants and then by defendants). It concludes with a discussion about whether reports are disclosed to the other side.

\section{Submitting and agreeing names}

In the great majority of cases, the claimant solicitor sent the defendant a list of expert names before commissioning medical evidence, as required under the protocol. Out of 141 post-Woolf cases with a claimant medical report, a list of experts was submitted in 118 cases ( 84 per cent). This left 23 cases (16 per cent) that appeared not to follow the procedure. Of these, five involved limitation problems, though in the remaining 18 cases there seemed to be no particular reason for the lack of names. Usual practice was to send one, two or three names. Out of the 118 cases following the procedure, onequarter (25 per cent) involved one name, around one-third (32 per cent) involved two names and the rest ( 43 per cent) involved three names. In around half of cases ( 51 per cent), names were sent with the letter of claim. In the remaining cases, they were sent later.

Claimant solicitors said that, in fast track cases, it was rare for defendants to object to names. The usual response was to agree all or some of the names - or, if the names were unknown, to ask for more information. This was supported by the file survey. Table 2.6.3 shows that in two-thirds of all cases, the defendant accepted at least one of the names. In most of the remaining cases, they either failed to respond or it was not established what their response had been. We found only four cases in which the defendant had objected to all the names submitted. It was even rarer for a report to be commissioned from a doctor that a defendant had objected to. In the whole study, we identified only one such case. 
Table 2.6.3 Post Woolf cases: defendant's response to the submission of names (unweighted data)

\begin{tabular}{lcc} 
& Number & $\%$ \\
\hline Agreed to all names & 59 & 50 \\
Agreed to some of the names & 20 & 17 \\
Agreed to none of the names & 4 & 3 \\
Failed to respond & 19 & 16 \\
Other/not known & 17 & 14 \\
All (where names submitted) & 119 & 100 \\
\hline
\end{tabular}

On the whole, claimant solicitors were reasonably happy with the procedure for submitting names. Their main complaint was that insurers kept inadequate records of experts, and instead made repetitive demands for more information:

Although we deal with the same insurers day in and day out, and they know the experts we deal with day in and day out, the standard response is: 'We don't know this person. Give us more information. Send us a CV.' Although we've sent them the CV 300 times. (Claimant solicitor - large firm)

It was also felt that insurers acted inconsistently:

You might be dealing with one insurance company in their office and you find that they've agreed this doctor and then you get somebody else dealing with the next claimant and they object. There's no consistency. (Claimant solicitor - large firml

For their part, insurers felt positive about the move away from partisan experts and welcomed the saving in time and money resulting from fewer medical reports. However, when questioned, they admitted that they found the procedure difficult to operate in practice. The move to national specialist centres meant that the number of possible experts was greater than they could keep tabs on. Two organisations had set up computerised databases of possible experts. One company with a strong local base felt that this was a useful, if time-consuming, exercise. The other, however, dealt with claims from the whole of England and Wales from a single office and, despite the database, were regularly sent names they knew nothing about. In these 
circumstances, they tried to keep their options open by saying that they would decide whether to commission their own reports only after they had seen the claimant's report:

If we don't know the person... [we say], 'We have no knowledge of this person. Can we suggest that you get your report and then when it comes in, we will then review whether we need our own report or can agree it.' If that report comes in and it's a fair, well-balanced report, we'll put them in the system: 'expert to be agreed for the future'. (Insurer)

Other companies held no central information about experts. One said that they left it up to claims handlers to draw on their own judgement and experience, or to ask around the office: 'if we're really in doubt, we always ask for CVs.' In the absence of systematic information, insurers clearly found it difficult to make reasoned objections to particular experts. Two insurers said they had effectively given up attempting to challenge names, except in the few cases where they knew the doctor to be unacceptable:

To a large extent we don't bother challenging doctors unless names come up where we go, 'uh uh, we're not having him'. (Insurer)

When we did our audits, we found that we spent loads of time arguing the toss about which consultant to use, and never once have we actually been successful in saying, well it shouldn't really be him. What we say now is... you've got a choice of three, so go for the one you've perhaps heard of. If there's one that's a bit of a rogue, then steer clear of him. (Insurer)

Insurers were wary of getting into discussions about particular people as the 'arguments you can get over that are phenomenal'. One asked for greater clarity about what might count as a reasonable objection.

Overall, the impression was that the nomination and agreement of expert names has had a positive effect as part of a wider culture change towards less partisan experts. On a practical day-to-day level, however, it works in a hitand-miss way, with insurers often lacking the information to make reasoned decisions. 


\section{Defendants proposing names}

We have already noted an ambiguity within the protocol over whether the onus was on the claimant to obtain a medical report or whether either side could use the procedure to propose names. Insurers interpreted the protocol so as to allow them to nominate medical experts:

The actual rules don't distinguish between the first and second party. They don't say the claimant is the first party... the insurer or defendant is the second party... The way it distinguishes it is by saying the person who nominates first... Sometime the solicitor would write a letter to us, and [the expert] won't be in their first letter of claim... Because we're quite switched on, we fire letters back saying thank you very much, we wish to nominate $x$ to examine your client. (Insurer)

All the insurers in the study said that, where the claimant failed to nominate experts in their letters of claim, they might use the opportunity to nominate an expert themselves:

If a nomination hasn't come in the letter of claim, yes, we'll go back and say:

'We nominate this agency - please confirm your agreement.' (Insurer)

If we have the opportunity, we grab it. (Insurer)

The main reason given was to prevent delay: 'It's a speed thing... we want our consultant on it as quickly as possible.'

However, insurers reported that their attempts to nominate the only medical expert were rarely successful. They met with strong resistance from claimant solicitors:

Claimant solicitors don't like it if we nominate up-front. They'll come back and say: 'Don't like any of them. Here are our nominations.' (Insurer)

We just get a point blank 'sorry, we're not accepting them'. And then two or three weeks, four weeks later: 'Here are our named experts.' (Insurer)

Claimant solicitors confirmed that defendant nominations were unpopular. Several regarded them as breaches of the protocol:

Defendants are very quick off the ground to say... here are our three experts... What's that all about? I mean, that wasn't what the protocol says. The protocol is that the claimant instructs. (Claimant solicitor - small firm) 
When faced with resistance, insurers found themselves in a weak bargaining position. They were reluctant to indulge in lengthy correspondence that they would end up paying for at the end of the case: 'to keep the peace we'll probably go with whom they've nominated.' They were also conscious that a medical examination required the claimant's presence. If the claimant refused to attend, there was little they could do:

Where a solicitor has blatantly refused or unnecessarily refused us access to their client for medico-legal examination, l've not yet seen a case where they've had a penalty imposed upon them for being unreasonable. (Insurer)

The main incentive on a claimant solicitor to agree to accept a single defendant report was that the defendant would then pay for it. For firms running uncertain cases under CFAs this could be attractive:

If somebody comes in with a backache, that kind of thing... and if the defendant suggests getting an expert I would sometimes go along with that, simply because they're going to pay for it and I'll see what the evidence is. So I'm not totally reluctant to defendants getting experts for that reason. IClaimant solicitor - small firml

This would suggest that there are some cases in which a single medical report is obtained and paid for by the defendant. However, such cases are rare. One insurer suggested that they obtained a medical report in around 10-15 per cent of cases. Our own evidence suggests that it is less frequent than this. We found only one case in which the defendant had obtained all the medical evidence. However, our sample contained relatively few cases funded by CFAs, and it may be more common in cases funded in this way.

\section{Instructing the medical expert}

Since the Woolf reforms, claimant solicitors have established a more armslength relationship with medical experts. They are now more likely to use a medical agency; instructions are now more neutral; and experts are less likely to be sent material not available to the defendants. 
Table 2.6.4 All cases: did the claimant solicitor instruct the first medical expert through an agency?

lweighted data)

\begin{tabular}{lcccc} 
& \multicolumn{2}{c}{ Pre-Woolf } & \multicolumn{2}{c}{ Post-Woolf } \\
& No. & $\%$ & No. & $\%$ \\
\hline Yes & 28 & 19 & 57 & 40 \\
No & 101 & 68 & 65 & 46 \\
Not available/not known & 19 & 13 & 19 & 13 \\
Total & 148 & 100 & 141 & 100 \\
\hline
\end{tabular}

Table 2.6.4 shows that the use of medical agencies has increased - from around one in five cases to two in five cases. National firms, operating without a local base, were particularly dependent on medical agencies, as they provided lists of experts in all parts of the country. The protocol had also encouraged the use of agencies. Some insurers had arrangements with large firms such that if they used certain agencies they would not need to agree names on an individual basis:

Medical agencies have found a niche where they've amalgamated lists of acceptable doctors to both claimants and defendant. (Claimant solicitor)

Finally, some firms reported that agencies were more prepared to postpone payment until the end of the case, thus easing the cash flow problems associated with CFAs. One solicitor explained his decision to use a medical agency as follows:

I had about eight experts I would generally use. I asked all of them: 'Would they agree to postpone payment of their invoices until the conclusion of the case?' And they all said 'No'. So I said: 'Well, sod you,' and I use this agency... who do exactly that. (Claimant solicitor - small firm)

The protocol contains a pro forma letter of instruction that provides strictly limited information about the claimant and the case. The only individual data it contains are the claimant's name, date of birth and telephone number, the date of the accident and a brief description of the main injuries. This has encouraged a more standardised approach to writing instructions. Table 2.6.5 below shows that around half of firms followed a version of the protocol letter, and most of the others used their own pro forma or letter giving a similar lor 
lower) level of information. Since the reforms, only around one in ten letters provided a greater level of individual information (compared with around one in four previously).

Table 2.6.5 All cases: nature of instructions used

(weighted data)

$$
\text { Pre-Woolf Post-Woolf }
$$

No. $\quad \% \quad$ No. $\quad \%$

Which best describes the instructions?

In broad terms, they followed the pro forma in the protocol, or used an abbreviated version of it 0 0 69

They followed the firm's own pro forma (or used a simple letter), giving no more individual

information than the protocol form

They followed the firm's own pro forma, but gave more individual information

They used an individual letter, giving

more information

$\begin{array}{llll}15 & 10 & 4 & 3\end{array}$

Instructions missing/not known

4

3

2

3

Total

148

100

141

A major change is that medical experts are now much less likely to be sent information not available to the defendant, such as a client statement or questionnaire. Table 2.6.6 shows that, while before the reform, almost half of experts were sent such information, it is now sent in less than one in ten cases. 
Table 2.6.6 All cases: was expert sent information about the case not made available to the defendant?

lweighted datal

\begin{tabular}{lrrrr} 
& \multicolumn{2}{c}{ Pre-Woolf } & \multicolumn{2}{c}{ Post-Woolf } \\
& No. & $\%$ & No. & $\%$ \\
\hline Yes: client statement sent & 38 & 26 & 7 & 5 \\
Yes: client questionnaire sent & 26 & 18 & 0 & 0 \\
Yes: other material sent & 4 & 3 & 4 & 3 \\
No & 76 & 51 & 124 & 88 \\
Not known & 4 & 3 & 6 & 4 \\
Total & 148 & 100 & 141 & 100 \\
\hline
\end{tabular}

One solicitor explained that he used to send a client statement so that the doctor would have a full account of what happened, as "clients are much more intimidated by doctors than they are by solicitors, and they often say things that actually are not quite the way it was'. However, since the reforms this was more difficult, as the court may order any documents sent to an expert to be disclosed:

I was [sending the client statement] until fairly recently - until I realised I really shouldn't be doing that, because the doctor was commenting on the statement and then I was having to disclose the statement. So obviously I was getting into a bit of a problem with that. (Claimant solicitor - small firm)

Insurers were pleased that doctors no longer received statements, particularly ones that concentrated on the disabling effects of the accident:

What sometimes I object to is the solicitor writing: 'Our client advises he can't do hoovering; he can't do washing-up, he can't do ironing, can't do this' when really it is the solicitor saying that. (Insurer) 
Respondents were asked whether instructions to medical experts should also be copied to the defendant. The replies revealed considerable confusion and variation. Claimant solicitors fell into three separate groups. The first group (comprising four solicitors) had assumed that under the protocol an agreed expert was jointly instructed, and had therefore developed procedure whereby the insurer was automatically sent a copy of the instructions. It was felt important that the defendant was 'on board':

I copy everything to the defendant. I make absolutely certain that the defendant is riding along with me on the same horse. (Claimant solicitor - small firm)

During the course of the interview, a couple of solicitors in this group reflected that under the protocol it might not be strictly necessary to copy instructions. However they still regarded it as good practice:

I think on a strict interpretation of the rules that's probably a step too far, or an unrequired step. But on fast-track cases, where you want straightforward... reports, my view would be that you do whatever you can to make sure that... the report you get is a joint report. (Claimant solicitor - large firm)

The second group (with six solicitors) argued that protocol reports were not joint reports. Thus as a matter of principle, instructions should not be sent to defendants:

There is nothing in the protocol to say it's got to be a joint report, both of us sending instructions. Quite the opposite. [Insurers] misunderstand that and cause a delay and frustration and sometimes anger. (Claimant solicitor large firml

We've had numerous run-ins... with insurers... trying to make out it's a joint instruction. It is not a joint instruction. It's a joint selection, but after that it is our instruction. (Claimant solicitor - medium-sized firm)

However some of this group admitted that if insurers demanded instructions it was sometimes 'quicker and easier' to send them a copy of the instructions as 'there's nothing particularly confidential in there'. The third group (comprising the rest of the sample) did not feel that it mattered, as their instructions were now 'pretty bland'. They would send copies if insurers asked for them. 
Most insurers argued that, as a matter of principle, they were entitled to see the instructions. Some would routinely ask for them. However, they rarely found anything to object to. As one manager put it, 'I've yet to see a bad one'. A couple of companies thought that now that instructions were more neutral, copying correspondence was not worth the additional paperwork:

On the bog standard... claims, the handlers probably don't want additional correspondence coming in. They've got enough letters without asking for a copy of the instructions to the doctor. (Insurer)

Table 2.6.7 shows that instructions were copied to the defendant in less than one-quarter of cases. Although this represents a change on previous practice, it is still the exception rather than the rule.

Table 2.6.7 Did the claimant solicitor show the instructions to the defendant before commissioning the report?

(weighted data)

\begin{tabular}{lrrrr} 
& \multicolumn{2}{c}{ Pre-Woolf } & \multicolumn{2}{c}{ Post-Woolf } \\
& No. & $\%$ & No. & $\%$ \\
\hline Yes: for information & 0 & 0 & 25 & 18 \\
Yes: for comment & 0 & 0 & 5 & 4 \\
No & 144 & 97 & 108 & 76 \\
Not known & 4 & 3 & 3 & 2 \\
Total & 148 & 100 & 141 & 100 \\
\hline
\end{tabular}

The file study supports the view that instructions rarely contain much that is controversial. We found only one case where the defendant objected to the contents of the instructions.

\section{Obtaining the claimant's medical notes}

The protocol states that where a medical expert is to be instructed the claimant's solicitor will organise access to relevant medical records', such as the general practitioner (GP) and hospital notes (para. 3.15). Insurers and defendant solicitors both stressed how important GP records could be to a case. They could be relevant both to causation and to the credibility of the claimant: 
The claimant will often say, 'er, I went to my GP on Day 1, and then I sort of made then other visits", and you might... look at the records and in fact find that the claimant didn't go on Day 1 but went on Day 41, and made no other visits. (Defendant solicitor)

It's not until you've got the GP records... that you will discover that he had a prolapsed disc or something due to a rugby match six months before the accident. (Claims handler)

Insurers complained that too many medical experts wrote reports without having considered the GP and hospital notes.

3.15 in the protocol is about the claimant's organising access to medical records for the expert. Still that doesn't happen. It's a lot better than it was, but we still find [reports]... based on simply seeing the person who was injured. (Claims handler)

There are an awful lot of cases out there where no GP records are reviewed. (Claims handler)

Claims handlers were therefore faced with the difficult choice of delaying settlement to obtain the notes, or settling on the basis of inadequate information.

These complaints receive some support from the file study. Table 2.6.8 shows that, as far as it is possible to tell, around one-quarter of reports had been written without access to medical records.

Table 2.6.8 Did the doctor have access to the client's GP notes in preparing the report?

(weighted data)

\begin{tabular}{lrrrr} 
& \multicolumn{2}{c}{ Pre-Woolf } & \multicolumn{2}{c}{ Post-Woolf } \\
& No. & $\%$ & No. & $\%$ \\
\hline Yes & 94 & 64 & 98 & 70 \\
No & 48 & 32 & 37 & 24 \\
Not known & 6 & 4 & 6 & 4 \\
Total & 148 & 100 & 141 & 100 \\
\hline
\end{tabular}


In around three-quarters of cases where the notes had been obtained, the claimant solicitor had written to the GP to ask for them. Increasingly, however, solicitors are delegating this time-consuming activity to medical agencies. In 17 post-Woolf cases, the agency had written for them, and in seven the task had been undertaken by the expert themselves.

\section{Claimant queries and amendments}

On receiving a medical report, claimant solicitors would routinely send it to their clients for comments. It was not unusual for the client to raise objections to the report. These ranged from minor mistakes of fact $-a$ misspelled name, or a mistyped date of birth - to matters of substance. In these circumstances, solicitors would need to raise questions with the expert or seek an amendment.

We have already noted the confusion over the status of protocol reports. This resulted in sharp differences of opinion between claimant solicitors on whether they needed to notify defendants of questions or to tell them that a report had been amended. A majority of those interviewed thought that it was important to be open about any changes. Thus requests for amendments were made in writing, and copied to the other side:

I will write to my expert and, as a matter of courtesy, I will write to my opponent and say... 'I want Mr So-and-So to clarify this... Here's a copy of the my letter.' (Claimant solicitor - medium-sized firm)

However, five solicitors in the study took the view that changes did not have to be notified to defendants. At least in the case of minor amendments, it might be simpler to say nothing:

On a certain case, I might ask the doctor to do me another report, and not refer to it as an amended report. I still think that's kosher. I don't see any problem with that, because I don't have to rely on a medical report. I mean that is the protocol. I don't have to disclose anything I'm not relying on. IClaimant solicitor - small firm)

I take that as being a fact that you should change it without disclosing the one that is wrong. So it's completely ethical, and it's confusing otherwise. If you've got a report that's wrong and one that's right... it's sod's law at the trial it's going to be the one that's wrong referred to and everyone is going to get confused. So I take it you can ignore the one that's wrong. (Claimant solicitor - large firml 
Insurers regarded non-notified changes of this sort as a breach of the spirit of the reforms:

The expert is no longer an expert to the parties, they're an expert to the court... so changing a report is a big no-no... The spirit of... the Woolf reforms is openness. (Insurer)

Insurers expressed the view that non-notified changes probably did take place, but were very difficult to identify: 'It's a worry, but you don't know it, you can't tell.'

Table 2.6.9 shows that questions were raised in only a minority of cases, but they were far from unknown. Among post-Woolf cases, the claimant solicitor questioned their medical expert in $14 \%$ of cases, usually without telling the defendant.

Table 2.6.9 Does the file show that the claimant solicitor raised any questions about the medical report with the doctor?

(weighted data)

\begin{tabular}{lrrrr} 
& \multicolumn{2}{c}{ Pre-Woolf } & \multicolumn{2}{c}{ Post-Woolf } \\
& No. & $\%$ & No. & $\%$ \\
\hline Yes: questions passed to the defendant & 4 & 3 & 6 & 4 \\
Yes: questions not passed to the defendant & 21 & 14 & 14 & 10 \\
No & 120 & 81 & 118 & 84 \\
Not known & 3 & 2 & 3 & 2 \\
Total & 148 & 100 & 141 & 100 \\
\hline
\end{tabular}

Actual amendments were rarer. Table 2.6 .10 suggests that they occur in less than one in 10 cases. However, they do occur. We found five post-Woolf cases where the first medical report had been changed without the defendant being notified. ${ }^{24}$ The issue of non-notified changes is a live one, and further clarification would appear to be needed. 
Table 2.6.10 Was the first medical report amended?

\begin{tabular}{lrrrr} 
(weighted data) & \multicolumn{2}{c}{ Pre-Woolf } & \multicolumn{2}{c}{ Post-Woolf } \\
& No. & $\%$ & No. & $\%$ \\
\hline & & & & \\
Yes: at the behest of the claimant solicitor, & 2 & 1 & 6 & 4 \\
with the defendant's knowledge & & & & \\
Yes: at the behest of the claimant solicitor, & 10 & 7 & 5 & 4 \\
without the defendant's knowledge & 1 & 1 & 2 & 1 \\
Yes: at the behest of the defendant & 132 & 89 & 125 & 89 \\
Not changed & 3 & 2 & 3 & 2 \\
Not known & 148 & 100 & 141 & 100 \\
Total & &
\end{tabular}

\section{Defendant questions}

The protocol allows defendants to ask agreed experts questions. Paragraph 3.19 provides that 'either party may send to an agreed expert written questions on the report, relevant to the issues, via the first party's solicitors'. Insurers thought that this was a useful provision. They suggested that they might ask a question if the prognosis was 'very woolly' or if, for example, the time off work seemed disproportionate to the injuries. One firm said that they had now started to ask questions in a more systematic way. All serious whiplash cases with prognoses of over two years were now sent to their own medical expert, for the expert to consider formulating questions:

We are getting some quite interesting questions that should be raised, and there are quite a few paragraphs coming back, with the [expert] stating that they are not at all happy with the way the evidence stacks up. (Claims handler)

The process was thought to have two advantages: it reminded claimant experts that they could be challenged and it educated claims handlers about the issues they should be looking for.

Despite the advantages of the defendant questions, the file survey suggested that they were quite rare. Out of 141 post-Woolf claimant medical reports, the defendant had attempted to raise questions on only six land only four questions had in fact been passed on to the expert). One defendant 
solicitor suggested that 'most insurers... don't really have the skills to form their questions at an early stage', and that serious challenges to the medical evidence were usually left until after proceedings had been issued.

\section{Disclosing the medical report}

The final test of whether a report is joint lies in whether the claimant has to disclose one they do not like. As might be imagined from the previous discussion, claimant solicitors expressed differing views. Some thought that any report obtained under the 'agreed expert' procedure had to be disclosed:

The mere fact that you don't like what they are saying is no grounds for changing it... If, at the end of the day, the report is saying the client is a malingerer and has a long history of reporting to doctors with symptoms for which there was no apparent clinical reason, I think you've really got to live with that. (Claimant solicitor - medium-sized firm)

Others, however, pointed out that the Court of Appeal did not require unfavourable reports to be disclosed:

You see, under the protocol, we still retain the edge. We nominate three doctors, the defendants agree, we instruct Doctor 1. If we don't like Doctor 1's report, it goes straight in the bin and we instruct Doctor 2. And that's the report they'll see. (Claimant solicitor - large firm)

I'm certainly not going to send a medical report that I'm not happy with if I think we can get better... I get a report and it comes back and I think I don't want any of this... I wouldn't disclose it. I mean I would just sit on it, and then I would make a decision with the client. (Claimant solicitor - small firm)

The main restraint on commissioning second reports was that an unused report could not be charged to the other side. Solicitors therefore often told clients that they would need to pay for further reports out of their own pockets:

I have to say to the client... if you want a second opinion, you are going to have to pay for it, and you may not get that back... if the second report is the same as the first. (Claimant solicitor - small firm)

Table 2.6.11 shows that it is quite rare for claimants to commission medical reports that they do not use, but we did find some examples. Out of 141 postWoolf files, six contained undisclosed reports (compared with 11 from the pre-Woolf sample). 
Table 2.6.11 Number of undisclosed reports found on the claimant's file (unweighted data)

\begin{tabular}{lrrrr} 
& \multicolumn{2}{c}{ Pre-Woolf } & \multicolumn{2}{c}{ Post-Woolf } \\
& No. & $\%$ & No. & $\%$ \\
\hline None & 137 & 93 & 135 & 96 \\
One & 8 & 5 & 5 & 4 \\
Two & 2 & 1 & 1 & 1 \\
Three & 1 & 1 & 0 & 0 \\
Total & 148 & 100 & 141 & 100 \\
\hline
\end{tabular}

\section{Delay and cost}

\section{Time taken}

One immediate impact of the protocol is that it now takes longer to instruct a medical expert. Solicitors can no longer send instructions shortly after the first interview. The protocol requires that the claimant solicitor sends a letter of claim and waits for the letter to be acknowledged. The defendant then has another 14 days to agree to the proposed names. As we have seen, in around half of all cases, the actual delay is greater than this, because the claimant solicitor sends expert names after the letter of claim.

Figure 2.6.1 shows that instructions are now much less likely to be sent in the first two months. The median number of days from when the solicitor is first notified of the claim to medical instructions has risen significantly, from 67 days pre-Woolf to 113 days post-Woolf. ${ }^{25}$ This is a considerable delay and it is questionable whether it is justified by the benefits brought about by the protocol procedure. This question is returned to in the conclusions. 
Figure 2.6.1 Time from solicitor first notified of claim to sending instructions to first medical expert

(weighted data)

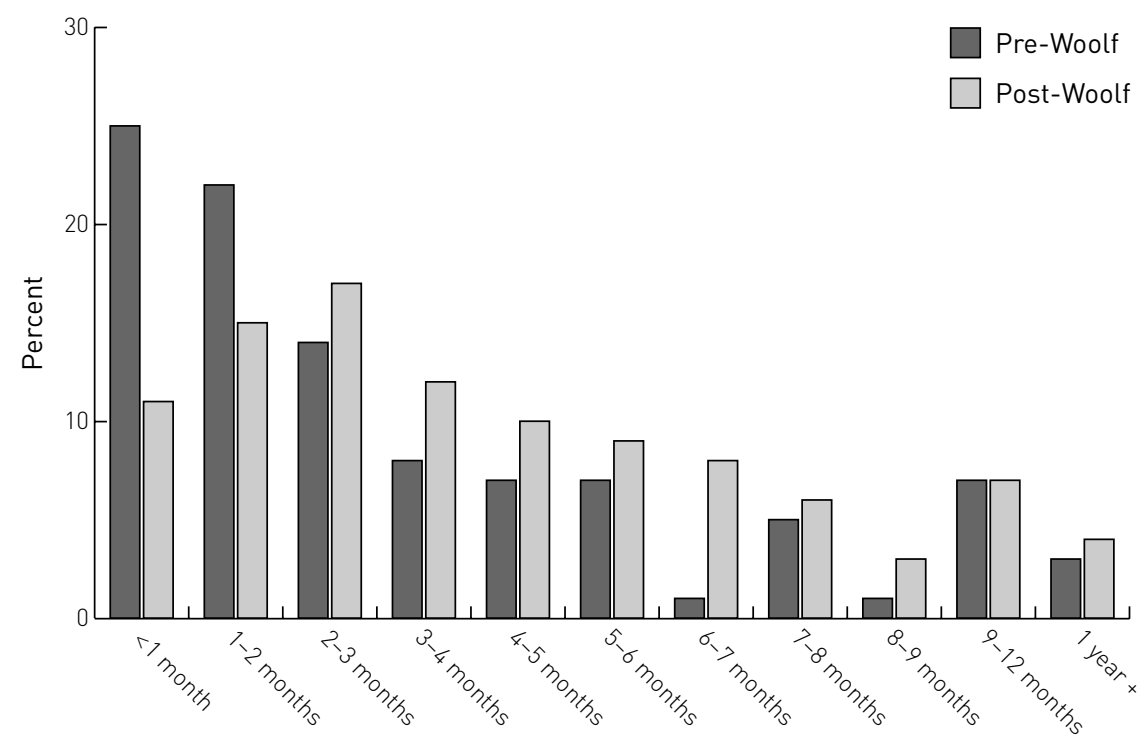

Time from solicitor first contacted to instructions

Base: all cases with claimant medical report where date known.

Unweighted: pre-Woolf 152; post-Woolf 140; weighted: pre-Woolf 147; post-Woolf 141

We asked claimant solicitors whether medical experts were taking any longer to produce reports. Most thought that the reforms had made no difference:

It's always been pretty lax. I mean, the experts are pretty slow, by and large.

There's no change there. (Claimant solicitor - small firm)

However, some solicitors thought that the process had become slower. They suggested that doctors had become more cautious l'bogged down by the requirements of Woolf'), and firms could no longer have special arrangements with experts who they knew to be quick:

Pre-Woolf we used to have our favourite doctors... I could ring up and say: 'Can you see Sue at 10 o'clock?' and they'd say: 'Yes, send her down.' And you'd have someone examined within two or three weeks, make a report within two weeks after that. Bingo, we're ready! And it was very, very quick. (Claimant solicitor small firm)

Data collected for this survey suggests that the time from instructing a medical expert to receiving the report may have increased, from a median of 64 days to 83 , but the difference is not significant. Figure 2.6.2 shows fewer 
very quick reports, provided within a month of instructions. Before 1999, GPs provided reports much more quickly - a median of 29 days compared with 83 for consultants. Since 1999, however, GPs and consultants appear to be taking the same length of time - around 83 days each.

Figure 2.6.2 Time taken from instructions to medical expert to receiving first medical report

(weighted data)

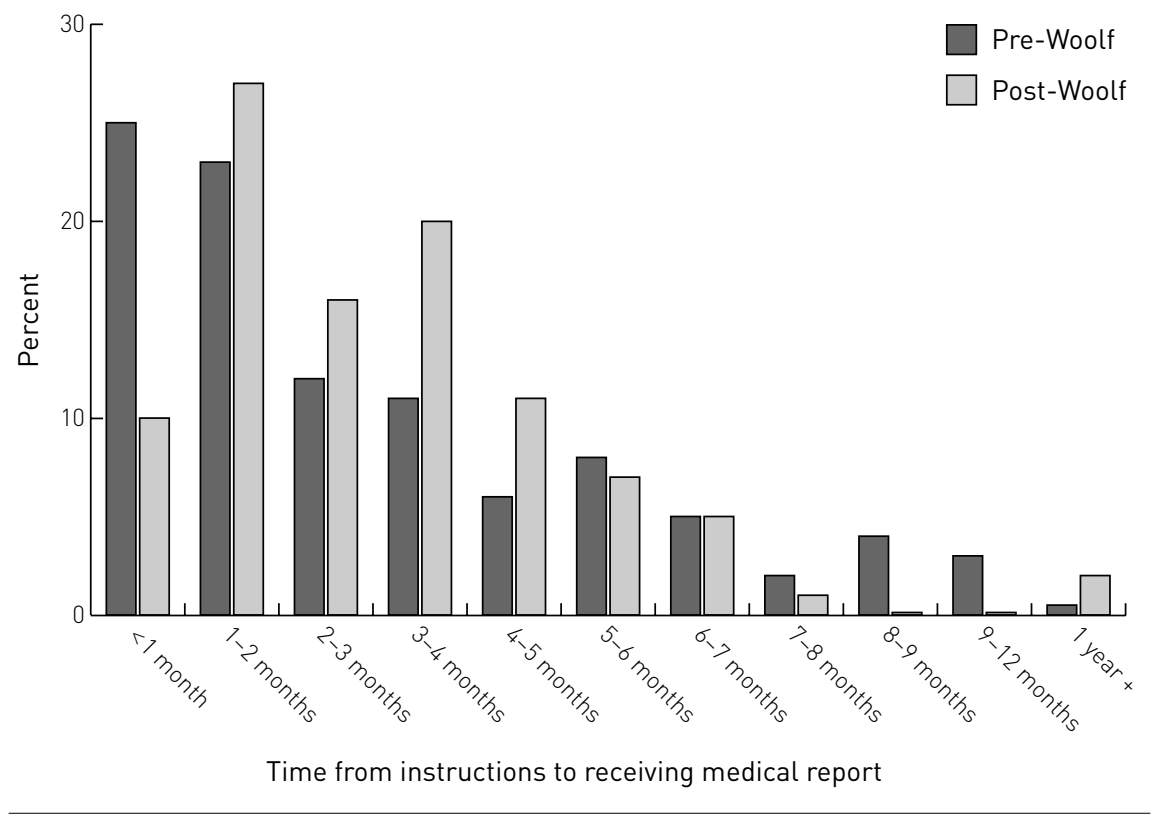

Base: all cases with claimant medical report where dates known:

Unweighted: pre-Woolf 151; post-Woolf 139; weighted: pre-Woolf 145; post-Woolf 140

The effect of these two increases is cumulative. The median time from first contact with the solicitors to receipt of a medical report has risen from 168 days to 206 days (significant difference). ${ }^{26}$ Thus as the response on liability has become quicker, the time to receipt of medical report has become longer. Most post-Woolf cases ( 86 per cent) involved a delay between receiving the response and waiting for medical evidence - with a median time spent waiting of 128 days.

All the insurers spoken to complained that medical reports took too long to obtain:

It is still not really satisfactory when you look at the completion of enquiries within a three-month period and you might wait six months for an appointment with a chosen consultant... That's where we find things stall and that's where we find a major log-jam occurring. (Loss adjuster) 
Insurers pointed out that, from their point of view, the important date was not when claimant solicitors received the report but when they received it. Claimants could introduce further delays as they mulled over and argued about reports:

I've got cases which are 18 months down the line, we haven't seen the medical report yet. I've had off-the-record chats with the claimant solicitor and he says, 'My client is just really unreasonable. I can't force him to send you the medical report'... There is nothing you can do. (Claims handler)

A major criticism that insurers made of the protocol was that although it provided a tight timetable for the response, there was no timetable for submission of medical evidence:

One thing with the pre-action protocol that always amazes me is that you have a time limit for the acknowledging the letter and a time limit for admitting liability and then the timetable runs out... There should be a target timetable [for the medical report]. (Insurer)

\section{Cost}

Medical reports are not only taking longer: they are also becoming more expensive. The median cost has risen from $€ 190$ to $€ 280 .{ }^{27}$ Figure 2.6 .3 shows that reports are now more likely to cost $€ 300$ or over.

Among post-Woolf cases, the median cost of a GP report was $£ 195$, while the median cost of a consultant's report was $€ 300$. 
Figure 2.6.3 Cost to claimant solicitor of first medical report

(weighted data)

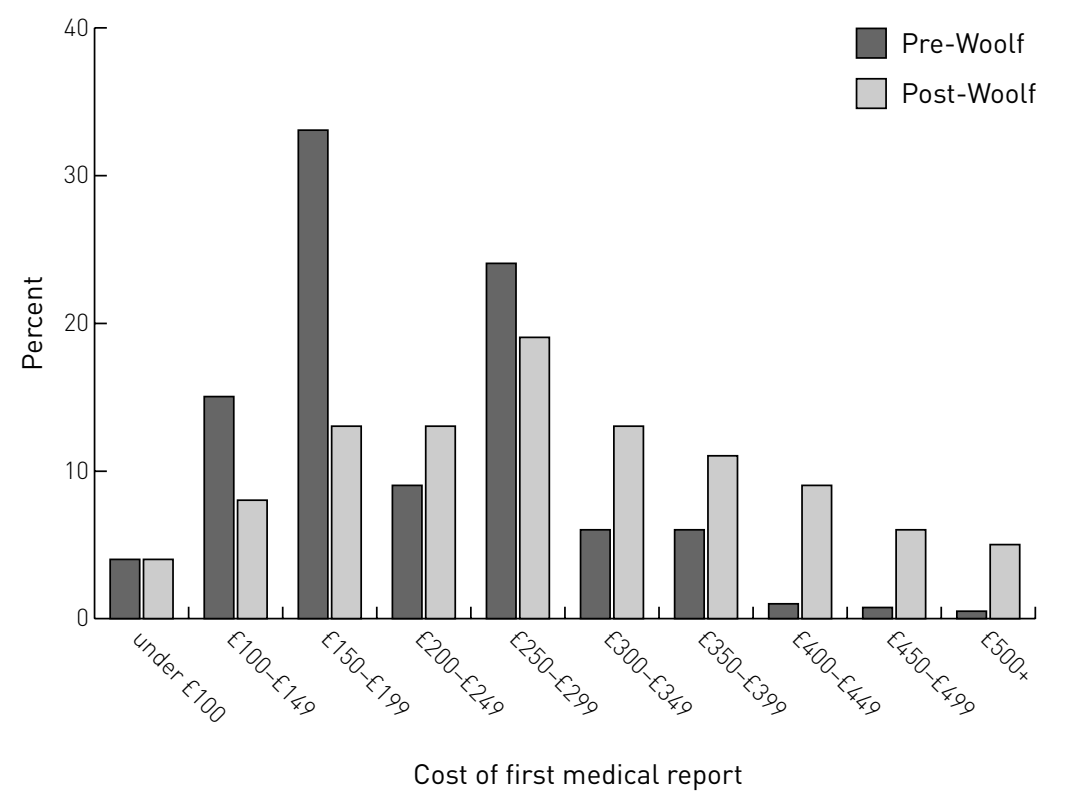

Base: all cases with claimant medical report where information available:

Unweighted: pre-Woolf 135; post-Woolf 109; weighted: pre-Woolf 121; post-Woolf 109

\section{Other experts}

In fast-track cases, it was rare for other experts to be used. The survey found only 10 post-Woolf fast track cases involving other experts: six used engineers while the other four included an accountant, an environmental health expert and a glass expert lin a product liability case over a shattering gold-fish bowl). We found no particular pattern to the way that other experts were commissioned. In five cases, only the claimant obtained other expert evidence; in two cases only the defendant obtained it; and in three cases each side used a separate expert.

\section{Experts in multi-track cases}

So far we have concentrated on smaller cases. All but four of our cases involved settlements of under $€ 20,0000$. Respondents agreed that when it came to large claims, procedures for obtaining expert evidence were quite different, although opinions varied about where the cut-off occurred. One claimant solicitor put the break point at $£ 25,000$, while an insurer suggested $€ 50,000$. There was general agreement that for these larger 
claims, each side should commission their own evidence for the key, controversial witnesses. However, other, secondary experts could be commissioned on a joint basis.

One characteristic of large cases is that they often involve many different quantum experts, looking at the various aspects of care and future loss. Solicitors identified medical and care aspects as the primary, controversial witnesses, but they also listed many other types of expertise:

Occupational therapists, nursing care, speech therapy, physiotherapy, architects, accountants... experts in... information technology and communication aids. (Claimant solicitor - leading firm)

Other solicitors added psychologists and employment specialists to the list, though employment specialists generate considerable controversy. One defendant solicitor described them as 'a compete waste of time', while an insurer stressed they should be 'used sparingly'. Claimant lawyers reported that courts were now less sympathetic to employment experts, though there was still a role for them in difficult cases.

Both sides were still keen to commission their own primary medical evidence, as it allowed them to seek confidential advice about the true strengths of their case:

It's infinitely better for me to have my own expert, that I can talk with off the record; that I can have in a conference with counsel; that I can say: 'Well, what are the real strengths and weaknesses with this?' That relationship is compromised if the other side have access to that expert. (Claimant solicitor leading firm)

It was also felt that care experts should be commissioned separately by each side, as considerable sums of money depended on their testimony:

Care experts are one of the biggest areas where you get a divide. One person will go in and look at somebody and they want Rolls Royce service... They effectively want to give this person so much care that in fact they do nothing for themselves anymore... Whereas we might go in and have a look with a reasonable perspective and... rather than saying they need someone to come in and do their washing-up every single day, [we] might get them a dishwasher. (Insurer) 
However, this still left plenty of scope for joint reports for, for example, physiotherapists, speech therapists, occupational therapists, architects and accountants. Some solicitors reported joint instructions for psychologists, although others were concerned that psychological evidence could be 'highly subjective'.

It was clear that the driving force in encouraging joint reports was the courts: in 'most cases the court is wanting a very, very good reason why it shouldn't be joint' One solicitor described agreeing joint reports as 'playing to the gallery'. Despite their initial reluctance to use joint experts, solicitors generally felt that it 'worked quite well'. One described a paraplegic case with seven joint experts and said there had been 'much less disagreement' than might be thought. Despite initial fears that instructions would be difficult to agree, several solicitors spoke positively about the level of co-operation between the parties, allowing a variety of approaches:

I've got [a case] where we're jointly instructing an employment consultant, an accountant and a psychiatrist. I do the instructions to the psychiatrist: I showed them the letter and they add a few paragraphs of their own. With the accountant, they've done the instruction and I've added a few paragraphs. With the employment consultant I think we've both done our own letter. IClaimant solicitor - leading firm)

There are, of course, some difficult issues about the use of experts in major cases. Several solicitors highlighted meetings of experts as a problem, a subject discussed in greater depth in the context of clinical negligence cases.

\section{Summary}

There are many positive aspects of the new approach to commissioning medical experts under the pre-action protocol. Respondents welcomed the fact that experts are now less partisan and that they are now instructed in a more neutral way. Data collected for this research suggests that (possibly) slightly fewer experts are now used, leading to less duplication of evidence. On a day-to-day level, the protocol procedure appears to work as intended. Most claimant solicitors nominate one, two or three doctors, and insurers agree to at least one of the names submitted. It is extremely rare for a doctor to be instructed to whom the defendants have objected.

However, as Lord Woolf pointed out, the issue of experts has considerable potential to generate conflict. The study revealed much confusion over the status medical reports obtained under the protocol procedure. Insurers and 
some claimant solicitors had started by assuming that such reports were effectively joint. Nevertheless, there is a strong current of thought among claimant lawyers that the claimant should 'own' their medical report. The first two years of the protocol have seen a battle between claimant lawyers and insurers over ownership of protocol reports. It is a battle that claimant solicitors have won. Despite insurers' attempts to commission the only medical evidence, this takes place very rarely. In most cases the claimant instructs the doctor, without showing their instructions to the opponent. Claimant solicitors retain the right to question their expert and ask for amendments without notifying the opponent. Claimants may also suppress reports they dislike. The sample of post-Woolf cases contained five cases where the first medical reports had been changed at the behest of the claimant solicitor without the defendant's knowledge, and six cases where medical reports had been obtained and not disclosed.

A major problem with the protocol procedure is that it has slowed the process of obtaining medical reports. Instead of instructing a doctor soon after the first meeting, solicitors must now contact the other side and wait for an acknowledgement. Defendants then have a further 14 days to agree to names. Thus the median time taken to issue instructions has increased by 46 days from just over two months to well over three months. This, coupled with increasing delays in writing reports, means that, post-Woolf, half of first medical reports took over six months (206 days) to obtain. As responses on liability are produced more quickly, there is an increasing problem of "dead time' after liability has been accepted, while the parties wait for medical evidence. In half of cases, over four months is spent in 'dead time' of this sort. Insurers complained vigorously about the delay in producing medical evidence, and asked for the protocol to provide a target timetable for disclose of the first medical report.

There is a case for reviewing the protocol procedure to examine whether the process of submitting and agreeing names justifies the delay involved. Our own view is that its initial effect was positive, in that it was part of a cultural shift towards less partisan experts. However, its benefits are diminishing as time goes on. On a practical level, insurers rarely have access to the information they would need to make reasoned decisions about which experts to agree. Given that claimants can ask for amendments without the defendant's knowledge and suppress reports they disagree with, the protocol procedure has only a limited effect in ensuring unbiased reports. Alternatives might include a central list of unacceptable experts, or a certificate from a claimant solicitor when a report is disclosed to say that they had not sought 
any undisclosed amendments or were not holding undisclosed reports. In the absence of such a certificate, defendants could have the right to obtain their own report.

Insurers complained that too many medical experts wrote reports without access to GP records. Our survey suggested that around one-quarter of reports were written without such access. A review of the protocol might also consider whether the absence of GP notes should trigger any particular sanction (such as giving defendants the right to obtain their own evidence if they wish).

In large multi-track cases, expert evidence is subject to a different regime, as set out in the CPR rather than the protocol. The common practice is for each side to commission their own 'key' experts (dealing with primary medical specialisms and the overall care regimel. However, lesser controversial specialist expertise is often commissioned on a joint basis (with joint instructions, and the report disclosed to both sides simultaneously). Many respondents spoke positively of these changes. 
Research Study 43 More Civil Justice? The impact of the Woolf reforms on pre-action behaviour 


\section{Chapter $2.7 \quad$ Settlement}

The process of settling a personal injury claim tends to follow a standard pattern. The prerequisites are that the defendant has accepted liability lat least tacitly) and the claimant has sent the defendant a final medical report and a schedule of special damages. Thereafter, the parties usually exchange a series of written offers setting out the upper and lower limits of a possible deal, followed by a telephone call to meet within the bargaining range. Several interviewees suggested that this traditional method has not changed greatly since the Woolf reforms:

You do the old thing. You get on the phone and you say: 'Look, can we split the difference between us?' And that still works. We still do that. IClaimant solicitor - medium-sized firml

There have been some changes, however. The most significant is the introduction of claimant offers under Part 36 of the CPR. For the first time, claimants have the opportunity to make formal written offers to settle a case that carry penalties if they are refused. Rule 36.21 states that where at trial 'a judgment against a defendant is more advantageous to the claimant' than the proposals contained in the offer, the court may award extra interest lup to 10 per cent above the normal base rate) and may grant the claimant costs on an indemnity basis.

This has the potential to transform negotiations in two ways. First, the Rules suggest that a claimant may gain a strategic advantage by making a first offer. Before the Woolf reforms, it was seen as a sign of frailty for the claimant to make a first offer: 'a sign that you were desperate to settle.' It would not be done except on the very weakest claims. We were interested to see how far Part 36 had encouraged claimants to make the first offer rather than wait for the defendant to put a figure to the claim. Secondly, insurers complained that, before Woolf, some claimants were reluctant to name any figure at all. Instead of reacting to an offer with a counter-offer, they would simply wait for the defendant to return with a higher figure. Part 36 was designed to encourage claimant solicitors to 'put their cards on the table' by establishing an upper limit to the negotiations. 


\section{This chapter is divided into six sections:}

- The first discusses the effect of claimant offers under Part 36. We start by outlining how personal injury negotiators viewed it overall, and how far it was used. Do claimant solicitors now make more offers in general, and more first offers in particular? We then look in more detail at how claimant solicitors reacted to the idea of making first offers and what they thought of the penalties contained in Rule 36.21.

- The next section asks whether any changes to the method of settling have taken place. During interviews, insurers extolled the virtues of greater use of the telephone, while claimants regretted the reduction in claims inspector visits. We outline the views expressed on these issues.

- Chapter 2.2 discussed insurers' claims that they are now more focused on quick settlement. The third section draws on the file survey to explore whether the settlement process now takes less time. We look both at the time taken from medical report to first offer and from first offer to settlement.

- The Civil Procedure Rules provide encouragement to use alternative means to resolve disputes, such as mediation. Previous research, however, has found that even when a mediation service was offered, it was almost never used to resolve personal injury claims. This study confirms the low take-up of mediation. The fourth section considers, briefly, the role that solicitors and insurers saw for mediation in personal injury work.

- One subject of discussion is whether the Woolf reforms have produced 'more settlements'. The is phrase is ambiguous. It can refer to the level of trials, or to the level of litigation, or indeed to the quality of settlements. Under the old system, so few cases went to trial that it would be difficult to discern any change. There is evidence, however, that fewer cases are now issued in court. It was also thought that settlements might be better informed.

- Finally, we discuss the effect of the protocol procedure in cases that do not settle before issue. One aim of the protocol is to support post-issue work, where litigation cannot be avoided. We set out interviewees' views on whether the protocol meets this objective. 


\section{Claimant offers under Part 36}

\section{Overall views}

Claimant solicitors were overwhelmingly positive about Part 36 claimant offers. Under the traditional system, after liability was accepted and quantum evidence exchanged, the claimant would wait for the defendant to make an offer. The weakness lay in the waiting. If the defendant failed to come back with an offer, all the claimant solicitor could do was threaten to issue proceedings - a slow and potentially expensive process. ${ }^{28}$ Claimants saw Part 36 as a means to 'make things happen', without necessarily issuing proceedings:

Part 36 is one of the highlights of the new regime. As a claimants' lawyer you can make things happen by issuing Part 36. Because before, all you were able to do was issue proceedings. And that was it. If there was no payment-in or whatever, then you got stuck... So I think that's made a big difference. (Claimant solicitor - medium-sized firm]

One solicitor enthused that Part 36 was 'like an Exocet missile... you get a response back almost immediately'. Others were more restrained: 'it doesn't scare them a lot, but they will take it more seriously.' One solicitor suggested that initially, claimant offers 'seemed to carry an awful lot of weight' but it was 'falling back a bit now' as insurers became more used to them. However the point was put, there was general agreement that claimant offers were a useful means of eliciting a response. They therefore helped speed up the settlement process:

It's got to be a benefit if it can bring a case to a satisfactory conclusion quicker. (Claimant solicitor - medium-sized firm)

Insurers were also positive about claimant offers, which were viewed as narrowing the issues and focusing minds. As one claims handler put it, they 'cut a lot of the blur'. A manager pointed out, once you 'get to the nuts and bolts of it', differences are less than they first appear:

[Claimant offers] certainly narrow the bands... In the bad old days... you'd ring up a claimant's solicitor and say, 'I'm going to offer you $£ 1,500$ and they would say, sorry, that's not acceptable', and you would say, 'What is?' and they would say, 'Sorry I'm not telling you'... Now... it might be diametrically opposed, but at least you know where the parties stand, and then you can work from there. And very often, when you actually get to the nuts and bolts of it, you find that it's one heading out of a dozen that's actually the real sticking point. (Insurer) 
Insurers confirmed that a claimant offer would be treated seriously. One firm, for example, said that they would be treated as priority post:

That type of thing would be taken out as a piece of urgent mail and would be physically set on the person's desk or handed to them. (Insurer)

Others said that their computer systems would trigger a review of the file within the 21 days set. In fact, the only criticism of Part 36 was from a claims handler who saw it as added pressure to respond quickly: 'you've then got to go straight back with a counter-offer.

\section{Use of claimant offers}

The main criticism insurers made of claimant offers was that they were not used enough:

It's very rare... We were preparing our advisors for medicals disclosed with an offer on a Part 36. It just didn't happen. (Insurer)

The culture of Part 36 offers hasn't really bitten with claimant solicitors - not to start the process. It's a reluctance to actually put a value to the claim first. I don't think that's right but that's where we're at. (Insurer)

The file survey shows that there was some truth in this. Table 2.7.1 suggests that the number of cases with a claimant offer has risen - but not radically. Pre-Woolf, 48 per cent of claims included an offer; post-Woolf, 58 per cent of claims did. ${ }^{29}$ When we looked only at standard fast track claims, the figures were similar: the proportion with a claimant offer had risen from 47 per cent to 55 per cent. ${ }^{30}$

Table 2.7.1 All cases: number of claimant offers made

(weighted data)

\begin{tabular}{lcccc} 
& \multicolumn{2}{c}{ Pre-Woolf } & \multicolumn{2}{c}{ Post-Woolf } \\
& No. & $\%$ & No. & $\%$ \\
None & 77 & 52 & 64 & 42 \\
One & 59 & 40 & 75 & 49 \\
Two & 12 & 8 & 12 & 8 \\
Three & 1 & 1 & 1 & 1 \\
Total & 149 & 100 & 152 & 100 \\
\hline
\end{tabular}


Not all claimant offers used the formalities of Rule 36.5 (which states, for example, that offers must be in writing and 'be expressed to remain open' for 21 days). In the file study, around one-third of offers were made on an informal basis, without using the formalities of Part 36.

Clearly, even before the reforms, solicitors made counter-defendant offers by naming an alternative sum. The crucial question is how far Part 36 has encouraged claimant solicitors to make the first offer in the case. Table 2.7.2 shows that pre-Woolf, this was extremely rare, occurring in only 3 per cent of all cases. It is now considerably less rare, but still occurs only in a small minority of cases ( 15 per cent). The proportion was similar if one looks only at standard fast track cases (13 per cent).

Table 2.7.2 All cases in which an offer made: who made first offer

\begin{tabular}{lcccc} 
(weighted data) & \multicolumn{2}{c}{ Pre-Woolf } & \multicolumn{2}{c}{ Post-Woolf } \\
& No. & $\%$ & No. & $\%$ \\
\hline Claimant made first offer & 4 & 3 & 22 & 15 \\
Defendant made first offer & 143 & 97 & 123 & 85 \\
Total (where offer made) & 147 & 100 & 145 & 100 \\
\hline
\end{tabular}

\section{Claimant solicitors' approaches to first offers}

When we asked claimant solicitors about their practice on making first offers, they split into two roughly even groups. The first group thought that a claimant solicitor should strive, wherever possible, to make the first offer. It was felt to be an important means of keeping control of the case and its timetable. For example, one solicitor said she would be 'shot' if she failed to make first offers. She thought it vital to analyse quantum continuously from the initial interview, and drive the case ahead. The file study suggested that, even among this group, first offers were made in only a minority of cases.

The second group said that they almost never made first offers. They felt that it was better to wait for the defendant to put their cards on the table. Their thinking was simple: there was always a chance that the defendant's initial offer might exceed the amount they had in mind: 
I always allow the other side to do it, always. And that hasn't changed... because I like to see how they value it first. (Claimant solicitor - medium-sized firml

One solicitor argued that, in fact, there was little delay between the medical report and first offer: 'that's the stage where the insurance company aren't particularly slow'. Thus it was worth waiting, rather than taking the risk of undervaluing the claim. Solicitors also said that some clients were reluctant to authorise initial offers:

Sometimes clients are unwilling to authorise you to make offers... If you're coming from an environment where there's a dockyard or something - you know, Joe Bloggs settled his case the other day for such and such... This is quite a culture shock for them. (Claimant solicitor - large firm)

Even those who believed in making first offers agreed that they could meet with some client resistance. Such solicitors also admitted that they could be caught out: 'On occasions... [defendants] pitched in a bit higher than I thought I was going to pitch in my Part 36.' Such under-valuations were rarely more than a few hundred pounds, and some solicitors thought that this was a price worth paying for speed. That said, several solicitors who would make first offers in small claims expressed greater reluctance to do so in larger claims, which were more uncertain and where an underbid could be more serious.

\section{Are the penalties appropriate?}

Under Rule 36.21, the penalties for failing to beat a claimant offer (10 per cent extra interest and possible indemnity costs) only apply if the case goes to trial. When we asked about sanctions, the most common reaction from interviewees on both sides of the divide was that they had no experience of sanctions being applied:

Never actually seen anyone trying to implement it. (Insurer)

l've never had a defendant punished yet. (Claimant solicitor - leading firm)

Claimant solicitors criticised the sanctions for being inadequate ("not very scary') and for being inappropriate in many cases. The first criticism was that the sanctions only applied at trial: 
[There's no] procedure for... compelling some penalty interest or costs [where] the matter hasn't been dealt with before the court. It was once raised by our opponents that they weren't liable to pay penalty interest: that was only something the judge could order at the trial... The interest in that case stood at something like $£ 40,000$. (Claimant solicitor - medium-sized firm)

The trouble with Part $36 \mathrm{~s}$ is they're only ever going to be effective on costs if you go to trial and you're never going to go to trial. IClaimant solicitor leading firm)

Thus, in the vast majority of negotiated settlements they had little practical effect. Secondly, in fast track cases the sums involved were small beer. As solicitors pointed out, if a $€ 2,000$ case came to trial six months after the offer, the maximum additional interest would be $£ 100$. A third criticism was that the sanctions had little bite in the lead-up to trial. While defendants had a major weapon in the form of a payment-in, the claimant could not apply commensurate pressure:

If a defendant makes a payment into court, say... just before trial, the claimant is at far more risk. Because what does the claimant have to gain?... Possibly a few pounds or so with interest. But what a claimant has to lose is potentially all his or her costs at trial and the defendant's costs at trial. (Claimant solicitor - leading firm)

One problem is that, with the move to conditional fees and collective conditional fees, there is great uncertainty about how much additional costs a claimant may expect if they are granted 'indemnity costs' under Rule 36.21(3). Claimant solicitors suggested that, rather than worry about the complexities of how much clients might nominally owe to their solicitors under CFAs, the court should simply award an percentage increase on normal costs lone solicitor suggested double). They did not specify, however, whether they saw this money primarily as a benefit for the client or the solicitor. The issue of which sanctions are most appropriately attached to claimant offers would benefit from review.

The most effective offers were made early in large cases, where the additional interest might amount to a substantial sum. One solicitor cited an offer of E2 million made one year before trial, which could have resulted in an additional $€ 200,000$ had the claim not settled. However, solicitors felt that rarely could one make a quantum offer so long before trial with such precision - especially without final expert reports, or if the condition was still developing. A few solicitors suggested that the greatest potential to use 
Part 36 strategically was to use it to make liability offers. For example, if a 99 per cent liability offer was made, it provided the potential to gain indemnity costs after success at trial. A defendant solicitor cited the following scenario:

The claimant solicitor, who clearly recognises that his client has got an excellent case, says my client will agree to accept 99 per cent liability... So [from then] up to the point at which we go to trial, he is in for indemnity costs... So he was very, very clever. He took advantage of the rule, quite properly. (Defendant solicitor)

It should be noted, however, that the effect of this strategy would depend crucially on the funding arrangement and the retainer the solicitor had with their own client. None of the solicitors spoken to had any experience of winning on liability offers, though one firm felt that this was an issue worth exploring:

We have some very interesting tactical discussions here about making Part 36 offers on liability and when you do it... I don't think Part 36 is used nearly enough... We are still learning how to use it. (Claimant solicitor - mediumsized firml

Most solicitors did not use Part 36 offers strategically to gain additional interest or costs but simply saw them as part of the standard settlement process. Their offer set an upper limit to the negotiations; the defendant offer sent the lower limit; and both sides then 'split the difference'. This emerged clearly when claimants were asked how they pitched offers: did they make a realistic offer, such that they genuinely thought they would get at trial, or did they go for the top end of the justifiable range? Most solicitors said they left themselves room for further bargaining:

The trick is in putting a Part 36 which takes into account the figure I think the claim should be settled at. It's not the figure I think the claim will be settled at, for obvious reasons. And generally speaking the Part 36 you get back is just below. So you ring them up... and say: 'Right, come on... You know what the game is... I've said this, you've said that, we'll have to meet somewhere in the middle, otherwise we're going to court.' (Claimant solicitor - small firm)

When I started these Part 36 offers, I thought let's make it a realistic figure... Now I'm tending to make it above the realistic figure, because I haven't met anyone who has come back to me and said, 'Yes, we'll take it as it stands'. (Claimant solicitor - small firm)

Finally, insurers were asked whether they thought that Part 36 led to higher settlements. They said that a well-judged offer early in the process could lead to them paying more money - but not much more. The figures quoted 
suggested between four to six per cent: from $€ 2,400$ to $€ 2,500$ or an additional $£ 300$ on a claim around $€ 5,000$. However, to secure more damages, the offer would need to be finely judged. Most solicitors, they felt, 'over-egged the pudding' and 'went in far too high'.

\section{Methods of settling}

As already seen, the traditional method of settling a small personal injury case is through an exchange of correspondence followed by a telephone call: the correspondence sets the limits, while the phone call 'splits the difference'. Claims handlers reported that the telephone call was often quick and rarely sophisticated: 'Within the five minute conversation you can agree settlement.' From our review of files, it rapidly became clear that the traditional method is robust. It was the typical means of reaching settlement in both pre- and postWoolf cases. Nevertheless, insurers regularly discussed alternatives particularly the greater use of telephones and/or face-to-face meetings. Here we look briefly at these other contact methods. A more radical alternative mediation - is discussed later in the chapter.

\section{Greater use of the telephone}

All the insurers we spoke to stressed that the telephone was their preferred method of contact. For example, one insurer, when asked whether his company could make any improvements to their claims handling processes, replied:

We should be getting on the phone more, rather than having letters... You can gain a lot more by negotiating on the telephone rather than hiding behind a letter. (Insurer)

That said, staff acknowledged that there were practical difficulties in "cold calling' with an initial offer. First, it was difficult to get through to solicitors, and even once one had got through, solicitors rarely engaged in the process:

There's no discussion at that point. It's 'let me look at the file. I'll take my client's instructions'... So it's more practical and easier simply to short-circuit that and write. (Insurer)

Interviewees reported that solicitors would usually ask for the offer in writing in any event. As one claims handler said, "phoning is what we are supposed to do' but 'they always ask for it in writing'. Thus the majority of offers were still made by post or fax: 
I would say about 60 to 70 per cent of the offers that we put are in writing [either] a fax or [other] written form. There are a reasonable number where it is expedient to have a chat with somebody over the phone, because there might be particular details about tax or... the ages of things... But I would probably say 70 per cent are in correspondence. (Claims handler)

\section{Face to face meetings}

One point of contention was whether insurers should send claims inspectors to claimant solicitors' offices to negotiate face to face. Insurers reported that controversy remained live:

The arguments on that go backwards and forwards. [Some] people swear by face-to-face negotiations. Others say: 'Well it can rarely save you money. You might as well do it by correspondence and telephone.' (Insurer)

Insurance companies differed in their approach. One large company said they had stopped all face-to-face meetings to reduce costs:

The claims inspectors used to go out and negotiate. Then a decision was made just to reduce costs. Claims inspectors are expensive - company cars, very senior people. And a decision was made that we would not entertain [face-toface] negotiation. (Insurer)

This interviewee also suggested that the Woolf reforms had made meetings less necessary, as information had already been exchanged earlier in the process:

Part of the process in the old days was that the claims inspector would go along and show the solicitor the actual statements, the documentation, lay all that on the desk. The Woolf reforms changed all that. You serve it all anyway, so the solicitor's got it all in front of him without facing the claims inspector. (Insurer)

On the other hand, another company said that they were now bringing back claims inspector visits:

We use claims inspectors now a lot more than we ever did... We've got stats to suggest that face-to-face discussion is more effective than a letter or somebody phoning up... The way somebody put it to me who used to work for a claimant's solicitor, is that they are as busy as anybody is... If you've got a letter or... a message to ring somebody back, they'll get to it when they can. If there's somebody sitting opposite them... then you can't run out. You've got to do something about it. (Insurer) 
Other insurers said they would send claims inspectors to some face-to-face meetings, but they did so selectively. They would use meetings in two circumstances - either where a particular large firm had many cases to discuss at once, or for particularly serious catastrophic injuries. One insurer said they had particular arrangements with four named firms:

The volumes you see from them... they're quite significant. So it's a bit of a coup to be honest to be able to discuss with them and to have that forum to discuss... They won't litigate against us until we have had the opportunity to discuss with them, so it is actually... quite a benefit. (Insurer)

For major cases, meetings could be used to discuss case management as well as settlement:

Our high-value claims handlers are probably on the road one or two days a week, out discussing... We see face-to-face meetings as not just about settlement but... about case management... Particularly in some of the catastrophic injuries, it's in everyone's interests... if you're into accommodation issues etc... rather than doing that remotely and having quite a confrontational bit of correspondence on what adaptations may or may not be needed. (Insurer)

These varying approaches meant that claimants had different experiences of meeting claims inspectors. Some extremely large or specialist firms reported little change. They had always regularly met with claims inspectors and they continued to do so. Other firms, particularly those experiencing recent growth, said that meetings had stopped but were now coming back:

I think there certainly have been more meetings. When I first qualified, meetings were really quite popular... But that completely went. The meetings stopped, the dialogue became much more closed... [Now] I certainly have more meetings with defendant's insurers and solicitors and that is very positive. (Claimant solicitor - large firm)

However, most solicitors - especially those in small and medium firms said that they almost never met insurers. This was greeted with regret:

In the good old days, before the [industry]... amalgamated, you'd have a local claims rep for each insurance company. He'd come along here with a dozen files - get them all sorted out. And that was ideal. That was superb. You knew him; he knew you; he knew your strengths and weaknesses. And he knew roughly what you'd be looking for in a case... But they don't have the resources to do that these days. (Claimant solicitor - small firm) 


\section{Time taken}

Chapter 2.2 reported how insurers claimed to be much more focused on quick settlements. The industry orthodoxy was that delay cost money (in terms of both costs and damages) and claims handlers were now monitored on how quickly they could settle cases. One would expect that this change of emphasis, together with Part 36, would produce quicker settlements. We were interested to see whether our file study supported such a claim.

The file study does appear to show that, since the reforms, the settlement process has become quicker - at least for standard, fast track cases. We started by measuring the time from the first medical report to the first offer (whether made by claimant or defendant) Figure 2.7.1 shows this for all cases in the sample, while Figure 2.7.2 provides a more direct comparison by looking at standard fast track cases only. They show that first offers are now less likely to take over six months to arrive: over three-quarters are made in less than four months. Pre-Woolf, half of all standard fast-track cases involved a delay of 87 days or more between medical evidence and offer. After 1999, half received an offer in 63 days or less, a significant difference. ${ }^{31}$

\section{Figure 2.7.1 All cases: time from first medical report to first offer}

(weighted data)

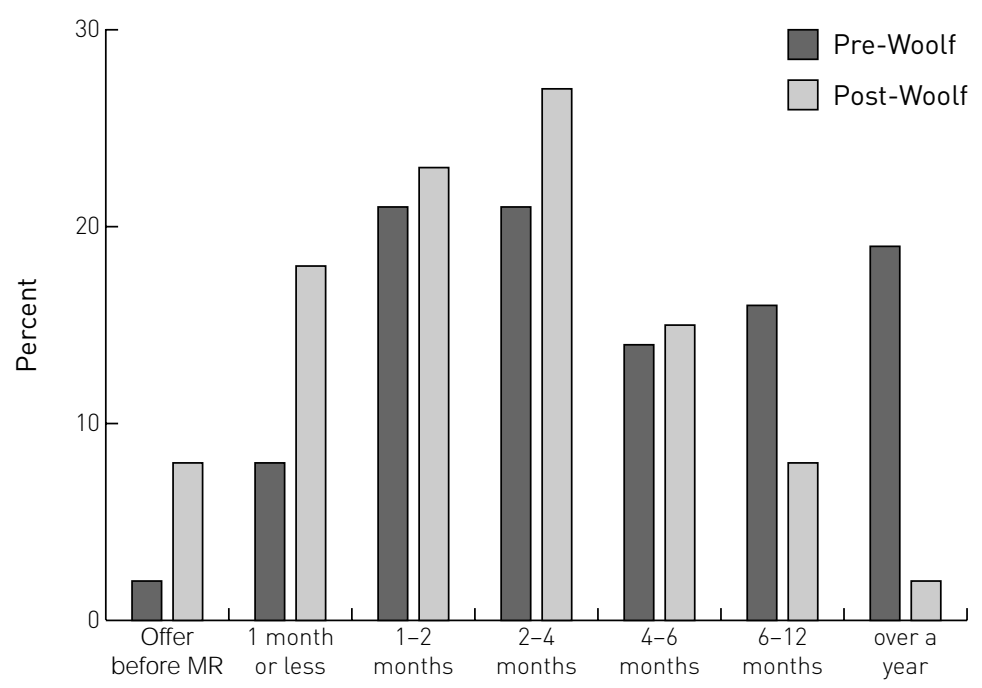

Time from medical report to first offer

Base: all cases with claimant medical report where information was available.

Unweighted: pre-Woolf 145; post-Woolf 130. Weighted: pre-Woolf 144; post-Woolf 130. 
Figure 2.7.2 Standard fast track cases only: time from first medical report to first offer

(weighted data)

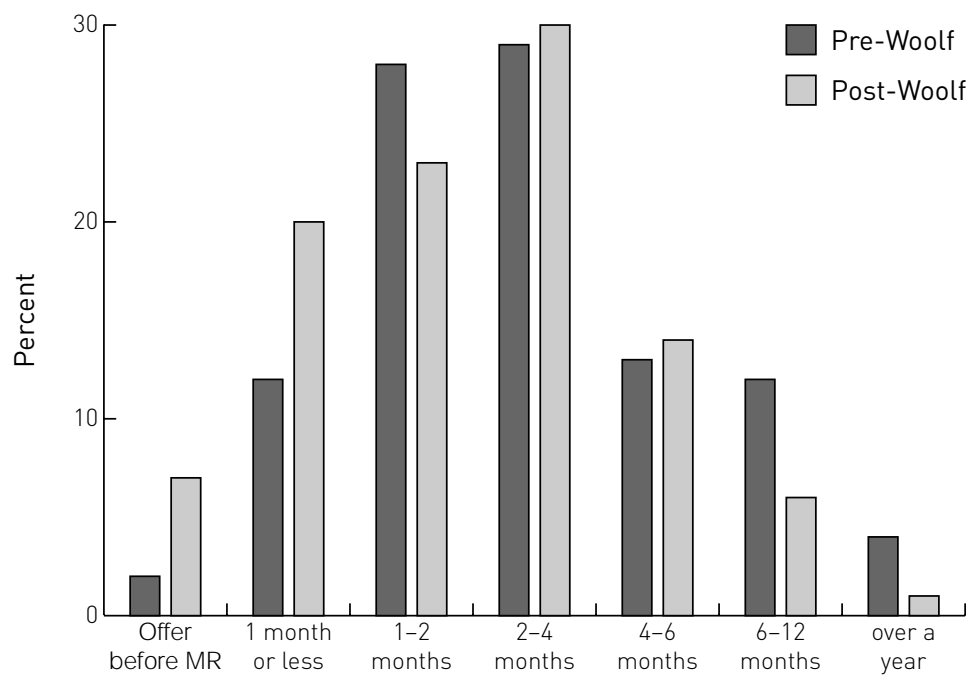

Time from medical report to first offer

Base: all standard fast track cases with claimant medical report where information was available. Unweighted: pre-Woolf 88; post-Woolf 102. Weighted: pre-Woolf 87; post-Woolf 101.

One possible change, discussed in Chapter 2.6.1, is that medical reports are now more definite. While pre-Woolf, 20 medical reports recommended that settlement should be delayed to wait for the condition to stabilise, this was recommended in only six post-Woolf cases. However, the number of cases was too small for this finding to be anything other than highly tentative. Among standard fast track cases, the figures were only six and four respectively. 
The file study found little change in the number of offers made. Neither set of files contained long series of offers. Table 2.7.3 shows that, across both samples, 90 per cent or more of cases were settled in one, two or three offers. It is usually sufficient for the defendant to make an offer, the claimant to counter-offer and the defendant to then provide a figure within an acceptable range.

Table 2.7.3 Standard fast track cases in which offers made: total number of offers made (by both defendant and claimant)

(weighted data)

\begin{tabular}{lrrrr} 
& \multicolumn{2}{c}{ Pre-Woolf } & \multicolumn{2}{c}{ Post-Woolf } \\
& No. & $\%$ & No. & $\%$ \\
\hline One & 36 & 38 & 41 & 33 \\
Two & 24 & 25 & 36 & 29 \\
Three & 30 & 32 & 34 & 28 \\
Four & 4 & 4 & 7 & 6 \\
Five & 1 & 1 & 4 & 3 \\
Six & 0 & 0 & 1 & 1 \\
Total & 95 & 100 & 123 & 100 \\
\hline
\end{tabular}

It would appear, however, that since the reforms, offers are exchanged more quickly. Figures 2.7.3 and 2.7.4 show that the time from first offer to settlement has fallen. This seems to hold true whether one looks at all cases within the study or only standard fast track cases. For standard fast track cases, the median time from first offer to settlement has reduced from 57 days pre-Woolf to 43 days post-Woolf. 


\section{Figure 2.7.3 All cases: time from first offer to settlement}

(weighted data)

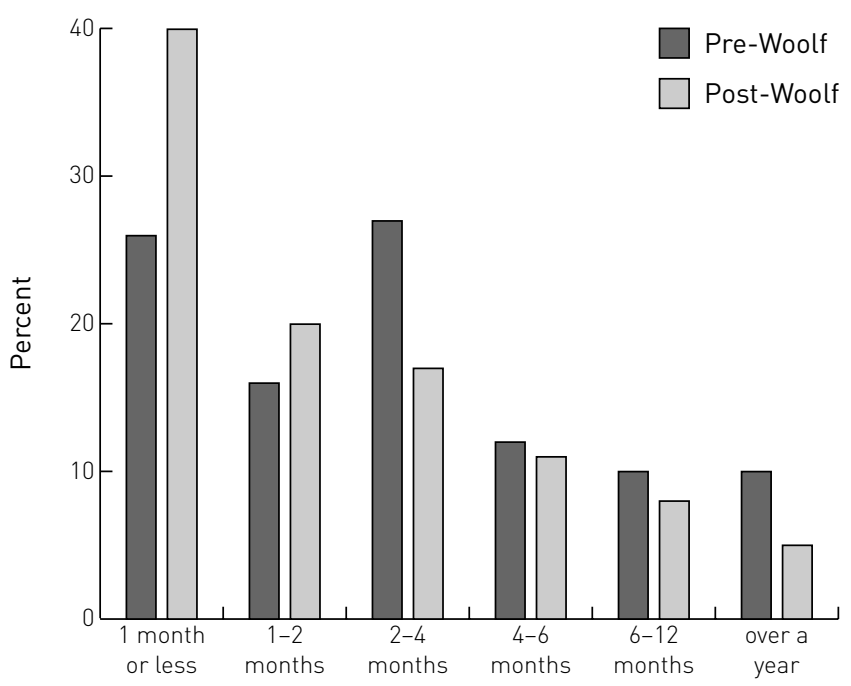

Time from first offer to settlement

Base: all cases with settlement where information was available.

Unweighted: pre-Woolf 147; post-Woolf 132. Weighted: pre-Woolf 142; post-Woolf 131.

Figure 2.7.4 Standard fast track cases only: time from first offer to settlement (weighted data)

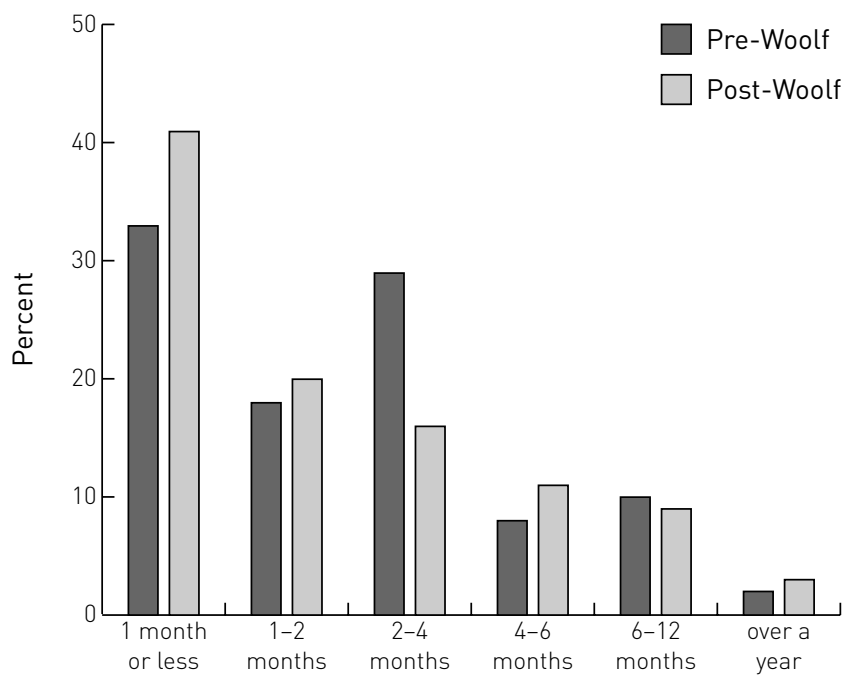

Time from first offer to settlement

Base: all standard fast track cases with settlement where information was available. Unweighted: pre-Woolf 91; post-Woolf 113. Weighted: pre-Woolf 90; post-Woolf 112. 
Since 1999, there does appear to have been a shift towards speedier settlement. In standard fast track cases, the time taken by the settlement process alone - as measured from the date the claimant solicitor received the medical report to the date a settlement is reached - has reduced from a median of 170 days pre-Woolf to 123 days post-Woolf. This difference is statistically signficant. ${ }^{32}$ It is difficult to point to any single explanation for this. It seems to be part of a wide cultural change, in which insurers have become more conscious of the value of quick settlements and Part 36 provides claimants with more opportunities to initiate action.

\section{Mediation}

The CPR attempt to encourage the use of alternative dispute resolution techniques, such as mediation. Thus Rule 1.4 establishes that courts are required to actively manage cases, one aspect of which is to encourage the parties to use an alternative dispute resolution procedure if the court considers that appropriate' (CRP 1.4.(2)(e)). When parties fill in an allocation questionnaire, they are asked specifically whether they would like the action to be stayed for a month to allow an attempt at settlement, by ADR or otherwise. Under Rule 26.4 the court may even direct such a stay on its own initiative.

Previous research has found that demand for mediation in personal injury cases was 'virtually non-existent' (Genn 1998, p.v). Despite vigorous attempts by Central London County Court to publicise a free mediation service, it was taken up in only one per cent of personal injury claims. Solicitors lacked knowledge or experience of mediation. They also felt it was important to 'look tough', and worried that even suggesting mediation could be perceived as a sign or weakness (Genn 1998).

This study confirms the Central London County Court evaluation by suggesting that the use of mediation in personal injury claims remains vanishingly low. The file survey did not include any case where mediation had been used. Furthermore, few of the solicitors interviewed had any direct personal experience of mediating personal injury cases, though some mentioned mediating other disputes (such as medical negligence or commercial claims) and a handful referred to one or two personal injury mediations carried out in the firm as a whole. 
Claimant solicitors differed in their feelings towards mediation. Some were actively opposed: 'I'm not convinced that mediation and personal injury go together.' Others were sympathetic, at least in theory:

I'm a big fan of mediation... I'm a CEDR-accredited mediator. I've mediated, although not on a huge basis, both as an assistant mediator and as a lead mediator. Having said all that, I'm not aware of having mediated a single Pl or clinical negligence case of my own. Although l've got one or two where I'm saying: 'Well, if this doesn't sort out, then maybe we will go down the route of mediation.' (Claimant solicitor - medium-sized firm)

A general warmth towards the idea of mediation, however, did not appear a sufficient catalyst to make it happen. The difficulty lay in identifying cases where mediation was felt to be a better solution that the usual inter-parties negotiations. The consensus was that it was not suited to standard, straightforward claims, where it was much cheaper simply to get on the phone to the other side'. There was also considerable concern about using it in large, catastrophic cases: 'It's a lot of money and you've got to argue it properly.' Arguing it properly was felt to involve a technical understanding of expert reports, outside the competence of either the claimant or lay defendant. Drawing on their experience of clinical negligence cases, some solicitors suggested it might be appropriate for low-value, high emotion cases such as the death of a child. Insurers, however, said that in road child-death cases they would just send a prompt cheque:

On a costing basis, it's $£ 7,500$ and... the funeral costs, which are normally $£ 2,500$. So it's $£ 10,000$ and it's easier just to send a cheque. (Insurer)

One solicitor suggested that mediations could be used in Court of Appeal cases, where the issues had already been clarified. Others thought they might be useful with particularly difficult clients. One defendant solicitor said that his own firm had experience of using it with clients who refused to listen to legal advice:

My firm had dealt with at least two [where]... the claimant was completely potty and wouldn't actually listen to their own solicitor... [They] wanted the experience of hearing the sound of their own voices and feeling they've had their say... It settled, so from that point of view it was beneficial, I think. (Defendant solicitor) 
On the defendant side, insurers and defendant solicitors thought that mediation rarely had much to recommend it over other forms of settlement. They frequently pointed out how expensive it was. One defendant solicitor also described the process as 'turgid':

You've got to let everybody talk themselves out and they... give up because of exhaustion rather than because they're at the answer. (Defendant solicitor)

Several suggested that the same benefits could be achieved by 'round table discussions' with counsel, solicitors and occasionally clients. This might be quicker and would not involve paying a mediator's fee.

One insurer saw some potential for mediation in multi-defendant actions, where you are 'trying to get the relevant parties round the table and smash their heads together'. The problems of arranging a mediation in such circumstances, though, were just as great as arranging any other form of settlement, and they had not yet succeeded in obtaining agreement to mediation from all the parties involved.

Thus, overall, mediation was seen as a solution looking for a problem, rather than a specific means of addressing the issues involved in personal injury litigation.

\section{More settlements?}

Much discussion had focused on whether the Woolf reforms have produced 'more settlements'. This question leads to confusion, as it can be interpreted in at least three ways.

The narrowest interpretation would look only at the number of trials. Do fewer cases now proceed to trial, rather than achieve settlement along the way? In this sense, personal injury litigation was already highly settlement-oriented before the reforms, with only a tiny proportion of cases going to trial. Any change in this small number would be very difficult to discern. As one claimant solicitor said:

98 per cent of cases were settling pre-Woolf, so if it has moved to 98.5, or has fallen to 97.5, I don't think I could say. IClaimant solicitor - medium-sized firml 
Furthermore, a small difference of this type would be unlikely to make much impact on the claims-resolution process.

The second interpretation looks at whether settlements are now more likely to be concluded before litigation is issued in the court. One of Lord Woolf's objectives was that litigation should "be avoided wherever possible" (1996, p.4). This appears to have succeeded. There was a general consensus that fast track claims were now less likely to involve the court. Two insurers independently estimated the reduction in issued claims at 'around one-third'. The fall in issued claims can also be seen from the court data. A report by the Lord Chancellor's Department concluded that, following a substantial drop in claims issued immediately after April 1999, the overall trend remains at a lower level than before' (LCD 2001, p.8).

There are two reasons for the reduction. First, the protocol provided an outof-court structure to the negotiations. It was no longer necessary for claimant solicitors to use the court timetable to secure a response from defendants: 'You are actually getting the information.' Secondly, the fast track timetable was so quick that solicitors felt they had to be prepared before issue. Thereafter, the courts provided insufficient time to obtain witness statements or expert reports.

The reduction in issue means more to some players than to others. Clearly, it is important to the courts themselves, which now receive less paperwork into their offices (though also fewer fees). It was well received by insurers, who saved the cost of external solicitors - though was slightly less appreciated by defendant solicitors. For claimant solicitors, however, it was not of primary importance. It changed the order of events but did not represent a fundamental shift in strategy.

The third interpretation looks at the quality of settlement rather than their quantity. Lord Woolf did not simply want more settlements, but more wellinformed settlements which genuinely satisfy both parties to dispute' (1996, p.107). This is echoed in the pre-action protocol, itself, which has as one of its objectives that it will put the parties in a position where they may be able to settle cases fairly and early without litigation' (para.1.2). This study did not measure client satisfaction with settlements. There is some evidence, however, that settlements are now better informed. Previous chapters reported improved information-exchange prior to settlement, while the following chapter suggests that settlements negotiations were now more 
focused on the issues in the case. They are less likely to have been arrived at through a process of attrition or tactical gamesmanship. As one defendant solicitor remarked, somewhat ruefully:

I just don't think people look at the strategic side of claims like the way we used to. I'm not sure claimant solicitors often did anyway, but certainly defendants used to look at strategy very, very carefully. The subtlety of that strategy was very important. And a lot of that has gone. (Defendant solicitor)

\section{If the case fails to settle: supporting subsequent litigation}

Not all cases can be settled before issue. One objective of pre-action protocols, as set out in the Protocol Practice Direction, is 'to support the efficient management of proceedings where litigation cannot be avoided' (para. 1(4)(3)). This is echoed in the personal injury protocol itself, which states that the last of five objectives is to enable proceedings to run to the court's timetable and efficiently, if litigation does become necessary' (para 1.2). We asked respondents how far they thought that the protocol achieved this aim.

The general feeling among claimant solicitors was that pre-issue work now provided a much firmer foundation for what happened after issue than in the past. Before the reforms, cases could be run in a fairly disorganised way:

Pre-Woolf, you'd go on a wing and a prayer - hoping that the medical evidence was straight by the time you got to a hearing... Even three or four weeks you'd still wing it, knowing that the other side are even more disorganised that you. (Claimant solicitor - small firm)

The fast track timetable meant that it was no longer feasible to issue on this basis: 'You need to be ready to roll... because you've got a very, very strict timetable once you issue.' Now 'you are getting your case in order' and 'thinking about things that you didn't use to think about'. The protocol was felt to help in this:

Having a protocol letter... makes people have to concentrate on those issues... If there is something that you have missed, if there is something that you think needs exploring, if there is something that you think is a weakness, they you have got time to sort it out by [issue]. (Claimant solicitor - medium-sized firm) 
That said, some claimant solicitors pointed out that it was rare to get all the preparation completed beforehand: an updated medical report was often needed, and schedules of special damages needed to be amended. More importantly, once the case was passed to defendant solicitors, new issues might be raised:

You issue - it's the first time you're engaging with a solicitor on the other side, and I think that is a different kettle of fish to dealing with an insurance company... They tend to be quite hot on trying to trip you up, trying to sort of upset the case that you've presented and issues can arise post issue that you hadn't really sort of contemplated. (Claimant solicitor - small firm)

Thus, for example, the formal defence may raise further issues not mentioned in the protocol response.

Defendant solicitors were much less likely to think that work carried out internally by insurance companies under the protocol was adequate preparation for what came later. They pointed out that claims handlers were not legally qualified, and that the standard of their work varied:

We come into it relatively later in the day... If there has been good work done, great. If there has been bad work done, you're either having to pick the pieces up or you're having to... say to them: 'We actually now need to do $A, B, C$ and $D$ and do it very fast.' (Defendant solicitor)

Thus it was common for defendant solicitors to carry out further preparation, including re-interviewing witnesses. One insurance manager accepted that this was the inevitable result of a system in which cases are passed to a different organisation once litigation takes place:

Most lawyers would want to re-interview the witnesses. I think most of our lawyers have a suspicion...[about what's] in our claims inspectors' statements... Our claims inspectors - this is a generalised comment - tend to include all the good bits and ignore the bad bits. (Insurer)

\section{Summary}

There has been little substantive change in the way that settlements are reached. Typically, the parties establish the lower (and sometimes upper) limit of the bargain through an exchange of correspondence, and then hold a telephone conversation to reach a settlement figure within the bargaining range. Although some large firms still carry out face-to-face negotiations with claims inspectors, medium-sized and small firms complain that they rarely meet an insurance representative. Mediation has made almost no 
impact on personal injury work. This study confirms the conclusion reached by the Central London County Court evaluation that demand for mediation in personal injury work is virtually non-existent.

The settlement process does seem to have become quicker. The file survey suggested that the median time from medical report to settlement had fallen from 170 days pre-Woolf to 123 days post-Woolf. This is partly because first offers are made sooner and partly because it takes less time after the first offer to reach a settlement. This provides support from the assertions made by insurance companies that they are now more focused on achieving settlements quickly.

The new provisions for claimant offers under Part 36 of the Civil Procedure Rules were also widely perceived as a useful means of preventing delays in reaching settlement. Claimant solicitors liked them because they provided a way of eliciting a response. Defendant insurers liked them because they set an upper limit to the bargaining range. However, insurers complained that claimant solicitors did not use them as much as they had anticipated. The file survey confirmed that the change in the use of claimant offers is evolutionary rather than revolutionary. The proportion of cases in the study containing a claimant offer of some sort had increased from 48 per cent pre-Woolf to 58 per cent post-Woolf.

Before the reforms, it was extremely rare for claimant solicitors to make the first offer. It is now less rare: 15 per cent of post-Woolf cases in our study contained a first offer by the claimant. However, they were only made in a small minority of cases. For many claimant solicitors, they represented a bridge too far. Around half of those interviewed said that they almost never made first offers. They thought it was better to wait to see what the defendant was offering rather than take the risk of undervaluing a claim. There was also thought to be client resistance to the idea.

Few interviewees had any experience of penalties being imposed on defendants who rejected claimant offers. The issue revealed considerable confusion, especially over the effect of receiving indemnity costs under Rule 36.21(3) for cases fought under a CFA or collective CFA. Claimant solicitors criticised the penalties for only biting on early offers in large cases. They felt that there was little sanction that a claimant could apply in small cases or in the run-up to trial. There is a case for reviewing the penalties contained within Rule 36.21 , to make them more appropriate to a wider variety of cases. 
One question that has been asked about the reforms is whether they have produced 'more settlements'. Before the reforms, so few cases went to trial that it would be extremely difficult to discern any changes in this proportion. What has changed, however, is that fewer cases are now issued before the court. A couple of insurers estimated the reduction at 'around one-third'. The protocol provides an out-of-court structure to negotiations, which reduces claimants' reliance on litigation. Meanwhile, the fast track timetable discourages solicitors from issuing until the case is fully prepared. Another encouraging sign, arising from evidence presented elsewhere in the report, is that settlements may be better informed. The level of information exchange prior to settlement appears to have increased, and respondents reported that discussions were more focused on the issues in the case.

Finally, one objective is that work done under the protocol should support the work required post-issue, where no settlement could be reached. By and large, claimant solicitors thought that the protocol met this objective: cases were now better prepared once litigation started. Defendant solicitors, however, were more sceptical that the work done by insurance companies under the protocol was an adequate preparation for litigation. 
Research Study 43 More Civil Justice? The impact of the Woolf reforms on pre-action behaviour 


\section{Chapter 2.8 Meeting the aims: is the process less adversarial, quicker or cheaper?}

In his 1995 interim report, Lord Woolf declared that 'the key problems facing civil justice today are cost, delay and complexity' (p.7). He pointed out that these are interrelated and arise largely from the adversarial nature of litigation. His final report also identified expense, delay and the adversarial culture as major obstacles. These were linked to other problems: lack of equality between the wealthy and poor; uncertainty; incomprehensibility; and fragmentation (Woolf 1996, p.2).

This chapter, considers how far the system has improved. Are standard personal injury claims now fought in a way that is less adversarial? Are they resolved more quickly? And is there any evidence that they cost less?

\section{Is the culture less adversarial?}

\section{Improvements in culture}

The good news is that almost everyone thought that there had been as least some improvement in the culture of negotiations. There was general agreement that there was now more 'openness', with parties willing to exchange more information earlier. This was widely believed to be a change for the better:

There's definitely more openness... We thought we would be forced to be more open, and we didn't really like that... But I think a lot of people now, in the discussions I have had with other solicitors and insurers, they actually want to be more open because you think: 'Well why not put your cards on the table?' (Claimant solicitor - large firm)

Claimant solicitors felt that the parties were now more focused on the joint enterprise of managing and resolving the case:

We work with a mutual recognition that we have to collectively manage the case to get it to trial. (Claimant solicitor - medium-sized firm)

The case management system at court has lead to a real change where you identify the issues, get a shake-down, get a move on... I think that's really positive. (Claimant solicitor - large firm) 
Defendant solicitors agreed that there was now greater co-operation between the parties:

I've found them to be a bit more co-operative, and I would suspect that they would probably say that they've found the majority of defendants to be a bit more co-operative. (Defendant solicitor)

Representatives were also thought to be politer to each other and less personally antagonistic:

Relations between ourselves and the opposition improved immensely. We don't yell at each other too much now. (Claimant solicitor - large firm)

My experience (with one or two exceptions) is you will disagree violently with people but you don't have to be disagreeable to do it. IClaimant solicitor large firm)

\section{Reservations}

The less good news, however, is that the great majority of respondents qualified their enthusiasm in some way. The most common complaints were that the change was 'marginal' rather than 'fundamental'; that some solicitors or insurers had failed to adapt to the new culture; or that the improvements in culture were being undermined by problems with CFAs or a lack of enforcement from the courts.

A common theme was that the basic nature of the litigation process remained unchanged. A claimant solicitor put the point as follows:

The old tactics have just adapted to the new rules... Like they used to say when Tsarist Russia became Communist Russia, in substance there were now changes... So I don't think there has been a fundamental shift. IClaimant solicitor - large firml

An insurer pointed out that the process was still essentially adversarial, albeit in friendlier form:

It is still seen too much as a pre-litigation process - it's part of a litigation process as opposed to a claims resolution process. So it's still adversarial. And I guess that we went into Woolf hoping that there'd be more claims resolution and less pre-litigation. (Insurer)

Secondly, most respondents mentioned that their opponents' response varied, with some solicitor firms or insurance companies much better than others. As discussed in Chapter 2.2, claimant solicitors complained that some 
insurers were too under-resourced or disorganised to respond appropriately, with claims handled by staff at too junior a level. Meanwhile, insurers felt that a few claimant firms were unacceptably aggressive and rude to their claims handlers:

I can pick up the phone and deal with lawyers and they are as nice as pie. There are other lawyers and... you could quite happily shoot them, because they are so rude. (Claims handler)

One company had special arrangements whereby some notoriously aggressive firms were dealt with by designated, particularly diplomatic staff. Other companies had not adopted this solution, although mention of the firms provoked a strong reaction:

We haven't gone down that avenue [of designated staff] because I think frankly if I had to deal with that particular firm all the time I would quite happily ask the RAF to fly over and napalm the building. It's that bad really. IClaims handlerl

Insurers were quick to differentiate firms who were personally rude from those who struck a good bargain for their client:

Most, if not all, of the union firms drive the hardest settlement for their clients, and will extract every ounce of a settlement, but they do so in a firm way... They're not aggressive. (Insurer)

Personal aggression (as opposed to firmness) was felt to be ineffective: it 'brings out the worst in you', resulting in more stonewalling and smaller settlements.

The third reservation was that the change in culture could not be taken for granted. Unless it was supported and reinforced by court-based sanctions, things would slip back:

From the cultural side, things improved radically. And now I don't think there's enough sanctions being hit home. And so I think people are starting to gradually retreat back to their old positions. (Claimant solicitor - large firm)

It was thought that the Woolf reforms were a good first step down a long road.

\section{Inter-party communications}

We read through the inter-party correspondence on files to see whether there was any evidence that communications were now less adversarial. This is not easy to judge. The protocol states as one of its aims that there should be 
'more pre-action contact between the parties' (para. 1.2). We interpreted this, however, to mean that there should be a better quality of contact - not simply more of it. A major criticism that respondents made of the old system was that there were too many repetitious or unnecessary letters. Claimant lawyers complained that insurers would attempt to stall by responding to letters with further requests for more information - or simply by not responding at all, necessitating further chasing letters:

The traditional problem has always been that defendants will dissemble, ask for more information, say: 'Oh, don't issue yet. Let's get some more information... We are quite interested in settling this one.' And it goes on and goes on and goes on. (Claimant solicitor - medium firm)

We have a lot of wasted correspondence - explaining what the pre-action protocol says and that sort of thing. And chasing letters, saying: 'Please reply to our letter, we attach copies of our letter,'... And that's a waste of time. It's frustrating and it happens so much. (Claimant solicitor - large firm)

Insurers also complained of too many letters. They felt that solicitors drip fed' information, often only in response to requests. They saw this as inevitable in a system in which the more letters that are written, the higher costs you pay'. They also felt that some solicitors deliberately wrote more letters than necessary in order to increase costs:

You get [several] letters that are written on the same day... You get letters written two days in a row... You get a telephone call and then a letter confirming the telephone call. Every variation you can think of in terms of extra units. (Insurer)

The file survey, looked first at the quantity of inter-parties communications. This showed little change. If one compares standard fast track cases settled pre-issue, the median number of communications lletters, phone calls or meetings) was 14 pre-Woolf and 15 post-Woolf. ${ }^{33}$ The median post-Woolf case involved eight letters from the claimant to the defendant, six from the defendant to the claimant and a phone call. Meetings were rare, occurring in under 10 per cent of cases.

We then considered the quality of the communications, to see if there was less repetitious or unnecessary correspondence, of the type complained about by respondents. Table 2.8.1 suggests some improvement. Now that letters of claim are fuller, insurers are less likely to respond by automatically seeking more information about the accident. The proportion of cases containing such 
requests has fallen from two-thirds to around one-third la significant difference). ${ }^{34}$ Claimants also make less use of the automatic (and often futile) threat to issue proceedings if a response is not forthcoming. ${ }^{35}$

Table 2.8.1 Did the inter-parties correspondence include...?

(all cases where information available: weighted data)

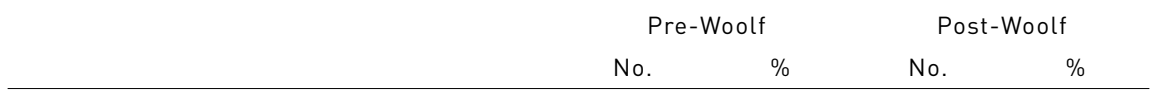

Requests for more information about the accident?

$\begin{array}{lrrrr}\text { None } & 48 & 32 & 93 & 63 \\ \text { One } & 62 & 42 & 37 & 25 \\ \text { More than one } & 39 & 26 & 17 & 12 \\ \text { Total } & 149 & 100 & 147 & 100\end{array}$

Repeated requests for a decision on liability?

None

$\begin{array}{rrrr}78 & 52 & 88 & 59 \\ 47 & 32 & 40 & 27 \\ 24 & 16 & 20 & 14 \\ 149 & 100 & 148 & 100\end{array}$

Chasing letters/telephone calls?

$\begin{array}{lrrrr}\text { None } & 56 & 38 & 70 & 47 \\ \text { One } & 34 & 23 & 22 & 15 \\ \text { More than one } & 58 & 39 & 57 & 38 \\ \text { Total } & 148 & 100 & 149 & 100\end{array}$

Other complaints that questions not answered?

$\begin{array}{lrrrr}\text { None } & 116 & 79 & 107 & 72 \\ \text { One } & 16 & 11 & 19 & 13 \\ \text { More than one } & 14 & 10 & 23 & 15 \\ \text { Total } & 146 & 100 & 149 & 100 \\ \text { Threats to issue proceedings? } & & & & \\ \text { None } & 64 & 44 & 86 & 57 \\ \text { One } & 49 & 34 & 32 & 21 \\ \text { More than one } & 33 & 23 & 32 & 21 \\ \text { Total } & 146 & 100 & 150 & 100\end{array}$


Continued

Pre-Woolf Post-Woolf

No. $\%$ No. $\%$

Complaints that protocol not complied with?

\begin{tabular}{lrrrr} 
None & 148 & 100 & 107 & 72 \\
One & 0 & 0 & 19 & 13 \\
More than one & 0 & 0 & 23 & 15 \\
Total & 148 & 100 & 148 & 100 \\
\hline
\end{tabular}

The data also suggests that, with clearer timetables, slightly fewer chasing letters may be sent, though this difference does not reach statistical significance. The change, however, goes only so far. Around half of files still include chasing letters; two out of five still contain threats to issue proceedings; one-third still contain requests for more information about the accident. Furthermore, the introduction of the protocol provides a whole new area of potential dispute. In some ways it is encouraging to note that, even in the early days of the protocol, only just over one-quarter of cases contained allegations of non-compliance. On the other hand, procedural arguments continue to exist. It would be wrong to think that adversarialism has ended.

\section{Speed}

Solicitors often found it difficult to say whether the total time taken from the start to end of a case had decreased. Most thought that is was probably quicker'. This was felt to be particularly true of larger claims, which were subject to court timetables. However, several solicitors pointed out that there were still opportunities for delay, especially in the post-protocol prelitigation gap', where no timetables existed.

Solicitors found it difficult to give hard information about how long cases took. They pointed out that traditionally the profession had been reluctant to give such estimates, partly because estimates could be 'dangerous' without provisos, and partly because 'telling clients that it might take over two years to get a case result is not a good thing to say at a first meeting'. Many were still overly optimistic in their estimates. For example, one solicitor declared that 'the majority of cases that settle would settle within six months'. He was unable to provide any files concluded in less than seven months and his firm's 
average duration (over nine post-Woolf standard fast track cases) was 13 months. Another, who gave an estimate of nine months to one year, had an average duration of 15 months.

Chapters 2.4 and 2.6 showed that the early stages of a case have become somewhat slower. It now takes longer to write the first letter of claim and to instruct a medical expert. The later stages, however, have become quicker. Chapter 2.7 found that once a medical report has been received, settlements are arrived at more quickly. Insurers were felt to be more focused on settlement, while Part 36 was regarded as a useful tool in eliciting a response. It is likely that speedier settlements have reduced overall case duration, especially in mid-range claims that previously took several months to settle after medical evidence had been obtained.

This survey looked only at quick cases. As discussed in Chapter 2.1, this survey was conducted between 20 and 28 months after the introduction of the Woolf reforms. We were therefore only able to consider the time taken by small, simple cases, normally concluded within two years. Among such quick claims, these two changes appear to cancel each other out: early delays have been offset by speedier settlements. This study looked specifically at standard fast track cases, defined as cases with minor or moderate injury obtaining less than $€ 7,000$ in damages and lasting for less than two years. We measured the total time taken from when the solicitor was first notified of the case to when the claimant received the bulk of their damages lor, in cases, with no damages, when the last work was done on the case). ${ }^{36}$ This showed that the overall time had remained much the same. Both before and after the reforms, the average standard fast track case took 13 months to conclude. This is true whether one takes the mean or median figure.

Figure 2.8.1 shows the distribution of cases. It suggests that the minimum time has become longer. Very few cases are now concluded within six months. This would appear to result from the changes in medical evidence. As discussed in Chapter 2.6, it now takes between three and four months to instruct a medical expert, and two to three months to receive one after instructions. 
Figure 2.8.1 Standard fast track cases: time from when the solicitor first notified of case to conclusion

(weighted data)

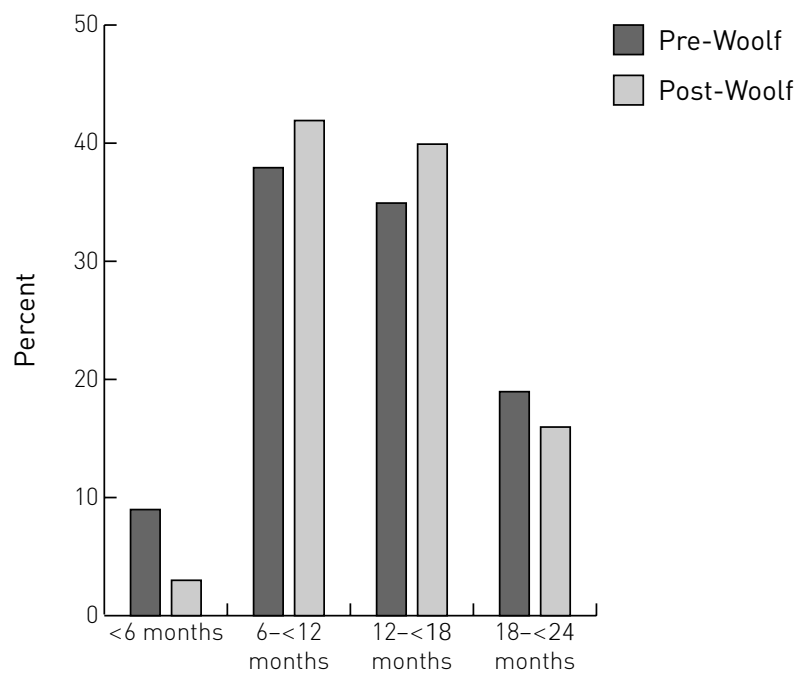

Time from solicitor first notified to conclusion

Base: all standard fast track cases where information available.

Unweighted: pre-Woolf 99; post-Woolf 129. Weighted: pre-Woolf 98; post-Woolf 128

\section{Cost}

\section{Claimant solicitors' views}

Claimant solicitors found it very difficult to say what impact the Woolf reforms had had on the overall cost of claims. They pointed out that different changes had had different effects. Some had led to cost decreases. The fact that fewer claims are now issued was thought to lead to 'obvious' cost reduction. It was also suggested that cases were now more focused, with fewer unnecessary disputes over side issues. The courts were also felt to put more emphasis on proportionality, with a consequent downward pressure on costs.

On the other hand, costs had been increased by 'front-loading', with more work needed at an earlier stage. As discussed in Chapter 2.4, more work was felt to be required before the letter of claim. Solicitors also thought more work was necessary before issue, as the fast-track timetable left little time to obtain expert evidence or witness statements once litigation had begun. 
By and large, claimant solicitors thought front-loading was right lin that it was work that should be done) but they suggested that, inevitably, it had a cost impact:

The costs are higher at the beginning. It's definitely a direct impact. But I don't think that's a bad thing... You hit them big, you hit them early and you get them sorted out. (Claimant solicitor - large firm)

The front-loading means that you have got more initial costs than you would have had previously. Having said that, all that does is show there that the job wasn't being done properly previously, because you really ought to investigate the claim before you issue - and get all your paperwork ready. (Claimant solicitor - small firml

Other factors increasing costs were the abolition of scale rates, together with some rises in the hourly rate now accepted as reasonable by local courts. As one solicitor put it:

I've been negotiating with District Judges locally to increase our rate, which was one of the lowest in the country... And we've got some reasonable rates, I'm pleased to say. So from the hourly-rate point of view, they've gone up. (Claimant solicitor - large firm)

Another spoke approvingly of the increase from $€ 120$ to $€ 150$ in the hourly rate now accepted in his local court.

The result was a lack of consensus among claimants concerning the overall impact of the Woolf reforms on cost. Around one-third of claimant solicitors said they could not tell whether costs had increased or decreased since the Woolf reforms. Many of the cases they were settling were transitional cases, rather than those run wholly under the reforms, and the issue was muddied by other factors, such as disputes over CFA recovery. One-third said that Woolf had made little difference: essentially, the amount of work required to settle a case remained unchanged. The final third were fairly equally split: half said costs had increased, while half said costs had decreased. Those saying costs had increased largely attributed the change to front-loading. Firms noticing a decrease had, previously, been noted for a particularly high rate of issue. In one case, the firm attributed the fall to a change in behaviour of one particular defendant with whom they often dealt and who, since Woolf, had become much more settlement-minded. 


\section{The insurance perspective}

By contrast, insurers were united in their views. They all said that, since April 1999, the average cost of a personal injury claim had increased markedly. They felt this to be the reforms' 'major weakness':

One of the drives was to get costs proportional... and it hasn't happened. That's the biggest disappointment out of it. It has not controlled solicitor costs. (Insurer)

Several firms undertook analyses of the cost of claims settled in-house for each year following the reforms. The fullest figures were provided by a company specialising in motor claims. These showed that from 1997 to 1999 , the amount paid to cover claimant solicitors' costs had increased in line with inflation: costs claimed had risen at around four per cent per year while costs paid had risen by around three per cent per year. From 1999 to 2001, however, costs had risen substantially more than inflation. Claimed costs had increased by an average of $15 \%$ a year, while costs paid had increased by an average of $12 \%$ per year. ${ }^{37}$ These figures did not include success fees or insurance premiums under the new CFA arrangements: 'CFA's don't impact on that yet because we haven't paid. We've been waiting for the outcome in Callery v. Gray.' The firm was bracing itself against anticipated further increases caused by the CFA changes.

Other insurers estimated the cost increases at similar orders of magnitude. One produced figures showing an increase in solicitors' costs paid on cases settled in house of around 14 per centper annum from 1999 to 2001. Another thought that the total increase over the two-year period was around ' 25 per cent, maybe 35 per cent'.

The main criticism that can be levied at these figures is that they only relate to claims settled in-house, before proceedings have been issued. As we have seen, cases are now less likely to involve court proceedings: one firm estimated the reduction in litigated claims at around one-third. This means that more large claims are now being settled in-house, with commensurate savings in the cost of litigated claims. Insurers admitted that the reduction in litigated claims had led to some savings, but they denied that this would be sufficient to off-set the large increases of the last two years. One insurer noted that 'out of every 100 claims that exist... we probably get six into litigation and one into court'. He argued that the savings on the few cases no 
longer litigated would not be sufficient to offset cost increases in the others. This level of litigation, however, is much lower than that indicated in previous research (Pleasence 1998) and would appear atypical.

The evidence provided by the insurance industry is strong prima facie evidence that the cost of personal injury claims has increased. One cannot be sure of the overall impact of the reforms, however, until one is able to take into account the costs of litigated claims. These may take another few years to work their way through the system.

\section{Evidence from the file study}

As discussed earlier, our own file study focused on small claims, settled quickly with little substantive dispute. Our data suggest that the cost of a standard fast track cases has increased. The median amount paid by opponents in post-Woolf cases was $€ 1,576$, compared with $€ 1,393$ for preWoolf cases (a difference that is just statistically significant). The mean rose to $£ 1,761$ from $€ 1,580$. This increase - of 11 per cent in around two years is less than those suggested by the insurers in the study, but higher than inflation (at around 8 per cent). The distribution is shown in Figure 2.8.2.

Figure 2.8.2 Standard fast track cases: overall costs paid by defendant

(weighted data)

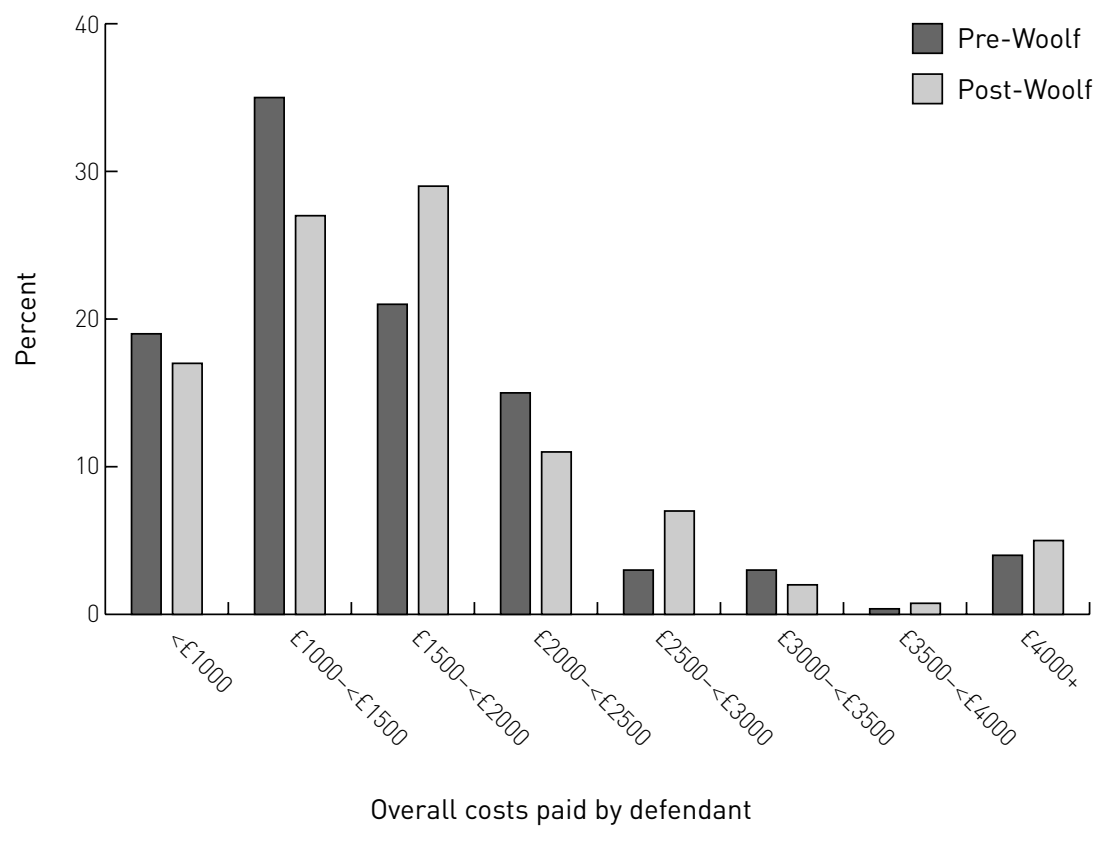

Base: all standard fast track cases with costs paid where information is available.

Unweighted: pre-Woolf 94; post-Woolf 123. Weighted: pre-Woolf 94; post-Woolf 122. 
These costs are inclusive of VAT and disbursements. As seen in Chapter 2.6, the cost of medical reports has risen particularly quickly. Average disbursements increased from a mean of $€ 268$ pre-Woolf to $€ 332$ post-Woolf (24 per cent).

This increase in total costs is not the result of recoverable success fees. Only eight post-Woolf standard fast track case in our sample were funded by conditional fees. None of these succeeded in recovering an insurance premium and only three recovered a success fee element. Excluding the three success fees has little effect on average costs. ${ }^{38}$

\section{Increases in damages}

The data suggest that the increase in costs is in line with an increase in damages. The median award of damages in standard fast track cases rose from $€ 2,150$ pre-Woolf, to $€ 2,345$ post-Woolf. The mean rose from $€ 2,330$ to $€ 2,607$. This represents a rate of increase very similar to that applying to costs: about 12 per cent over two years (though this does not reach statistical significance).

When we asked respondents whether the last couple of years had seen any increase in the damages paid for minor and moderate injuries, views were mixed. Many solicitors pointed out that the policy changes (in, for example, awards of damages or the discount rate) applied only to larger claims. They were not aware of any increase for smaller claims. A couple of claimant solicitors, however, thought that whiplash damages may have increased: the climate of opinion had become more sympathetic to whiplash injuries, with greater recognition that it could be a long-term injury.

On the other hand, most insurers thought that damages had increased. This was in line with a long-term trend in which damages increased each year above the rate of inflation:

Damages are always going up... People's expectations go up all the time and the courts support people's expectations. (Insurer)

Although the largest increases have been for severe injuries, one insurer commented that general damages 'have an elastic quality': 'It is not possible to pull one end of the band without stretching the other.' Another thought that they were probably 'a little overgenerous now', because they were more focused on early settlement. A defendant solicitor added that, even for minor injuries, claimant solicitors were becoming more adept at adding in 'another 
$£ 1,000 \ldots$ for a bit of care and a bit of DIY', which could add substantially to the overall damages. Our own data would tend to confirm a general upward trend higher than the rate of inflation.

\section{The relationship between damages and costs}

As damages increase, so do costs. Although claimant solicitors' frequently pointed out that small claims may be expensive, there is a statistical link between costs and damages. Figure 2.8 .3 shows this relationship as a scatter graph. Despite a few outliers, there is a significant correlation between the damages awarded and the costs paid in a case. ${ }^{39}$

The relationship between costs and damages appears similar for both preand post-Woolf cases. When one looked at mean costs as a proportion of mean damages, there was no difference between the samples. Costs amounted to 68 per cent of damages for both pre- and post-Woolf cases.

Figure 2.8.3 Standard fast track cases: scatter graph showing overall damages against overall costs

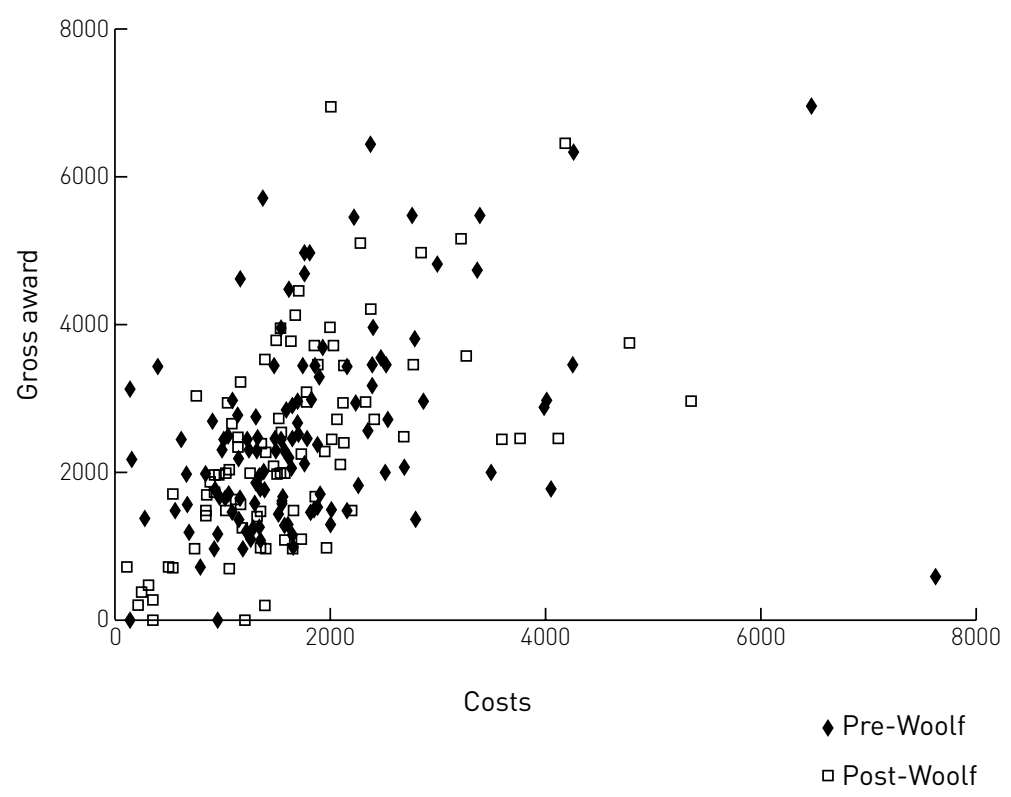


Previous research found that, once controls were applied for other factors, case category had no significant effect on either costs or damages (Pleasance 1998, p.73). This also seemed to be true of for this study. Although it was occasionally suggested that liability could be more difficult to establish in work accidents than road accidents, very few standard fast track cases involved any real dispute over liability. Among post-Woolf standard fast track cases, costs amounted to 71 per cent of damages in road cases and 66 per cent of damages in work cases. This does not suggest that work cases are automatically more expensive than road cases, other things being equal.

This previous study used a six-point scale to assess the severity of the claimant's injuries. It was found to be by far the best predictor of both costs and damages: the study concluded that it was 'the most significant driver' of the outcome of personal injury cases (Pleasence 1998, p.71-2). Given its importance, we used the same scale, in a slightly adapted format. ${ }^{40}$ This allowed us to consider whether the apparent increase in both costs and damages might reflect different types of cases with the two samples.

Table 2.8.2 shows the median level of damages and costs for each level of minor and moderate injury. Given that some of the sample sizes are small, it would be wrong to over-analyse this table. However, it does present a consistent picture. First, damages and (with one exception) costs increased at each level of severity. Secondly, at each level, both damages and costs were higher in post-Woolf cases than in pre-Woolf cases.

Table 2.8.2 Standard fast track cases: median damages and median costs for each level of injury

(all cases where information was available: weighted data)

\begin{tabular}{ccccc}
\multicolumn{2}{c}{ Pre-Woolf } & \multicolumn{2}{c}{ Post-Woolf } \\
& No. & $\%$ & No. & $\%$ \\
\hline
\end{tabular}

Minor, full recovery within three months

$\begin{array}{lllll}\text { Damages } & £ 761 & 15 & £ 1,514 & 19 \\ \text { Costs } & £ 966 & 15 & £ 1,346 & 19\end{array}$

Minor, full recovery three months to one year

$\begin{array}{lllll}\text { Damages } & £ 1,921 & 40 & £ 2,250 & 64 \\ \text { Costs } & £ 1,392 & 40 & £ 1,482 & 62\end{array}$

Minor, full recover one to two years

$\begin{array}{lllll}\text { Damages } & £ 2,542 & 29 & £ 3,000 & 30 \\ \text { Costs } & £ 1,535 & 26 & £ 1,667 & 30\end{array}$


No. $\%$ No. Moderate (no full recovery within three years)

\begin{tabular}{llclc} 
Damages & $£ 3,709$ & 13 & $£ 4,500$ & 11 \\
Costs & $£ 1,510$ & 13 & $£ 2,378$ & 11 \\
All standard fast track cases & & & & \\
Damages & $£ 2,150$ & 97 & $£ 2,345$ & 124 \\
Costs & $€ 1,393$ & 94 & $€ 1,576$ & 122 \\
\hline
\end{tabular}

In fact, compared with the pre-Woolf sample, the post-Woolf sample contains slightly more minor injuries, involving recovery within one year, and slightly fewer moderate injuries. If the mean costs of post-Woolf cases were weighted so as to reflect the balance of cases within the pre-Woolf sample, the increase in costs would be slightly more than first appears - an average increase of 17 per cent over two years.

\section{Disputes over costs}

A frequent complaint, made on both sides on the personal injury fence, was that too much time was spent arguing about costs. This was a problem before CFA recoverability and had been exacerbated by the changes:

It's a huge problem now... People are spending more time arguing about costs, the levels of success fees and all this business, than they are about the issues in the case. (Defendant solicitor)

Claimant solicitors particularly resented the rise of cost consultants or negotiators, employed by insurers to reduce their bills. They complained that negotiators were often paid by results, used poorly qualified staff ('very junior fee earners who don't have a clue'), and relied on standardised bullying techniques rather than detailed argument:

[The] industry uses these people all the time. They are not qualified, as far as I can tell, anyway. So they are very, very difficult to argue against. They send us... two, three, four-page standard letters: 'We think the amount of letters you've sent is unreasonable and disproportionate in the circumstances. '... It is very, very frustrating. You either have to get detailed assessments and get the courts to decide, or you have to negotiate with these people. IClaimant solicitor - large firml 
What seems much more of a pain is that Woolf seems to have enabled cost arguers to develop and I really get hacked off with that now... Some person will ring me up and say: 'We've looked at your costs and we don't agree with them,' and I will say: 'Well, I'm not really interested. I'm going to court.' And then they make you an offer. (Claimant solicitor - small firm)

This new approach was contrasted unfavourably with the previous system, whereby costs were negotiated with 'someone who you'd dealt with, had a history of a relationship with' and who understood the case.

Cost negotiators predated the Woolf reforms, but the file survey suggests that their use has grown. There was evidence on file that an external negotiator had been used in $28 \%$ of post-Woolf cases, compared to 20 per cent of preWoolf cases. This post-Woolf figure appears low, which may reflect the low numbers of CFA cases with the sample.

Insurers also expressed qualms about the rising use of cost negotiators: 'another little cottage industry on top of the claims-handling process.' They used negotiators because they produced short-term savings, but they were aware that they new industry needed to be paid for - producing long-term costs. They suspected that claimant solicitors pre-empted negotiations by inflating the original bill. As one defendant solicitor put it:

A lot of solicitors stick in huge bills. Proportionality means they get half. That half is still more than they ever earned before. (Defendant solicitor)

Insurers argued that the answer to cost disputes was a regime of fixed costs. One manager described fixed costs as a necessary part of the reform package:

I think that Woolf could only have worked properly if its costs [proposals] had been implemented. They haven't and therefore it falls short. (Insurer)

\section{The Woolf reforms and costs: our current state of understanding}

We found no evidence that the cost of personal injury disputes has decreased since 1999. This is disappointing, as reducing costs was a major objective of the reform process.

Lord Woolf was particularly concerned that, in lower-value cases, costs may be disproportionate to the damages involved. Again, we found no evidence that in smaller cases the proportion of costs to damages had decreased. Although there is a statistical link between costs and damages, many 
claimant solicitors rejected the concept of proportionality. A dispute on liability, they said, cost what it cost, irrespective of the amount involved. One solicitor summed up this view by describing proportionality as 'twaddle':

It's utter twaddle. I mean, proportionality, what does it really mean? It's the one bit of Woolf that never really worked... The fortunate thing is that it doesn't really come into my life. Occasionally an insurer will say on a bill, 'Proportionality', and I will write back and say, 'you weren't running the case'. (Claimant solicitor - small firm)

There is some evidence, based on insurers' analyses, of substantial increases in average case costs since the reforms were introduced in 1999. This is an issue that needs to be investigated further, through a deeper analysis of data from a wider range of companies. It would be particularly interesting to include the cost of litigated cases, as well as those settled in-house.

Our own data is limited to relatively quickly resolved, small cases. They also suggest an increase in both costs and damages that is higher than the rate of inflation.

There are two possible explanations for an increase in costs since 1999. One relates to front-loading. More work is now required before the initial letter of claim. As one insurance manager put it:

In the good old days, quite a lot of solicitors used to write a letter of claim, see what the insurer made of it. If the insurance company admitted liability, well, that was it - great - you've had enough. (Insurer)

As discussed in Chapter 2.4, most firms now did more work before contacting the defendant. They were more likely to see the client; generally held longer meetings with the client; and were more likely to take an initial statement. There does seem to be some front-loading. However, this effect can be exaggerated. Letters of claim are rarely complex. As one solicitor put it, for simple road accidents, enough information can usually be extracted within 20 minutes. Even before Woolf, most claims did involve some discussion with the client, if only about the nature of the injuries.

The other explanation is that there is general inflation within the personal injury industry, at a rate that is higher than the Retail Price Index. Expectations increase; damages increase in line with expectations; and costs increase in line with damages. Although increasing resources are now spent 
on arguing about costs, the techniques are crude. If policy-makers wish to reduce the level of social resources spent in allocating compensation to accident victims, new approaches need to be discussed, such as fixed fees.

\section{Summary}

Almost everyone in the study thought that the culture of negotiations had improved. It was felt that the parties were now more open with information, and more co-operative in moving cases towards resolution. Personal antagonisms had reduced.

That said, most respondents thought the process still had some way to go. There were widespread complaints that the changes were marginal rather than fundamental, and that some opponents had adapted better than others. Claimant solicitors complained that some insurers lacked resources and used inexperienced staff. Insurers complained that a few solicitors were still unacceptably rude, a factor that clearly added to the stress claims-handlers experienced in their day-to-day work. It was felt that the new 'landscape of litigation' needed constant tending. Left to its own devices, the old undergrowth would re-appear.

One objective of the protocol was that there should be "more pre-action contact between the parties'. This needs to be interpreted in terms of quality rather than quantity. One criticism of the old system was that it produced large numbers of wasted letters, including demands for more information about the accident; chasing letters; repeated requests for decisions on liability; and futile threats to issue proceedings.

The file study suggested that the overall number of pre-action contacts remains much the same. The median standard fast track case now involves around 15 contacts: eight letters from the claimant to the defendant, six letters from the defendant to the claimant, and a phone call to finalise settlement.

We found some evidence that quality had improved. As discussed previously, letters of claim now contain more information, while insurers' responses are quicker and less ambiguous. At the same time, the level of wasted letters has reduced. The new system provoked fewer requests for more information about the accident, and slightly fewer chasing letters and futile threats of litigation. Nevertheless, it would be wrong to think that chasing letters have disappeared. They can still be found on half of all files. The protocol also 
provides a whole new area for procedural disputes. Over one-quarter of postWoolf cases contained allegations that the other side had failed to comply with the protocol in some way. The survey was conducted at a time when the protocol was 'bedding down', so the level of dispute could have been worse. However, procedural arguments have clearly not been eliminated.

Previous chapters have shown that the early stages of a case have become somewhat slower. It now takes longer for claimant solicitors to make their first contact with defendants and to instruct a medical expert. However, after a medical report has been received, the process of settling a case has become quicker. Insurers were thought to be more focused on settlement, while Part 36 provided a useful means of eliciting a response. Overall, respondents thought that cases were probably concluded more quickly than previously, with the greatest improvements for larger and slower claims. Unfortunately, our own file survey was only able to gather data on small, quickly resolved cases. Within this sector, the two changes largely cancelled each other out. The minimum time for concluding a case had become slightly longer. Very few settlements were now secured in less than six months.

The greatest disappointment is that there is no evidence that claims have become cheaper. Nor was any evidence found that, in smaller cases, costs had fallen as a proportion of damages. Most of the evidence provided by insurers pointed to a substantial increase in costs since 1999. Our own small and limited survey also suggested that costs had risen at above the rate of inflation. It was felt that cases are now 'front-loaded' with more work required before the initial letter of claim. There may also be a general inflationary trend within personal injury claims, whereby expectations rise, damages rise in line with expectations, and costs rise in line with damages. This is an issue that needs to be investigated further.

A final criticism was that far too much time was now spent arguing about costs, a problem now exacerbated by the introduction of recoverable success fees and insurance premiums in CFA cases. The use of cost negotiators has increased over the last two years, so as to become another 'cottage industry' in the claims-handling process. Insurers complained that without a fixed fee regime, the Woolf proposals had been only partially implemented. The Civil Justice Council should consider whether it would be possible to introduce a fixed fee regime, at least for small fast track personal injury cases, that would provide claimant solicitors with appropriate remuneration, without the same level of dispute and wasted resources. 
Research Study 43 More Civil Justice? The impact of the Woolf reforms on pre-action behaviour 
Section 3. Clinical Negligence Work 
Research Study 43 More Civil Justice? The impact of the Woolf reforms on pre-action behaviour 


\section{Chapter 3.1 Clinical negligence work: introduction and context}

This section considers the effect of the reforms on pre-action behaviour and attitudes of those dealing with clinical negligence disputes. Lord Woolf identified that in clinical negligence claims, the pre-issue stage is one of the main sources of cost and delay. There were organisational reasons for this: inadequate incident reporting within trusts made it difficult to establish facts several years after the event and insufficient resources within trusts made it impossible to investigate every incident. Other reasons included the fact that patients gave little or no notice of a firm intention to pursue a claim and clinicians' reluctance to admit negligence, apologise or negotiate with claimants. Lord Woolf recommended that the parties to these disputes should work more closely to resolve disputes co-operatively, rather than proceed to litigation. He specifically recommended a pre-action protocol.

In response to this recommendation, the Clinical Disputes Protocol was developed by the Clinical Disputes Forum. It is broadly divided into two sections. One section deals with 'Good Practice Commitments'. This summarises the guiding principles which the parties are invited to endorse when dealing with patient dissatisfaction with treatment and potential complaints and claims. The other section contains a timed sequence of steps for patients, healthcare providers and their advisers to follow when a dispute arises.

This chapter discusses the wider context in which the protocol should be considered. These include initiatives aimed at reducing the cost of clinical negligence claims when they arise and also those aimed at reducing the number of claims through improved patient safety and enhanced quality of care. Arrangements for handling claims made against the National Health Service (NHS) are summarised, and the pivotal role of the National Health Service Litigation Authority (NHSLA) is discussed. The final issue discussed is the funding of clinical negligence claims and the use of conditional fees.

\section{Reforming the NHS}

The protocol and the Woolf reforms constitute one aspect of the work aimed at addressing the cost to the NHS of dealing with clinical negligence claims. There are other initiatives, both existing and planned, which affect the NHS. 
Whilst these initiatives are partly aimed at tackling the problem of cost, they also seek to address the wider issues of patient safety and the quality of services delivered within the NHS.

\section{Initiatives to address the cost of claims}

Clinical Negligence has long been the subject of considerable government attention. Every pound spent on clinical negligence claims may reduce resources to fund public healthcare. A National Audit Office Report (NAO 2001) recently highlighted the scale of the sums involved. In 1999/2000 the NHS paid out almost $€ 400$ million in clinical negligence cases. The report found that around 10,000 new claims were received in 1999/2000. At 31 March 2000 there were an estimated 23,000 claims outstanding, with an estimated net present value of $€ 2.6$ billion. It estimated liability of a further $€ 1.3$ billion where negligent episodes are likely to have occurred but where claims have not yet been received. The report also found that a relatively small proportion of cerebral palsy and brain damage claims account for a high proportion of the total cost of the claims. In this context, 11 per cent of claims closed in 1999/2000 arose from such injuries and accounted for 44 per cent of settlements by value. ${ }^{41}$ Some of the data upon which the report relies is incomplete as it was extracted from the NHSLA's database on the Existing Liabilities Scheme to which trusts and health authorities were not required to notify all existing claims.

The rising cost of these claims has prompted the Government to consider fundamental reform of the system. A White Paper detailing its proposals is due later this year. In advance of this, the Chief Medical Officer is to chair a committee to consider suggestions to make the system faster and fairer. The Department of Health has published a consultation document seeking ideas on options for reform ( $\mathrm{DOH} 2001)$. Among other things, views are sought on no-fault compensation, greater use of structured settlements, schemes with fixed tariffs for specific injuries and greater use of mediation and other ways of resolving disputes.

Patients are encouraged to use the complaints system rather than litigation as a means of resolving their dissatisfaction. The present complaints system has been in operation since April 1996. However, research evaluating the procedure found a high level of dissatisfaction amongst complainants and a number of elements requiring improvement (Mulcahy et al 2001, DOH 2001). Proposals for reworking the system have been published by the Department of Health (DOH 2001). In addition, the Clinical Disputes Forum is at present 
consulting with members over a proposal to include in the complaints procedure a right of access to a tribunal considering the complaint of a patient and having the ability to award a limited amount of compensation.

\section{Initiatives relating to patient safety and quality of service}

When exploring the changes in clinical negligence litigation, it should be borne in mind that other Government initiatives in progress also affect patients receiving NHS care. Some of these influence the role of claims managers and the interaction between claims and risk assessment departments within trusts.

The Health Act 1999 aimed to improve the quality of care provided to NHS patients. It placed a new statutory duty of quality on NHS Trusts. It also established a new statutory body, the Commission for Health Improvement (CHI) with the aim of improving the quality of patient care in the NHS. In 2000 , the National Institute for Clinical Excellence (NICE) began operating. Its purpose is to define national standards for clinical care. Following the publication of An Organisation with a Memor' (DOH 2000), the Government outlined its plans for promoting patient safety in Building a Safer NHS for Patients (DOH 2001). These include the establishment of a new mandatory national reporting scheme for adverse incidents and near misses in the NHS, a National Patient Safety Agency and targeting specific risks for action. More recently, in 2001, the National Clinical Assessment Authority (NCAA) was established to which NHS organisations can refer doctors for advice, assessment and support where there is concern about their clinical performance.

\section{Defending clinical negligence litigation}

Important changes have also occurred in how the NHS manages clinical negligence claims. In 1995 the NHSLA was set up as a special health authority. Prior to this, each health authority or trust was responsible for appointing its own solicitors and meeting the cost of clinical negligence claims. Claims against the NHS are now managed by the NHSLA according to their value and their age as shown in Table 3.1.1. 
Table 3.1.1 Management and funding of claims against the NHS

\begin{tabular}{|c|c|c|c|c|}
\hline $\begin{array}{l}\text { Date of } \\
\text { Incident }\end{array}$ & Scheme & $\begin{array}{c}\text { Excess payable } \\
\text { by trust }\end{array}$ & $\begin{array}{l}\text { Management } \\
\text { of claim }\end{array}$ & $\begin{array}{l}\text { Funding of } \\
\text { claim }\end{array}$ \\
\hline $\begin{array}{l}\text { Incident } \\
\text { prior to } \\
1.4 .95\end{array}$ & $\begin{array}{l}\text { Existing } \\
\text { Liabilities } \\
\text { Scheme (ELS) }\end{array}$ & $£ 10,000$ & $\begin{array}{l}\text { April } 2000 \\
\text { NHSLA } \\
\text { manages all } \\
\text { claims }\end{array}$ & $\begin{array}{l}\text { April } 2000 \\
\text { NHSLA funds } \\
\text { claims from } \\
\text { ELS }\end{array}$ \\
\hline $\begin{array}{l}\text { Incident } \\
\text { after } \\
1.4 .95\end{array}$ & $\begin{array}{l}\text { Clinical } \\
\text { Negligence } \\
\text { Scheme for } \\
\text { Trusts (CNST) } \\
\text { Voluntary } \\
\text { scheme. } \\
\text { Introduced } \\
1995 \text { as means } \\
\text { of limiting } \\
\text { liability of } \\
\text { members for } \\
\text { clinical } \\
\text { negligence } \\
\text { claims. All } \\
\text { trusts (save } \\
\text { one) are } \\
\text { members. } \\
\text { Trusts pay } \\
\text { premiums to } \\
\text { fund scheme } \\
\text { which then } \\
\text { meets the cost } \\
\text { of claims. }\end{array}$ & $\begin{array}{l}\text { Trust selects } \\
\text { excess level. } \\
\text { Discounts up to } \\
25 \text { per cent } \\
\text { on CNST } \\
\text { subscription } \\
\text { for attaining } \\
\text { prescribed } \\
\text { levels of risk } \\
\text { management } \\
\text { standards. }\end{array}$ & $\begin{array}{l}\text { Below excess } \\
\text { claims - trusts } \\
\text { manage. May } \\
\text { choose in- } \\
\text { house claims } \\
\text { management or } \\
\text { instruct } \\
\text { external } \\
\text { solicitors. } \\
\text { Above excess } \\
\text { claims April } \\
1995 \text { to March } \\
\text { 1998 - } \\
\text { managed by } \\
\text { trusts. } \\
\text { March } 1998 \\
\text { managed by } \\
\text { NHSLA through } \\
\text { panel of } \\
\text { solicitors. }\end{array}$ & $\begin{array}{l}\text { Below excess } \\
\text { claims - trusts } \\
\text { meet the cost } \\
\text { of claims. } \\
\text { Above excess } \\
\text { claims - trust } \\
\text { pays excess + } \\
20 \text { per cent } \\
\text { above it lup to } \\
\text { threshold). } \\
\text { NHSLA pays } \\
\text { the balance of } \\
\text { settlement } \\
\text { from CNST. }\end{array}$ \\
\hline
\end{tabular}

Source: National Audit Office Report (2001).

The NAO report estimates that at March 2000, the NHSLA was handling about 42 per cent of clinical negligence claims made against the NHS (NAO 2001, p.29).

Concern that claims handling within trusts is not cost effective has led the Department of Health to reorganise claims-handling functions from 1 April 2002. Changes are to come into effect whereby financial and claims management responsibility for all Clinical Negligence Scheme for Trusts cases from trusts will be transferred to the NHSLA. Legal liability will remain with the body responsible for the negligence. The NHSLA will instruct and negotiate on all claims and will settle claims directly with claimants. The aim is to enable trusts to concentrate on the prevention of negligence through risk 
management. Trusts will pay an annual contribution to the CNST, which will be increased due to the fact that the trust will no longer have to fund below excess claims. These changes are likely to have an impact on the role of claims managers within trusts as their role in managing below excess claims will be reduced. During our fieldwork with claims managers carried out for this report, the anticipated changes were explored. Their views are discussed in Chapter 3.2.

\section{The NHSLA panel firms}

Prior to the creation of the NHSLA, trusts could select their own firms of solicitors. At that time, approximately 100 'defendant' firms were providing legal advice to the various trusts. The NHSLA began by instructing 'gatekeeper' firms to review the management of claims and settlements whilst it recruited staff. Then, in 1998, the Authority created a panel of 18 firms of solicitors (later reduced to 16 through withdrawals) to deal with all future CNST claims. From April 1998, the panel also dealt with Existing Liability Scheme claims. The panel was revised to 15 firms in April 2001. The Authority monitors the performance of its panel firms and individuals working within them. Through an auditing procedure, the Authority can require firms to make changes to their claims handling or to remove named individuals from undertaking the work.

\section{Developments affecting claimants}

Public funding remains available for clinical negligence work, although claims under $€ 10,000$ are unlikely to qualify. All of the claimant firms that took part in the study were holders of a Legal Services Commission franchise. They did advertise (in one case outside the firm's immediate locality) but also received work through a variety of sources. These included Action for Victims of Medical Accidents (AVMA), Citizens Advice Bureau, Community Health Councils and other firms of solicitors which did not undertake clinical negligence work as they did not have a franchise. One firm was on the panel of a legal expenses insurer and another obtained referrals through a bulk referrer.

Some solicitors had developed ways of dealing with the funding problem in low value clinical negligence claims. One obtained the GP records only, formed a view on the likely prospects of success and then approached the trust to settle the claim. This approach was confined to claims where we have 
seen it all before and we know... there's a breach of duty'. Trusts were agreeing to settle claims on this basis. Clients with more complex low value claims would not benefit from this approach. As this solicitor put it:

If you walked in the door with a low value case involving a procedure I knew nothing about, which sounded good in principle but which I knew I would need an expert's report, then I wouldn't take it on. (Claimant solicitor)

\section{Use of conditional fees}

Although the government has taken steps to make conditional fees more attractive to claimants by making the risk element of the success fee and the insurance premium recoverable from the unsuccessful defendant, none of the claimant solicitors interviewed for this study had had much experience of using CFAs. In fact, experiences of using CFAs were confined to one or two cases per firm.

There are two interrelated reasons for their limited use. Firstly, before a CFA can be offered, the firm needs to assess the risks of the case by investigating the prospects of success. As one solicitor put it, 'as a firm we won't do it until we have the evidence that the claim's likely to succeed rather than any 50 per cent nonsense'. This initial investigation needs to be funded. Even if the solicitor is prepared to waive their fee, there remains the need to pay for an expert's report. One solicitor said this would be a minimum of $€ 500$ and some were upwards of $€ 1,000$. One firm charged a set fee to cover obtaining the report. Solicitors reported that while some clients were meeting these costs, many simply could not afford this initial investigation.

Secondly, even if the client has the ability to fund this investigation and the solicitor agrees to take the case as a CFA, there is a lack of affordable afterthe-event insurance policies on the market to support the claim. Premiums can run into thousands of pounds; one solicitor had received an offer of cover for a premium in excess of $€ 10,000$. Clients were also surprised to learn that payment of such sums were involved; advertising for general personal injury claims using the 'no win no fee' wording created an expectation that there would be nothing to pay.

The funding difficulties faced by those with low value claims may be ameliorated by a new fast track fixed fee pilot scheme for claims under $£ 15,000$ which has recently been announced (Gibb 2001). The scheme is an association between the NHSLA and Resolve (part of the Access to Justice 2000 legal insurers group). Under the scheme, pilot law firms will do 10 hours 
work for a capped $€ 1,500$ fee, only paid if the claim succeeds. The solicitor will access the medical records and advise on the prospects for success. If prospects are good, a claim form is submitted to Resolve for a merits assessment. On passing this, a single joint expert is appointed on a fixed fee. Thereafter, the claim reverts to resolve with quantum assessed by the solicitor. A final agreed claim goes to the NHSLA and if damages cannot be agreed, an adjudicator is appointed to settle the issue.

\section{Methods}

This part of the report is based upon 12 semi-structured interviews with claimant and defendant solicitors and claims managers within trusts. It also draws on the comments of an additional claimant solicitor who was interviewed for the personal injury part of the study but undertook a considerable amount of clinical negligence litigation. Further details of the method and selection of interviewees are contained in Appendix 2.

Although the protocol is intended to apply to all aspects of the health service, primary and secondary, public and private sectors, the size and timescale of this project made it necessary to confine it to the views of healthcare providers working within National Health Service Trusts. Similarly, given the size of the sample, the aim of the project is to present a range of views and approaches to clinical negligence litigation. It does not seek to measure quantitatively the extent to which those views are more widely reflected amongst those working in this field.

\section{Structure}

The remainder of this part of the report is organised as follows:

- Chapter 3.2 considers respondents' overall views on the reforms and the structural and management effects of the reforms on solicitors and trusts. This chapter also presents views on the impact of the Woolf reforms on the courts in terms of administration and case management.

- Chapter 3.3 explores the success of the Protocol in meeting its wider aim of restoring or maintaining the relationship between patient and healthcare provider. 
- Chapter 3.4 discusses the timed sequence of steps recommended by the Protocol and explores the extent to which it has streamlined requests for records and led to increased communication between claimant and defendant by means of the letters of claim and response. The incidence of admissions of liability is also discussed.

- Chapter 3.5 explores the effect of the reforms on the use of expert evidence including arrangements for joint experts and meetings of experts.

- Chapter 3.6 discusses Part 36 offers to settle and the impact of the reforms in promoting a settlement culture. 


\section{Chapter 3.2 The Woolf reforms: overall views and their impact on methods of work}

This chapter explores respondents' views of the Woolf reforms as a whole. It begins with overall attitudes, before focusing on respondents' views of the effect of the reforms on the cost of cases.

The practical effects of the Woolf reforms on respondents in relation to, for example, workloads, skills and use of counsel, are examined. Broadly speaking, the reforms were thought to develop existing trends rather than introduce 'a sea change'. Solicitors were already used to some aspects of case management as embodied in, for example, Practice Direction 49 and legal aid franchising. Within NHS trusts, there has been a trend towards handling smaller claims in-house. The implications of this are discussed and the effect of transferring responsibility to the NHSLA is considered.

Finally, practitioners' views on changes in court administration and case management are discussed.

\section{Overall views}

Generally, interviewees were positive or very positive about the reforms and their effects regardless of whether they represented claimants or defendants. A particular area singled out for praise was the ability to make Part 36 offers. One interviewee thought this had 'transformed claimant litigation'. The preaction procedure, particularly the requirement to produce a detailed letter of claim and the procedure for disclosure of medical records, were cited as making it easier to settle a claim at an early stage. Although one interviewee complained about the short lead-in time for the rules, he conceded that the new rules were now thoroughly accepted:

I think it was probably a good thing that we were bullied into jumping into CPR as early as we did. It meant that we got our feet wet right away and... 12 months into CPR I think we've completely forgotten about the old court rules and it's as if we've been litigating on the CPR forever. (Claimant solicitor) 
There were some sceptics, however. One claimant solicitor saw the reforms as a 'mixed blessing' and thought that the promised simplification of procedures had not really happened:

The CPR book we got, started off very thin. But it's multiplied so it's very thick now. There are practice directions left, right and centre, so procedurally it's really no more straightforward than it used to be. If anything, it's more complicated, because you've got the old White Book, and you've got the CPR and you've got the old Green Book and... what applies, what doesn't. You still have to look up the whole damn thing. (Claimant solicitor)

Generally claims managers were also positive about the reforms. One view was that the rules made it possible to get claims moving, to know what stage the case had reached, and the steps that ought to have been taken, rather than claims being 'in the air'. The rules could also be used to compel claimant solicitors to clarify the allegations before they responded to the claim. Another view was that information was now more forthcoming from claimant solicitors:

I think the biggest change which has come about, and certainly didn't happen as a change over that date... is that claimant solicitors are much more proactive and much more upfront. Certainly [it is] not so difficult to get things from them as it was pre-[Woolf]. I think that's the biggest difference. (Claims managerl

\section{A change in culture}

Given the requirements to disclose information at an earlier stage and work toward earlier settlement where possible, we explored whether a greater spirit of openness could be detected in the relationship between both parties' solicitors. A common response to this area of questioning was that much would depend on the firms or individuals involved: with some opponents there could be greater dialogue and openness but not with others. One catalyst for greater cooperation was the threat of sanctions. As one claimant solicitor put it:

...everybody has recognised that they are not going to look good if they turn up before a Master having been uncooperative... so that's the... sanction in the background.

One defendant solicitor thought that there was now more dialogue with claimant solicitors. Two stated that their policy lattributed to the NHSLA in one casel was to get the right money for the right people at the right time. One added '...even if that means conceding from the outset. We don't defend the indefensible'. 
Generally, claimant solicitors reported that their 'cards on the table' approach to litigation had existed prior to the reforms. Some examples of this included: disclosing evidence 'up front'; when writing to a trust requesting records giving as much information as possible at that stage about the nature of the case against them; having meetings with both side's barristers and experts and even making offers to settle. However, where Woolf has made a difference is in formalising these procedures and requiring both sides to cooperate:

So we've waited for ages and then suddenly we can see all this CPR and Woolf and 'oh isn't it innovative'... We were thinking 'yes, we did it anyway'. We've been doing this for years, you know... I suppose we have more success at it now because the other side have accepted that that's how it is. (Claimant solicitor)

Some solicitors reported a less formal and more open approach to discussing a case: 'having a chat' had replaced the more formal 'without prejudice' discussions. One view was that the reforms had encouraged people to do more telephone work and get to know their opponent. Another was that the effects of openness could be cumulative; being more open led to positive experiences and so the pattern could continue.

However, in some cases, claimant solicitors found it hard to detect a 'cards on the table' approach emanating from their opposite number:

...you used to play your cards very close to your chest before and now there's... more from the claimant's side, a spirit of openness... I don't see it coming from the defendant's side, because they're always faffing about before they get their evidence and they refuse to disclose it. So they are still carrying on in a very cloak and dagger sort of way, whereas... we've been very frank and very open. (Claimant solicitor)

Some defendant solicitors were said to use the NHSLA as a tactical excuse:

They use it as a double-edged sword. It's either 'oh, we need to get all these authorities from the NHSLA' or it's... the other way round, 'oh, they are being obstructive, it's their fault that we're taking so long'. And you never really know what the truth is. (Claimant solicitor)

Another claimant solicitor drew a distinction between the spirit of openness with claims managers as distinct from that with defendant solicitors:

We work very much in the spirit of cooperation, particularly with the trust. I have to say that the spirit of cooperation doesn't always spill over into the litigation and our relationship with the defendant firm of solicitors. 
The attitude of some defendant firms was said to be more adversarial. Some took an aggressive approach to litigation, which might be connected to the level of experience of the fee earner: the less experienced, the more adversarial an approach could be taken. Another view was that whilst dialogue with the trust's in-house team was possible, once the claim left the trust and went to defence lawyers they were 'scuppered'.

\section{Negatives}

Even those who were positive about the reforms were not unequivocal in their praise. Relationships with the courts and judiciary were a particular cause for concern. One criticism was the uncertainty in court decisions, the lack of specialist judges and the lack of continuity of judges, particularly outside London. Another was that the system could be organised better if the courts did not always regard clinical negligence as a 'special case'. Views on court administration and case management are discussed further in Chapter 3.3.

Another area of dissatisfaction concerned the use of experts. The particular problems which were highlighted in relation to joint experts and meetings of experts are discussed in Chapter 3.5. Both claimant and defendant solicitors were critical of a gap in the rules whereby there was no time limit stated by which an expert had to provide a written response to questions asked by the other side's solicitor.

\section{This is an area in which the rules should be clarified.}

One defendant solicitor expressed the view that the rules were very proclaimant, that claimants have ample time at the start of the claim yet the rules do not sufficiently protect defendants. This view was echoed by one of the claims managers. Other less positive aspects of the reforms cited included increased bureaucracy and the requirement to produce timeconsuming interim costs schedules.

\section{Views on cost}

One of the aims of the Woolf reforms is to reduce the costs associated with clinical negligence claims and to retain proportionality in pursuing claims. The protocol also emphasises the need to reduce delay and costs. There are three interrelated issues when assessing the impact of the Woolf reforms on 
the cost of claims. First, the impact of the protocol steps themselves. Secondly, the effect of the CPR as a whole and thirdly, proportionality. Other factors said to affect costs are also discussed.

\section{Effect of the protocol}

There was some evidence that the protocol itself had had some impact in reducing costs. There were several reasons advanced for this. First, the provisions for the disclosure of medical records had removed the need for 'faffing around' with pre-action disclosure.

Secondly, the earlier exchange of information could lead to speedier settlements, as both sides would be aware of the issues much sooner. One solicitor thought that there had been a dramatic impact on the costs of cases that settled pre-litigation and as a result had seen a reduction in the firm's income at this stage:

The protocol has had a dramatic impact on our costs... Previously you would not get a detailed response to a letter of claim. You might put all your cards on the table before you've issued the proceedings, and all you've got back is 'oh well, we note what you say but liability is in issue'. So you've got to issue your court proceedings. You then go down the road (of) litigation until exchange of experts' reports. Then you might find you've got a settlement. So you're obviously making more money in that case scenario than you are if they give you a full response and you don't have to issue and you negotiate and the case settles. (Claimant solicitor)

However, the nature of clinical negligence cases is such that substantial costs will need to be incurred to progress through the stages of the protocol in any event. Unlike the personal injury protocol, a report on liability must be obtained to proceed with the claim and agreed instructions to a single expert for such a report are unlikely. As discussed below, interviewees had a strong sense of the need to front-load the work on cases to comply with the protocol. However, some claimant solicitors perceived little change in this regard as they had always had to front-load cases:

For clinical negligence I think the costs have always been front-loaded. I cannot see much difference in the way... I prepare to get to (thel letter of claim. It really is merely bringing issue of proceedings three months in advance. (Claimant solicitor)

Assuming the protocol produces some front-loading, a crucial question relating to its success in reducing costs is whether more cases actually settle as a result of having gone through its stages. As discussed in Chapter 3.6, 
there is some evidence that more cases are settling prior to the issue of proceedings. However, there is also evidence that these settlements are being achieved more often in the lower value claims. One view expressed by a claimant solicitor is that costs savings made by early settlements in lower value cases were outweighed by the increase in costs in larger claims.

Costs savings achieved through an increase in the number of settlements in lower value claims might also be negated by defendants front-loading the work on claims. In some respects, front-loading is more of a culture change for defendant solicitors who can no longer adopt a 'wait and see' approach to requests for records:

It has decreased the time a case takes to come to conclusion so that's good. The problem is it hasn't reduced the costs of that case because you still have to do the same things, you just have to deal with them in a shorter period of time. And the problem... is, some of them you investigate and do the work but you're doing it at this earlier stage. Whereas before Woolf... 10 or 20 per cent of those claims you may never needed to have done that. (Defendant solicitor)

In-house claims management within trusts has become similarly frontloaded with an associated increase in costs:

There's lots and lots of work on cases earlier on, only to find sometimes that they're not pursued. Whereas before you might have said 'this sounds a bit dubious, let's wait and see if this is going to be pursued', now there's time, resources, money put into things that don't often go anywhere. So I think it will all probably cost more, post-Woolf. (Claims manager)

Some defendants responding to the CDF questionnaire raised similar issues; that the extra workload, including time spent dealing with cases that did not proceed, had increased costs generally. However, not all defendants in our sample considered that front-loading increased costs. This solicitor regarded the reforms as an endorsement of pre-existing advice to clients to front-load cases for the very reason that this would reduce costs:

I've been saying to client trusts for about three years before that: 'Look there's a real costs incentive to front-loading your cases, even as complaints. If it's obvious something's gone wrong, sort it, settle it, save on the legal costs.' And I got quite a lot of cynicism at first. I think they thought I was running up the costs, but after a couple of years they could see that there were real advantages. We were getting rid of claims... very, very quickly. And so when the new rules came in and said 'pre-action protocol, front-load', I thought 'great, whoopee, I've got the back-up I need'. And then the Part 36 offer was like manna from heaven. (Defendant solicitor) 


\section{Effect of the Civil Procedure Rules}

Whilst the extent to which the CPR as a whole have had an impact on the cost of claims was not explored in detail, there was some evidence that overall, the costs of cases had not changed and in some respects had increased. Some solicitors attributed this increase to aspects of the rules themselves:

In terms of the bad things... the costs angle is still an absolute nightmare. If Part 36 is the best side of it, the worst side of it is the costs. These... interim schedules every time you go along to these applications, 90 per cent of which are never used or utilised, are just so time-consuming and a waste. Because you're effectively spending time and costs costing, it's like charging interest on interest, it's just a crazy situation. (Defendant solicitor)

Other aspects of the rules that were criticised as adding to costs were the need to file allocation questionnaires, and listing questionnaires with detailed breakdowns of costs and projected costs. In one case, these were passed to an external costs draftsman thereby incurring further costs. More time was also being spent away from the office attending hearings, which prior to the reforms would have been agreed with the other side. Despite sending agreed directions to the court, the parties were often summoned to case management conferences. In some cases, additional costs were also being incurred in appealing orders that were imposed by the court against the parties' wishes.

These aspects of the rules, which were cited as adding to the cost of claims in which proceedings are issued, should be kept under review. In particular, the extent to which prepared interim schedules of costs are put to use should be reviewed.

\section{Proportionality}

There was a divergence of opinion amongst interviewees as to the extent to which the parties abide by the ideology of proportionality, which underpins the Woolf reforms. The CDF survey included some comments from claimant lawyers that their costs were attacked on proportionality grounds whilst defendants spent as much as they wanted on costs. Here too, we found that old hostilities may linger, with each side holding the other accountable for increasing costs:

Proportionality really irritates me... The times that a defendant firm of solicitors has made a rod for its client's back on cost because they have refused to take on board the issues. They haven't done this they haven't done that. I've had to ask for debarring orders, and costs increase, increase, 
increase, and ultimately go beyond the value of the claim. And then it might settle just before trial. And let's suppose we settle a case at 50 and the costs are 75. They'll send me a letter and say 'What about proportionality?' then. That really irritates me because those costs would not be 75 if they'd conducted the case differently. (Claimant solicitor)

However, there was some evidence in our sample that proportionality was being taken into account in the conduct of cases. From the claimant's point of view, there is a need to consider each step and attempt to achieve an early settlement: here the constraints of public funding will contribute to the approach taken to the conduct of the case.

There's proportionality so you have to think very hard about how... you litigate a less expensive claim... There'd be much more emphasis on trying to settle, trying to mediate, trying to find an early solution. (Claimant solicitor)

\section{Other factors affecting costs}

However, the cost of cases was also said to be rising due to factors unconnected with the reforms. Costs may be affected by the requirement to report claims to the NHSLA. Whilst lawyers' fees may be reducing as they become more skilled at carrying out work more efficiently, experts' fees may be increasing due to more sophisticated charging structures, for example, with cancellation fees if the case settled:

The care experts, the occupational therapists, the employment experts, who've become a sort of supply industry to litigation, who do nothing but litigation support... have made an awful lot of money out of this work. They get paid quickly; very profitable and very lucrative for them. And the costs of the experts now in these brain damage cases will easily equal my costs. IClaimant solicitor)

\section{Speed after issue}

The protocol seeks to support the efficient management of proceedings where litigation cannot be avoided. We explored the extent to which the protocol steps affected the conduct of the claim, particularly in relation to whether cases moved more quickly after issue. Responses were inconclusive and patchy and it is difficult to draw any clear conclusions in this area.

There was some evidence that, following the protocol, steps did have a positive effect on the speed with which cases progressed after issue. However, another contributory factor is stricter court-imposed timetables: 
When you get your allocation questionnaire, you have to address your mind... You have to propose directions, so you have to think very early on what the timetable's going to be. And the court is then quite keen to give you a very early trial date and everything's fixed for this ultimate trial date. Come hell or high water they don't want to shift the trial date. So even if there has to be some movement within that timetable they're not going to alter the end date. Yes, I think the shelf-life is much quicker. (Defendant solicitor)

A third factor is that front-loading the work on cases to comply with the protocol meant that there is less to do after issue and therefore less delay:

When I issue proceedings and I serve my proceedings, I'm immediately serving with the claim form, not only the particulars of claim and the schedule, but also all my medical expert evidence is disclosed. All my witness statements... I'll send them all out as well. I'll disclose my list of documents if I need to do one, and I'll also always send them a draft directions order, which... has blanks in it for the dates. And we'll get on the telephone and we'll agree what those directions should be. So they've got absolutely everything up front. (Claimant solicitor)

\section{The impact on methods of work}

Broadly speaking, solicitors did not report any major changes made within their practices to deal with the new regime. This was attributed to two main factors. In relation to High Court cases, several solicitors cited Practice Direction 49 as the impetus for change that pre-dated the reforms. Introduced in November 1996, it required the plaintiff to serve each intended defendant with a letter before action, at least three months before issue of the writ, setting out the fullest available information as to the basis for the claim. Furthermore, on the summons for directions, it required the parties to provide the court with chronologies, lists of outstanding issues, and details of potential witnesses, both factual and expert. Solicitors suggested that it was a good preparation for active case management:

I think we all had very good preparation for Woolf... certainly those who did High Court clinical negligence... which really meant we were doing a lot of Woolf before we started. We'd already got into the idea of having judgemanaged litigation and he was effective in getting us to work through a timetable and to address cost issues and organisational issues. I don't think it's the culture shock it was for a lot of firms who hadn't embarked on that process before. (Claimant solicitor) 
Another impetus for change pre-dating Woolf was the concentration of clinical negligence work in specialist firms through legal aid franchising. With smaller panels operating on both sides, the change had resulted in greater continuity and therefore more chance of forging good working relationships. Another aspect of the legal aid changes was greater organisation. Those who had specialised for some time in this area already had the required systems in place and continued with them: the transition to a new way of working under Woolf was therefore less difficult. Firms without a steady throughput of claims could no longer continue in the same way. As one claimant solicitor put it:

No longer could you say 'oh yes, I find clinical negligence quite interesting, and I do three cases in my cabinets'... The profession was never going to sort it out by themselves, it did take the legal aid basically saying 'sorry, cut off point, you either get qualified or you don't bother'. (Claimant solicitor)

The associated auditing requirements also required practitioners to begin to actively manage cases. As a result, the Woolf reforms required less of a sea change in approach:

We've always managed cases very carefully, we've had to with legal aid franchising... legal aid franchising came along long before protocols did, and accompanied with that is the need to... show that you are managing your part properly. And you have your audits and so on. (Claimant solicitor)

Broadly speaking, claims managers viewed their obligations in meeting the protocol timetables very seriously and aimed to streamline procedures relating to the disclosure of medical records and obtaining clinicians comments in order to comply with these. However, there was little evidence of major modifications to daily tasks:

Everybody sort of wound us all up to think that... we needed to panic. I have to say I did not change a thing I did from pre to post, personally. (Claims manager)

However, in many cases it was difficult to identify whether the catalyst for changes which had occurred were the reforms themselves or NHSLA or CNST requirements.

\section{Increased workloads}

Such changes as had been made within solicitors' practices to accommodate the new rules included the organisation of staff training to introduce the rules, amending precedent manuals, and amending diary systems. 
There was also evidence of increased workloads: this was mentioned by one claimant solicitor but was echoed by all of the respondents from defendant firms. The CDF questionnaire produced similar responses from defendant firms. For claimant firms, an increase in work might also be due to a concentration of publicly funded clinical negligence work in fewer firms. As discussed above, heavier workloads for defendants is partly due to the fact that they are wary of adopting a 'wait and see' approach when case notes are disclosed. Both claimants and defendants were working at containing their caseloads, a process which had already started and, in one case, this had led to a requirement for more fee earners:

We did go on a recruitment drive, because I was concerned that... if a case landed on my desk and I thought this is an obvious settler, then I would frontload it and make an offer. But the ones that... previously you'd have left, you'd have given them the case-note disclosure and then waited to see what happened, we no longer could. And therefore there were going to be quite a big chunk of cases that previously we wouldn't have been terribly active on that suddenly we were going to have to be very active on. And therefore we did recruit additional people. And we're still working on getting the caseloads down. (Defendant solicitor)

Staffing levels within the trusts had not altered significantly. In one case, the interviewee's post had evolved as a result of the reforms (prior to this, complaints and claims had been dealt with by the same person). In our sample, the teams were small within the area of legal claims. Two of the trusts had around 1,000 beds whilst the other had around 650 . None of the departments had more than three members, some of whom had clerical and administrative roles.

These teams dealing with legal claims within trusts have a variety of associated functions. These included: risk management, health and safety issues, data protection, dealing with inquests, subject access to medical records, and general advice and training for staff on issues relating to legal claims. As legal claims are not confined to clinical negligence, the team may also be dealing with employment disputes and personal injury claims.

One defendant solicitor thought that trusts had not made significant changes to deal with the reforms, given the increase in workloads:

Maybe they have recruited one more person, but the number of complaints is also rising. And most of the claims and complaints are dealt with by similar teams of people, often in adjoining offices. I have yet to come across a trust that has got sufficient manpower to be dealing with it in-house properly, on their own. (Defendant solicitor) 
All of the interviewees within trusts reported increased workloads but gave differing explanations as to the reason for this increase. Whether the increase in work was attributable to a greater number of claims, or whether there was more input into claims was unclear; both appear to be a contributory factor. So too were the imposition of stricter timetables and the requirements of membership of the CNST:

I think Woolf was quite an impetus for the change because the realisation that the Trust was at risk... of cost penalties... if they didn't meet the time limits was... quite a substantial influence. However, it is also about the fact that the workload in the department was increasing anyway and it's also about the CNST reporting guidelines. (Claims manager)

In one trust, there had been a decline in unmeritorious claims yet, at the same time, the work on genuine claims had increased. The additional aspects of the legal claims role discussed above had also contributed to an increase in work:

It's not necessarily the claims management bit of it... A lot of it is about the fact that staff are much more aware of... problems they may encounter and tend to require more advice and support and input... On the claims side of it, it probably hasn't increased that much... It has possibly changed slightly in that you don't get... as much of the spurious claims through that you felt you needed to at least put some investigation into but really didn't feel it was going anywhere... All you're doing now is probably putting more effort and energy into... the appropriate claim rather than potentially spurious claims. (Claims manager)

\section{Skills of practitioners}

There was some evidence that the CPR and protocol timetables required solicitors to formulate and pursue clearer and more immediate strategies for cases. One view was that the reforms required lawyers to be more practical and less litigious than before. There was also felt to be increased pressure on solicitors to deal with cases more quickly. One claimant solicitor thought that the reforms required solicitors to quantify cases earlier so that they could make and respond to Part 36 offers. The same solicitor also identified changes emanating from defendant firms:

I do feel that in the past... they haven't actually got to grips with what the case is about until the pre-trial period... They've... pushed it this way and that, they've got counsel to draft a defence, they've got somebody else to draw up the witness statements. And they don't actually put it together until they realise that the case isn't going to go away. And therefore offers came very late... payments in very late. You didn't really actually get an impression... that the defendants were completely on top of what the case was all about until that 
point. Whereas now I think certainly the better firms of defendant solicitors are recognising that good risk management and claims management requires you to know what the case is about at an early stage and then set out an appropriate strategy for dealing with it. (Claimant solicitor)

\section{Use of counsel}

There was some evidence that the use of counsel had changed. Generally, solicitors relied less on counsel, preferring to draft the letter of claim land in some cases the particulars of claim) themselves. The findings are consistent with the CDF survey. In some cases, the use of counsel was confined to higher value cases only. However, one claimant firm was undertaking the drafting of high value schedules of loss, rather than sending these to counsel. Developing these skills is an opportunity to retain fee-earning work in-house and retain control over a case:

Big schedules of damages in brain injury cases which traditionally you'd give to a barrister to do, we are now starting to do in-house... It's a lot of money that could go to us, so it's better that we work the case, in terms of the profit share, but also in terms of our control and understanding of the case. IClaimant solicitor)

However, there were new areas in which counsel could be employed. These included drafting agreed agendas for meetings of experts and attending case management conferences, as solicitors were reluctant to spend time waiting at court for these appointments.

\section{Pro-active claims management within trusts}

Although higher value claims are automatically reported to and managed by the NHSLA through its panel of solicitors, trusts presently retain control of claims below their CNST excess. They may choose to manage these claims in-house for as long as possible prior to the issue of proceedings, or to instruct their own solicitors to deal with them.

In-house claims management might include: gathering information, identifying clinicians, disclosure of records and the preliminary analysis of the claim for the NHSLA. One noticeable trend amongst our interviewees was that claims managers were endeavouring to manage more straightforward claims in-house, postponing the point at which they were passed to external solicitors and, in some cases, avoiding the need to do this at all if they were able to settle the claim. This trend had developed over time: as claims 
managers became more skilled at identifying the issues and quantum of claims, so they were able to judge whether they should be settled at an early stage and if so, for what amount. In one trust a corollary of this approach was a raised profile for the department leading to increased involvement in educating hospital staff about time limits and prevention, linking claims and clinical risk. Reliance on solicitors was therefore lessening. Several reasons were identified for this trend. These included the cost of using solicitors and the desire to use existing skills:

There's a feeling of satisfaction, it may be a tiny bit more work but we're saving on defence costs and people are conscious of the fact it's public purse's money here... and we shouldn't be shipping outside... Let's try and use our skills as well... We've... got a diploma in claims management and it's such a shame not to use that training and the skills we have to manage in-house as much as possible. (Claims manager)

Even when claims were sent out to solicitors, there was evidence of a greater input into the management of the claim than previously:

Once proceedings are issued I would say you've got more involvement probably whereas at one time it... just went to the solicitors and they dealt with it... Now we tend to have more involvement in the decision-making process and, perhaps, gathering the information. (Claims manager)

All of the trusts used solicitors as a resource to augment their in-house claims handling rather than handing the case over as a whole. Arrangements had been made for lawyers to visit the trusts on a regular basis (weekly or quarterly), to discuss claims and give advice on issues such as quantum, responses to letters of claim and Part 36 offers. Here again, the reasons for a change in approach were twofold.

We're moving towards bringing it in-house and that's... more in a way in response to CNST reporting guidelines and the NHSLA's requirements than actually to the procedure rules. But it's also in response to looking at protocols because... the time limits are so much shorter. (Claims manager)

Solicitors might also be used sporadically to obtain a particular piece of advice.

If I then looked at it and thought 'oh dear, I'm very uncomfortable with this and I think it's something we ought to settle,' I might then send it. Not to ask them to manage it but perhaps to ask for advice and review, at which time l'd bring it back and continue to manage it in-house. Because I try where possible to manage all our under-excess claims in-house. (Claims manager) 
However, where there was a need to obtain an independent expert opinion, claims managers did turn to solicitors to do this, either because the work involved was too great in addition to the existing administrative tasks or it was difficult to identify an appropriate expert without an in-house database. More practical considerations were also mentioned:

You make the decision to appoint our solicitors on those cases where the experts need to be brought in. And they tend to know the experts and the experts know them, they trust them. They know they're going to get their fees paid by these firms, they don't know us claims managers at all... so there may be a delay in the service too. (Claims manager)

Solicitors would also be instructed at an earlier stage in below-excess claims if it appeared from the outset that proceedings were likely to be issued or had been issued immediately due to the imminent expiry of the limitation period. Similarly, if there was media interest or if it would appear to be better managed from the claimant's perspective by someone independent, the claim would be passed to solicitors at an early stage.

Defendant solicitors also mentioned a more proactive role for claims managers, although there were mixed views on the effects of this. One commented that trusts 'are much more conscientious about the disclosure of medical records' and of 'the timetables that are involved... hospitals are becoming a lot more autonomous in the way they manage claims, more work is being done within the hospital'. Conversely, another defendant firm was getting involved with claims at an earlier stage, even pre-issue, due to the complexity of cases and the fact that the response letter is usually in the form of a pleading.

The extent to which claims managers across all trusts are adopting this proactive approach to in-house claims management is unclear. Certainly, those in our sample were doing so. One defendant solicitor divided trusts into two main categories; firstly those who disclose the notes, obtain preliminary comments and then hand the file over on receipt of a letter of claim, and secondly, those sending the case-note disclosure form to the solicitors and asking them to deal with it. Within the first group were those individuals who, as in our sample, would telephone for advice on the issues and deal with the claim in-house. For this defendant, in-house claims handling could cause difficulties:

Personally, the comments they get are not very good, because it's too scattergun. They are not looking through the notes and actually working out, well what is this really all about. They're not narrowing down... I still prefer the 
second approach and it's not just from a cost point of view that we get more money in, but simply because you can establish, then, what is it really all about. You can get the case notes, you can go through them, you can get the right statements from the right people, and deciding if we should be making an offer to settle or defending it, or getting an expert opinion or whatever. (Defendant solicitor)

Where panel firms were instructed through the NHSLA for higher value claims, there was little change to relationships with solicitors notwithstanding the Woolf reforms. However, changes to the panel could signal the end of longstanding relationships

There isn't the same relationship, we don't know half the solicitors now, [and] we're receiving correspondence from strangers. (Claims manager)

Claimant solicitors thought that more pro-active claims management had resulted in improved administrative procedures in some trusts. We discuss below the extent to which medical records were being supplied in accordance with the timetable set out in the protocol. Although most claimant solicitors reported that records were generally being supplied in a timely manner, we found two opposing views:

I think they've [trusts] really got their act together a lot more recently in the last two years. In fact a noticeable difference in a way... letters get through to the right person to start with, they're not floating around the hospital waiting to be allocated to the right person. And that person, the medical records officer or litigation assistant, will generally write to us on first name terms which is nice, and we'll ring them if we have a problem. (Claimant solicitor)

Trusts... have probably got better things to do than sending records out to solicitors. And... they delegate it, quite rightly, to relatively junior people, and records are all over the hospital... Most hospitals are pretty poor at managing papers. Quite often you get things in dribs and drabs and in a mess... key documents are missing... Nothing's changed there in my perception. (Claimant solicitorl

More efficient in-house claims management could also lead to a more open culture which, in turn, made early settlement more likely. This is explored further in Chapter 3.5. As discussed earlier, from April 2002, financial and claims management responsibility for all CNST cases will be transferred from trusts to the NHSLA. The NHSLA will instruct and negotiate on all claims and will settle claims directly with claimants. We explored claims managers' views on the anticipated changes. All of the claims managers interviewed thought that, despite this 'call-in' of below-excess claims, there would still be 
a role for them to play. This might include becoming more closely involved with risk management and clinical governance. However, one claims manager thought that the change might mean less opportunity for claims managers to use their skills:

We've had authority to settle up to [excess] and it does make us feel like we're using our skills a bit more. That is going to be a loss when it comes to zero excess, plus it's once again just relying on feedback from another body outside, it just feels like less your case. (Claims manager)

To this claims manager, another potential disadvantage of the call-in was that trusts would become less aware of the connection between claims and risk management:

The other thing about zero excess is that the trust then doesn't begin to hear about this financial burden. We've always felt clinical risk management has come about [from] all those things, removal of Crown immunity... trusts are financially burdened by these claims and therefore they try and keep proactively making things better and prevent things from happening. (Claims manager) 
Two claims managers highlighted the importance of on-site claims handling and relationships with clinicians which might be compromised by a call-in. One said:

If you're working with clinicians all day, everyday, and... they know you're around, they ring you for advice, they rely on you for certain things... To be dealing with someone remotely who can't pop in at 8.30 in the morning or for 10 minutes at 12.50 because that's convenient for them... it could actually slow things down if it was all done remotely. (Claims manager)

However, the need to obtain records and liase with clinicians would remain, as would the need to provide a valuable point of contact for clinicians:

There's the counselling with the doctors which we do... the reality is we're dealing with human beings down here and they come to us. If they receive a letter from the NHSLA directly or our solicitors, they don't trust that letter, they come to us first, and that's normal human sort of reaction I think. IClaims managerl

\section{Courts and the Woolf reforms}

Generally practitioners had very few positive comments about court administration. Whilst some thought that efficiency varied between courts, the reforms had resulted in little if any improvement in this area:

I can't say they don't do their best and we know that they have difficulties because of lack of funding and lack of... trained or qualified staff. But I can't say that it has in any shape or form whatsoever improved the efficiency of the courts. (Claimant solicitor)

Funding difficulties were also at the root of problems experienced by a defendant solicitor who said 'we can get to court and find we've got no judge'. This caused additional problems with regard to expert witnesses. This claimant solicitor had experienced similar problems:

I'm becoming slightly more jaundiced really because of the practicalities that have started to arise through the cases... we're finding that... there's not enough funds within the court system, trials are being moved because they haven't got judges. And that has an impact on the experts... I've had two experts meetings completely ruined because of trials being moved. (Claimant solicitor) 


\section{Case management}

Case management received a mixed reception. Generally, the experience had been a positive one in relation to High Court Masters in London, which led to a greater incentive to reach agreement before the hearing:

You know when you're speaking to a solicitor on the other side... that if you're not sorting it out, you're both going to be seeing Master Murray or Master Ungley. And he knows you, and you know him, and... it's not like you can say, 'well, you know, it might be him, or it might be someone else... and l'll send my trainee anyway'. So I think there's a bit of... individual responsibility. I think that's why our case management works well. (Claimant solicitor)

However, outside London, experiences were less positive. Criticisms included inconsistency in decisions where courts had more than one district judge:

In the County Court you get different district judges looking at it and... it doesn't really work. You also get the traditional problem, which hasn't changed really, of you're never really sure whether the district judge is going to apply the rules or not. Sometimes, there's great latitude all round, and... 'oh well, let's have some extra time'. And sometimes it's taken very seriously, and, 'what's the point of case management if I don't punish you?'. So you're never really sure what you're going to get. (Claimant solicitor)

Other criticisms included the lack of specialist clinical negligence judges. This led to a lack of understanding about the particular problems faced by busy clinicians with heavy calls on their time and resulted in some unwanted orders:

The clinical negligence practitioners reach agreement with their opposite number... And we go to court and the whole thing's changed by the judge completely. That is my biggest bugbear about all of this, that we were told that we would get clinical negligence judges who have experience of clinical negligence claims... There are clinical negligence judges but they don't have experience of clinical negligence claims, and when the court is busy you don't get to see them anyway on an urgent application. So we come back with the most bizarre orders. (Claimant solicitor)

Other solicitors cited a number of examples of such orders. These included the judge fixing a trial date without waiting for the parties to notify the listing officer of witnesses' availability to attend trial. In another case, a date was fixed when the parties were not available: the parties were told that they would have to work around it. In a third example, a split trial on liability was 
ordered when the parties had requested a stay to explore settlement of the case. This order was appealed, a process which took several weeks and several thousand pounds to complete.

This study's preliminary findings suggest that in certain respects, case management in the County Courts is an area of concern for practitioners. The research currently being undertaken by Professor Peysner, which will address case management issues in more detail is to be welcomed.

Not all respondents were critical of case management. This defendant solicitor thought it provided a strategy for the case:

I like the idea of case management conferences. I think they work very well... instead of each thing being dealt with in an itsy bitsy way, there's an overall plan. This is the case, how are we going to move it forward, what do we need to move it forward? Instead of all these separate bits of applications that used to get made. No one had an overall idea of where we were going and if you ever said to the judge 'well, I need you to deal with this', they would say 'we'll have to make an application for that'. Whereas now there's... much more a plan of: who's dealing with this; where are we going with it; what do we need, and what's the time frame that we can deal with it within? (Defendant solicitor)

\section{Summary}

Broadly speaking, the reforms were positively received by all three groups interviewed for this research. Part 36 offers were particularly praised. The requirements of the protocol in relation to disclosure of medical records and detailed letters of claim were regarded as facilitators for earlier settlement. However, even those who were generally positive about the reforms highlighted certain areas in which they had particular areas of concern. Relationships with the courts and judiciary and the use of expert evidence were two of these areas.

The overall picture relating to costs is a varied one. There was some evidence that the protocol had resulted in a reduction in pre-issue costs. Streamlined procedures for the release of medical records minimised the need for applications for pre-action disclosure. Earlier exchange of information could lead to earlier settlement and a resulting reduction in costs. However, given the need to obtain medical records and an expert's report, costs are frontloaded. For claimant solicitors this is nothing new. However, for defendants, the necessity to front-load the investigation of claims could increase costs. 
This would counteract costs savings due to earlier settlements. It is difficult to provide a definitive view on this given the limited number of interviews. Further research in this area could clarify the position.

Broadly speaking, interviewees reported that post-issue the cost of claims had not decreased and in some cases were rising. This was attributed to increased court attendance and the need to produce interim schedules of costs.

The use to which these schedules are put is an area which should be reviewed. However, it is important to take into account the fact that overall costs in clinical negligence claims include experts' fees. The protocol is not prescriptive about the use of joint experts and, whilst they may be used on quantum issues, joint experts on liability are rare. Given the pivotal role of the expert in these claims, it is difficult to see how this aspect of overall costs can be addressed.

Generally, solicitors had not made major changes to their practices or ways of working to deal with the new regime. Practice Direction 49 and legal aid franchising already required active case management and specialised systems to deal with these claims. Claimant solicitors reported that they had previously adopted a 'cards on the table' approach to litigation so here, too, there was little need for major change. However, old antagonism is difficult to cast off and some claimants were critical of defendants who did not respond in a similar way, and in some cases used the NHSLA as a tactical excuse. More open relationships between claims managers and claimant solicitors were evolving.

Shorter timetables and more active case management required by the CPR had resulted in increased workloads for solicitors and the need to pursue clearer and more immediate strategies for cases. Claims managers also reported increased workloads due, in part, to greater input into individual claims. One noticeable trend was that claims managers were electing to manage a greater number of 'below excess' claims in-house rather than sending them to solicitors. Solicitors were used to augment claims management, providing occasional advice. Nevertheless, claims managers had not taken on the task of instructing experts and solicitors were instructed for this purpose. Defendant solicitors had mixed views on this more pro-active claims management, but claimant solicitors thought that this had resulted in improved administrative procedures in some trusts. 
There was some evidence that there was less reliance on counsel. Solicitors were undertaking more drafting in-house, retaining more fee-earning work and maintaining control over a case and its timetable. However, the reforms had given rise to new areas of work for counsel, such as drafting agendas for experts' meetings.

Clearly, difficulties remain with court administration where there had been little improvement and little evidence of change to cope with the reforms. Case management was far more positively received in London than outside, where there are problems with providing experienced judges and apparently inconsistent decisions.

This is an area requiring further study and the fact that further research has been commissioned is to be welcomed. 


\section{Chapter 3.3 General aims of the clinical disputes protocol}

This chapter explores the extent to which the wider aims of the protocol are being met. The protocol differs in a major respect from its personal injury counterpart in that one of its specific aims is to maintain/restore the relationship between patient and healthcare provider and, in so doing, work towards removing the mistrust that characterised such disputes.

Given the NHS initiatives discussed in the introduction, it was difficult to identify any changes in adverse outcome reporting or risk management which were directly referable to the protocol. Below we concentrate on the interface between the complaints system and claims, and the relationship between claimant solicitors and trusts.

\section{Wider aims of the protocol}

The specific objectives of the protocol include the encouragement of a culture of more open communication. Patients should be able to voice concerns and healthcare providers should develop reporting and investigation systems and provide prompt explanations to patients (para. 2.2).

The preamble makes reference to clinical governance issues that have a bearing on healthcare providers' ability to meet the standards in the protocol such as: clinical risk management, adverse outcome reporting and the professional's duty to report (para. 2.3). It does not provide guidance on these issues which, as discussed in the introduction above, are the subject of several government initiatives.

The protocol itself has a section dealing with 'Good Practice Commitments'. It summarises the guiding principles which the parties are invited to endorse when dealing with patient dissatisfaction with treatment and potential complaints and claims (para. 3.4). Most relevantly, healthcare providers should:

- ensure appropriate training in healthcare law, complaints and civil litigation practice for key staff;

- set up adverse outcome reporting systems to enable evidence to be gathered quickly to facilitate an accurate explanation and to defend or settle any subsequent claims; and, 
- advise patients of a serious adverse outcome and provide on request an explanation of what happened and further steps open to the patient, including an apology, changes in procedure which will benefit patients, and/or compensation.

For patients, the commitments include reporting concerns as soon as reasonable, considering the full range of options (including a complaint) and informing the healthcare provider when the patient is satisfied the matter is concluded (para. 3.5).

\section{Interaction with the complaints system}

The patient who is dissatisfied with clinical care may turn to the NHS complaints system. At present, the system has no mechanism for awarding compensation. Research has shown that complainants are dissatisfied with the system and that it does not meet their needs (Mulcahy et al 2001). The complaints procedure is entirely separate from the protocol and was not the focus of this study. However, it was possible to explore the extent of communication between complaints and claims departments within trusts and seek views on whether the culture of openness promoted by the protocol had had any bearing on the complaints process.

\section{Communication between departments}

Theoretically, claims managers who are notified about complaints at an early stage will be in a better position to respond to allegations if they become claims. They will therefore be better able to comply with the obligations and the time limits in the protocol. Disseminating information about claims to those with responsibility for clinical risk should ultimately serve to reduce the number of claims.

All the claims managers interviewed indicated that they had established strong links with their complaints departments. They were able to access complaint files either manually or electronically. Communication was supported by databases detailing, for example, clinical incidents, complaints and claims. In some cases following an adverse incident, details would be passed to both claims and complaints. The protocol was regarded as the catalyst for this change: 
I think another big effect of it has been that it has... compelled this Trust to bring complaints, adverse incidents and claims together and see adverse incident reporting and complaints as an indicator... of what may possibly lead to a claim. (Claims manager)

There were clear benefits to the claims manager in this exchange of information as it could provide an indication as to whether a claim might materialise:

I work very closely with complaints on a regular basis... When you get to litigation you never see the actual claimant. She sees the people herself and... she gets a good feel at meetings, conciliation meetings as to whether they're potential litigants or whether there's residual concerns. (Claims manager)

\section{The complaints process: claimant solicitors' views}

Several claimant solicitors had negative opinions about the complaints process. Potential claimants were directed towards the procedure as a prelude to a claim, particularly where there were funding difficulties. However, a commonly held view was that the culture of openness had not permeated this procedure.

Most clients we encourage to go through the complaints procedure, especially since the issue with the public funding and financial eligibility's happened... And generally they will come back to us because they've not been happy, and that's not good when you consider how long this complaints process has been actually put in place... So there's still not, there's not as much honesty as you would hope for. (Claimant solicitor)

One solicitor who pushed clients towards the complaints procedure thought that there was very rarely an admission or a recommendation that the client take legal advice. Another solicitor echoed this view, saying that they had never seen an admission of liability in response to a complaint, and explained why claimants were dissatisfied with the system: a culture of openness could not, of itself, address this issue:

Unless... the client gets a letter back saying we admit breach of duty, we admit causation, and we're willing to discuss terms of settlement, which they never do, the client's never going to be satisfied with the NHS complaints procedure, because they don't perceive it as being wholly independent. Even if someone independent is brought in to arbitrate at some point they don't perceive it to be independent. If they've got their own independent expert's report then they're more likely to accept the conclusions if they're not positive. (Claimant solicitor) 
A third claimant solicitor thought the complaints system was 'a farce'. Here, too, there was the suggestion that the 'cards on the table' approach did not apply:

I have seen many complaints that utterly deny any dereliction of duty and have then gone on to win the case, and have had full and open admissions of liability. And you sit the complaint letter next to your admission letter and it doesn't make very pleasant or palatable reading... You have to read very carefully between the lines to realise what they're actually not saying in a complaint letter. They will pick up on slightly erroneous use of medical terms and merely give you an explanation, you will find you are mistaken in believing that... without answering the question which was so blatantly obvious from your letter... the client is utterly deceived by that response. (Claimant solicitor)

\section{Defendant views}

In contrast to the views of claimant solicitors, some claims managers considered the complaints procedure to have been more open than litigation. The culture of openness advocated by the protocol was bringing the two roles closer together:

There used to be two hats, I think, on litigation and complaints management. I used to find it very confusing when I had to manage both. Complaints, you admit to everything, you open up, you tell the truth, you give all the chronology, say everything. Litigation, you didn't have to say everything, you can privilege certain documents. And it just felt like you were kind of hiding the truth as long as you could almost. There was almost that emphasis I think years ago on trusts being quite defensive. Whereas now I think they're kind of moving parallel... You're admitting to things very quickly, you're stating the facts... so I think Lord Woolf has actually made justice that bit more accessible, certainly to the claimant. (Claims manager)

Defendant solicitors thought that claimant solicitors might also be culpable of being less than open when dealing with the complaints system. It was suggested that some encouraged clients to make a complaint as a precursor to litigation without saying that a lawyer had also been consulted:

Claimant solicitors are... encouraging clients to make an NHS complaint... and not telling us... they're already advising... that is just duplicating time and money. Somebody has to deal with that as an NHS complaint, only to have to start the whole process again when it becomes a legal claim... I think they should just be open. Why don't they say from the outset that they're investigating a potential claim?... I think the reason they do it is that they think, 'Oh well if we make it as an NHS complaint the solicitors won't be involved, the clinicians will say all sorts of daft things that no lawyer would let them say and 
we'll find out what's really going on'... That is implicitly saying that they think there's some big cover up in legal claims and, believe me, it doesn't. (Defendant solicitor)

\section{The duty to be open with patients}

The extent of the duty to be open with patients who might later become claimants has practical implications. One claims manager explained the difficulties of dealing with questions about adverse outcomes in meetings with patients and their families. Whilst there was an emphasis in the protocol on openness, one view was that there was insufficient NHS guidance on how to go about providing apologies and admissions that things have gone wrong:

On the one hand you want to be open and people are not silly, they know that things have gone wrong... and they know people are avoiding telling them something, but on the other hand the CNST guidelines say you can't make admissions in these sorts of meetings. (Claims manager)

Other claims managers also emphasised the conflicting pressures inherent in openness. Whilst an investigation following an adverse incident or a request for records could disclose that there are grounds for a claim, this might give rise to conflicting duties for claims managers. Openness might be tempered by more pragmatic concerns:

A lot of this is also about cost saving so I don't want to... be so open that we're going out to people and almost saying... 'come on, why aren't you suing us'. Because we realise there's a problem but there is a sort of ethical issue about that as well... I think that's one of the problems with front-loading where, if you investigate something, you realise that... there has been negligence and this person would have a claim. (Claims manager)

Another claims manager highlighted the same issue. In practical terms, where this individual became aware of the potential for a claim, it would be investigated so that it could be dealt with promptly rather than providing the potential claimant with an unprompted admission:

You don't obviously... go up to somebody and say, 'oh dear, we've got this wrong'... We're not going that far and offering up the fact that we were negligent, although we're moving much more towards open, honest, level playing fields. And we do... tell people if something has happened that we didn't expect. But if I make an assessment that, should the person decide they want to sue us... then I would go in and request the statements... If a claim comes in, we can deal with it early and up front, if there's an element of negligence or sub-optimal care, we don't have to beat about the bush with the claimant solicitor... Morally and ethically as an organisation our view is... things do go 
wrong... it's not always negligence. But if somebody is due a compensation payment then that should be paid as early and as appropriately as possible. (Claims manager)

The issue of the provision of information to patients who have suffered adverse incidents was also raised by the National Audit Office Report (NAO 2001). The report points out that the Department of Health's policy is that patients should be told where they have suffered an adverse medical incident and should be offered remedial healthcare, a factual explanation and an apology. It states:

\footnotetext{
...the Department of Health have told us that they do not see it as the business of the NHS to advise patients that there might, on the face of it, be grounds to believe an adverse medical event may have been due to negligence or suggest patients seek legal advice or admit liability. There is, however, no clear departmental guidance to staff about this policy and there are cases where staff give indications to patients that there are grounds for suspecting negligence was a factor in an adverse incident or advise them to consult a solicitor (NAO 2001, p.4)
}

Our interviews with claims managers have highlighted that this issue is a particular concern for them, particularly in the light of the need for early investigation required to comply with the protocol's timetable.

Whilst not linked directly to this study, we echo the NAO's recommendation that there is a need for clearer guidance on what information claims managers may give to patients who have suffered negligent harm.

\section{Relationships between claimant solicitors and trusts}

There was a strong sense amongst claimant solicitors and claims managers that there had been an improvement in their working relationships. Unlike their comments about the complaints system, claimant solicitors were aware of a more open culture permeating the NHS:

There's a growing awareness amongst the medical profession that they've got to be less secretive because they're coming in for some adverse publicity. So it seems that the trusts that are aware of that and are trying to make themselves more patient friendly. (Claimant solicitor) 
This change is most likely to be both protocol driven and also part of the wider development of risk management strategies within the NHS. One solicitor who thought it was risk management driven commented:

The health service management generally is trying to get to grips with the quality of service that they're providing, and the adequacy of response, and to become less defensive and less closed off as institutions. This [the protocol] is an element of that...(Claimant solicitor)

One example of a more open relationship was the practice of discussing the claim more candidly. As one claims manager explained: 'I think the difference in working for us is that we can phone up the claimant solicitors and negotiate over the phone.' Another claimant solicitor drew a distinction between dealing with trusts and with defence solicitors: more open attitudes were evolving within the trusts themselves but by the time it reaches the defendant solicitors often it's lost'.

As discussed in Chapter 3.4, more proactive claims management could also contribute to an increase in early settlements:

We've had some very good instances of quick settlements because we've got very sensible, very well informed claims managers who deal with it in-house... and I think I have seen instances of quick apologies with quick settlements which is lovely. (Claimant solicitor)

However, the culture varied according to the ethos and the experience of the claims manager. The attitudes described were thought to be patchy. Much will depend on the resources of the department involved: where a lone claims manager fields a number of claims and associated tasks, it will be difficult for that individual to make time to review a claim and decide on a strategy to pursue:

Some trusts will let us have copies of their reports... they offer us the complaint if there's been a complaint in case we don't know about it. And other trusts it's like pulling teeth trying to get any information. They won't even let us have the standard protocols. Classic example: 'Do you have a protocol on the management of shoulder dystosia episodes?' 'Well we might do but we're not telling you.' 'Well, thank you for your openness and your full and frank disclosure.' (Claimant solicitor) 
Finally, the protocol aims to maintain or restore the relationship between patient and healthcare provider. One claims manager remarked that this was not a problem, as patients appear to regard their legal claim as separate from their care:

Historically... patients will sue you for something and still be quite happy to come back to your hospital and might actually, whilst doing it, be coming back to your hospital and being treated by you... I'm not quite sure how much that [the legal claim] affected people's view of their health provider or their local trust anyway. I think they saw it as a one-off issue. (Claims manager)

\section{Summary}

Whilst the complaints procedure itself is separate from the pursuit of a legal claim, the Good Practice Commitments in the protocol apply equally to potential complaints and claims. Patients who are satisfied with the outcome of the complaints procedure might choose not to pursue a legal claim. If a culture of openness is to be instilled, the complaints procedure should be an example of such good practice.

There was a strong feeling among respondents that the culture of openness had not permeated the complaints procedure. Some claimant solicitors were highly critical of the process, whilst defendants thought that claimant solicitors themselves were less than open about the use of the procedure. There is clearly room for greater candour in this regard.

Whilst channels of communication between complaints and claims departments within trusts were well established, there is also some uncertainty amongst claims managers as to the extent of their duty in advising patients on the further steps open to them following an adverse incident. There remains a reluctance to admit liability unprompted by a claim or to advise patients to seek legal advice. This is Department of Health policy. We echo the NAO's recommendation that clearer guidance needs to be provided to NHS Trusts on what information they may give to those who may have suffered negligent harm. One positive effect of the protocol is that there is greater openness between claims managers and claimant solicitors. A willingness to engage in open discussions makes it more likely that an earlier settlement can be achieved. Here, too, the picture varied between trusts. 


\section{Chapter 3.4 Formulating and responding to the claim}

As discussed above, the protocol contains timed steps for patients and healthcare providers to follow when a dispute arises. The aim is to facilitate and speed up the exchange of relevant information and increase the prospects of resolving the dispute without litigation.

This chapter explores each of the main steps. The first section deals with obtaining medical records. The second considers the steps taken by trusts to investigate claims. The third discusses views on the letter of claim, the work involved in preparing them and their content. Finally, there is an investigation of the letter of response and the extent to which it includes a detailed reply or admission of the claim. The protocol refers throughout to 'patients' and 'healthcare providers'. Here reference is made to trusts rather than healthcare providers, as it was trusts that constituted the focus of the sample taken for this report.

\section{Requests for medical records}

Requests for copies of a patient's clinical records by the patient or their advisor should be made using the Law Society/Department of Health approved form (para. 3.8). The copy records should be provided within 40 days of the request (para. 3.9). Where the trust has difficulty in complying within the time limit, the problem should be explained quickly and details given of what is being done to resolve it (para. 3.10). An application for pre-action disclosure can be made in the event of failure to supply the records (para. 3.12).

\section{Information provided when requesting records}

Most claimant solicitors were using the approved form, which asks for details of the likely nature of the claim, the grounds for the claim and the approximate dates of the events involved. All the claimant solicitors reported that they provided trusts with as much information as possible about the potential claim when making a request for the records. In most cases, this included the potential allegations against the trust. In some cases the information given exceeded the requirements of the application form. One solicitor used the request for records as an opportunity to write a full 
letter, setting out anticipated liability and causation issues and, in broad terms, the likely quantum of the claim. However, the letter concluded 'for the avoidance of doubt, this is not intended to be a detailed letter of claim'. Conversely, another claimant solicitor was providing less information than prior to adopting the form because previously they had to show that there was a strong prima facie case in order to obtain the records.

Whilst the interviews with the claimant solicitors appeared to indicate that the standard form was widely used, defendant solicitors and trusts painted a different picture. Although the form pre-dated the reforms, its use was patchy.

I should say 75 per cent of the time it was being used. 25 per cent of [the] time people looked at you as if you were mad when you said 'well, can we have you filling in a protocol form, '... Believe me, there are still solicitors even now who don't know about that standard form even now. Which is staggering really. (Defendant solicitor)

Interviewees in one trust reported that the request for records might simply state: "Please give us access to these records" and that's it... Often they don't say, so either us or medical records will ask them "is this request in relation to... a claim or whatever?".'

Another claims manager commented that whilst the form was being used more frequently, it was not always filled in 100 per cent accurately. Larger claimant firms would give information about the potential allegations and dates of treatment, yet others would only give sufficient details to identify the patient and possibly the year of treatment.

\section{Patient access to medical records}

The Data Protection Act 1998, which came into force on 1 March 2000, gives patients a right to access their health records. This is termed 'subject access'. There are prescribed fees which may be charged for granting access, depending on whether the records are automatically produced or are manual records. A written request is made to the 'data controller', which should contain enough information to allow the data controller to identify the individual and locate the information requested (s.7). Difficulties arise for claims managers where, in relation to a potential claim, requests for records are made by means of subject access rather than by solicitors' using the Law Society form. A claims manager commented that such requests where they didn't have to declare anything... could be a fishing expedition'. They had to be 
screened on receipt to establish if there was to be a potential claim to ensure, that an investigation could be carried out, ready to respond to a letter of claim. One claimant solicitor encouraged clients to ask for their own records where there were problems with funding. This might explain why notes are sought by this route. However, claimant solicitors expressed the view that subject access could affect the quality of the notes disclosed:

Many, many of my clients have tried to get their own records to be told, 'well, it's very difficult', or 'well no, you can't really have them', or 'oh well, here they are'. And they give them three sheets of paper... They don't happen to have the operation notes to hand or... the nursing records or the correspondence. And it's just incorrect, they should be given full and frank disclosure if they ask for it... without all this 'Oh, you've asked for it wrong'... they haven't quoted the Data Protection Act, so you can't have. (Claimant solicitor)

Generally, however, respondents' comments about the use of the standard form and the information provided to obtain the records were positive. Two refinements were suggested. First, that the form should state whether the patient had received treatment elsewhere. Secondly, that there should be a fast track system for obtaining the records where the client was terminally ill or where there were limitation problems. These are issues which should be considered when the Clinical Disputes Forum reviews the protocol.

\section{Release of medical records}

Broadly speaking, respondents' comments concerning the time scale for the release of the records were positive. Claimant solicitors reported that the notes were usually supplied within the 40 -day period and that procedures for the provision of notes had been streamlined. This contrasts with the CDF's own questionnaire which, although generally positive about the disclosure of records, found that the 40-day time period was regularly exceeded. However, claimant firms did not always demand strict compliance. In cases that predated the reforms, difficulties could occur where the claimant solicitor was seeking updated records

Where it is not possible to supply the records within the time limit, claimant solicitors reported that they were, in the main, contacted and an explanation given for the delay.

On the whole I tend to find I have no trouble whatsoever. I'll write to the trust, I know the person at the trust by name, I've dealt with him or her before. I'll get a letter saying 'we're collating the notes'. If they're having difficulty getting 
them to me in time they'll drop me a line or phone me up and say 'look [solicitor's name], I'm having a bit of difficulty but I'm dealing with it'. IClaimant solicitor)

Broadly speaking, defendant solicitors thought that the process for the release of records was more efficient. However, in many cases this stage will be dealt with in-house by claims managers rather than the external firms instructed. One defendant solicitor commented that the time limit was 'about right' and that most of the time it was possible to comply with it. Difficulties could arise if the patient was continuing to undergo treatment and the notes were still required for this purpose.

One claims manager said that the trust 'usually nearly meets' the 40-day time limit. This trust had changed the procedure for release of the notes to improve compliance with the time limit. They now copied the notes in-house rather than sending them to solicitors, who in turn, would have them copied off site. Nevertheless, this had not solved the problem completely:

Even with this set-up we've got now where we get them here and copy them here and check them here, we don't always meet the deadlines... On the times we do meet them, sometimes what we really mean is that we've got the bulk of the records to the claimant solicitor but there's still a possibility that there may be other bits and pieces that we can't get hold of. (Claims manager)

In another trust the claims manager indicated that records were rarely released within the time limit: usually they were supplied 'just over' that period but in some cases it might be longer. Records were copied in-house in this trust also to save costs.

In contrast to this, a third claims manager stated that in probably 99 per cent of cases the 40-day time limit was met: in fact most of the records were sent out within a fortnight, if not less. In this trust the speed with which the records were disclosed was attributed to two factors: not waiting for clinicians to approve disclosure of the notes, and limiting the amount of notes sent out:

I have got an agreement with virtually all my consultants. I don't send it to them, they'll get disclosure anyway... I'm not going to send it to them for approval, I will screen the notes... In my original letter I say... 'we will send you, unless you suggest otherwise, the records relevant to the claim that you're making'. And we never send $x$-rays until they request [them]... we list them for them, explain what we've got. (Claims manager) 
Several reasons emerged for the delay in supplying the notes. Some were similar to the CDF responses. These included: the fact that the records were required for clinical care; that they needed to be collated from different sites; that the trust had a poor system of record management; or that consultants took too long to read the records and give their consent to the release to the claimant's solicitor.

\section{Pre-action disclosure}

Consistent with the positive nature of the comments about this area of the protocol, applications for pre-action disclosure were rare. One claimant interviewee spoke of previously having to fight for the records and explain why they were wanted. Now requests were no longer met with refusals. Many of those interviewed had not made, or had to respond to, such an application. Here, too, the findings are consistent with the CDF research. In some cases applications for pre-action disclosure had been threatened but not proceeded with as the records had been supplied.

Whilst one explanation for fewer applications for disclosure is compliance with the protocol, there are other explanations. One claims manager (who had reported that it was rare to get the records out on timel commented that claimant solicitors were not issuing pre-action disclosure applications. 'It's like... they don't want to go down that route either... they don't want to incur costs if the case loses or whatever.'

\section{Investigating claims}

The protocol recommends that trusts should adopt a policy on which cases will be investigated when records are requested (para. 3.11). In this context there are two conflicting pressures on claims managers and the solicitors they (or the NHSLA) instruct. The first is to contain costs. This might point towards investigating as few cases as possible when the records are requested and waiting to see whether they become claims. The second is to front-load the investigation on a greater number of requests for records so as to be prepared to meet the deadlines set out in the protocol and the CPR timetable in the event that proceedings are issued. As discussed in Chapter 3.2, trusts and defendant solicitors appear to prefer to front-load the investigation. We explored with defendant solicitors and trusts how they choose which cases to investigate when records are requested. 
In many cases, this is difficult to analyse as it will be based on the familiarity of dealing with these types of claims. As one defendant solicitor put it, 'it's experience... which ones you need to do something about and... when they've got completely the wrong end of the stick'. Another defendant solicitor said the decision to investigate a case depended on all sorts of extraneous information'. This might include press interest or the claimant's solicitor making early contact to say that the case was particularly bad and needed to be taken seriously.

One claims manager said that deciding which cases to investigate depended on the nature of the request for records. Associated information would also have an influence, for example, whether a complaint had already been made. Such decisions would also need to be made even if the patient made the request for records themselves, rather than through a solicitor. The benefits of having a claims manager in situ, able to approach staff directly and informally, are well illustrated here:

I will always look at the notes myself and have a considered view on whether there looked to be any aspects in there that are cause for concern. If indeed, it does... say visited $A \& E$ on day $X$ and then I see an orthopaedic report six months later which says fracture noted... and I think... there's a possibility we missed it, then I will gather statements on the assumption that it's more likely than not that, although I've not had it formally though the Law Society form, there is somebody else in the background. (Claims manager)

One claims manager followed up requests for records after three months, asking claimant solicitors which issues the trust should consider to try and make them realise that we're taking it seriously and we want to know and we want to understand, we want to understand really early'. Another indicated that in some cases, where records are requested, there is a 'bit of wait and see' in relation to investigation. The health records department ask claimant solicitors whether there is likely to be any evidence and if they are willing to indicate this, the trust will look at the claim.

As discussed in Chapter 3.3, this claims manager highlighted the importance of good communication with the medical records department. The request forms themselves could provide an opportunity to screen for potential claims:

Now that most of the requests for records for patients who are alive is under (the) Data Protection Act, they all come here. We do the central bit in terms of the invoicing and all sorts of things, which also gives me the opportunity to screen them... I've got an excellent colleague in medical records as well who, 
because she does the copying, occasionally she'll pick something up and she'll ring me up and say what do you think about this, do you want to have a look at it?'. (Claims manager)

In another trust, the information given on the request for records form was used to decide whether to investigate. If a claim was intimated, the consultant involved would be asked for an opinion on the care given, any witnesses and any long-term problems as a result of the treatment. Here, too, the approach was to err on the side of investigation rather than not. This was a change from previously; the crucial factor leading to this change was the need to be prepared to meet the three-month time limit for responding to the letter of claim. However, the effect on the cost of claims was clear:

I think it costs more post-Woolf and I think it's because there is so much work done on cases very early on that might not be of any merit. (Claims manager)

However, in some cases defendants were not given the opportunity of deciding which claims to investigate. This solicitor referred to a practice which made front-loading essential, even without a request for the records:

We have plenty of cases... of solicitors who will use the letter of claim system as a means of passing the investigation of the claim back onto the defendant... They'll put in a Part 36 offer straight away, without having seen any medical records, and they'll make allegations which are very general and vague. We are then obliged to, at the very least, consider whether we take the risk of ignoring the letter and carrying out the usual preliminary assessments or running the risk of finding the claim does come at the expiry of the three months of the service of letter of response following which a court will take a very dim view of your failure to respond. (Defendant solicitor)

\section{Letters of claim}

\section{Protocol requirements}

Following receipt and analysis of the records and expert advice, a letter of claim should be sent as soon as practicable to the healthcare provider if there are grounds for a claim (para. 3.15). The letter should:

- contain a clear summary of the facts on which the claim is based, including the alleged adverse outcome and the main allegations of negligence; 
- describe the patient's injuries and present condition and prognosis;

- outline the financial loss incurred with an indication of the heads of damage to be claimed unless this is impracticable (para. 3.16).

In more complex cases, a chronology should be provided and the letter should refer to any relevant documents and, if possible, enclose copies of those which will not already be in the potential defendant's possession -GP records for example (para. 3.17, 3.18). Proceedings should not be issued until after three months from the letter of claim unless there is a limitation problem (para. 3.21).

\section{Overall views}

There were mixed views about the letter of claim. On the positive side, a clear theme which emerged was that they contained much more detail than the old-style letter before action. This helped defendants respond to the claim and opened up the potential to settle a claim at an earlier stage than previously. This view was expressed by both claimant and defendant solicitors alike:

The letter of claim and the Part 36 offer are the two things that have made a huge difference... The letter of claim and response has also gone some way towards forcing particularly defendants to be open about their case... That's one of the things that hasn't been completely successful in my experience, but the requirement is there and that's the right thing and... it does make it potentially much easier to settle the claim at an early stage. (Claimant solicitorl

Over the first year... we would find that obviously the letter of claim and the letter of response made a huge difference in that it gave us, it gave defendants more time to prepare cases, taking a clear view. And I think to that extent it probably did help early settlement; settlement pre-action. (Defendant solicitor)

There was also some praise amongst claims managers for letters of claim with comments indicating that they were serving the purpose of clarifying the issues:

Previously you... got a... fairly waffly letter... quite often it looked as if sometimes they weren't necessarily supported by an expert report. Whereas now you get a much greater clarity in a formal letter of claim about what they believe the breach to be, why they believe that to be a breach, what the causative issues are... I think that is really helpful because that [causation] was quite often the bit that would get very woolly and that you'd be disagreeing on. I think making... within the letter of claim the responsibility on them to show 
the link between the breach of duty, the loss, that middle bit, in a much clearer way, is exceedingly helpful. And you can see that it has been done... now obviously with the benefit of having got preliminary expert reports. (Claims managerl

However, the picture was not wholly positive. Generally we found that practitioners made no distinction between potential fast track and multi-track claims in following the protocol. One claimant solicitor expressed concern that the letter of claim stage made little difference to the overall process of larger, more complex claims and in some cases merely delayed the inevitable issue of proceedings:

They do end up actually opening up a wealth of correspondence often in a CP [cerebral palsy] case, which I'm not entirely sure is the right forum for it in cases of large value. Because it's all going to be dealt with in medical evidence later and you could end up having correspondence that would last a year just deferring the case. So often, it starts a process that in some cases I'm quite happy to go down, i.e. lower value cases where there may be a problem with funding, where I don't mind that we've opened up correspondence earlier. But in cases where the value's very high, we don't yet know what the prognosis is for the child, or [what] their requirements are, I'm less comfortable about doing it in those cases... I don't think it achieves anything... all it's done is buy the defendants a further three months. (Claimant solicitor)

The protocol was seen as far more useful in lower value claims where there might be funding difficulties. Opening up correspondence at this stage might lead to early settlement of the claim. However, the informality of the process could also cause concern:

What I have found is sometimes it's opened up a process of 'well we've got our evidence, here it is, you show us yours, on a without-prejudice basis'. And there's this great exchange, and you start feeling a little uncomfortable that it isn't happening within a formal process. Because you're doing it sometimes without access to witness statements, say... I've slightly felt uneasy about whether we are getting the same information as we would have done if we had just issued proceedings and pursued it. Because you're sort of side-stepping the rest of the process, that's how it's felt. (Claimant solicitor)

There was also some evidence that the formal letter of claim stage was not universally followed. This approach was not confined to those firms who had little experience of clinical negligence claims. In some cases limitation problems were used as an explanation: 
There's a huge number [of] cases we're not getting [a] letter of claim at all, pre-action... We just get the court proceedings served... And we always just make an application to the court, which... are all granted, sympathetically with costs... It's not confined to those who don't know what they're doing. And some of the bigger firms who are also doing it, are using limitation as an excuse. But when you say to them, 'well, you had the case notes two years ago so how come limitation's your problem? (Defendant solicitor)

\section{Work involved in preparing a letter of claim}

We explored the work involved in preparing the letter of claim and how they differed from the old-style letters before action. The protocol states that letters of claim are not intended to have the same formal status as a pleading, nor should any sanctions necessarily apply if the letter of claim and any subsequent particulars of claim in the proceedings differ (para. 3.20). However, there was clear evidence that claimant solicitors were anxious to ensure that the letter of claim would match the eventual particulars of claim. One claimant solicitor thought that the letter of claim had evolved into nothing less than a trial run at a pleading. Another echoed this view:

[The letter of claim] will be almost like a pleading... I know it's not a pleading and that we can change it when we want to but that's how we approach it. We're going to be quite specific and quite clear about... allegations of negligence and we see that as being important because then the defendants are going to start investigating. If we did that wrong then they're going to be running up costs in relation to wrong allegations and we don't want that to be the situation. (Claimant solicitor)

However, this practice of elevating the letter of claim to the status of a pleading could cause problems and increase costs. As one claimant solicitor explained:

Points are being scored in relation to whether your pleadings then match your letter of claim. [This] increases costs, really doesn't achieve very much. (Claimant solicitor)

This solicitor prepared the letter of claim at the same time and to the same standard as the particulars of claim and then waited three months to issue proceedings. She did not consider that the letter of claim helped to explore settlement in lower value cases. Another claimant solicitor was also unhappy to prolong the period before proceeding with the claim, having produced what would effectively serve as the particulars of claim. 
It is a fully pleaded document... Then you waste three months, sit kicking your heels before you can actually issue because they are allowed three months to respond... I'm just not sure it's adding very much any more... It's almost like a... three-month pause before you just think 'oh, to heck with it', and issue it anyway. (Claimant solicitor)

Some claimant solicitors clearly resent the three-month period that defendants have to respond to the letter of claim. One reason is that they consider the defendant's investigation of the claim should begin when the adverse incident occurs. Given the in-house clinical expertise within the trusts, one claimant solicitor did not see why defendants relied on the other side to indicate which areas to look into, although the burden of proof rests on the claimant to establish the claim. Defendants might argue that they are entitled to be informed of the allegations they will have to meet. This is in sharp contrast to the presumption of liability approach evident in low-value fast track personal injury claims.

Our interviewees suggested that the work involved in preparing a letter of claim is much greater than that required for the old-style letter before action. A major reason for this is that the main function of letters before action in clinical negligence claims was to obtain the medical records. It would have been a general statement based on information supplied by the client and on what, in the solicitor's experience, were likely to be the allegations made:

The old letter before action, you would actually write at the outset when asking for the notes. It could be a work of fiction to be honest, because you had to work from what the client told you. And either you say 'at this stage it is not clear', and you frequently get bad letters from solicitors saying without the allegations we will not give you the records'. So you'd see your client again and make up allegations because you couldn't do anything else. (Claimant solicitor)

Now, when the letter of claim is written, the solicitor's understanding of the case is likely to be greater. They will have seen and considered the records, obtained an expert's report and, in some cases, attended a conference with counsel. Several solicitors referred to using the expert's report heavily to draft the letter of claim. Getting to this stage is time consuming and costly. One solicitor was prepared to allow defendants longer to respond having realised the complexities involved:

We take much longer [than three months] but then we've got a lot more to do, haven't we?... Investigating a case can take a long time and you can embark on an investigation and find that actually there are a whole load of other things that you have to investigate before you can formulate the claim. You may need further reports, you may need further notes, so it often takes us quite a bit 
more even than six to eight months. And, you know, in a complicated case we're open to realising that the defendants can't be expected just to slap it all together in three months, that would be unreasonable because each case is different. (Claimant solicitor)

\section{Defendants' views}

Amongst defendants, views on the letter of claim stage were also mixed. On the one hand, they received praise:

The new letter of claim is, in l'd say 99 per cent of cases, or perhaps 95 per cent of cases we get, it's very detailed, very clear. Generally specific about what is alleged, it's almost invariably backed up by some form of independent medical assessment. There are the isolated cases... which are just totally on a word processor... I'd say the majority of cases that l've seen where a letter of claim has been served, there has subsequently been proceedings or the matter is settled. (Defendant solicitor)

However, whilst there were improvements on old-style letters before action, some defendants were concerned that adherence to the requirements of the protocol were patchy. Here this study's findings are consistent with the CDF research, particularly in relation to a lack of detail on causation and quantum. This finding is also consistent across all three areas examined for this report. One defendant solicitor complained about missing information which, whilst not impossible to obtain (this solicitor estimated that 50 per cent of claimant solicitors would agree to supply it), the effect on costs is clear:

It is very, very unusual to get a letter of claim that meets all the requirements... as set out in the... clinical negligence pre-action protocol. I think they are good at telling us in general terms the allegations of negligence and they're reasonably good in general terms at telling us what damage they say has been suffered. They are truly hopeless at telling us about quantum. They don't seem to think that we need (it)... I think it's 3.19 says [that] they must give you sufficient information to enable you to put an initial valuation on a claim, well very few can do that. (Defendant solicitor)

Claims managers also reported that adherence to the requirements of the protocol were patchy. As one put it:

I would say we've never in our time received a proper letter of claim with all the bits and pieces you're meant to have in, down to the national insurance number, [and] date of birth. 
Another claims manager had written back to claimant solicitors on occasion to inform them that the letter did not comply with the requirements. She thought that the level of information in letters of claim had increased due to such objections raised and requests for clarification by defendants. Rather than point scoring, however, there were indications that claims managers were taking a pragmatic view of the rules:

If it's that sort of info [basic information about the claimant] I don't tend to be too pernickety about it. But if we don't get a causative link and I don't get proper quantification then I do send it back and it is not, as far as I'm concerned, acceptable as a letter of claim. Because it's not serving the purpose that in effect a letter of claim was intended to do, which is them setting out what their basis for making a claim is... and they are being paid to do it. (Claims manager)

The protocol does not specifically require the letter of claim to contain details of the claimant's case on causation. It refers more generally to 'allegations of negligence', and it appears that claimant solicitors are taking this to mean allegations of breach of duty only. This is an area of the protocol which could benefit from greater clarification.

\section{Enclosures}

We explored the extent to which letters of claim were accompanied by enclosures such as chronologies, expert evidence, medical records not in the defendant's possession or schedules of loss. All the claimant solicitors reported that they were sending this information where it was possible to do so. Schedules were more likely to be sent in lower value claims where the injury and loss were clear, so that it was possible to quantify that loss at an early stage. In more complex cases all that could be supplied was an indication of the heads of damage likely to be claimed. However, one claimant solicitor thought that the defendant's requirements were out of step with those of the protocol:

I think the defendants feel that at that point we should be sending a fully set out schedule and... 25 medical reports or else we're in breach of the protocol... Actually, what the protocol says is that you have to say what injuries have been caused and it says that you have to give indications of what the heads of damage are, certainly as far as the future is concerned and... perhaps something a bit more specific about the quantum to-date. But it's only actually if you're making a Part 36 offer that you have to serve medical evidence, isn't it? (Claimant solicitor) 
Another solicitor objected to defendants asking for sight of a liability report, after having received a long protocol letter taken almost verbatim from that report. Some claimant solicitors feel they need to issue proceedings before the allegations being made are seen as validated, thereby undermining the potential costs savings of the protocol. This solicitor reported '...they still seem to want to see a medical report or see that you've issued'.

Whilst chronologies and schedules of loss may be less contentious than liability reports and witness evidence, some claimant solicitors reported that they also disclosed this type of evidence. This was in a spirit of openness, reflecting the new 'cards on the table' approach to litigation. One said: 'I'm quite happy to send my reports out to all and sundry to support it.' A second claimant solicitor also adopted this approach:

If I think the liability expert's report is in disclosable format I don't think anything of sending it out with my detailed letter of claim. And more likely than not, if I think my witness evidence is in disclosable format I will disclose that as well at that stage. If I don't disclose experts' reports with my detailed letter of claim it's simply because I don't consider it to be in disclosable format at that stage. But certainly when I serve my proceedings I will disclose my expert evidence and my witness statement at the same time. I send it all off as soon as possible. (Claimant solicitor)

Nevertheless, as previously noted, claimant solicitors complained that defendants were not taking the same approach to disclosing reports. This had not deterred one from continuing to disclose available evidence:

I've always been a believer in 'cards on the table' and if I've got it I will send it. Which sometimes means I get my fingers burnt, because... they basically use it against you, 'we've seen your first report, which doesn't tally with this that and the other'. But no, I will send it and I will keep sending it on the basis that it should be open disclosure. We should be working with them... but I don't often get the same attitude in response. But I will send all my reports, draft schedules, the works. (Claimant solicitor)

One defendant solicitor said that letters of claim are 'almost invariably backed up by some form of independent medical assessment'. However, other defendant solicitors and trusts reported that they did not always receive this evidence.

One claims manager said that letters of claim did come with supporting evidence from the bigger firms but it was rare to receive experts' reports, and solicitors would say that they had supporting evidence but they would not actually disclose it. Another claims manager routinely asked claimant 
solicitors to share causation or condition and prognosis reports once a breach of duty had been admitted. This was generally provided. Even where there was a dispute concerning liability it was still possible to obtain this evidence, which could then be shared with the clinicians concerned:

If I haven't admitted it but we are already in... communication either verbally or written and they realise and are happy and have worked with me before, quite often if they feel they've got a good supportive breach of duty report they will disclose that anyway. Because they'll know that I will consider it and I will look at it, and it's helpful because I can go back to our clinicians and say, 'what do you feel'? (Claims manager)

The value of supplying this evidence is clear. As one solicitor explained: a defendant who is concerned about a particular case, faced with a detailed letter of claim, backed by expert evidence, is able to obtain comments from the clinicians and make a Part 36 offer. Whilst the letter of claim is the catalyst for making the offer, the expert's report has another important role to play:

You know that a solicitor must have an expert backing up what he is saying. To get the expert report as well to be honest is the icing on the cake. Because if the consultant in charge has got any doubts about it, you can say, well, you know, Fred is an expert, is backing this'. (Defendant solicitor)

At present the letter of claim template in the protocol lists schedules of loss and supporting evidence as possible enclosures. Consideration should be given to issuing further guidance to claimant solicitors as to when such enclosures should be supplied.

\section{Letters of response}

The protocol provides that the letter of claim should be acknowledged within 14 days of receipt (para. 3.24). Within three months of the letter of claim the healthcare provider should provide a reasoned answer. If the claim is admitted, this should be stated in clear terms. If only part of the claim is admitted, the healthcare provider should make clear which issues of breach of duty and/or causation are admitted and which are denied and why. If the claim is denied, the letter of response should include specific comments on the allegations of negligence (para. 3.25).

Broadly speaking, the 14-day period for acknowledging the letter of claim was of little consequence: more attention is focused on the three-month period for a fully reasoned answer to the claim. One claimant solicitor did not check if 
the acknowledgement had been received, preferring to diarise the longer period instead. This approach is consistent with the fact that the claim is fully prepared and can be issued in the event that there is no substantive response within the protocol period.

We explored the extent to which defendants were adhering to the threemonth time limit for provision of the detailed response and, where this was not possible, the reasons for the delay. We also aimed to ascertain the extent to which admissions were being made and detailed responses provided to the letter of claim.

\section{Adhering to time limits - claimant views}

Claimant solicitors varied in their experiences of receiving detailed letters of response within the time limit. Whilst one view was that, on the whole, the three month period is adhered to, two solicitors indicated that this was not generally the case. Another reported that after receipt of the letter of claim, defendants would request an extension stating that they needed to obtain expert evidence. A third had received admissions of breach of duty with a Part 36 offer even prior to the expiry of the three-month period. Another solicitor had received rapid admissions in response to the request for records but had experienced delays in relation to the letter of claim:

I've had a letter of claim completely ignored... I've had what I would term as barn door cases, where they've taken the full three months, they've begged and wheedled an extra two or three weeks out of me and then come on and given me a full admission. And I suppose that's just their ineptitude to work to the timetable. If you get to a full letter of claim they normally wait for the kill. They make you wait the three months. (Claimant solicitor)

Where claimant solicitors were met with requests for extensions of time, these were generally acceded to. Here our findings were similar to those in the CDF survey. Two reasons were given for this latitude. Firstly, one claimant solicitor was sympathetic to the fact that the solicitors firm may only recently have been instructed by the trust.

I've heard defendants... say that this is really a huge pressure on defendants and their solicitors because they don't know out of all the protocol forms which ones are going to come through. They can make an educated guess but they're not always right... the letter arrives, very often they don't get it till a month after the hospital has got it, if they haven't been instructed beforehand. Then they have to get hold of the notes, they have to try and find an expert and... actually 
for them to achieve that in three months is a real problem. I mean there have been some cases where perfectly reasonable extensions have been asked for and we've agreed to that and that's fine. (Claimant solicitor)

Claimant solicitors were also mindful of the time it had taken them to investigate and formulate a complex claim:

I'm not going to be unreasonable if somebody comes to me and asks for more time. Why would I? If I know it's taken me eight to 10 months to get the case together... I'm not going to come down hard on someone who says, 'well, I don't think I can do it within 12 weeks'. (Claimant solicitor)

However, one solicitor expressed the opposite view and found requests for more time irritating because the process of investigation within the trust should have started sooner than on receipt of the letter of claim.

\section{Adhering to time limits - defendant views}

Most of the defendant solicitors and claims managers found the three-month period insufficient to reply to the letter of claim in all but the most straightforward cases. Here, too, interviewees' views were consistent with those in the CDF survey in which respondents suggested four or six months would be more reasonable. Cases involving children were cited as a particular difficulty by one defendant solicitor as they may not be activated until several years after the event. Contacting the clinical staff can be time consuming and expensive and is unlikely to be completed within the time frame. Another solicitor indicated that the timescale was difficult when dealing with a case with no prior knowledge of it (for example, if the trust has dealt with case note disclosurel as there was a need to obtain both expert evidence and factual evidence from several sources. They would not have had an opportunity themselves to read through the notes, obtain preliminary comments and, in the more complex claims, obtain an expert's report:

Where it is totally insufficient are the one-third of cases that trusts are dealing with themselves, where you haven't seen the case notes, you've got no preliminary comments. What the trust have obtained themselves is usually not good. You've no independent evidence... and you are scrambling around to locate the witnesses... because most of these people move round the NHS, to locate the rightful case notes... wouldn't think to do that, which we would have done. And to do all that and get comments and possibly also get an independent report in three months is impossible. (Defendant solicitor) 
However, defendant solicitors also reported that requests for more time were generally met, particularly if a time frame was explained. One view was that, notwithstanding the provisions of the protocol, in reality the parties still agree on the time limits. Given the limited number of practitioners working in this area, pre-existing relationships might lead to a more sympathetic response.

So if you can say, 'well, I've instructed $X$, he's due to report in another month, can you give us six weeks, because we'll be able to write you a more meaningful response in six than we can now?', the majority are reasonable about that. Providing they haven't got limitation problems and providing you've been reasonable with them if they've wanted time or whatever it happens to be. (Defendant solicitor)

Claims managers echoed these views, although the extent to which they are involved in drafting the letter of response varied. They also requested extensions of time and stated the importance of keeping claimant solicitors informed. The three-month period is used to carry out a fuller investigation and obtain views from additional clinical staff involved. One stated that three months was sufficient on a 'nice, simple, one set of records' case or a 'fairly black and white defend it or don't defend it' case but was unrealistic in cases 'where you're not sure'.

In another trust, the claims managers did not often draft letters of response. Where appropriate they would respond with an admission of breach of duty, without setting out 'the whole story behind it'. Letters of response tended to be confined to claims made by litigants in person. Nevertheless, it was rare for this trust to be able to comply with the time limit set.

Another claims manager interviewed was, in most circumstances, quite comfortable' with the timetable for responding to the letter of claim provided it had been investigated at the request-for-records stage. Claimant solicitors were contacted three months after disclosure, to enquire how they were proceeding. Work was delayed on those claims where no information was forthcoming. If a letter of claim then appeared, complying with the time limit could be difficult. Here, too, requests were met sympathetically:

I usually write back immediately saying, 'thank you very much, it may be that I can't respond within the statutory period, we will endeavour to do so, could you confirm however that you're happy... that you'll accept that it might be a bit of a delay?'. And quite often if you do that they are quite understanding of the work you need to do. I think again, having built up a rapport they know that you will respond as quickly as you can. (Claims manager) 
Whilst it is clear that there are difficulties involved in meeting the time limit for a letter of response, the system for seeking and granting extensions of time in appropriate circumstances appears to work well. For this reason, we do not recommend any changes to the present arrangements.

Providing a reasoned answer - comments on the allegations of negligence

The letter of response has a crucial role to play in the early resolution of claims as it provides the opportunity to narrow the issues in dispute. We explored the extent to which defendants were complying with the requirement to provide specific comments on the allegations of negligence.

Claimant solicitors were divided in their approval or disapproval of the detail in defendants' responses. On the positive side, one claimant solicitor stated that a more detailed response is being provided where previously defendants would have investigated the case and replied with a bare denial.

Another claimant solicitor had had mixed experiences of the effectiveness of the letter of response, which varied according to the approach of the defendant's solicitors. In some cases, the response was a 'blocking defence' which did not take the case any further. After pointing out that the response was outside the spirit of the reforms, if no reply was forthcoming, there was no alternative but to issue proceedings. In other cases the solicitor had found that this stage of the protocol was complied with but with variable results:

Not all defendants have taken on board their responsibility to provide a full response. Certainly I have had cases where I've had a full response... and I've actually used that as... a sort of starting point... and perhaps two or three letters have passed to and fro to try and get the defendants to expand on what they're saying happened and maybe they've asked me some more questions as well, and there has been a clarification exercise at that point. What has surprised me is that that doesn't necessarily then reflect the handling of the case... I went through a lengthy exercise on one case in which I said all of that and it didn't seem to produce the admission that l'd expected. But in another case it did actually and I think it was a really useful exercise. (Claimant solicitorl

Another view was that whilst the content of the letter of response demonstrated that a lot of work had gone into it, this stage did not "necessarily move things forward at all'. It simply raised issues which would have to be dealt with by way of evidence anyway. This may be an argument confined to more complex cases. 
Defendants commented that the letter of claim would be responded to in the same level of detail as it was drafted. One solicitor was prepared to disclose expert evidence with the letter of response where the claimant's solicitors had done so, or where the claimant's case was hopeless and the solicitor had clear evidence of that. Detailed letters of claim were likely to be met with detailed letters of response.

If they've done their best to set out their case in full and give me some evidence, the least I can do is respond. But if they've given me a rather vague, woolly, letter of claim, and I'm sure that when the particulars of claim comes in it's going to [be] much more detailed and a very different sort of case, then I don't see any point. (Defendant solicitor)

A claims manager made a slightly different point, indicating that the detail in the letter of response would depend on the amount of information supplied by the clinicians. Even so, a more detailed letter of claim would solicit a more detailed answer:

I don't think the response is different. I think our ability to be more definite about specific issues is better because they [claimant solicitors] are being more defined in the information they're giving you. So the previous problem was they tended to waffle around causation... so you didn't quite know what you were dealing with. So I think our responses are probably more defined to the issues by the fact that we receive a much clearer picture of their concerns. (Claims manager)

\section{Providing a reasoned answer - making admissions}

Research prior to the introduction of the reforms (Goriely et al 1998), indicated concerns among practitioners that defendants might be reluctant to admit liability in clear terms lor might later attempt to resile from admissions). In clinical negligence cases, issues relating to causation can be more strongly contested than liability. Whilst it may be possible to admit breach of duty, this need not be accompanied by admitting causation. The protocol recognises this in providing that if only part of the claim is admitted, the healthcare provider should make clear which issues of breach of duty and/or causation are admitted and which are denied and why.

Generally, claimants reported that comprehensive admissions of liability were not made more frequently post-Woolf. There was a tendency to admit breach of duty but deny causation. Whilst this relieves the claimant of the costs and time involved in obtaining expert evidence on breach of duty, there remains the requirement to prove causation. However, in some cases, 
comprehensive admissions of liability did occur - during the interview one claimant solicitor referred to a letter which admitted liability and causation and accepted the Part 36 offer which had been put forward. This solicitor commented that a 'hedging of bets' was unlikely because of the experience of claimant firms:

They know that they're dealing with specialist firms... Even if we don't have the notes, and even if we don't have an expert's report they're going to know that this is probably something that we have seen before, we know that there's been a breach of duty and we know it's winnable. So if you're asking whether... they give me a vague response in the hope that l'll go away and not investigate further the answer is 'no' (Claimant solicitor)

The rarity of full admissions did not preclude early settlement. One solicitor who reported that defendants would rarely do more than admit negligence but deny causation, could not think of any cases where there had been a need to issue proceedings after a Part 36 offer had been made by the firm and met with a counter offer. Part 36 offers and settlement are discussed more generally in Chapter 3.6.

Another claimant solicitor reported that very few, if any, admissions had been received in response to the letter of claim. In some cases, the response would be, 'we'd better discuss this' rather than a clear admission. Inconsistent messages were also being received from defendants as they had been prior to the reforms:

We got two letters back in response to the letter of claim, one going through it all and absolutely denying it, and a letter attached to it saying, 'well, we deny it but we can make an offer of a hundred thousand at this stage'... That was from the solicitors. So on the one hand they were... keeping their options open by denying it officially whilst at the same time sort of going, 'yes well okay, we concede there might be, we'll give you this'. (Claimant solicitor)

Two claimant solicitors echoed this view, having been surprised and disappointed that admissions were being withheld for so long in cases which, in their view, could not be defended. In one case, an admission was received 10 days from trial in a case where the consultant involved had advised the claimant to sue.

One defendant solicitor explained that offers of settlement might be made without admissions of liability where, on the face of it, the case appeared defensible but the witnesses might have moved abroad or there might be difficulties with the levels of experience of the clinicians concerned. Putting this all in the balance, an offer might be necessary. Claims managers 
confirmed that whilst they might admit breach of duty, it was not usual to admit causation as well. One claims manager explained that the admission might be couched in more neutral terms for the benefit of the clinicians involved:

Sometimes the clinicians are kind of accepting enough to know that there's enough area of doubt that we're going to have to pay but they're reluctant to be perceived [as] negligent.

Another explained the reasons behind the approach of reserving judgment on causation as economic and pragmatic:

We will get off early admissions of liability or breach of duty which I will always declare without any commitment to causation or damage. So I'll admit the breach of duty so we get that out of the way and they don't go and expend money on... liability experts, but obviously reserving my position on causation and damage and loss. Because... you might be able to admit breach early but until they share with you certain information you really cannot assess causation or the quantification of a claim. (Claims manager)

\section{Timing of admissions}

Where admissions were being made, the timing varied. One view was that they would be made on receipt of the request for records, and another where there was to be an inquest - an early admission would avoid publicity in these cases. One solicitor said that, apart from an isolated case, admissions were not being made any more regularly than prior to the reforms - there were now approximately 5 per cent admissions sooner (i.e. earlier in the timescale) than previously. There was some evidence that admissions were being made more often in lower value claims where proportionality was likely to be the motivating force.

This claims manager reported that admissions of breach of duty were being made at an earlier stage:

I think we're doing it much earlier in the process than we were before and I think, where we're unsure, we're making more effort to be sure one way or the other earlier. Because at the end of the day, if they were a good firm of claimant solicitors, they're going to get you to admit breach of duty at some point anyway. So I doubt that we're admitting it in more cases, I suspect it's at a different stage, it's at an earlier stage if anything that we might be admitting it, if we're convinced that they're a serious claimant. (Claims manager) 


\section{Summary}

Generally, comments were positive about the use of the Law Society/ Department of Health request-for-records form, although its use was still not universal. There was a clear feeling among claimant solicitors that the mechanics of releasing medical records within 40 days were working well: records were generally dispatched in time or clear reasons were given for the delay. Although claims managers were less confident of their ability to release the notes on time, applications for pre-action disclosure were now rare.

When the Clinical Disputes Forum reviews the operation of the protocol, it should consider whether there should be a mechanism for informing the healthcare provider from whom the records are sought that the patient had received treatment elsewhere. Consideration should also be given to the practicality of instituting a fast track system for obtaining the records where the client was terminally ill or where there were limitation problems.

There is a tension between keeping costs down and investigating claims following a request for records. In the light of tighter timetables and the need to respond substantively to letters of claim, claims managers were careful to screen requests for records and to maintain good communication with medical records departments to ensure that likely claims were investigated. There was some evidence that a greater number of potential claims were now being investigated.

There were mixed views on the effectiveness of the letter of claim. On the positive side, there was a strong sense that providing detailed information about the claim in this way opened up the potential to settle at an earlier stage. On the negative side, there were concerns that it was of limited use in larger claims where the complexity of the issues and difficulties in quantifying the case at this stage made settlement far less likely. Contrary to the intention of the protocol, letters of claim are being regarded as a trial run at the particulars of claim: here again there are implications for increasing the costs of the claim. Claims managers and defendant solicitors confirmed that detailed letters of claim served to clarify issues and promote earlier settlement. However, compliance with the requirements of the protocol was not uniform. There were also differences in opinion as to the extent of the evidence that should accompany the letter. 
The protocol does not specifically require the letter of claim to contain details of the claimant's case on causation. It refers more generally to 'allegations of negligence' and it appears claimant solicitors are taking this to mean allegations of breach of duty only. This is an area of the protocol that could benefit from greater clarification. At present the letter of claim template in the protocol lists schedules of loss and supporting evidence as possible enclosures. Consideration should be given to issuing further guidance to claimant solicitors as to when such enclosures should be supplied.

Letters of response were not always provided within the stipulated three-month period, but requests for extensions were generally acceded to. Most of the defendant solicitors and claims managers found the three-month period insufficient in all but the most straightforward cases. Whilst it is clear that there are difficulties involved in meeting the time limit for a letter of response, the system for seeking and granting extensions of time in appropriate circumstances appears to work well. For this reason, we do not recommend any changes to the present arrangements.

Whilst defendant solicitors reported that they were providing full letters of response, claimant solicitors had mixed views on their effectiveness. This stage also appears to be of most benefit in lower value, less complex claims, where it was most likely to lead to settlement. As might have been expected, there were few admissions of breach of duty and causation in letters of response; defendants tended to admit breach but deny causation. Again, this was more likely in lower value claims. In some cases, admissions continued to be made at a very advanced stage of the claim.

Overall it appears that the protocol works well as a framework for the early exchange of information. All parties were conscious of the timetables and were striving to meet them. There are isolated cases of tactical use of the timetable and failures to provide information. It is arguable that the protocol's main significance is in its application to low value claims. Settlement at this stage is unlikely with more complex high value cases, although the exchange of information about the issues remains of benefit to the parties. 


\section{Chapter 3.5 Expert evidence}

Medical experts are central to clinical negligence claims. Breach of duty is established by the claimant proving that the defendant has not acted in accordance with a practice accepted as proper by a responsible body of medical opinion (the Bolam test ${ }^{42}$ ). Both parties will call evidence to demonstrate whether such a body would support its conduct. This concept, based on adversarial principles, is central to any clinical negligence claim.

The protocol recognises this premise and, unlike its personal injury counterpart, it does not prescribe a framework for the parties to agree experts. It does, however, imply that the parties should consider joint experts. It states that:

Decisions on whether experts might be instructed jointly and on whether reports might be disclosed sequentially or by exchange should rest with the parties and their advisers. Sharing expert evidence may be appropriate on issues relating to the value of the claim. However, this protocol does not attempt to be prescriptive on issues in relation to expert evidence. (para. 4.2)

The first section of this chapter, looks at the extent to which the use of experts and instructions to experts have changed as a result of the Woolf reforms. Next, the extent to which interviewees had experience of joint instructions to experts is discussed and their views on this process are examined. Finally, many respondents were keen to discuss meetings of experts and matters relating to expert evidence during litigation, which fell outside the remit of this research. However, given the importance of these areas to respondents and their impact on perceptions of the reforms as a whole, it seems important that they should be mentioned.

Generally speaking, the views in this chapter are those of practitioners. As previously explained, the claims managers interviewed had very little, if any, experience of instructing experts. Whilst they did express an interest in doing so, at present this was a task passed to solicitors when it became necessary.

\section{Changes to the identity and use of experts}

A strong theme which emerged from the interviews was that the identity of the experts instructed in clinical negligence claims had changed post-Woolf as they had done in personal injury claims. Individuals who had previously 
been noted for a strong claimant or defendant bias were not receiving instructions. Generally it was agreed that the 'extremists' and the 'hired guns' were no longer being used. One reason for this was that it was easier to discredit such experts and, in clinical negligence, the identity of the expert was of crucial importance. This change was not necessarily linked to the reforms. As one claimant solicitor put it:

For us, experts have always been so important. In clinical negligence litigation having good independent experts who are saying what they're saying because that's what they know and that's what they believe, rather than because it's what you want to hear, is what is necessary in order to win a case. (Claimant solicitor)

However, this view was not uniform; this solicitor thought that some of these experts were still being used:

I'm sure every solicitor you interview... would be able to give you a list of totally biased experts, and we all know who they are, I'm sure the courts know who they are, unfortunately some people are still using them. I can't imagine why... sheer madness... and I'm sure they are on both sides. (Defendant solicitor)

The knock-on effect of this was that there was a smaller pool of experts from which solicitors could choose and that this was becoming an increasing problem as they became 'fed up' with the CPR and thought they were 'too bureaucratic':

They can handle less, just like we can handle less cases. Because they know that once they get a case, it's not a case of just looking at the records quickly, examining him for an hour and then doing a report in an hour and get rid of the file. They know that that case will then produce experts' meetings and all sorts of things, telephone discussions, whereas it never happened before. So they can't handle as much and there aren't that many experts that want to come flooding into this work. (Defendant solicitor)

Another marked concern was that experts' obligations under the CPR were greater than previously. One claimant solicitor thought that experts were 'starting to completely sink with the additional administrative work'. Another view was that experts had not taken on board the full implications of the CPR:

It's made life even more difficult in fact, when you try to keep to timetables for experts and you ring up and 'oh they've gone on a lecture tour of Canada for the whole of August'. And... I'm not entirely sure that experts have taken on board how... important it is and... they do the report and then the next thing they expect to see you in court. And I'm not sure they realise just how serious it is that they're available. (Claimant solicitor) 


\section{Content of instructions}

Most of the solicitors indicated that the reforms had not altered the way in which they drafted instructions to their own experts lother than reminding them of the requirements in Part 35 relating to expert reports). One solicitor referred to changes in instructions linked to the overriding objective of the reforms:

One of the other things Woolf is asking us to do is to be a bit more... critical about what's relevant... You shouldn't send them everything all the time because otherwise it's too expensive... perhaps that has made us ask, 'do we actually have to do this?'. Because we had this... Rolls Royce way of approaching everything and... you'd send the expert everything and... five volumes of lever-arch. And we do now try and produce core bundles on appropriate cases and perhaps from a cost-cutting point of view, try and hone in on what he actually needs to see rather than worriedly giving him everything just in case there's something on page 3,002 that you hadn't thought about. (Claimant solicitor)

Another potential problem is that Part 35.10 provides that the expert must refer to all documents relied upon to produce the report. The opposing party might then request sight of any documents referred to which may not have been finalised and therefore not yet disclosed. There was some concern that these rules might limit the free flow of information between solicitor and expert. One claimant solicitor no longer asked the expert "can you advise us, if you were a defendant what would be an arguable defence to this?'. Another was also concerned about this aspect of Part 35:

There's no question of holding back on asking them questions or anything like that because you've got to explore it thoroughly. I think l'd be more reserved about what I showed them after they'd produced their report or what I showed them in order to produce their report. (Claimant solicitor)

Another concern was that the rules limited discussions with experts. Previously, it would be possible to send a report that the solicitor was uncomfortable with (for example, if the expert had not really addressed the issues) to another expert for comment. This might not be possible now as the provisions of Part 35 mean that the solicitor might then have to disclose to the other side the original report that they did not want to use. One potentially costly way around this problem was to go through the case with a medical advisor prior to sending out the instructions. 


\title{
Joint reports
}

\section{Liability}

We discussed the extent to which parties were agreeing to use a single joint expert in clinical negligence cases. There was a strong sense that all parties were against the use of joint experts. Such arrangements were predictably rare and used only where the trust was, in effect, not contesting liability. This claimant solicitor explained the resistance to joint experts on liability:

\begin{abstract}
It's infinitely better for me to have my own expert, that I can talk with off the record, that I can have in a conference with counsel, that I can say, 'well, what are the real strengths or weaknesses with this?'. That relationship is compromised if the other side have access to that expert. It's the conflict between the fact that we're operating an adversarial system and that's pushing us towards some sort of inquisitorial thing. Where you have experts who are arbitrators between the two, and they're... the experts are deciding. I think... I would be losing... one of the weapons in my armoury if I relinquished my right to have experts on my side. (Claimant solicitor)
\end{abstract}

One defendant solicitor was in the process of appealing, together with the claimant's solicitor, an order for a joint report on liability and causation made by a district judge. A third solicitor also referred to district judges who sometimes made these orders.

\section{Quantum and condition and prognosis}

There was more experience, on both sides, of instructing joint experts on issues relating to quantum or on condition and prognosis. Here, too, the court was increasingly intervening to order such reports. As one claimant solicitor put it:

On complex cases where there is a lot of care and therapy required, then you're really going to have to come up with a good argument as to why those experts should be instructed singly rather than jointly.

Some of these experiences had been positive. One defendant solicitor who considered a joint report quite useful for condition and prognosis usually chose to draft the instructions, and insisted that the expert sent out the report simultaneously to both sides. It appeared that the selection of experts did not cause many difficulties: here too, the demise of the partial expert made agreement easier. Another solicitor indicated that there was a team of about 
30 experts on quantum who are known to all the courts and are extremely good. If one of these individuals is nominated, there will generally be no objection and they will be instructed jointly.

Even where it is possible to agree and formulate joint instructions, there remains a fundamental variance in the aims of claimant and defendant practitioners. The practicalities of achieving these aims with jointly instructed experts was discussed with respondents. One claimant solicitor said that this could be done by asking questions in correspondence and by copying in the other side. However, the solicitor pointed out that there might be some sharp practitioners around who might not do that: 'These are experts you talk to about other cases... it can be easy to sort of sidestep the rules a bit really.'

Another solicitor highlighted some of the other practical difficulties associated with joint instructions:

I do have the most awful arguments with the other side about what is going in the instructions and the enclosures and the client's statement. Because they always say 'it's... too evocative'. I say 'it's my client's statement, you can't tell them what to say, it's merely a statement'. And we have dreadful arguments about how it should be phrased and what questions we should ask. But I tend to win out on the basis of joint instructions, you can say what you want, I can say what I want, and it's merely making sure we say everything that everybody wants but you cannot vet what I am saying. It's just not appropriate.' So I tend to win the day but it adds to the costs. (Claimant solicitor)

A third solicitor had experienced difficulties in following up issues raised in the expert's report:

[The instructions were] agreed between the two of us, and cooperation certainly helps... it's sensible... just, this is what we suggest, what do you think?'. That's been quite enjoyable on occasions to see... how they do their letters of instruction. It's quite a learning curve to see their input that they give to a letter... Where we get into difficulties is where... I get the report and I want to ask the expert something and how do you copy that in? Strictly speaking you should, but... I'm a telephone person which makes it a bit more awkward, so you have to have quite a note that you've made. But what I found was on the jointly instructed [expert] on one case, both of us were ringing him up and he would report back to us. Not because he felt he had to, just because he did, and it made for a muddying of the waters really. (Claimant solicitor)

One consequence of a joint report is that the expert might view their obligations differently. One claimant solicitor had been discouraged from agreeing a joint report in future, based upon the expert's comments: 
I've had some experts who do actually say the content of my report is different on a joint instruction', which is quite disturbing really, i.e., 'if you'd instructed me I would have gone for the optimum and I'm going for the middle road,'... Well... maybe settlement would have achieved a middle road anyway, but I'm a bit uncomfortable about that really... and again the Woolf rules require that it's a range of opinion. But he's not giving a range, he's just giving a middle ground because he's jointly instructed. So I think that's... slightly perturbing from my point of view, and having had somebody honest enough to tell me that; yes, I wouldn't go joint instruction again on quantum or in a large case. (Claimant solicitor)

Another claimant solicitor had had to pacify jointly instructed experts who were concerned about their duties to both parties, particularly in relation to attending conferences:

Where I perceive it's not going to work... is in large cases, even quantum cerebral palsy cases, where already the experts are starting to say we're uncomfortable about coming to a con[ference], because how can we come to a con[ference] when we're actually... reporting to another side as well?'. Now I keep reassuring them 'in duty to the court you'll be saying the same to us in these meetings as you'll be saying to them. How can we prepare your case if we don't have access to you?', and I forged on and arranged a con[ference] with all my jointly instructed experts, and just told the other side that that was what I was doing and didn't anticipate that they'd have a problem with that. (Claimant solicitor)

The Court of Appeal has recently addressed this question of conferences with jointly instructed experts, holding that it would be inconsistent to allow one party to conduct a conference with joint experts in the absence of the other, unless all the parties agree in writing. ${ }^{43}$

At the time of writing, the Clinical Disputes Forum is consulting with its members on a series of guidelines for instructing single joint experts in situations where the parties had agreed or the court ordered that a single joint expert should be instructed. This initiative is to be welcomed. The CDF should review the issues raised here when finalising the guidelines and consider whether further specific guidance to experts is required in these circumstances. 


\section{Meetings of experts}

The court has the power under Rule 35.12 to direct a meeting of experts at any stage of the proceedings. As stated above, whilst this aspect of the CPR did not fall within this research remit, it was an area mentioned by many interviewees when giving their overall views on the reforms and for this reason it is included here. Three sets of guidelines on experts' meetings have been formulated. The Code of Guidance on Expert Evidence was issued in December 2001 and relates to expert evidence generally. It was produced by a working party set up in 1997 by Sir Richard Scott, then Head of Civil Justice. The Academy of Experts has produced its own guide, which is also in use. Finally, the Clinical Disputes Forum has also published draft Guidelines on Experts' Discussions in the Context of Clinical Disputes. This has yet to be finalised.

All but one of the practitioners interviewed had experience of these meetings and, generally, the view was expressed that they were increasing. As one solicitor put it: 'You won't get up to trial without having said "my experts have met and this is the outcome"'. Views on the value of experts' meetings varied. Defendants were more positive: one said that they could be productive and another thought they were one of the more positive things about the Woolf reforms. One claimant solicitor thought they could be helpful but, where there were two very distinct reports to begin with, experts tended to stand by their reports and settlement was no closer. A strong criticism was the time, effort and difficulty involved in arranging meetings.

\section{Presence of solicitors}

There has been some debate in relation to the question of whether lawyers should attend experts' meeting. The CDF advocates a default position; that the lawyers should attend unless all the parties agree or the court orders otherwise. If lawyers do attend, they should not normally intervene save to answer questions put to them by the experts or advise them on the law. A major issue for many of those interviewed was the presence of solicitors at these meetings. One defendant solicitor felt it was claimant solicitors rather than defendants who preferred to have solicitors present:

From the defendant point of view they feel that the experts should discuss amongst themselves and forget the legal people. The claimants say we want to be there because if our expert shoots us we want to find out why, we want to educate him'... I think defendants like to see an agenda and I think that that's 
a common ground between the two parties, but defendants often find, I suppose, that the claims are being promoted by the claimant solicitors, there's always that suspicion. (Defendant solicitor)

Our sample did suggest that claimant solicitors were keener on being present at meetings of experts, the main reason being the need to understand the case as fully as possible. One view was that, due to the sensitive nature of these claims, it was important not to have the case resolved behind closed doors:

We've always argued that solicitors should be there... for both sides really... We're conducting the case, we're central to the case, and it's completely inconsistent with the idea that you're managing a case that something should happen that's behind closed doors. Also it's completely the antithesis of what should happen in [a] clinical negligence case, because it arises on the claimant's behalf, because doctors have made decisions effectively behind closed doors... It fundamentally flaws what the whole business is about if experts are allowed to have secret conversations... I'm supposed to be managing the case and know everything about it on behalf of my client. I can't do that if there are meetings going on, that I don't know what the conversations are. (Claimant solicitor)

There was also the concern that more junior experts could be pressurised by their more senior colleagues to accept a viewpoint they had initially criticised. The meeting was an important opportunity to assess how likely the expert was to perform well in court in the face of opposition. The same claimant solicitor continued:

You also get to see the dynamics of the relationship between the experts, because often they know each other, often there's one-upmanship... I know him... he's a big player in this field, I defer to him'. Or, 'I'm a bigger player, he defers to me'. All of that kind of psychology is all actually very important in your assessment of the case, on whether your expert's going to go wobbly when he gives evidence. So the dynamics of the relationship between the experts is hugely important. Partly you're listening to what they're saying, but also you're watching them to see how they're coming across really. (Claimant solicitor)

Another claimant solicitor had asked the court to have solicitors present at a particular meeting of experts. This was to avoid the younger expert feeling intimidated, to enable the solicitor to understand the issues, and to ask the experts to explain matters factually in a way a judge could understand. This application was granted. When the solicitor did attend 'there was all sorts of bullying tactics going on there'. 
A defendant solicitor, who had attended one meeting at court, found it illuminating, because for the first time I realised just how little experts knew about the Bolam test'. Nevertheless, this solicitor continued to think that the meetings were better without solicitors present. However, it was essential to have a clear agenda setting out the test for experts to apply and the questions to have in their minds as well as arranging for a trainee to attend to take notes. There was a clear consensus that such agendas for the meetings were crucial, but arriving at an agreed agenda could be time consuming and difficult:

First we have to agree an agenda. Which I insist on having an input into. And there have been furious arguments. And in the end I do the same that I do with my letters of instruction, I say you ask all the questions you want to ask and I will ask my questions, and if there are overlaps we will say this is coming from this side, this is coming from that side'. And I have been gleeful in saying 'I do note that neither expert was able to answer your question seven that I didn't want going in, in the first place'. So it's spatting behind the scenes. IClaimant solicitor)

Some solicitors thought that the experts themselves preferred the solicitors not to attend. One claimant solicitor said 'experts tend to prefer not to have solicitors there, it cramps their style'. Another said:

The experts might feel that it's difficult to for them to discuss the issues openly because they've got the claimant's solicitor and the defendant's solicitor watching them like hawks. (Claimant solicitor)

However, a third solicitor who 'battled' on each and every case to attend reported: 'All the experts that I work with do say: "We're very glad of you being here. Because otherwise we've made all that effort, we've travelled a long way and the case won't be as productive if you can't be present."'

Not all meetings of experts were in person; some solicitors had had experience of meetings by telephone. Whilst this was cheaper, it was not seen as being as effective:

I much prefer the experts to meet in person if possible. And I know that's more expensive but it pays dividend. And if it sees the end of a claim, whichever way it goes, it's got to be money well spent. My experiences of telephone experts' meetings are that the two aren't necessarily looking at the same documents, that one of them isn't really concentrating on it. It's all far too flippant and it's an important thing. (Defendant solicitor) 


\section{Effect on costs and settlement}

During the interviews, the extent to which meetings of experts had an effect on the costs of the case was explored. Generally, respondents felt that meetings of experts increased the cost of claims. The main reason for this was the time and effort involved in arranging the meetings and the experts' time in attending. As one claimant solicitor put it, 'experts' meetings are quite expensive. Very expensive and valueless... It's a really time-consuming nightmare'.

Another solicitor was able to put an actual figure on the cost of organising such a meeting:

But the cost of actually organising the experts' meetings... one expert who doesn't have a diary that's accurate or up to date, or liaises enough with his secretary, one piece of information that's wrong will have a knock-on effect... And if you don't have a cooperative expert on the other side or your side, whoever it is, it could easily amount up to an extra $£ 1,000$ profit costs just by the amount of calls that have to then be done to try and rework it all. (Claimant solicitorl

Another view was that, despite the additional cost, if the agenda was tightly constructed enough, it should be possible to determine the success or otherwise of the claim at the end of the meeting.

\section{Summary}

Generally, the identity of experts used in clinical negligence claims had changed: with some exceptions, those traditionally known to have a claimant or defendant bias were no longer instructed. As a result, the pool of available experts had been reduced. The additional administration and obligations that the CPR placed upon experts also made them less willing to undertake medico-legal work. Whilst the CPR had not generally affected the content of the instructions, some solicitors were more cautious about the enclosures sent to experts.

Generally joint experts on liability were rare (and not agreed) but some solicitors had experience of district judges making such orders. There was more experience of joint instructions to quantum experts. Here, too, the courts were driving this approach and some solicitors found this to be a positive move. Nevertheless, formulating joint instructions could be difficult, with the claimant seeking to maximise the claim and the defendant to minimise it. So too was arranging to obtain follow-up information from a 
jointly instructed expert. There was some evidence that the experts themselves found joint instructions difficult, particularly where they were asked to attend conferences with one side and then the other.

At the time of writing, the Clinical Disputes Forum is consulting with its members on a series of guidelines for instructing single joint experts in situations where the parties had agreed or the court ordered that a single joint expert should be instructed. This initiative is to be welcomed. The CDF should review the issues raised here when finalising the guidelines and consider whether further specific guidance to experts is required in these circumstances.

All but one of the solicitors interviewed had had experience of meetings of experts; the courts were driving this approach. Defendants were more positive about the value of such meetings. However, there was strong criticism of the time, effort and difficulty in arranging the meetings. One issue of particular concern was whether solicitors should be present at the meeting. Broadly speaking, claimant solicitors were more in favour of attendance than defendants. It was agreed that carefully drafted agendas were an essential part of the process. Respondents largely agreed that experts' meetings increased the cost of claims. Where the experts had entirely opposing views, the meeting was unlikely to provide a means of resolving the claim or issues within it. 
Research Study 43 More Civil Justice? The impact of the Woolf reforms on pre-action behaviour 


\section{Chapter 3.6 Settlement}

This chapter is in four parts. It begins by discussing whether there is evidence of a shift to a settlement culture and explores what factors are driving the parties towards settlement. It also investigates whether it is claimants or defendants who are leading the way towards settlement.

Secondly, claimant offers under Part 36 of the CPR are discussed. Whilst claimant lawyers have always had the ability to offer to settle a claim for a certain sum, Part 36 formalises the process and imposes penalties on defendants who unreasonably decline claimants' offers. Respondents' thoughts about claimant offers, when they were used and their effect on settlement are also examined.

The third section looks at whether there have been any changes in the way that defendants make offers.

Finally, respondents' experiences and views on mediation are explored.

\section{A shift to a settlement culture?}

Many of those interviewed reported an increased incidence of settlement, although this opinion may be based on several different factors. Respondents might perceive that a greater number of settlements are occurring because this is happening earlier in the process than previously. Indeed there was evidence that settlement was occurring pre-issue. One claimant solicitor reported issuing in fewer cases and estimated that at least 50 per cent fewer cases were now being litigated. A defendant solicitor had also found that the number of cases in which proceedings were issued had declined. Fewer cases issuing may be due to early offers of settlement in response to the letter of claim.

Other reasons may explain the perception of an increased incidence in settlement. The letter of claim stage requires claimants to be much clearer and more certain about their cases because they will have conducted a thorough investigation. As a result, a greater number of cases may be abandoned before getting to this stage which would have survived the writing 
of a letter before action. The cases that remain may have more merit and therefore be more likely to settle. Finally, there was a feeling that settlement is achieved by a process of discussion and thought rather than attrition.

The main changes thought to underlie a shift towards a settlement culture are discussed below.

\title{
'Cards on the table' approach
}

The reported increase in the incidence of settlement was attributed to a variety of factors. A 'cards on the table' culture was described as a major factor promoting settlement. Where the parties are prepared to communicate and exchange information about a case at an earlier stage, they are more likely to identify contentious issues and, where these can be resolved, to compromise the claim and so avoid the issue of proceedings. Earlier information about the defendant's case might also lead the claimant to decide not to proceed with the claim. This claimant solicitor complained that a 'cards on the table' approach did not work pre-Woolf. However:

\begin{abstract}
Now of course you get... a good indication up front as to what their case is about. You can go and discuss it with your expert. Your expert may say ' $h m m$, yes, they've got a point,' and we might not proceed with the case. Or he may say 'well that's rubbish' and he will comment upon it. And we'll go back to them before we issue saying 'well, we've discussed your response to our protocol letter with our own expert, he says this, we invite you to reconsider your position'. And they might, and the case might settle. (Claimant solicitor)
\end{abstract}

Another view was that the change in culture was already beginning to pervade this type of litigation but that the reforms had helped to encourage it and had created penalties for those who did not adopt it. The extent to which such penalties have permeated the system are discussed below.

\section{Part 36 offers}

There was a strong consensus that claimant Part 36 offers were also a crucial element in promoting settlement. Part 36 offers are discussed in more detail below, but there was a clear sense that they concentrated defendants' minds on the value of the claim, forcing them to be 'more financially aware'. The economics of the case were seen as the basis for decisions about settlement:

The Part 36 offer... just concentrates the mind... It's like the old days when you had the payment in, that is the point that you would very seriously think about quantum because you have something to work on that's concrete really, and I think the defendants see it that way as well. To them it's all important what 
price tag's attached to it; they won't even consider settlements until they really know, because often the hospitals have excesses... that determines whether they're going to settle within the excess, [or] not within the excess, whether they're going to the NHSLA... And the sooner we tell them how much we think the price tag attached to it is, that does seem to move things along. (Claimant solicitorl

\section{Proportionality}

Despite the potential for costs to exceed damages, particularly in lower value claims, only one respondent, a claims manager, cited proportionality as a factor driving settlement:

I think people can very much see the rationale behind not allowing costs to run out of control so that the costs exceed the settlement... so there's that kind of realisation, why let it drag on and on and on if you know early on that you're going to settle?

\section{Specialisation}

However, factors which were not directly linked to the protocol or the reforms were also put forward as justifications for an increased willingness to settle. One of these was the increased specialisation amongst firms:

I am seeing... slightly more... cases of people willing to settle. But whether that's due to Woolf or whether it's due to the fact that in London you know each other and you think 'oh, so and so's on the other side, they generally know what they're talking about'... if they say there's a case then there probably is. (Claimant solicitor)

\section{Defendant case management}

One of the claims managers cited the NHSLA 'wanting to see action' as a factor in promoting settlement. Claimant solicitors also cited the influence of the NHSLA on defendant solicitors as another factor. Settlements were also said to be more likely once the trust passed the claim to their solicitors as the latter were aware of 'court attitude' to deserving claimants in need of compensation:

The cases where it's clear that something has gone wrong are on the whole settling earlier and I think on the whole the NHSLA has made the defendant firms... take a more realistic attitude towards offers which are now, on the whole, better judged than they used to be. (Claimant solicitor) 
Whilst pragmatism and economics featured strongly as factors motivating early settlement, this claims manager pointed to wider, more idealistic concerns. The effect of clinical negligence claims on individual members of staff was also borne in mind:

Our ethos, morally and ethically [is that]... we all believe that if somebody is entitled to something, they're entitled to it, and if you can give that to them sooner rather than later it's better for all concerned... But we mustn't forget the staff in that... they don't want something hanging around forever... even if it's an unfortunate situation where... it is deemed that they didn't do what they should have done. (Claims manager)

\section{Value of settled cases}

There were mixed views on whether higher or lower value cases were more likely to settle. One claimant firm was finding smaller claims more difficult to settle: whilst with larger claims there was a tendency to want to get them settled and out of the way, defendants had a tendency to think that holding out and running up costs might make the claim go away. However, a more widely held view was that lower value cases were settling sooner into proceedings, if not before issue: higher value claims were more difficult to quantify until a later stage and therefore less likely to reach an early compromise.

Despite the generally positive picture that settlements were easier to negotiate and therefore more plentiful, some defendant solicitors were more cynical about the motives of claimant firms:

There's a fundamental dichotomy between the aims of institutional defendants and claimants or particular claimant solicitors... For a claimant solicitor there is a positive incentive to draw claims out, to make them last as long as they possibly can. A common tactic... is for claimant solicitors to put in a claim, to delay settlement as long as they can, to change the value of the claim, to change the type of claim that it is, because that way the costs will creep up gradually... I don't say this of all claimant solicitors, there are plenty who believe that their clients' interests are in a quick settlement, but there are also plenty who believe that a full, comprehensive and lengthy investigation of a claim is in their client's best interest. In reality it's in their best interest because it generates more money for them. That is why, for example, it is frequently almost impossible to settle a claim early on by negotiation. Because the claimant solicitor will say, well, we had to get counsel's advice, we had to get an expert's advice, because we will be sued by our client if we get it wrong'. (Defendant solicitor) 


\section{Claimant Part 36 offers}

\section{Claimants' views}

Respondents' views on claimant Part 36 offers and the extent to which they were being used were investigated. The ability to make these offers was regarded by many claimant solicitors as one of the most positive aspects of the reforms. There was a general feeling that they had gained a new element of control over the progress of the claim. As one claimant solicitor stated: 'I've always wanted the ability to be able to ask for how much I want, because... I've been frustrated by the waste of healthcare money.' Quantifying claims in order to make Part 36 offers could, however, lead to additional burdens on solicitors. One solicitor summed up the pressures involved:

The whole thing... has required us to quantify cases earlier and we have a real problem with that because we are caught between being expected to know everything about the case before we start and being severely cost limited on publicly funded cases and also on privately funded cases... What we haven't ever done in the past is to put forward a figure, we've responded to a figure. And it is quite nerve-racking actually to say to the client, right, I think you should do this, I think you should make this offer'. You have to calculate it, you have to discount appropriately with the litigation the risk of proving particular elements of the claim. That is a change in culture for us but... maybe it's forcing us to take responsibility for our client's position... rather more than it was. (Claimant solicitor)

All but one of the claimant firms involved in the research were making Part 36 offers. Some of the respondents were particularly enthusiastic, referring to them as 'marvellous', 'wonderful', and having 'transformed claimant litigation'. One solicitor was using Part 36 to make offers on liability. As to the timing of the offers, several claimant solicitors reported making offers in the letter of claim. One reported 'always' making Part 36 offers at this stage (although cerebral palsy cases were the exception). As the majority of the work on the case had been done, there were clear incentives to do so:

The protocol says that we've got to quantify it in broad terms for the defendant anyway so we've got to give them a good idea of what it's worth, and if we've got to do that then why not make a Part 36 offer? Assuming your client is willing to accept your advice on the value of the claim, why not? Because the benefits to us are quite great. We would not be looking at taxing our costs only on the standard basis... we would have the benefit of the doubt on the value of the work that we've done and why. (Claimant solicitor) 


\section{Timing and tactics}

The timing and tactics of making a Part 36 offer may be linked to funding. One solicitor worked pro bono on cases which did not qualify for public funding, sending a letter of claim with a Part 36 offer on the information available. Another solicitor echoed the view that problems with funding and proportionality were likely to lead to early Part 36 offers. The timing and tactics of a Part 36 offer may also be linked to the value of the claim:

Some of the lower value claims you'll go in very early and say: 'It's a waste of time, you've been arguing this, you've been getting reports on this, you owe me E2,500, now pay up.' And some of them do... I've also gone in with the bigger cases saying 'we can at least sort out this aspect of the claim', and I Part 36 as soon as I can on most cases... You can always withdraw it if you suddenly change your mind... with full client consent it can be a very useful tool. Which we've never had before, so it's an exciting new toy as far as I'm concerned... From a claimant point of view, you no longer have to sit there being shtum. You can make offers and you can continue to make offers. (Claimant solicitor)

However, this solicitor did not confine Part 36 offers to low value claims. She continued:

I do find... on more of my bigger cases we just kept repeating the same figure. I mean, you're daft not to accept it... what is your problem here? And it worked in the end.

\section{Effects on the bargaining process}

There was some evidence that the new formality of the process of making offers had affected the bargaining process. One view was that the old practice of presenting an inflated value of the claim as an opening position, which would eventually result in a settlement at the correct level, was no longer operating. Here the influence of guideline figures for general damages is clear:

Previously... we always over-egged the pudding for the purpose of negotiation... Now... we've got Kemp \& Kemp but, in particular, the Judicial Studies Board guidelines, everyone's got a copy of that within easy reach. What would be the point in me saying this case is worth 50 if these guidelines clearly show that it's worth 30, and Kemp \& Kemp clearly says it's worth 30... We tend to adopt a more reasonable approach to negotiating settlements in these cases... They know that if I make a Part 36 at 20 or at 30 or at 50 then that's the minimum that we're willing to accept. That valuation was based on the JSB guidelines, 
they will have gone away and looked at it and what can they say, what's the point of the defendant coming back trying to haggle me down? (Claimant solicitor)

A defendant solicitor also indicated that offers were more realistic:

Historically you would ask the claimant what money they want and they'd give you a ludicrous offer, if it was worth $£ 50,000$, they'd say it was $£ 100,000$ and hope we would offer $€ 75,000$. Now it's not really in their interest for that to carry on so much, it could go awry in terms of costs, so it's in their interest to actually put together a realistic figure.

However, there was other evidence that former practices were continuing. Another defendant solicitor commented: 'They pitch it high with a view to getting a deal at what they think is the right amount.'

One claimant firm preferred not to make formal Part 36 offers. Instead, the letter of claim would state: 'Our client will settle for compensation of $x$ reflecting the JSB guidelines.' There was a sense in the department that there was no need to use Part 36 and that this device was used more in personal injury claims. Later in the claim, a schedule, rather than a Part 36 offer would be used. Once submitted, the parties were 'kind of talking'. There was also some reluctance to put forward a figure for discussion:

You want to see what the other side will offer first. You don't really want to really do ridiculous Part 36 offers that are way above. Because sometimes your client's wrong or... they don't always tell you the right information. (Claimant solicitor)

\section{Responses to offers}

The responses that claimant solicitors had received to their Part 36 offers were explored. Here too there was positive feedback although, in some cases, defendants had been slow to respond, unless threatened with proceedings. There was also some criticism that, whilst defendants did not ignore Part 36 offers, where they had not properly investigated cases they would allow the 21-day period to elapse without appearing to be concerned about the consequences. Even so, the offer could also act as a catalyst for defendants to hurry up and think about it [the case] and try and get what further information they need in order to make a decision about the offer'. Another stated that a 'good number [of offers] are accepted'. If not, the offer served to 
prompt negotiations. '[You] often get the Dutch auction where they counteroffer you, but at least then you're in business and you're talking openly about it.'

Effective responses were not confined to defendant solicitors. Claims managers appeared less likely to counter offer: they would respond by accepting the offer or denying liability:

You don't need to be dealing with a lawyer at the trust for them to know what Part 36 is... these in-house complaints handlers at the trusts know all about Part 36, and they want to limit the trust's outlay if they can... I have to say, if I'm dealing with a trust I tend not to get counter offers. I often find that they just accept what I have to say. Or alternatively they just deny liability. IClaimant solicitor]

\section{Defendant views}

Broadly speaking, there was less praise for Part 36 offers amongst defendant solicitors and trusts. There was also much less experience of receiving them than the interviews with claimant solicitors would have indicated. One solicitor said that offers to settle in the letter of claim were rare: indeed, only one had been received. There was some scepticism about why the number of offers was low:

Does the claimant solicitor really want to settle that soon or would the claimant solicitor [like] to run up a nice little bundle of costs before they settle?... I wonder why we don't get more, but we don't. One thing I do find rather frustrating is if you've made a Part 36 offer to settle you don't even get a counter offer... If it's a case that they do want to settle, why don't they make us a counter offer? (Defendant solicitor)

Conversely, as noted above, another defendant solicitor had experience of Part 36 offers being made prior to release of the medical records. A third view was that Part 36 offers were more useful in personal injury claims than in clinical negligence where an expert's report was still required before the case could be quantified.

It might have been expected from the interviews with claimant solicitors that claims managers would report receiving a fair number of early Part 36 offers. However, this was not the case. Despite being warned to expect these offers in training sessions with panel firms prior to the introduction of the reforms, there was a sense amongst the claims managers interviewed that the predicted deluge had not materialised. One claims manager speculated that claimant lawyers were too busy with conditional fees and the greater 
throughput of work caused by CLS franchising. There was also a sense that claimant solicitors were reluctant to put offers forward because of a lack of information rather than a costs-building exercise:

You have to also be pretty sure about your case. Because if they make a Part 36 offer which is... completely wrong then it's certainly not in their interest... If they've made a Part 36 offer they've got to say what that was based on... how they're arriving at it, what their case is essentially. So they've got to know what the case is early on, before they do that. I suppose perhaps they've worried about showing what their case is very early on, unless they're really certain that it's something that can't be... defended. (Claims manager)

One claims manager indicated that Part 36 offers tended to be received later in the case than at the letter of claim stage. Receiving one at this early stage had caused some 'initial panic'. Another said the trust 'sometimes' received Part 36 offers: this might be where the solicitor did not have enough information and was 'trying it on'.

\section{Defendant Part 36 offers and payments}

Views on the tactics and timing of defendant Part 36 offers and payments were examined. Whilst the ability to make such payments is not new, one claimant solicitor was surprised that payments were still being made very close to trial:

Once the case has started litigating then I will find the defendant will make a Part 36 offer, either in correspondence immediately or certainly they make a Part 36 payment into court... It's quite surprising actually how many cases I still see in which defendants don't make Part 36 offers and don't make payments into court until very close to trial... It might have something to do with the experience of... the defendant's solicitors. It might be that they simply genuinely don't believe that the claimant's case has any realistic prospect of success.

Conversely, other claimant solicitors had been receiving pre-proceedings Part 36 offers from defendants. One had received admissions of breach of duty and Part 36 offers before the medical records were disclosed. This solicitor considered the offer was premature and it left them unable to value the claim. However, the solicitor conceded: 'It's a good tactic, if I was a defendant l'd use it a lot more.' Another 'worked on' pre-proceedings Part 36 offers from defendants to avoid having to issue at all. 
Defendants suggested that the detailed allegations in the letter of claim enabled them to make earlier offers. One solicitor was particularly positive about early offers. Although these were usually in the letter of response, they could on occasion accompany the case notes.

If you've already made some preliminary enquiries and you're worried and then [you] get a letter of claim which sets out in even more detail. And you think, 'well, they must have some evidence to back this up', you've got three months in which to go back to your clinicians on some specific allegations and make a Part 36. We make dozens and dozens [of] Part 36 offers of settlement. That's the best thing about the new rules. (Defendant solicitor)

There was some evidence that claims managers were also making early Part 36 offers. In one trust, such offers might also accompany the letter of response. However, these offers were confined to lower value claims.

\section{Effects on the bargaining process}

Defendants also suggested that their Part 36 offers were now more serious.

They were less likely to make a low early offer and then top it up later:

Other people may take the view, we're paying this, we're making this offer so early, we can really keep it low and just see how it goes'. I'm not doing that, I mean it as a serious offer... l've just rather shocked a claimant solicitor by paying in exactly the same sum as l'd offered... I think l've got good costs protection. (Defendant solicitor)

This approach was not confined to smaller claims, which are easier to quantify at an early stage. The NHSLA, which handles larger, more complex claims, has adopted a similar approach:

We try to not to drip feed payments in, we've always adhered to that policy. That's not to say we're not sensible if we've learnt something new, or it doesn't mean we won't negotiate but we don't do the whole insurance industry trick of... put 25 quid in and... top it up in 14 days if they haven't taken it. We set all our stall out. We think we've earned some credibility because otherwise... if people don't think you're acting in good faith... you might as well not bother. (NHSLA) 


\section{Penalties}

Whilst the costs consequences of failing to beat a payment into court are well known to claimant lawyers, there are new sanctions in the rules in terms of interest and indemnity costs which can be applied to defendants who unreasonably refuse a claimant's offer to settle. Claimant lawyers feel that these sanctions have served to enhance their bargaining position:

I think we've always just felt disadvantaged because... you could be sitting at your desk and the payment then arrives and you have to explain to the client that they are going to be penalised in costs and you've never had a comparative ability to penalise the defendants in costs. Well, the ability to penalise defendants in costs is slightly limited by the legal aid requirements but, nonetheless, we're conscious that we now have an equal power to force the defendants into considering the case at any stage that we choose and to take a view on the prospects of success and the value. And we are aware that that puts pressure on them and we're aware that it's a very valuable tool (Claimant solicitor)

Claims managers were particularly concerned about possible penalties of failing to respond to Part 36 offers. As one put it: 'the thought of any financial penalty would actually force us to want to adhere to trying to resolve the matter quickly.'

However, few respondents had experience of the courts actually imposing these penalties. Only one defendant firm had experience of sanctions being applied, although this was in a very limited number of cases. This may be because those interviewed were complying with the rules and acting upon offers made, or because, as presently drafted, the penalties in Part 36 apply only to cases which go to trial. One claimant solicitor hoped that there would be more reported cases of Part 36 offers where the costs consequences and injurious penalties were applied: this would be reassuring and would make them work more efficiently. Another thought that the penalties which could be applied to defendants were not as 'ghastly' as the claimant not getting their costs paid where they failed to beat a Part 36 payment. A defendant solicitor was concerned that the costs rules of Part 36 offers should be applied to claimants:

There are lots of cases... where I have made a very reasonable Part 36 offer a long time ago and a case had trundled on, trundled on, and it's eventually settled... And you think, 'well, I've got some arguments on costs here'. They then send you a whacking great bill in and you think, 'do I really want to go through all the hassle of arguing about this and taking this to detailed 
assessment? Will I really win, will I really get the court to say, 'well, they didn't need all this additional expert evidence and no, they didn't need to investigate it any further, ?' It's a risk. (Defendant solicitor)

There is some scope for reviewing the penalties attached to unreasonable refusal of Part 36 offers. At present the penalties apply only where the case goes to trial and, as such, the penalties are of limited effect in the majority of clinical negligence cases.

\section{Mediation}

The NHS mediation pilot scheme was launched in April 1995 in two regions. It was anticipated that up to 40 cases would be mediated over a two-year period but the scheme was extended another year as numbers of referrals were low. By the end of the third year, 12 cases had been mediated and settlement reached in 11 of them. Concerns about low take-up with the scheme were associated with reticence amongst solicitors to refer cases. (Mulcahy et al 2001)

Generally, respondents had little, if any, experience of mediation. Several solicitors agreed that it was most suitable for low value claims, particularly stillbirth claims and fatalities. They were also aware of the need to consider mediation to satisfy NHSLA and LSC requirements. However, there were a number of perceived disadvantages.

Some claimant solicitors felt at a disadvantage in mediation as the trust would have 'in-house expertise' to advise on the claim. Both sides cited cost as another disadvantage. A claimant solicitor who had been through the process said the costs were 'astronomical'. Both sides thought that mediation could achieve the same outcome as negotiation and, given that the latter was cheaper and did not involve any outside involvement, negotiation was the preferred means of concluding the case:

I don't really see what good it's going to do, because what is going to happen during a session of mediation that wouldn't happen during without-prejudice discussion between myself and my opponent? (Claimant solicitor)

My mind's not closed to it, but I cannot see the costs advantage... If I have a complaint or a claim that I'm asked to advise on, and I think it wants settling, I'll settle it. And I can't see why I would want to pay a mediator to do that job for me. (Defendant solicitor) 
As might have been expected, claimant solicitors blamed defendants for the low number of mediated cases and vice versa. A claimant solicitor who asked for mediation 'long before Woolf' said that such requests 'rarely met with agreement from defendants'. Another said they had been met with 'a pretty kind of frosty response from the other side'. The CDF questionnaire produced similar findings.

Defendant solicitors were more cynical of the reasons behind their opponents' refusals to mediate. These two solicitors thought that financial considerations for claimant firms were acting as a barrier to mediation:

All the mediations that we've promoted -we haven't had any of them taken up by the claimant solicitors... There is a saying that ADR actually stands for 'alarming drop in revenue'... for the claimant side. (Defendant solicitor)

One of the main difficulties we have is that claimant solicitors will not negotiate and will not mediate unless it is in their interests to do so. And that normally means, if the alternative is running up huge costs by protracted litigation, then they would rather go down that path. (Defendant solicitor)

A new NHSLA initiative, launched in Spring 2000, requires panel firms to consider whether mediation is appropriate and make recommendations to the Authority. LSC guidance applicable from June 2001 encourages greater use of mediation. It requires solicitors to consider ADR with clients, to keep it in mind at all stages of the case, and report to the regional office at appropriate stages explaining the reasons why it has not been pursued.

\section{Summary}

There was a strong sense that claims were now easier to settle and respondents reported a greater incidence of settlement. There may be several reasons for this perception: respondents might perceive that a greater number of settlements are occurring because this is happening earlier in the process than previously. Fewer cases issuing may be due to early offers of settlement in response to the letter of claim and cases that survive to this stage may have more merit and therefore be more likely to settle. Respondents might also perceive that settlement is occurring more often than prior to the Woolf reforms because it is achieved by a process of discussion and thought rather than attrition.

The increased incidence of settlement was attributed by respondents to the 'cards on the table' culture embodied in the protocol and, more specifically, the claimant Part 36 offer. Lower value cases were more likely to settle at an 
earlier stage. This is consistent with the fact that quantification of these claims is easier. However, some scepticism remained as to the motives of some claimant solicitors who might delay settlement of claims. Claimant Part 36 offers were regarded by many as one of the most positive aspects of the reforms. Often these accompanied the letter of claim as envisaged in the protocol. There was some inconsistency between the incidence of offers reported by claimant solicitors, and those received by defendants.

There was some evidence of altered bargaining practices: more realistic sums were being put forward and parties were less likely to offer to settle at inflated (claimant) or reduced (defendant) values. Experiences of defendants' responses to Part 36 offers were also positive. There were mixed views about defendant Part 36 offers and payments. In some circumstances these were still being made very close to trial, but equally there were experiences of early offers (even prior to the disclosure of the records). Penalties for unreasonable failure to respond to a Part 36 offer serve to enhance claimants' bargaining position and certainly affected claims managers' handling of cases. However, those interviewed had little experience of such sanctions actually being applied. It is difficult to establish whether the courts are in fact imposing these sanctions: it may be that this particular group had avoided them by complying with the rules and acting upon offers made. However, the penalties only apply when the case goes to trial. There is some scope for reviewing the penalties attached to unreasonable refusal of Part 36 offers to ensure their effectiveness in achieving early settlement.

There was very limited experience of mediation. There was some consensus that certain low value claims could be appropriate for mediation. Parties found it difficult to identify real advantages of mediation as settlement could be achieved through a process of negotiation without the need for an external mediator. Both sides were critical of their opponents' reluctance to accept mediation: defendant solicitors thought the other side's motivation for refusing was financial self-interest. 


\section{Chapter 3.7 Clinical negligence work: do the reforms meet their aims?}

Broadly speaking, the Woolf reforms and the protocol were positively received by all three groups interviewed for this part of the study. It is important to bear in mind the wider context in which the protocol operates when considering its effects. Together with the rest of the Woolf reforms it constitutes one of many developments aimed at addressing the rising cost of clinical negligence claims. As a result, it is often difficult to gauge whether changes in practice have occurred as a result of the protocol or are attributable to NHSLA requirements or funding issues.

Here we consider the evidence presented and evaluate whether the protocol is succeeding in meeting its aims. Changes are not uniform and, notwithstanding examples of good practice, there remain some practitioners who are not complying with the CPR or entering into the spirit of the protocol. Nevertheless, the overall picture appears a positive one. The Practice Direction governing the protocol includes objectives which are applicable to protocols in general. The protocol itself states its aims and specific objectives. The discussion here is presented thematically to encompass the aims and objectives of both the Practice Direction and the protocol.

\section{Facilitating settlement without litigation}

There was a clear sense that claims were now easier to settle and respondents reported a greater incidence of settlement. It is difficult to be certain exactly what is meant by 'more settlement'. It could mean fewer trials, fewer abandoned cases, settlements earlier in the process, more realistic bargaining strategies, or settlements arrived at through a process of negotiation rather than attrition. Interviewees' perceptions may be based on a combination of some or all of these factors. Thorough investigation is now required to produce the letter of claim so that cases reaching this stage are likely to have sufficient merit to make settlement more of a possibility. There is also evidence that settlement is occurring earlier in the process than previously and more often in lower value claims. 
There are several changes introduced by the Woolf reforms which would appear to lead towards a greater incidence of settlement. Firstly, a pervading culture of openness described below has contributed to a 'cards on the table' approach to claims. As a result, the parties are more likely to discuss claims and exchange information. Detailed letters of claim and letters of response oblige the parties to grasp the issues involved in the claim at an early stage. This in turn makes settlement possible at an earlier stage. The use of Part 36 offers provides a mechanism for the claimant to have some control over the settlement process. Finally, increased specialisation among practitioners encourages dialogue between knowledgeable colleagues.

However, some notes of caution must be sounded. The frequency of Part 36 offers reported by defendants and claims managers was much lower than the interviews with claimant solicitors might have led us to expect. Defendant Part 36 payments continue in some circumstances to be made very close to trial. There was very little experience of the courts applying penalties for failure to respond to a Part 36 offer or payment. This may be because the penalties are only applicable when the case goes to trial and are therefore rarely encountered. Alternatively, it might indicate that the penalties are working well to ensure that the parties comply with the rules and act on offers made.

\section{Is the culture more open?}

The perceived shift towards earlier settlement was accompanied by a sense that claims were being resolved in a less adversarial manner. The clearest impression of this was demonstrated in relationships between claims managers and claimant solicitors. The development of in-house claims management within trusts was a noticeable trend. As claims managers reduce their reliance on external solicitors, they have been able to strengthen their relationships with claimant solicitors. Those interviewed demonstrated the value of on-site claims management and of forging links between complaints and clinical risk departments. From April 2002, the NHSLA will handle all below-excess claims. It is difficult to assess the likely impact of this planned 'call-in' of claims, but the interviews demonstrated the value of the claims manager's role in maintaining relationships and reducing adversarialism in the process.

There was also evidence amongst practitioners of a greater willingness to engage with each other in resolving claims. However, old antagonism is difficult to cast off and negative comments frequently offset positive ones. 
Claimants reproached defendants for not being as open as they were. Defendants reproached claimants for seeking to prolong cases for financial gain. Both sides blamed each other for a reluctance to use mediation. Notwithstanding these obstacles, both sides could find themselves united in challenging case management decisions or working together to agree agendas for expert meetings.

There was a clear sense that the 'dabblers' in clinical negligence litigation were a thing of the past. A smaller number of specialist practitioners were better able to reach agreement on case management issues, to allow each other more time to comply with obligations to provide information, and to pursue clearer and more immediate strategies for dealing with claims. However, there was little evidence that the claims process had been subject to the same sort of routinisation pervading the personal injury market.

\section{Exchange of early and full information}

Here there was evidence that the protocol was working well as a framework for the early exchange of information. All parties were conscious of the timetables and were striving to meet them, although there were isolated cases of tactical use of the timetable and failures to provide information. The requirements for disclosure of medical records and letters of claim and response were regarded as facilitators for earlier settlement. Although changes to High Court clinical negligence litigation case management had already begun with Practice Direction 49, the protocol's requirements as well as tighter timetables had resulted in increased workloads for all three groups of interviewees. Some reported containing caseloads and recruiting staff.

There was little criticism from claimant solicitors relating to the provision of medical records, and applications for pre-action disclosure were predictably rare. If anything, claims managers were less confident of their ability to dispatch the records on time. Channels of communication between medical records, complaints and claims departments appear to be well established, with claims managers considering carefully which requests for records should be investigated. There was evidence that a greater number of potential claims were being investigated than previously. In lower value claims, this could enable the claims manager to make an early offer of settlement where the claim materialised, but would mean unnecessary work where it did not. 
Letters of claim are regarded as facilitators for early settlement, particularly in low value claims. Some solicitors believe that they are of less value in more complex cases where litigation was often felt to be inevitable and, as such, this stage merely required the parties to rehearse the evidence they would need to disclose during the course of the claim. However, it is arguable that there is still value in the process of clarifying the likely issues at an early stage. In content, letters of claim are clearly an improvement on the old-style letter before action as they are prepared on the basis of expert evidence. However, here too there were some critics. The practice of regarding letters of claim as a trial run at the particulars of claim has obvious costs implications. Compliance with the template letter of claim in the protocol was not uniform and there were differences in opinion as to the enclosures that should accompany the letter.

There was a strong sense that the three-month period for providing a letter of response was inadequate in all but the most straightforward claims. Here, the value of knowing your opponent and the problems associated with tracing doctors was clear; claimant solicitors generally acceded to requests for extensions of time. Once provided, letters of response rarely contained admissions of both breach of duty and causation; defendants tended to admit breach of duty where appropriate but deny causation. Despite the more open culture discussed above and the need to comprehend the issues in cases earlier, admissions were still being withheld in some cases until a relatively late stage in the claim. It is not clear why this is so. It may be that late admissions are now occurring in the advanced stages of pre-Woolf cases which were not originally subject to the protocol. Further research incorporating file review could clarify whether this is so.

\section{If the case fails to settle: supporting subsequent litigation}

Whilst the protocol steps serve to prepare the parties for litigation where settlement cannot be achieved, a common concern amongst interviewees was that court administration did not itself support the efficient management of proceedings. Here, the parties reported little improvement and little evidence of change to contend with the Woolf reforms. Although interviewees blamed the shortcomings on a lack of funding rather than the courts themselves, they clearly found them frustrating. Case management appears to be working well in London but less so elsewhere due to reported inconsistency in decisions by district judges. There were examples of costs being incurred in challenging what were considered to be inappropriate orders; for example, joint expert reports on liability. 


\section{Speed and cost}

The picture in relation to costs is a varied one. There was some evidence that the protocol has succeeded in reducing pre-issue costs. Procedures for the release of medical records have effectively removed the need for applications for pre-action disclosure. Having exchanged information according to the protocol steps, an earlier settlement would have a resulting reduction in costs. However, costs in clinical negligence claims are, of necessity, frontloaded. For claimants, this is not protocol driven as there has always been the need to obtain medical records and an expert's report. However, defendants are clearly having to investigate a greater number of claims when, prior to the Woolf reforms, they might have adopted a 'wait and see' approach. Frontloading this work has led to an increase in costs. Whether this increase counteracts costs savings from earlier settlements is difficult to demonstrate. Further research in this area could clarify the position.

Broadly speaking, the cost of claims post-issue has not decreased and in some cases may be rising due to increased court attendance and the need to produce interim schedules of costs. Overall, costs in clinical negligence claims include experts' fees. The protocol is not prescriptive about the use of joint experts and, whilst they may be used on quantum issues, joint experts on liability are rare. Given the pivotal role of the expert in these claims, it is difficult to see how this aspect of overall costs can be addressed. However, the use of joint experts on quantum issues could have potential costs savings. Difficulties with agreeing the content of instructions and arranging conferences with jointly instructed experts may be overcome as practitioners gain experience of doing so. Meetings of experts are a particular area where increased costs are being incurred. More evidence is required to establish whether these costs are usefully expended in arriving at a resolution of the claim.

\section{Overall}

Given the limited number of interviews on which this part of the study is based, it is difficult to generalise about the impact of the protocol. This area of practice is by its very nature and complexity, one that requires considerable input in terms of time and cost to resolve claims. The investigation of liability, causation and quantum is often complex and requires expert evidence. In many ways the protocol contributes to a process of specialisation and streamlining of case management which had already begun prior to the introduction of the Woolf reforms. The very existence of the Clinical Disputes 
Forum and its formulation of the protocol is testament to the willingness of those involved in clinical negligence claims to encourage a more open culture and to resolve claims in a timely and proportionate manner. The protocol itself provides a framework within which this culture can thrive. Broadly speaking, it appears to be doing so. 
Section 4. Housing Disrepair Work 
Research Study 43 More Civil Justice? The impact of the Woolf reforms on pre-action behaviour 


\section{Chapter 4.1 Housing disrepair work: introduction}

Housing law is a major source of litigation and, following the demise of publicly funded personal injury cases, is one of the main areas of legallyaided civil litigation. Housing law raises difficult issues about the role of lawyers and courts over resource decisions by local authorities. It is frequently also fundamental to the living standards of tenants. For Lord Woolf, housing litigation was of 'fundamental importance', meriting 'a special study' in his final report:

These cases often raise very difficult problems, involving the rights and obligations of individuals and sometimes the constitutional function of public bodies.

Additionally, Woolf emphasised that many of the problems of housing law are products of substantive rather than procedural complexity. As suggested by Lord Woolf, the Law Commission is now carrying out a review of housing law (Law Commission 2001). Housing law covers a wide field. It includes repossession cases, homelessness, commercial land law, and disrepair cases. The latter, where a tenant is seeking compensation and/or remedial work for disrepairs, can take place within possession proceedings or as stand alone civil proceedings loften referred to as 'Section 11' cases, because of the landlord's obligations under the Landlords and Tenants Act 1985). It is also possible to pursue disrepair as a statutory nuisance under $\mathrm{s.82}$ of the Environmental Protection Act (EPA) 1990, through criminal proceedings in the magistrates' court. This research concentrates on stand alone civil cases.

All areas of disrepair litigation have given rise to strong feelings about the merits of such litigation. Lord Woolf adverted to the inherent conflict of interest between tenants and landlords in spite of the fact that "landlords and tenants have a common interest in maintaining housing stock in good condition' (Woolf 1996, p.211):

Tenants who have recourse to litigation, and their representatives say that this is sometimes the only effective way of getting repairs carried out, and to obtain appropriate compensation... Landlords point at overstretched resources as the underlying reason for any failure to carry out their obligations... They say that tenants that resort to litigation are effectively jumping the queue, which results in an unfair distribution of limited resources among the body of tenants as a whole. (Woolf 1996, p.212) 
The hostility (or mistrust) behind these opposed positions is thought to be behind the slow progress on a pre-action protocol for housing disrepair cases. The Woolf report also noted landlords' complaints that experts' reports reveal areas of disrepair that the tenant previously did not know about. The landlords' suggestion was that tenants should not be able to claim for such disrepairs. Similarly, landlords attacked the ethics of tenant solicitors for drumming up business by leafleting estates whilst also criticising the "unfair advantage' provided by legal aid, because it protects, usually impecunious, tenants from costs orders should they lose litigation.

Prior to his report, the Housing Law Practitioners Association and public sector landlords bodies had drawn up their own potential pre-action protocols (Woolf 1996, p.213). In spite of this, a draft pre-action protocol has only very recently been produced and is unlikely to be agreed until $2002 .{ }^{44}$ Some of Lord Woolf's suggestions for a pre-action protocol are not contained within the current draft, such as the proposal that each local authority keeps a list of proposed experts (Woolf 1996, p.214). Furthermore, the proposed timescales continue to be a source of controversy (see below). In relation to expert reports, Woolf rejected the suggestion that they should be restricted to the particular disrepair which is the subject of the tenant's complaint (Woolf 1996, p.215). This is still an issue which continues to exercise landlord lawyers, as this report will demonstrate.

The slow progress towards a pre-action protocol in housing disrepair cases and the continuing debates about points which Lord Woolf hoped to end, ${ }^{45}$ suggest that hopes for a non-adversarial, post-Woolf culture in housing litigation were in vain. This section of the report examines whether this is so. As with the sections on clinical negligence and personal injury, it concentrates on pre-action behaviour but also contains data relevant to postaction behaviour. In spite of the apparently unpromising distance between landlords and tenants' lawyers, there are signs of significant improvement in the way that disrepair litigation is conducted.

[At the time the research was carried out, the draft Housing Disrepair Preaction Protocol was still being developed. The Protocol was issued for consultation in January 2001 and the comments on the draft Protocol in this research relate to that document. An amended version of the draft Protocol has now been forwarded to the Lord Chancellor's department for consideration as to whether it should be adopted into the Civil Procedure Rules.] 


\section{Other relevant literature}

Research on housing disrepair litigation relevant to a discussion of Woolf is very limited. The main study of relevance concerns itself with criminal proceedings under the Environmental Protection Act 1990 (Ormandy et al 1995). It evidences a dominant local authority attitude, which sees disrepair litigation as a diversion of resources from planned repairs and improvement programmes. It also shows that local authorities were particularly resentful of the level of costs claimed by tenant advisers and their alleged methods of raising business through leafleting la process now largely prohibited by the Legal Services Commission). Local authorities also complained that tenants' advisors tended to exaggerate tenants complaints in making claims. The research itself points out that, whether or not tenant lawyers encourage or simply provide the ability to litigate disrepair, the existence of disrepair and tenants willing to bring claims are preconditions for a disrepair claim. It is not down to lawyers alone. The research's recommendations for guidance and advice for local authority legal departments make clear that there was variability in the quality and speed with which local authorities responded to disrepair complaints.

The DETR (now DLTR) ${ }^{46}$ has commissioned a further study to provide good practice guidance on avoiding and dealing with housing disrepair litigation for local authorities and social landlords, which is due to report shortly. The Local Government Association has also conducted a survey of local authorities in relation to housing disrepair litigation (LGA 1977). This makes similar points to the Ormandy et al study: landlords allege the cost of disrepair litigation is disproportionate to the cost of repair work and that disrepair work is based on solicitors' targeting of estates where tenants are in receipt of income support and therefore eligible for legal aid.

\section{Methods}

Twelve semi-structured interviews were conducted with housing practitioners. The selection of interviewees is discussed further in Appendix 3. It became clear during the pilot stage of the research that there was greater diversity amongst landlords and landlord solicitors than there was likely to be amongst tenant lawyers. In particular, landlord representatives were likely to fall into three groups: 'resolvers', 'adversaries' and 'failures'. Because of the greater diversity amongst landlord representatives, it was agreed that four tenant representatives and eight landlord representatives would be interviewed. Landlord representatives included in-house housing disrepair and legal 
teams, lawyers in private practice who specialised in representing landlords, and housing association lawyers. Tenant representatives were chosen from private practice firms and a law centre, all of which had Legal Services Commission contracts for the provision of housing advice. Geographically, interviewees came from London, the Midlands and the North. There was a degree of geographical match between landlords and tenant lawyers interviewed to enable some reality checking of any self-serving responses to interview questions.

Interviewees included both qualified solicitors and non-qualified, as well as partners and non-partners amongst the solicitors.

\section{Structure}

Chapter 4.2 considers the context for housing disrepair litigation, particularly the impact of funding changes and the considerable scepticisms of tenants and their lawyers expressed by landlord representatives. Chapter 4.3 then discusses practitioners' overall views of the Woolf reforms, positive and negative. Chapters 4.4, 4.5 and 4.6 look in more detail at the specifics of preaction work with regard to: letters of claim; disclosure of the housing file; experts; and settlement. Chapter 4.7 summarises the findings of this study of housing disrepair litigation. 


\section{Chapter 4.2 The context for housing disrepair}

Housing disrepair litigation differs in three respects from personal injury and clinical negligence claims. First and foremost, there is currently no pre-action protocol, although a draft protocol is being proposed for adoption (see below). Secondly, tenant lawyers tend to act mainly against one defendant - their local authority - whereas personal injury lawyers would typically act against a number of insurance companies. Work against private landlords and housing associations was generally perceived to give rise to fewer cases, although the private rented sector has the higher proportion of property in poor condition (Crook et al 2001). As tenant lawyers are typically dealing with one organisation in the majority of their claims, their responses to the Woolf reforms were likely to be highly specific to how they perceived that organisation had dealt with Woolf. Thirdly, funding is largely confined to legal aid, rather than CFAs. This chapter discusses these differing contexts and explains some of the background to disrepair litigation.

\section{Fast track or multi-track?}

All respondents, bar two, were in agreement that their disrepair caseload consisted overwhelmingly of fast track cases - they suggested a figure of about $90-95$ per cent. One landlord private practitioner had about 40 per cent multi-track cases and one local authority lawyer claimed that most of his disrepair cases were multi-track. Some respondents indicated they had no multi-track cases. Respondents were in agreement that whether a case was fast track or multi-track made little substantive difference to the pre-action stages of the case:

[Multi-track cases may] be more important and given more time because there's more money involved... They will have their own directions like fast track directions, and there is nothing inherent in a multi-track case, apart from obviously it is more complicated or more expensive. (Landlord lawyer)

Interestingly, one tenant lawyer indicated that initially judges had been more inclined to allocate housing cases to multi-track but that has now changed:

Initially... quite a lot of the cases were allocated to multi-track but it seems as though the judiciary are less likely to put things into multi-track now, say, than they were a year ago. I would say the tendency is put all housing disrepair claims in fast track. (Tenant lawyer) 
Post issue there would be obvious differences, including more judicial intervention on the issue of experts:

I think judges will tend to take a more proactive role in those cases in terms of wanting to see agreed expert evidence from either a single expert or joint expert, joint inspection. (Tenant lawyer)

\section{The funding context}

Unlike personal injury litigation, the vast majority of housing disrepair claimants are legally aided. One landlord lawyer said all the claims brought against them were legally aided, and most of the others said 95 per cent of disrepair claims were legally aided. Similarly, the tenant lawyers we spoke to said virtually all their clients were legally aided, although one respondent's work (a Law Centre) was part-funded by the local authority. Cases where there was private funding were regarded as exceptional. One landlord lawyer, who did some non-legal aid work for tenants, pointed out that private funding might be confined to early, rudimentary advice from more junior solicitors:

We get a lot more enquiries from people who don't want to pay and go away... Private paying tenants are a fairly small number and who may be given some advice and set on the right track... A couple of hours of advice and talking through stuff with them and then not doing much more. (Landlord lawyer)

Several landlord lawyers made comments which suggested, implicitly or explicitly, that legal aid left them at a significant disadvantage in seeking to negotiate appropriate settlements:

Costs... everyone is legally aided and you just get nailed, that's why you settle.

(Landlord lawyer)

Whilst landlords were at a disadvantage, in the sense that they would never effectively be in a position to reclaim legal costs from a tenant, cost sanctions should have some effect on tenants given the existence of the statutory charge and the potential for Part 36 offers (or payments). Several landlord lawyers suggested that, even so, legal aid clients just would not settle, and that judges were reluctant to award costs against legally-aided clients.

\section{Funding causing a decrease in work?}

Another important factor affecting disrepair litigation is an apparent drop in the number of disrepair claims. Several landlords reported a decrease in disrepair claims. One landlord lawyer quoted figures, showing that their 
cases had dropped from 340 cases per annum in 1998-1999, to 300 new cases in 1999 to 2000, and down to 200 in 2000-2001. Landlords typically attributed these drops to tighter legal aid funding. Tenant lawyers rejected the suggestion that there had been any dropping off of work, or that there were tighter merits tests under the funding code. It is clear, however, that the number of housing cases has dropped, as figures from the Legal Services Commission show. In 2000, 3,168 legal aid certificates were issued for housing disrepair, compared with 3,854 in $1999,{ }^{47}$ a drop of 18 per cent. ${ }^{48}$

Explanations offered by interviewees included a reduced supply of housing disrepair advice and/or more cases settling without involving legal claims departments. Several respondents pointed out that the number of firms doing housing work in their area had reduced significantly as a result of legal aid contracting. Even firms with contracts said they were not in a position to take on cases:

Of those that are listed in the CLS directory that do housing, there are probably about four to five firms that do, and of that four or five firms you'll probably find only two or three at any one time are taking on work. (Tenant lawyer)

One private practice landlord lawyer, who had previously done tenant work under a legal aid franchise, also pointed to the same problem: 'There are probably about four main ones and... a lot of the time they tell us they aren't taking on new work because they're swamped.' One tenant lawyer added another explanation: 'It's profitability as well, because prior to changes in legal aid, more so than Woolf, you were able to hit a housing claim twice, you could do EPA [statutory nuisance] and get your costs and do the Section 11 [civil claim] and get your costs. Now it's a case of a toss-up between the two.' This suggests that the legal aid system has been tightened up to reduce the number of cases, in addition to any impact caused by the reduction in supply of housing advice caused by contracting.

\section{Has funding changed the way lawyers work?}

In spite of claiming that the amount of disrepair work which they took on had not been reduced by funding changes, several tenant lawyers pointed out that legal aid contracting and, in particular, the Funding Code (Legal Services Commission 2001) had a significant impact on the way that they worked. They also suggested this might be as, or more, important than the Woolf reforms. Thus, letters before action were written with future applications for legal aid funding in mind: 
Our behaviour... is not just governed by Woolf, it's also governed... by the Funding Code... You have to do a letter before action before you can apply for funding, for example, and give a reasonable chance for response, and you have to attach a copy of that letter to your application. (Tenant lawyer)

It was clear that, for this lawyer, the economics of practice also governed how they worked, and that the combined impact of the economics and bureaucracy of contracting was more influential than Woolf on how they worked. For obvious reasons they were keen to discuss the potential impact of fixed costs in the fast track:

None of the changes wrought by the CPR are anything like as significant as... the prescribed rates set by the Legal Services Commission... and contracting...Those sorts of changes are infinitely more significant to the practice... than changes wrought by the CPR... The real crunch then may come if fixed costs are brought in for fast track cases... Fixing the costs arbitrarily would completely revolutionise everything and the way we would have to do things, and whether we would be able to do them at all. (Tenant lawyer)

Another tenant lawyer reported that the Funding Code had not affected what they could do, although the way they framed applications had changed:

We thought that we would have problems but what we have to do is, in your statement when you apply for funding, explain why you're not using the ombudsman's scheme, why there isn't any mediation available, and... the fact that it's gone on for such a long time. But we haven't ever been rejected. (Tenant lawyer)

Legal aid is important to an understanding of housing disrepair in two respects. The Legal Service Commission's control over what work can be done and how it can be done is, according to some of the tenant lawyer interviewees, a strong factor governing how they work. Some of the aims of the Woolf reforms may actually have been achieved by legal aid changes rather than court reform. The second issue is that, rightly or wrongly, the legal aid scheme is perceived by landlord lawyers as antithetical to the fair resolution of disputes. As such their perception contributes to, or is engendered by, a suspicion of tenants and tenant lawyers, which seems to be part of the culture of litigation in this area.

\section{Drumming up business}

A further factor which plays on the minds of landlord lawyers is the way they claim that tenant lawyers generate business. In spite of, or perhaps because of, the apparent drop in disrepair claims, several landlord representatives 
referred to tenant lawyers 'drumming up' business. This landlord lawyer was typical, alleging that leafleting and other possibly unethical attempts to generate business were being employed by intermediaries acting for solicitors:

There's been a lot of mischievousness done by these third parties acting for solicitors in terms of leaflet dropping... in the past twelve months. And I don't know if there's a direct link with... Woolf making them look harder for work.... Outside of the pubs they have a little stall with pictures with, you've got this in your house, we'll get you £2,000. If you've got that, then...' They're going dressed as civic council officials to gain access and video the property... They're also offering tenants... inducements of fifty quid if they sign up with things like this. (Landlord lawyer)

They were asked to provide example leaflets but did not and this interviewee's colleague, who was also in the interview, suggested that his claims were "just allegations'. Nevertheless, other landlords made similar, if less detailed allegations, about a particular firm in Manchester that had leafleted estates in London on disrepair claims, which generated high levels of small 'nuisance' claims. Even the law centre lawyer agreed in part: 'You can get solicitors going round and putting cards through peoples' doors, etc.'

\section{CFAs}

As seen in Section 2, conditional fee agreements (CFAs) give rise to considerable concerns amongst defendants. In theory, it is possible to conduct housing disrepair cases under CFAs, especially as landlords and tenants seemed to agree that disrepair cases are nearly always settled in favour of tenants. Experience of CFAs was, however, rare. Most landlords said they had never received a claim supported by a CFA or that they had only received one or two. The main reason given was that claimants were typically on benefits and so always qualified for legal aid. The tenant lawyers interviewed had similar perspectives on CFAs. One had seriously considered CFAs, but explained that the difficulties that he faced in seeking to use CFAs in disrepair cases were mainly due to insurance problems. Interestingly he also reported great use for CFAs in EPA cases:

I've not yet signed a single conditional fee agreement but not for want of trying. I have in criminal, in Environmental Protection Act cases, but not in civil proceedings. A couple of reasons: most clients are eligible for legal aid.... The ones that are not, you try and find an insurer to pay and insure against the [other side's costs]... and it is a nightmare. No insurer is really familiar with housing disrepair cases, the only quote we got... the client was, or we were, expected to stump up, I think it was $£ 3,333$ out of our estimated $£ 10,000$ 
[damages]; that was going to be the premium which, given that the risks I think of that case were similar to a personal injury rear-ender where I think you just pay $£ 150$ or something. (Tenant lawyer)

None of the other tenant lawyers had done any CFAs. However, one had experience of another firm which had tried, unsuccessfully in his view, to use CFAs, before the provisions permitting recovery of the success fee had come into being. Under the pre-recovery system, costs recovered on uplifts from damages had not been sufficient to offset legal costs and give the client a reasonable damages payment.

Even where landlords claimed experience of CFAs, it was not transparently clear that all the cases that were thought to be CFA cases were actually being funded on conditional fee agreements. One landlord suspected that the firms involved (who they disliked anyway) were involved in something dubious, that they had not got legal aid for their clients but equally had not declared the agreement as a CFA:

We never get, haven't yet got, behind the funding agreements because we never go to taxation on them where we might be obliged to sort of ask them for their agreements. I've seen one... The particular firm I think [are] very sharp operators and I suspect that if there were a conditional fee it might be hidden. (Landlord lawyer)

If uplifts and/or insurance premiums are being concealed, it is a breach of the CFA regulations. Another landlord lawyer reported a similar flood of claims under insurance-backed schemes, which may or may not have been CFAs:

There [are] an awful lot of outfits out there with this insurance-backed scheme now. Where the tenant signs two forms, one kicks in a loan and one kicks in an insurance policy, which will be deducted from any success, and if they're not successful, the policy covers the loan. And we've seen hundreds and hundreds and hundreds of those. (Landlord lawyer)

Although the precise nature of these schemes is uncertain, these comments suggest that some tenant firms may have begun to operate outside of legal aid and use CFAs, or after the event insurance to support disrepair claims. Nevertheless, it should be remembered that the overwhelming experience of practitioners we interviewed showed that legal aid was by far the most dominant form of funding for disrepair cases. 


\section{Landlords' scepticism of tenants and their lawyers}

One of the messages indicated - by local authority lawyers in particular, but also to an extent by other defendant lawyers - was their scepticism of some tenants and some lawyers. The quotations above outline allegations of sharp marketing practices. There was a sense amongst several local authority lawyers that their employers had somehow been singled out for attention. Thus some landlord lawyers referred to the local authority as being 'targeted' by particular firms of solicitors. There was a common concern amongst landlords that resources were being wasted on legal costs and feckless clients rather than spent on improving their housing stock:

Is it morally right that someone who doesn't look after their property themselves for years on end, has never painted it, can then sue the local authority and get up to $£ 3,500$ damages a year? Money that can be well used... in actually improving the property... The tenant may not even have done anything to look after the property themsel[ves] but could be suddenly getting some big money. (Landlord lawyer)

Another aspect of landlords' psychology was a concern that courts were against local authorities. This landlord lawyer perceived bias in courts:

The courts are not really enforcing this proportionality rule... they're still getting legal costs that are totally out of proportion to the compensation. Tenants are getting a lot of special damages when they can never produce receipts, which is a case of the judge taking the view, 'well, I'm being a bit sympathetic to the tenant', and he just takes their word for it, and their not being able to produce any documentary evidence. (Landlord lawyer)

Another landlord lawyer pointed to a similar feeling that they never got the rub of the green:

You do feel sometimes that you're just not getting that support at court and judges aren't even looking at... the facts of the case and that they're still willing to be very, very anti local authority... We'll be making applications to get cases struck out, that... we would see in terms of Woolf, and dealing with the cases efficiently and effectively, and looking at proportionality, and conduct of the parties, and we don't feel we're getting often the decisions that we should be. (Landlord lawyer)

Other examples showed how local authority lawyers saw themselves and their authorities as victims of a system stacked against them. Their comments on the legal aid system, which they perceive as being structured against them, and suggestions about being 'targeted', 'getting nailed' or being 'stuffed', all suggest that they feel victimised. Interestingly, alongside the 
feeling of victimhood, there was some acknowledgement, albeit tentative, of the local authority's inadequacy, but also the familiar suggestion that housing litigation was a waste of resources that could be spent elsewhere:

It seems futile. You're trying to protect this great groaning organisation that doesn't really... have the adequate systems in place, but likewise it doesn't seem to have any support from [the] judiciary and I guess doesn't have a great deal of support in terms of legislation... I think it needs to be radically overhauled... take it away from the lawyers, and I think there's billions of pounds going on all over. (Landlord lawyer)

He returned to this theme later in the interview, pointing to the ability of tenants to bring dubious claims, which some other landlord lawyers referred to as nuisance claims.

Landlords raised four further concerns to suggest that legal aid claims were in some way illegitimate or unfair. The first, shared by several landlord lawyers, was that disrepair allegations were made in response to possession claims. For landlord lawyers these were, almost by definition, thought to be dubious:
A lot of claims... are coming into the category of 'fairly dubious' I'm afraid... and still those claims coming off the backs of rent arrears actions... where the tenant hasn't paid their rent... and before you know it... you're clearing their rent account. (Landlord lawyer)

Secondly, a landlord lawyer portrayed litigation as queue jumping. Tenants who were expected to wait their turn for repairs, 'start court proceedings and it gets priority. So, yes, it is a way of jumping the repairs queue most definitely.

Thirdly, concern was raised that tenants deliberately prevented landlords from obtaining access to inspect or repair the property in the hope of increasing compensation: 'Quite often... they're of the opinion that if they can delay us getting in, they always get more compensation.'

Finally, landlords were often suspicious of the costs claims made by tenant lawyers. Some went as far as claiming 'certain firms' were 'acting underhand'. A particular concern here was the inexplicable variability in costs claimed by tenant lawyers for apparently similar cases. 
Part of the sense of unfairness that in-house landlord lawyers in particular harboured was driven by lack of resources to conduct their work properly. Two in-house landlord lawyers referred to cuts and financial limitations on filling posts. One also pointed to a general lack of good quality lawyers: 'We won't get people working in the local authorities, that's one problem.'

Tenant lawyers were not asked about these attitudes directly, but on occasions their unbidden comments contradicted those of the defendant lawyers. One tenant lawyer commented at length on what it was that tenants wanted. Interestingly, this lawyer suggested that more adversarial tenant behaviour and, in particular, the desire for compensation, was usually motivated by the client's treatment at the hands of the local authorities:

By and large... people weren't saying, 'I want compensation.'... It's not a compensation culture... Nine times out of 10, they say, 'I just want the works done. I don't want anything else.'... But, because of the way they were being treated, pre-Woolf... people would get really annoyed. Whereas now, you're finding people saying: 'No, great, the works are done. They've finished it all off... that's fine.' (Tenant lawyer)

It is impossible, in a study of this sort, to evaluate competing views on motivation and the resulting problems caused in such litigation. More detailed empirical work, based on objective records and/or observation of disrepair cases, would be necessary.

At the heart of local authority comments lay three particular worries: the first was that of the local authority as the victim of 'sharp' tenant lawyers, feckless tenants and biased courts. The second was a perception that disrepair litigation was somehow without merit or inappropriate, usually because tenants' behaviour rendered their claims morally dubious, however legally grounded, due perhaps to their failure to pay rent or to look after the property themselves. Indeed, landlord lawyers tend to blame tenant lawyers for housing claims, whereas, as Lord Woolf has pointed out, the remedy against 'drumming up business' is in part in the landlord's hands. If they had clear and understandable programmes of repair, tenants might not turn so readily to lawyers for help (Woolf, Para 55). Finally, there was the common view that housing disrepair litigation was generally an inappropriate use of resources.

These criticisms do not attack the heart of the legal claim, whether there is actionable disrepair. Only the argument that nuisance claims were common did that. Tenant lawyers generally recognised the difficulties that local 
authorities faced, but were understandably keen to advance the view that clients had critical interests at stake, which were only protected by making a formal claim.

\section{Towards a protocol}

The housing disrepair protocol working group (HDPWG), supported by the Law Society, has produced a draft pre-action protocol which has been consulted on (HDPWG 2001). The final version has been settled by the working group and awaits the agreement of Lord Justice May to proceed to being a pre-action protocol. This latest version has not been published. Many of the respondents were aware of the draft protocol and had responded to it. Landlord respondents tended to express concern about the protocol (particularly with regard to the time with which they were provided to complete investigations) but also with the make-up of the working group itself (they thought it was biased towards the tenant). ${ }^{49}$

\section{Absence of a protocol}

As there is no pre-action protocol for housing disrepair, it might have been predicted that the Woolf reforms would not have had much effect on preaction behaviour in housing disrepair cases. Several respondents commented on what they had said about the absence of a protocol. Some landlord lawyers had suggested their own protocol to local tenant lawyers. One agreed to acknowledge tenant letters within 28 days, and investigate within four months. Another suggested a 90-day period to try and deal with the claim. Nor was the approach confined to the local authorities. One private practice landlord lawyer had produced a protocol suggesting a three-month period for the claim to be made and investigated: 'We could see it would save our clients a lot of money in terms of the work that we have to do.' As one of the tenant lawyer interviewees made clear, many local authorities other than those interviewed seemed to be adopting a similar approach. He saw this as predominantly an attempt to buy time for the local authority:

In terms of the actual steps they're all very sensible... but that's one of the ways that the authorities... [are]... thinking of it adversarially... They've tried to use Woolf to fend off claims and give themselves some more time to deal with them. (Tenant lawyer)

Even though these self-imposed deadlines were more generous than the draft protocol, landlord lawyers acknowledged that their clients or housing department had not always been able to meet those deadlines. 
Views were also mixed on whether unilaterally imposed protocols were accepted by the other side. One private practice landlord lawyer suggested that they generally were: 'Most tenants' solicitors agree to an informal protocol period.' But it was clear that this lawyer had a reputation with tenant lawyers for dealing with claims properly and expeditiously. Another local authority landlord lawyer reported 'poor take-up by solicitors' of their protocol, although some tenant solicitors had started to follow it.

\section{Responses to the draft protocol}

Several landlord respondents brought up the subject of the draft protocol with some hostility and/or concern. Whilst some were broadly supportive of the concept of a protocol, most were concerned with the speed required under the protocol. Under the draft pre-action protocol for housing disrepair cases, the landlord was expected to make a substantial reply to an early notification letter or a letter of claim within 21 days of posting. The 21-day time limit, which may have been relaxed in the current unpublished draft, was met with incredulity by some landlords. This comment was typical in expressing the impracticability of a 21-day time limit:

There is absolutely no way that [an organisation] like this can turn around a claim within 21 days of the date of the letter... We have 80,000 to 90,000 houses, 700-800 claims a year, and we're expected to acknowledge the claim, send it off to our housing department, expect them to investigate it, produce all the information... inspect the house, then go back to us, and we're expected to look at that information, assess quantum and write back to the other side. There's just no way. (Landlord lawyer)

When asked what would happen should the deadline be imposed under the protocol, her response was pithy: 'I don't know, I think we'll all hide under our desks.'

The only other concern expressed in relation to the protocol during interviews (which were not specifically addressing the practitioners' views on protocol) was a concern about cases involving personal injury. Some landlord interviewees perceived these as rising. Both tenant and landlord respondents wanted clarity about how personal injury cases should be dealt with. The draft protocol suggests that the disrepair protocol will apply to all civil claims which include a claim for a disrepair, but not counterclaims or set offs,' (p.13). That this includes disrepair cases with a claim for personal injuries is made clear (p.15). Confusingly, however: 'If there is a personal injury case which is 
serious enough to be dealt with separately, on behalf of any claimant, the personal injury protocol should be followed, as appropriate, with necessary modifications.

This is an area where it may be sensible for stronger definition in the preaction protocol. Whether a personal injury case is serious enough to be dealt with separately' is likely to be subjectively interpreted. Nor is it clear what 'necessary modifications' should be made to the personal injury protocol in such circumstances. Further consideration may need to be given to the overlap between disrepair and personal injury protocols.

\section{Changes to levels of damages}

To aid understanding of the context for housing disrepair, respondents were asked whether they felt damage levels had increased or decreased over recent years. Several respondents stated that damages had gone up (landlords and one tenant lawyer). Most pointed to courts making higher awards and one landlord lawyer argued that very specific requests by the tenant solicitor for heightened... increased damages and that court decisions had increased the tariff'. Other factors, such as a change in the local district judge, had also led to higher awards from a previous, more conservative DJ. One landlord lawyer, however, felt that 'the final figures are usually less than they used to be, more realistic, which is obviously a good thing from the landlord's point of view.'

These changes do not suggest a relationship between the Woolf reforms and levels of damages. Other respondents felt the position on damages had remained unchanged, although a tenant lawyer thought it was possible that Woolf had had some downward pressure on damages as a result of local authorities getting repairs done more quickly:

If the cases end quicker, damages might be slightly lower... If you've got disrepair continuing for two years during... the course of the case, the damages sort of racking up as time goes on... general damages, if they settle quicker then the damages might be slightly lower, so that might have had a marginal impact. (Tenant lawyer)

Another tenant lawyer echoed that assessment but also pointed to improvements in local authority handling of housing disrepair which reduced the friction between landlord and tenant, affecting damages in a downwards direction: 
The clients' attitudes have changed as well, because if they've had to wait eighteen months, two years before [the local authority would] even lift a finger in terms of doing the works, they would be really gunning for them. And they would be wanting maximum damages, and saying, 'no, I'm not going to settle... I want the maximum amount...'. Whereas now we find... they think, 'I've been to my solicitor, and my solicitor wrote a letter, and, the surveyor's come in and they're going to do the works'. And so when they get the offer of compensation, they think, 'yeah, okay, great'. And you say to them, 'well, actually you could get a little bit more if you went to trial'. And they say, 'no, no, no, no'. (Tenant lawyer)

A landlord lawyer echoed the latter comments when he described their housing team's new approach to responding quickly to tenants complaints, claiming that this led to a reduced incidence of tenants wanting to claim compensation. Another landlord lawyer also pointed to a reduction in average levels of compensation, contradicting his more specific remarks on court decisions increasing the levels of compensation awarded.

Thus practitioners perceived that the courts had increased the level of damages to be awarded to housing disrepair claimants but generally did not perceive any relationship between damages and the Woolf reforms. Interestingly, several respondents (landlord and tenant lawyers) felt that an improved settlement culture reduced damages, either because tenants were appeased by the landlords' promptness or because repairs were being conducted sufficiently quickly to reduce general damages. It may be that the potential for court awards to increase damages is negated by negotiated settlements decreasing payments. This may be because quick settlements reduce the level of general damages because repairs are completed more quickly. It might also be a product of quicker settlements being produced because tenant lawyers are now more willing to compromise for lower levels of damages for their clients. This could be a product of Woolf reforms or the Legal Services Commission's greater focus on the cost-benefit test in the funding code. In any event, it suggests that one consequence of a less adversarial culture may be lower damages for tenants.

\section{Other changes}

Understanding the context for housing disrepair litigation and the Woolf reforms generally involves a recognition that a number of changes relevant to the management of private practice and legal services departments have been taking place simultaneously. As already noted, changes in the legal aid scheme have emphasised similar values to the Woolf reforms, particularly 
greater emphasis on managerialism and efficiency. Respondents felt that their behaviour had been greatly influenced by these other processes. Local authorities had also reorganised in ways that may have been attributable to the Woolf reforms, but could also have been caused by a greater recognition amongst authorities of the need to deal effectively with housing disrepair complaints. Thus, some landlord lawyers had reorganised the early handling of disrepair complaints centrally, separate from their legal department and local housing offices. A non-legal housing team would deal with any letter before action that was solely housing disrepair related, arrange an inspection, and collate the necessary documents. Landlords saw great merit in centralisation, taking the task away from large numbers of dispersed housing officers and giving it to centralised, specialised teams of building surveyors and environmental health officers. Legal services were only involved predominantly when proceedings were issued.

As well as these beneficial reorganisations, which may or may not have been attributable to Woolf, there were other reorganisations that were ongoing in two of the authorities interviewed which had a detrimental impact on their ability to handle cases expeditiously. Reorganisations had undermined job security, and so people left at the earliest opportunity. Contracting out had left people confused about who was doing what.

\section{Summary}

It is important to keep in mind, when considering the potential impact of the Woolf reforms on housing disrepair litigation, the specific context of housing. There is, certainly from the perspective of landlord lawyers, a degree of scepticism of tenants and their lawyers which could lead to quite serious levels of hostility and adversarialism. Equally, however, the fact that both tenant lawyers and landlord lawyers are under a degree of pressure to ensure that cases are handled as cheaply as possible leither from the local authorities or from the Legal Services Commission) may mean that there is a reasonably strong incentive to settle cases quickly. Other aspects of managerial change have all added to a framework which emphasises pragmatism and settlement over adversarialism.

There are some other interesting aspects to the environment in which housing disrepair cases arise. The apparent absence of work against private landlords is notable, particularly given that the quality of housing stock is particularly poor in the private sector (Crook et al 2000). This may be due to differences in security of tenure for private tenants, or differences in their 
income levels, and hence their ability to qualify for legal aid. More directly relevant to this study, there are some indications that pragmatism and pressure towards settlement may be reducing the compensation payments to tenants, thus reducing the overall cost of the housing disrepair litigation process to landlords. There are also interesting indications of conditional fee agreements beginning to have a role in housing disrepair litigation, although only a minor one.

This description of the context for housing disrepair points in conflicting directions. There is a great deal of evidence of a general pressure towards pragmatism and economical settlement. Equally, there is evidence that such litigation is permeated with a good deal of hostility and mistrust. The next chapter examines whether the Woolf reforms have had any broad effect on such litigation. 
Research Study 43 More Civil Justice? The impact of the Woolf reforms on pre-action behaviour 


\section{Chapter 4.3 The Woolf reforms: overall views and their impact on methods of work}

This chapter considers respondents' general reactions to the Woolf reforms, positive and negative. It looks at whether the broad aims of Woolf have been met, such as whether cases are dealt with more quickly, whether costs have been reduced and whether the parties are adopting a more 'cards on the table' approach to housing disrepair claims. Next to be considered are changes in the organisation and management of bodies handling disrepair complaints and litigation, looking at changes in personnel, the skills required, and the use of counsel, IT systems, and office procedures. The chapter concludes with a discussion of the perceived negative elements of the reforms, including heightened stress levels, inefficiency in the courts and problems with sanctions.

\section{Overall views}

Broadly speaking, almost all landlord respondents were positive about the Woolf reforms. Most tenant lawyers were also positive, at least in part. Indeed, all respondents found themselves saying something positive about the Woolf reforms during the interviews. One landlord lawyer was strongly positive: he thought that information was better and exchanged earlier; there was stronger engagement between the parties; and, greater onus on settlement. He said:

Overall there seems to have been... better exchange of information and earlier on in the case... a better engagement between parties to discuss the case... and hopefully narrower issues, and... hopefully there does seem to be more onus on getting the case settled, and obviously speed is the key. (Landlord lawyer)

Another landlord lawyer said: 'it has been a wholly positive thing.' Meanwhile, an experienced tenant lawyer pointed to quite substantial changes in their main opponent, the local authority. He painted a vivid picture of life pre-Woolf, where claims were settled at the last minute after progressing through the court system on a procedural auto-pilot:

Prior to the Woolf reforms, we found that the local authority were not actually responding to any of our letters... [we would] write a letter before action, wait 14 days, apply for funding, get legal aid and then issue proceedings. Knowing that they weren't going to do anything until... witness statements were due to 
be exchanged... we would have to take them all the way to trial, in order to actually get settlement. Whilst they were gearing up for Woolf, they suddenly got their act together and set up a special task force to deal with disrepair only [with] dedicated lawyers, dedicated surveyors...[We] found that that worked. And since Woolf has come in, the amount [of] proceedings that we've had to issue has dropped dramatically. And they do actually respond with offers fairly early, and they do get surveyors' reports in very, very early. (Landlord lawyer)

On the other hand, some respondents doubted that the reforms had made much difference. They located the Woolf reforms in the context of broader forces discussed in Chapter 4.2 l'reforms within our opponents, who tend to be council housing departments rather than anything to do with civil procedure') or suggested that the changes were fairly modest. Even here, though, it was acknowledged that approaches to site inspections by experts and approaches to settlement had changed:

We always agreed to a joint inspection... rather than having our own experts independently, but I would say that what Woolf has done has made that practice pretty much universal and commonplace in that the other side... will almost all now invariably agree to a joint inspection when one is suggested, whereas in the past they may have ignored your thing or every other piece of correspondence you sent them... So to that extent, that sort of dialogue which obviously does encourage early settlement has been improved. (Tenant lawyer)

Two tenant respondents were sceptical. One landlord lawyer felt that Woolf had affected initial claims 'not a great deal', and one tenant lawyer felt there had been little or no change as a result of Woolf. Whilst there had been some superficial change, they continued to have problems with one particular landlord:

Previously we'd send out a 14-day letter, they wouldn't respond, apply for legal aid and go for it. Now the situation is you send them out a 21-day, 28-day letter, they don't respond, we apply for legal aid and we issue, so in that respect the majority of our work hasn't really changed because [the main opponent] doesn't react, they don't move on any indication to actually settle a claim. (Tenant lawyer)

Although with respect to his own behaviour he felt there might have been some changes:

In effect we're being a bit more open and being a bit more substantive with the claim that we're putting forward... In reality, that's something that we should have been doing before Woolf anyway. 
It is interesting to note the way this practitioner dismisses positive change as something which should have been happening anyway. This suggested a certain resistance to change being imposed from without. A similar perspective on the reforms came from two other practitioners who felt they had behaved in a spirit of Woolf before the inception of the reforms.

\section{Patchy changes}

As we will see, even those respondents who gave very positive views on the Woolf reforms had concerns about the consistency with which those reforms were being implemented. Several respondents knew of opponents who did not, in their view, operate in anything approaching the spirit of Woolf. Similarly, not all aspects of the reforms had been fully adopted. For example, one tenant lawyer was very positive about the changes in her local authority, but pointed to another local authority that she took cases against that had not changed its practices:

Some boroughs it hasn't made any difference... hasn't made a blind bit of difference at all, we're just going down the road and doing exactly what we did before. (Tenant lawyer)

Similarly, landlord lawyers typically felt that there were firms which operated the Woolf reforms well and others which had paid little or no apparent heed to them. Landlord estimates of the number of cases that were handled appropriately by tenants ranged from 50 per cent to 80 per cent. On the whole, landlords thought that the larger, specialist solicitors had responded most positively to the reforms lalthough one landlord lawyer felt the response depended on individual solicitors rather than firms). There seemed to be two reasons for the specialists' better response. One was that these firms knew what they were doing by virtue of their specialism, and so more easily adopted Woolf-like approaches (or may have been doing it already). Another was the potential for tenants and landlords to develop working relationships which meant that either they trusted each other more, or they had 'trained' opponents into taking a 'reasonable' approach. One landlord lawyer pointed to the potential for developing working relationships with repeat players:

You see vast numbers of claims coming from one particular set of solicitors. From our point of view that's better, because they have a working relationship professionally with us... and they understand the system that we operate to try and resolve the matter. The problem arises when we're dealing with one-off solicitors who, with the greatest of respect, haven't got all that much experience of housing litigation. (Landlord lawyer) 
A number of landlord lawyers emphasised the benefits of proper experience of housing law. This comment is typical:

Well, there has been a big change, it's really working with some of the city centre firms who have got housing franchises, do loads of housing, are really experienced... And then if we're dealing with some of the small firms, I don't know if they're legally aided or not, they're franchisees or not, they don't always give you much information. They're sometimes pretty hopeless because they just don't have the housing law knowledge or expertise to actually know what the claim is worth and so you don't get a lot out of them. (Landlord lawyer)

One of the private practice landlord lawyers hinted at attempts to persuade claimant lawyers towards a Woolf-like approach through the threat of cost sanctions, but also pointed out that there were limits to the success of that strategy where cases were never going to get near a court:

So we have seen a change in practice [in some lawyers] by sort of bombarding them with the rules but, you know, [other] firms... just ignore the rules and they're going to go off and bring these sort of bulk, almost nuisance claims... you tend to on a commercial basis almost want to settle them quite quickly so we never again get to the court to argue... costs really. (Landlord lawyer)

Similar variability was admitted by, or pointed out amongst, landlords. Several tenant lawyers distinguished between different local authorities in their area. A landlord private practice firm was seen as more strategic or adversarial in their use of Woolf:

They're much more in your face with it, you know, overriding objective, bits and pieces, proportionality, anything they can find they'll throw at you. (Tenant lawyer)

Another tenant lawyer pointed out that as well as variability across local authorities there was also variability within local authorities: 'One housing office will say, yes, we will do the works. Sometimes with some housing officers you just won't get the response at all.'

These responses suggest that the Woolf reforms have delivered some, sometimes significant, positive change. However, that change is not consistent. Some firms are too inexperienced in housing or otherwise unwilling to adopt a pragmatic, expeditious approach to claims.

It is worth examining in more detail the main themes of the Woolf reforms. 


\section{Speed}

Specific aims of the draft pre-action protocol include promoting speedy and appropriate repairs, early exchange of information, and ensuring that tenants receive appropriate compensation as soon as possible. Most respondents, landlords and tenants, suggested that cases were quicker post-Woolf. Several reasons were given for this. Many comments related to post-issue, especially the speed and rigidity of the fast track timetable:

The latitude of the parties to let things lay dormant is not there. The time periods now are not open to serious extensions. (Landlord lawyer)

The directions given by the court are much tighter I think, it's not left to the parties to sort of ramble on and have their own dates as suits them. (Landlord lawyer)

Greater speed was not confined to post-issue. Changed approaches to experts; greater willingness to exchange offers; greater use of Part 36; a change of attitude to settlement; and sometimes quite simple things, such as a greater willingness to answer correspondence, were all suggested as leading to quicker resolution of cases. Several respondents said they tended to settle a lot more cases pre-action and were much less likely to ignore matters or let them drag on:

But I think the impression I got...before we waited till the summons came in... we tended to let matters drag on. (Landlord lawyer)

Another landlord lawyer suggested that proceedings had dropped dramatically: 'We've got very little, the figures now are about thirteen per cent proceedings, from something like sixty per cent.' Tenant lawyers also pointed out that they were issuing fewer claims.

\section{How much quicker?}

Several respondents, both landlord and tenant lawyers, spoke in quite dramatic terms about the change in timing of settlements, pointing to a switch from an approach which generally delayed settlement until close to trial, to one where settlement pre-action was common, or even the norm. One landlord lawyer provided an assessment of the overall impact of the changes in terms of time taken to reach a settlement. It should be remembered that they might be keen to hold themselves out as settling cases quickly lalthough a tenant lawyer from the same area seemed to agree that they did). They said that an average, unproblematic case would probably be 
over in about five to six months, whereas previously it could take up to two years. Others (landlords and tenants) also suggested that the timescale had dropped considerably. Housing claims had once typically taken between 18 months and three years, but some suggested that it now took as little as three to six months. This data should be treated with care: Section 2 discusses how lawyers routinely under-estimated the time cases took. Nevertheless, these results are strongly suggestive of improvement.

\section{Cost}

The draft pre-action protocol for housing disrepair cases emphasises that one of its aims is to 'Keep the costs of resolving disputes down', (p.5) which 'is especially important in claims of lower value'. There are three issues on costs. Are they more predictable? Have they reduced? And are they proportionate to the damages? No interviewee indicated that costs were now more predictable. The great majority of both landlord and tenant lawyer interviewees thought that costs had reduced as a result of the Woolf reforms. On the other hand, some landlord lawyers felt there had been little or no change in the position on costs.

A private practice landlord lawyer was asked to explain how much her costs had gone down by. She provided an insight into how settling cases pre-action and being ready for the fast-track timetable had changed things. Now she typically had far fewer procedural steps to deal with:

We'd do a bare denial defence because we didn't have any choice, because we didn't have the papers from our client. We'd then get requests for further and better particulars, and interrogatories, sometimes... they used to take ages to complete... and then drafting written statements, lists of documents, all that sort of thing. So... fees were quite high and only after you got through all of that did you then generally say, well, now we've done some written statements we'll assess the damages now, because often there wasn't a time in the timetable to do that earlier on. (Landlord lawyer)

She estimated that her average costs on civil disrepair cases had reduced from $£ 5,000$ or more to $€ 1,000-€ 1,500$. For obvious reasons, tenant lawyers were also keen to suggest their costs had been reduced, with a reduction in the number of procedural applications being reduced: 
Before we were having to make applications all the time for the local authority to file a defence, to file a list of documents, to file a list of statements, and to comply with the time limit. We've found that we don't have to do that anymore, so a lot of... the time that we wasted doing that, we're not doing anymore. (Tenant lawyer)

Hence, one tenant lawyer felt that costs had 'dropped dramatically' because of proportionality but also because of legal aid reasons: 'If a case then grows out of proportion you're looking at legal aid implications and things like that, so they all tie in.' Another tenant lawyer was uncertain whether cost improvements were attributable to Woolf or to more general improvements in the efficiency of local authorities and greater willingness to do repairs. $\mathrm{He}$ also predicted that settling much earlier would have a strong effect, though it was not an effect that had impacted on his firm's bottom line strongly enough to worry him:

I haven't actually sat down and done the figures... It doesn't seem to have made a huge difference to the sort of income of the department. It has made some difference but not enough for it to merit me spending a lot of time working [it] out. (Tenant lawyer)

Whilst it might be tempting to adduce from the apparently weak effect on this firm's bottom line that costs had not reduced markedly, there is an alternative explanation. This tenant lawyer suggested that one of the reasons he was not concerned about the drop in income was a surfeit of clients seeking help with housing problems. These could be taken on to replace the lost work caused by a reduction in disrepair costs. This point was also made more forcefully by another tenant lawyer, who explained that lost work could be replaced because they had enough work to be able to cherry-pick the best cases:

I think there is an element of cherry-picking because you'll find that the amount of housing firms doing housing [is very small], you'll see the CLS manual which they give you every six months or so, it's totally out of date, it's an absolute appalling mess... Of those that are listed in there that do housing there's probably about four to five firms that do, and of that four to five firms you'll probably find only two or three at any one time are taking on work. So there's a big pool of work out there that you can actually take on board and you can, if you choose to do so, be selective what you take on. So that's part of it. (Tenant lawyer) 
A third tenant lawyer also pointed to the same ability to top up lost disrepair work with different types of housing cases:

We have so much housing work here... we can actually choose what type of cases we take on. So, pre-Woolf... if you looked at any one person's case-load and you looked at the proportion of fees earned from disrepair cases, they would be quite high... If you look at somebody's caseload now, you'll see that the fees are, for disrepair, not more than fifty per cent, because we're doing a lot more, defending possession proceedings and a lot more homelessness cases... But because the local authorities have got their act together and they're doing the work much quicker, you know, we're not earning huge fees on disrepair cases any more. (Tenant lawyer)

\section{Proportionality}

Whilst landlord respondents usually felt that costs had reduced, there remained trenchant concerns about proportionality. This comment was typical:

It was always to be that costs were to be proportional to the amount of compensation a client received and I think that has become a bit of a nonsense really because we've settled claims, you know, where it is $€ 3,000-€ 4,000$ compensation and we're getting legal bills for $£ 9,000-£ 10,000$, and we challenge them and we advance the argument about proportionality and so on and so forth, but the judges are always tenant biased and they usually get all their costs, which seems to undermine the whole process. (Landlord lawyer)

This landlord lawyer felt that costs were improving, although they echoed complaints about lack of proportionality:

The costs sometimes quadruple the damage bill. Will often quadruple the damages. And it's now going the other way. The costs may still be higher than the damages, but it's going better. (Landlord lawyer)

Indeed it was common for landlord lawyers to see costs as the issue driving the litigation. Landlord lawyers suggested a typical ratio would be three pounds in costs for every one pound in damages. Interestingly, a tenant lawyer described an identical ratio but for pre-Woolf cases. This tenant lawyer claimed proportionality did weigh in his own mind when he was deciding how to progress cases:

It wasn't uncommon before Woolf that you'd have claims set in damages, housing disrepair, for $€ 3,000$, and you could have a bill for about $£ 9,000$, $£ 9,000-£ 10,000$, [now] you're not going to see that. (Tenant lawyer) 
Another landlord lawyer was able to provide some historical figures during the interview which suggested that, for his authority at least, costs did not outweigh damages significantly:

I have some figures for you... 1999-2000 we had a total of E1.9 million on damages and costs, and... it was $£ 1.1$ million damages and $£ 960,000$ costs. In 2000-2001, a good thing to see is damages were less, E650,419 and costs E672,408, so I mean again you can see pretty even actually. (Landlord lawyer)

Several landlords indicated their surprise at the level of costs claimed when cases settled pre-action. This may indicate front-loading. One landlord lawyer referred to some cost claims as 'ridiculous' and had threatened cost assessment to get these reduced. As another landlord lawyer pointed out, cost assessment was a tool of last resort:

I have taken a couple [of cases to costs assessment] but you'll appreciate that it costs us money to take on assessments because then you have to put it to a cost draftsman and [in more distant courts he would need to instruct] our solicitors to represent on an agency basis, so sometimes it's often $E 500$ just to pursue the assessment, and are you going to save that at the end of the day? So we're in a difficult position really. (Landlord lawyer)

Another private practice landlord lawyer thought that tenant and landlord costs had gone down initially, but things were beginning to change on tenants' legal costs:

Costs have gone down definitely for disrepair claims, in terms of our costs to the client. Initially, we thought that the tenants' solicitors' costs had gone down a lot because we were settling a lot earlier and not issuing, but they've started to creep up again recently which is alarming us and our clients, so costs are going back up to about $£ 2,500$ now for a tenant's claim... as far as we're concerned, the claim has only been sort of going for six months or more so that's something that has changed a bit. (Landlord lawyer)

\section{Frontloading}

Some landlord lawyers felt that costs were now 'front-loaded', because landlords now needed to be more proactive in gathering evidence. This required more work to be done earlier, and the work to be carried out by more senior staff:

By spending more time on it because you've got to concentrate more on the case and you spend more time looking at the documents... [you] sift through unnecessary documentation whereas before you used to... do a long list of 
documents... and there may be some documents... against, so you've got to make a decision of the documents to be disclosed... so you spend more time, whereas you used to allocate that to somebody else. (Landlord lawyer).

One of the tenant lawyers also adverted to front-loading of costs, but suggested that this was generally counterbalanced by overall reductions in costs. Others also commented generally supporting the proposition that front-loading occurred:

You just front-load things a lot more, I don't know if your work goes down as such because what you would do later on in the proceedings you just do early on. (Landlord lawyer)

I don't think it would have added to costs overall. It's obviously meant you're incurring a lot of costs at an earlier stage which to me doesn't particularly seem to be a problem. (Tenant lawyer)

Overall then, the balance of evidence suggests that costs have reduced although we saw in the personal injury section of this report that such evidence of cost reductions may be unreliable. It is unsurprising that tenant lawyers would suggest that costs had been reduced, but half of the landlord lawyers also suggested this. Landlord lawyers did, however, have much stronger concerns about proportionality. They felt that movement in this direction was not sufficient. There is, though, evidence of front-loading, the balance of respondents views suggested that whilst costs might be higher on early settlements, the combination of more early settlements and lower costs overall meant that the cost position had improved.

\section{Fixed costs}

Proportionality and certainty of costs are related to a further aim of the Woolf reforms: fixed costs. This project was not directly concerned with the feasibility of fixed costs. None of the respondents for this study felt the costs were more predictable. Whilst proportionality appeared to weigh in the minds of tenants, defendants felt that it was an area where the Woolf reforms were more honoured in the breach. Housing disrepair actions present other problems to a fixed costs regime. A large part of the action may be for repairs to be carried out (i.e. a non monetary claim). Where landlords perform the repairs themselves, the cost of those repairs may not be transparent, particularly if costs issues hang upon the level of costs (i.e. if fixed costs increase when repairs are more expensive, local authorities will have an incentive to minimise the apparent cost of repairs to reduce the fixed costs 
payable). Similarly, if there were considerable front-loading of costs as a result of all work being done pre-action, then the kinds of percentage figure discussed in Lord Woolf's matrix would need reconsidering (Woolf Final Report, p.52). Also, one claimant solicitor suggested that fixed costs might make the practice of housing disrepair unviable, although that would depend on the level of fixed costs introduced.

Were fixed costs to be introduced, their viability would need to be tested by other research methodologies; however, these interviews do not point to a particularly favourable environment for introducing fixed costs. That said, claimant lawyers were clearly portraying the handling of disrepair as involving reduced costs and lower levels of litigation. That should lead to greater predictability and ability to fix costs at a proportionate level. Equally, that ability is contingent on factors larger than the litigation system (in particular the capacity of local authorities to handle housing disrepair cases quickly and carry out the necessary repairs satisfactorily).

\section{An open culture?}

Consistent with the practice direction on protocols in the Civil Procedure Rules, one of the aims of the draft pre-action protocol on disrepair is to promote the early exchange of information. Specific approaches to letters of claim and disclosure are discussed later in this report. However, this report aimed to get practitioners' general views in relation to the production and exchange of information on the claim.

Several respondents pointed to improvements in the way information was dealt with. Most felt better information was provided earlier in the claim, with both tenants and landlords being seen as more willing to identify issues earlier and get on with the claim:

Landlords... have to get their act together far quicker than they used to have to. And they do identify the issues pretty quickly, whereas before... the emphasis was on us saying, 'this, this, this, this and here's the report, and here's the issues. This is what we're going for'... putting all the... in particulars of the claim or whatever. Whereas now, the other side are having to look at the issues more closely, quickly. (Tenant lawyer) 
Some landlord representatives pointed to more realistic stances from tenant representatives and not putting forward trivial complaints as section 11 claims for disrepair:

The major advantage is that, it's made claimants... focus on issues and has certainly stopped some of the more litigious firms from arguing about things that they haven't got any cause to argue about, as a cost-building exercise. (Landlord lawyer)

These interviewees also suggested that realism in the framing of claims and the approach to information had a broader impact on settlement culture.

\section{Greater willingness to engage and negotiate}

One outcome of better and earlier exchange of information was a perceived willingness to communicate, rather than obfuscate:

It basically gets the lawyers to think at an early stage about settling the case, what the issues are and everything else, and it also gets the court officials to look at the issues at an early stage and saves on adversarial tactics and makes you become more paper orientated and actually narrows... gets you down to look at things at an early stage and try and settle it. It concentrates your mind. (Landlord lawyer)

The main advantage, I think, is it's made certain solicitors stop and think, and talk. Trying to resolve. And certainly the use of Part 36 has, is a major advantage on both sides. (Landlord lawyer)

As we will see in later sections, this improvement was partly a greater willingness to engage and partly due to a greater willingness to give landlords some time to investigate the claim before issuing proceedings. It was also commonly said that lawyers had begun to think earlier, and with greater clarity, about the cases they faced. Nevertheless, landlords complained that some tenants still issued prematurely, even where cases were not urgent. This was a problem acknowledged by a tenant lawyer: 'I'm afraid I know that some solicitors' practices, for example, would [write a letter of claim] without really giving a realistic chance for the other side to respond.' Several landlords had sought to persuade tenant lawyers to agree a period of grace for investigation of a claim rather than issue regardless of urgency, with some success. Conversely, several of the tenant lawyers pointed to local authorities who would fail to investigate a case even where they were given reasonable periods of grace. Implementation of the draft protocol may improve practice here. 


\section{Relationships with clients}

Another interesting facet of the Woolf reforms is whether it has changed the relationship between lawyers and their clients in any way. One of the common refrains from landlord lawyers, when pointing to difficulties in complying with proposed time limits under the draft pre-action protocol, for instance, was the difficulty in getting their client organisations (local authorities or housing associations) to provide information quickly enough. Landlord and tenant lawyers said they had to be more 'assertive with clients... get them to do what they have to do,' (tenant lawyer). Other changes in the relationship between lawyer and client were more subtle. One landlord lawyer suggested that his local authority was much more aware of costs issues, because they would come along to interlocutory appointments at court and see the schedules of costs that needed to be prepared. Furthermore it encouraged cost-benefit analyses at each stage of litigation:

Each stage you try and put your client on notice that it's going to cost them, notify at each stage the likely settlement that it should be. It brings you more close to your client. (Landlord lawyer)

There were other suggestions that relationships with clients had somehow changed, and that the Woolf reforms had thrown greater responsibility onto the litigants. Thus a private practice landlord lawyer pointed to the substantial training programme that her firm had put in place for landlord clients:

We wanted to warn them that they weren't going to be able to hide in a defence anymore, that they would have to be upfront, talked about discovery of documents in fact, statements of truth, the fact they'd have to sign the documents themselves, the fact that we'd be asking them to sign all our pleadings... it was extremely popular so they'd all obviously heard about the reforms and didn't know what they meant. (Landlord lawyer)

\section{Other benefits?}

Occasionally, interviewees suggested other benefits of the Woolf reforms. One landlord suggested that they had made the legal professional become more aware of their responsibilities of the court. Another more commonly remarked on change was the shift away from practitioner control of directions and timetables to the fast track and court management. This appears to have aided a shift towards realism, and dealing with the substance of the claim over process, even if some practitioners resented court intervention. Some 
comments on this have already been given, showing how it had affected the speed of the process, but it is interesting to see how it forces a focus on substantive rather than procedural issues. Thus, one landlord lawyer said:

But on the whole it's much better, you know. When I started four years ago there were a lot of problems with people making applications here and there for, you know, just disclosure, the witness statements to be exchanged and all of those... and a lot of useless orders and a lot of chivvying along, and I do get the impression that... it seems to be a much better system that you do have a constraint, that you do have this six-month timescale and both parties are pushed towards that, and I like that. (Landlord lawyer)

A landlord lawyer pointed to a change in the undercurrent of, and approach to, litigation:

It has crystallised how litigation is to be run, what the point of it all is and whether it's: 'agree with the other side' or be pragmatic about what you want and what you get... I think the undercurrent has changed dramatically... What you need to do is mindset back five years... and I can remember fire-fighting ex parte applications, injunctions and, you know. (Landlord lawyer)

Another landlord lawyer explained that the old approach of procedural infighting had been replaced by investigation and negotiation:

It has given both sides the opportunity to investigate the case... before, we were complying with directions without actually exchanging any information at all because we were on such a tight timescale, short notice, and also of course you basically used to hide information, you would not give information away until you absolutely had to. So that has changed completely, the whole concept of not being so aggressive but actually saying to the client: 'it's in your interest to give us the information and for us to be upfront about what the position is as soon as possible'. (Landlord lawyer)

Other landlord lawyers made similar comments. It is interesting that it is the apparent rigidity of the fast track process which may, as much as anything, have produced the cultural shifts described above. It is also worth emphasising that this process of constructive engagement appears to take place in spite of the suspicion and hostility landlord lawyers appeared to have for tenants and their lawyers. 


\section{The impact on methods of work}

We have already seen some suggestions that the Woolf reforms, along with other changes such as legal aid contracting, may have had an impact on the working practices of organisations handling disrepair claims. Several local authorities had centralised housing staff in order to specialise in the handling of disrepair complaints. From tenant firms, there was the consistent suggestion that they would do less work on disrepair cases, leading them to take on more cases (doing them more quickly but at lower cost), or alternative cases (shifting the focus of their practice to other types of housing case). This next section considers some of the other potential management changes that Woolf may have engendered. Issues considered were: whether the Woolf reforms had encouraged any changes in the level of staff handling claims; whether the skills practitioners needed had altered; whether their use of counsel had changed; and whether there had been any developments in the use of information technology or office procedures.

\section{Changes in personnel}

Generally, interviewees felt there had not been any changes in their personnel as a result of Woolf. This was true for all of the tenant lawyers and several of the landlord lawyers. Other landlord representatives had made changes to staffing. One said that greater emphasis on pre-action settlement had allowed greater use of non-qualified staff, with supervision and support provided by solicitors, although there was also a suggestion that the authority's reorganisation of legal services had more to do with this than Woolf. Another landlord lawyer, who had increased the number of solicitors working in their department, felt that the fast track increased the need for qualified staff "because of the amount of procedural requirements... [and] because you've got to identify the issues and everything else and you have to act rather quickly'. One of the private practice landlord lawyers also emphasised that files needed to be handled by qualified solicitors on both sides if they were to progress properly. For her, unqualified and/or inexperienced staff were unable to understand and get on top of cases: 'If you don't have qualified staff and they're just acting as a sort of paper processing machine.'

There were no standard staffing patterns in the local authorities interviewed. One did not generally employ solicitors to deal with housing litigation to save costs, whereas another only employed solicitors or barristers, rather than unqualified staff. Others had a mixture of staff, qualified and unqualified. 
Those that had developed specialist teams employed building surveyors to deal with initial pre-proceedings claims. The surveyors would investigate claims, conduct inspections, draft reports and even handle disclosure.

Finally, one landlord lawyer identified more subtle reallocations of work within her team rather than marked shifts towards one particular type of feeearner, although her remarks suggest the role of the senior solicitors has become more pivotal:

\footnotetext{
If anything it has meant that more senior staff have to do them because they are assessing damages at an early stage... [but] because we've standardised our systems and our clients' systems, we did start using trainees and paralegals to acknowledge files, send standard letters... asking for the documents and then get everything organised, but then it would get passed to one of the solicitors or more senior solicitors to do the assessment and actually say, what's this claim worth? (Landlord lawyer)
}

Thus, whilst some organisations have reacted to the Woolf reforms by changing personnel structures, most have not. Those that had changed showed inconsistent attitudes to the use of non-qualified staff. Some lusually solicitors themselves) saw the need for solicitors as being heightened by Woolf, others (both solicitors and non-qualifieds) felt that the reforms facilitated greater use of non-qualifieds. One rationalisation of these contradictions is that approaches to staffing were largely dictated by other organisational needs. Absence of change may be due to other organisational needs, or a reluctance to change staff patterns. Another explanation is that, in some respects, Woolf de-skills litigation (procedure is more predictable), but in others it puts a premium on expertise (speed requires good judgement). However, the economics of practices and local authorities may be more important to staffing profiles than more subtle shifts in the work itself. It may also be that mixed teams of unqualified and qualified staff have adapted to any change in other ways. The next section addresses this possibility.

\section{Skills of practitioners}

Comparatively few interviewees felt that the skills they or their colleagues needed had changed. Although some pointed to a change of emphasis, early assessment of the costs and risks on cases was more important:

Straight away a commercial decision, how much they're claiming and how much is it going to cost you to sort, defend it really, and what's the sort of value. (Landlord lawyer) 
Another landlord lawyer made similar points. Lawyers had to change from tending to prevaricate: 'It takes a different kind of lawyer to sit down and actually try and sort things out... Lawyers... have had to change their fundamental way of thinking.' Tenant lawyers pointed towards another skill, case management:

You're going to have to be a lot more on the ball, you're going to have to be a lot more with it, you're going to have to be a lot more aware of time limits and things like that... And penalties of course in respect of costs; I mean, cost is a fundamental issue. (Tenant lawyer)

Well, if you call it a skill. I think an awareness of time has changed and the need to be more aware of deadlines, whatever, that has changed. (Tenant lawyer)

Skills of non-lawyers were also an issue for landlords employing in-house experts. It was suggested that they had trained in-house surveyors to appear more like independent experts, and also to provide more definite, robust descriptions of disrepair, which would aid the settlement of a claim:

All the surveyors have been on the certified remedial treatment course... I've tried to teach them to address things like degree of disrepair. Instead of just saying things are in disrepair... in terms of deciding the, the liability. And also, their general understanding of the law in relation to section 11 ... For example, they can say, 'there is dampness'. But I want to know how bad that dampness is, and what effect that is having on the tenant's lifestyle, as well as the cause of the dampness, which is all relevant to legal liability. (Landlord lawyer)

\section{Use of counsel}

Some practitioners felt that the way they used counsel had changed. One landlord lawyer was less inclined to use them for interlocutory hearings:

\footnotetext{
Now you tend to go yourself because you have the conduct of the case, you're familiar with the case, you also want to have your client present as well because they will have to know what the costs are in each stage of the proceedings so they become aware of the cost issue and, having become aware of the cost issue, then a commercial decision is made whether or not to fully defend or whether to settle at an early stage. (Landlord lawyer)
}

Several landlords and one tenant lawyer felt that, because speed was at a premium, there was less opportunity to use counsel for pleadings. Others were using counsel less because fewer cases were going to trial or even being issued. Otherwise, respondents felt that their use of counsel was generally unchanged. 
Thus, while there may have been some small changes in the way that counsel are used by some practitioners, the overall view was that these practitioners were instructing counsel on the same types of tasks that they would have instructed previously. However, if it is right that there has been a general decline in the number of claims that have been issued and also the number of cases which would proceed to trial, then the amount of work done by counsel should have decreased.

\section{Use of IT}

The Woolf reforms came at a time when there was heightened interest in the use of computers to improve the efficiency of legal practice. Some practitioners said that they had introduced information technology as a result of the Woolf reforms. A landlord lawyer pointed to a much more 'IT minded' approach, which he said was driven in part by a greater desire to hit case management deadlines. Generally, respondents felt that there had not been significant developments in IT as a result of Woolf, or struggled to disentangle changes in IT that would have happened anyway.

\section{Changes in office procedures}

Several respondents (landlord and tenant) said they had no centralised systems to change and saw them as an anathema to solicitors dealing with a case on its merits. Generally, as with IT, respondents indicated that Woolf had no, or only minor, impact on office procedures, such as changes to precedent letters and some 'tightening up' of procedures. These were seen more within the context of general good management or legal aid franchising than Woolf. There was some indication that the draft protocol might have a stronger effect for some interviewees. Changes were more apparent amongst landlord lawyers, with a general tightening up being seen as necessary if claims were to be responded to speedily:

We have had to tighten... better procedures for opening cases, for getting the surveyor round to the property as quickly as possible, getting a specification prepared... And then more regular monitoring by management, so regular supervision meetings every six to eight weeks and case updates, regular case lists, monthly case lists, get those updated... Checking basically and getting each fee-earner to ensure that their case lists are up to date and that they're up to date on the Excel spreadsheet as well... I can't say that it was just because of Woolf... [but] you could say that certainly the case management... [was] in view of the fact that there were going to be tighter timescales and that we definitely had to be sharper and deal with cases more promptly. (Landlord lawyerl 
Whilst practitioners do seem, on the whole, to have perceived improvements in the way that cases are handled both in terms of their speed, attitude to exchange of information and a stronger, more sensible, engagement between the parties in settling cases, these changes do not appear to have wrought dramatically different approaches to organising or managing work. Whilst the broad thrust of the interviews has pointed to positive changes in the way that work is managed, they also pointed to several negatives. These are discussed in the next section.

\section{Negatives}

\section{Stress}

One landlord lawyer felt that, whilst generally positive, the Woolf reforms had created more stress for practitioners due to a loss of control over the timetable for cases:

Previously, lawyers used to have control of the way in which the litigation was conducted... [now that cases are] dictated by the court, that puts more additional pressure on the lawyers and more stress on the lawyers to meet the deadlines, because basically your claim could be struck out and... costs consequences arise. (Landlord lawyer)

\section{Court timetables and the emphasis on speed}

Whilst there was a strong level of support for the proposition that Woolf had speeded up disrepair cases, speed was not always seen as beneficial. Several landlord lawyers said the speed expected under Woolf was a disadvantage to them. It did not provide them with adequate time to prepare. One tenant lawyer complained that speed led to ill-considered settlements which unravelled later on:

People have come to us and complained where cases have been resolved by Tomlin orders in respect of repairs... the person was represented, and the council simply didn't do the repairs. The client then went back to the solicitor and said the council won't do the repairs, and then they applied for the legal aid funding to be extended to apply for an enforced Tomlin order. That was refused, so the solicitor basically said to the client: there is nothing we can do about it... cases are pushed through so quick and you do get some sort of an agreed order, but it is not necessarily an order that has been sufficiently thought out and that does lead to problems. I also think that judges do feel unnecessarily interventionist in trying to push things through too quickly. (Tenant lawyer) 
A landlord lawyer made similar points about the court timetable, but emphasised the problems for their own work patterns:

Obviously, when proceedings are issued, the timetable is very quick and that's a key development, one that actually doesn't, I think, always work well. Often I think it's too quick and you find that, especially if you have a large caseload, that you can be being rushed on. You can miss deadlines and I think it's very good to try and stick to a speedy timetable but I just can tell from staff I manage as well that sometimes things do get missed. (Landlord lawyer)

\section{Levels of staff}

As already seen, the approaches to staffing varied. One issue that this raised is whether the Woolf reforms require experienced housing specialists to make them work. A number of respondents criticised opponents' staffing levels. A tenant lawyer criticised one firm which had started to act for housing associations, and appeared to employ only recently qualified solicitors and unqualified clerks. A private practice landlord firm criticised tenant firms on the same basis; lack of experience hindered the exercise of professional judgement and purposeful handling of the cases:

I think it may be unqualified staff, and it's almost like pressing a button, they have standard forms and letters... It's just like press the button, hey presto, letter one, letter two, and you can't budge them almost from those precedents. (Landlord lawyer)

\section{Courts and the Woolf reforms}

A number of respondents commented on problems with court administration:

The failure of the court administration to actually deliver... that's very frustrating when you're trying to... stick to timetables or enforce timetables and the court office just isn't up to it. (Landlord lawyer)

This was a concern primarily relevant to post-issue. It was noted that the feeling that Woolf could be ignored might seep into the pre-action stages. One problem was an inability to get applications listed:

[The local] County Court administration have been awful and, you know, you make an application... it might get listed, seven weeks time... There's just no point... You've got no threats to enforce against an opponent who is just ignoring directions. (Landlord lawyer) 
A tenant lawyer agreed, talking about the same court:

The main difficulties that we actually face tend to be on the court side because the court seems to be up to their eyes in applications and there seems to be very few resources available to the courts to actually implement the actual changes, the practicalities that those changes have brought about. (Tenant lawyer)

He pointed to very basic resource issues, with it taking four weeks to get orders printed and sent out:

You'd probably find that it says...order by fifth of January, but you probably wouldn't receive that order till, say, something towards the end of January. (Tenant lawyer)

Resourcing comments were echoed by another landlord lawyer:

[Court A] is just absolutely appalling... they don't seem to be as compliant with the CPR themselves... allocation questions weren't going out when they should... They hadn't got the stuff in the office to deal with the admin, and the judges are so overworked, and there isn't enough of them, that I don't think that they can possibly case manage anyway... they just haven't the time. (Landlord lawyer)

Partly this was a resources issue, but also there were perceived differences in the attitude of judges:

I think it depends on the judges... If you've got the younger district judges they're more inclined, but the older ones are just sort of set in their ways, and certainly the circuit judge at [Court A] just kept going on about the old days, and I can't imagine that judges like that are very geared up for being more hands on, really, which is required of them. (Landlord lawyer)

There was also some variability between courts:

[Court B] seem a bit more geared up for it really and l've been to one there where the judge was very hands on, and even the solicitor on the other side didn't turn up and she telephoned her and we had a case management on the phone, me there and the other solicitor on the phone, and she was much more proactive. (Landlord lawyer)

\section{Sanctions}

None of the respondents were aware of the courts imposing sanctions for misbehaviour during the pre-action stages of disrepair cases. Some interviewees threatened cost sanctions against opponents who delayed, or 
failed to provide sufficient information, and it is possible that these threats either modified behaviour or affected settlements on costs. Thus one private practice landlord lawyer has a practice of threatening opponents with costs if they do not set out claims clearly at the appropriate stages:

If you don't provide us with the information we'll apply to have appropriate costs order against you to be set off against any damages and again, trying to use the overriding objective, and you need to supply information tied within costs as a weapon to try to sort of then force the road of compliance in a way. (Landlord lawyer)

Another landlord lawyer was more wary of court sanctions impacting very much on the conduct of claims:

\begin{abstract}
You will see in claim letters... warnings about costs... if you don't tell us or if we have to issue or whatever... you will be liable in costs... and the interest on damages and all the rest of it. To be honest, both day to day and financially, I do not think that all of that really has made much of a difference to the way we [do things]... we will try and keep costs down... and [anyway] costs are almost always agreed. (Landlord lawyer)
\end{abstract}

And a tenant lawyer pointed out that they were impervious to threats made by landlords because those threats were never carried out in practice. This suggests that, as one might expect, there is little evidence of a direct nexus between court sanctions and behaviour pre-action, although one of the private practice landlord lawyers was seeking to strike out some claims that were pleaded too generally.

\title{
Which reform is producing the effect?
}

Another cautionary note in this assessment of the overall impact of the Woolf reforms points to the similarity in a number of broader trends in legal practice which may have produced similar or stronger effects. Improvements may be attributable to forces other than Woolf. Legal aid contracting and the funding code have heightened an emphasis on cost benefit (i.e. proportionality) as well as managerialism. A level of computerisation is also a requirement of the contract. Several respondents (landlords and tenants) pointed out that it was quite difficult for them to assess the impact of the Woolf reforms when other similar changes had occurred in their organisations as a result of broader pressures for greater efficiency. The new market for professional indemnity insurance was even seen as exerting pressure to improved organisation and management. The views of local authorities on internally driven improvement 
were not self-serving. Some tenant lawyers recognised a change in local authority behaviour which they thought might pre-date, but be reinforced by, Woolf:

There are fewer housing disrepair claims now, and the in-house legal departments from my authorities... have become more adept at dealing with them... At first sight you might think that's due to Woolf, but I'm not sure that the bigger factor is not... greater efficiency on the part of local authorities... but I do think the actual emphasis in Woolf has concentrated their minds on making the offers as well as just the improvements in the efficiency of the local authorities. (Tenant lawyer).

Just as organisational changes had led to some improvements, those advances could be reversed by other changes. Recent reorganisations and financial difficulties had impacted on some of our interviewees and were likely to undo some of the progress made on claims handling. Another cautionary note is that several respondents claimed that Woolf had not affected their own behaviour, though often it had affected their opponent's behaviour: 'I like to think that, as a responsible practice, Woolf simply enacted what was good practice already.'

\section{Summary}

Broadly speaking, the reforms have been positively received by housing practitioners interviewed for this research. The positive responses were also laced with some caution. In particular, there was a feeling that the Woolf reforms had not been adopted uniformly throughout the profession, with a particular concern focusing on less specialised solicitors and those with inexperienced or unqualified staff dealing with housing complaints. There was also a strong sense that larger forces, especially resourcing issues in local authorities, lay behind the success or failure of an approach which puts a premium on the quick investigation and resolution of claims.

Respondents generally reported that cases were settling more quickly postWoolf and, in particular, more cases were settling pre-issue. It was sensed that, as well as providing a timetable for speedy handling for issued claims, the housing practitioners we interviewed had been more willing to entertain pre-action negotiations and allow the time necessary for landlords to investigate claims without issuing. This was not a uniform picture however. Our tenant lawyers pointed out that there were local authorities or private practice firms representing landlords who simply did not did not deal with claims unless forced to by litigation. 
The impact of the Woolf reforms on the costs of housing disrepair claims was usually reported to be positive. As one would expect, tenant lawyers reported that the cost of disrepair claims had dropped. This view was supported by enough landlord representatives to suggest that the change was real rather than imaginary. Our data on personal injury cases suggests, however, that practitioner views on costs have to be treated with caution as their views may be different from the reality. Similarly, landlord lawyers remained concerned about the disproportionate level of costs to damages.

The perceived shift towards quicker and cheaper resolution of disputes was matched by a perceived improvement in the way information was provided and the way that the parties engaged in resolving housing claims. This is partly attributable to a change of attitude amongst local authorities but also to the parties recognising that procedural reforms meant that there was less opportunity for engaging in adversarial use of procedure. Thus, in many ways, the most impressive aspect of the reforms is that they do appear to have influenced practitioners towards a significant change in culture. This change is not, as we have repeatedly emphasised, uniform, although the draft protocol may improve practice. There are those who continue to ignore claims and force tenants into making applications. Nevertheless, the overall improvement, at least for the majority of our respondents, is significant.

Additionally, some respondents adverted to particular problems with the Woolf reforms. The most common concern was with an unwillingness or inability amongst some courts (mainly through resources but also through some judicial resistance) to implement Woolf reforms. Some courts were unable to list applications quickly enough for procedural timetables to have much bite. Nor was it apparent that courts were sanctioning misbehaviour pre-action in the courts that these practitioners dealt with. Nevertheless, the respondents' overall assessment of the Woolf reforms was a positive one, with some room for improvement. A more detailed look at specific aspects of pre-action behaviour reveals where improvement is most needed. 


\section{Chapter 4.4 Formulating and responding to the claim}

In order to establish a housing disrepair claim, the tenant needs to show what the disrepair actually is, whether it is actionable and how long it has been outstanding. A further factor is crucial to the issue of compensation: whether the tenant has notified the landlord previously of repairs, and, if so, when. Similarly, there is a need to understand the impact of any disrepair on the client both in general terms (for an assessment of general damages) but also more specifically, in terms of any medical problems that have arisen and, most often, any special damages which have occurred as a result of the disrepair.

The main sources of evidence for these issues are the client's instructions, the local authority records relating to the tenant's property, and expert opinions on the nature and extent of any disrepair. The use of expert evidence is dealt with principally in the next chapter. How tenant representatives frame letters of claim, how landlords respond and how disclosure is dealt with, provides the crucial framework for all early negotiations and any decision to issue proceedings. This chapter considers whether and how practitioners' approaches to informing landlords of potential disrepair claims have changed. Similarly, the approach for requesting and providing disclosure of relevant documents is discussed.

\section{Notification of housing claims}

It is worth identifying what the landlord interviewees saw as the problems in the way that housing disrepair claims were dealt with pre-Woolf:

- Solicitors issuing proceedings for disrepair without having provided the local authority with prior notification of a legal claim, or providing such notification without providing a reasonable time for the local authority to respond.

- A lack of specificity about what the disrepair alleged is.

- A lack of specificity about how long the disrepair has been outstanding.

- A lack of specificity about when, to whom, and how a tenant notified the landlord of disrepair. 
- A lack of information indicating the size of any general damages for a potential disrepair claim.

- A lack of any information about special damages.

- A lack of specificity about what repairs it is that the tenant requires or expects to be carried out on their property.

Several landlords commented on a (sometimes continuing) approach by tenant representatives which barely specified disrepair, preferring to rely on the landlord's file to evidence the claim:

We usually get a letter from the tenant solicitor saying the client experienced delay in having his work carried out and we would be obliged if you would give us all the information as to when they notified you, blah, blah, blah. (Landlord lawyerl

Sometimes it feels like they are just sort of firing off a letter and then looking for the file to sort of almost bring the claim. (Landlord lawyer)

The reasons for this lack of detail, if indeed it exits, will be explored more thoroughly in the coming sections. It is worth bearing in mind the criticisms as a baseline against which to measure any change post-Woolf. It is also worth emphasising, however, that some of the respondents pointed out that there were firms of solicitors who have traditionally provided good levels of information when making a claim. Sometimes these claims were made by tenant lawyers describing themselves, but it was also a point made by landlords: 'It's not fair to say that firms of solicitors were bad in the past and have radically changed as a result of Woolf.'

\section{Have there been improvements?}

Just over half of our respondents (landlords and tenants) felt that there had been no or only marginal change in the approach of tenants to notifying claims. Tenants of this opinion explained that they had been acting in the spirit of Woolf for at least five years pre-Woolf. A landlord lawyer captured the sense of some, albeit marginal, change amongst the better firms:

If you actually look at the letters themselves, there isn't a noticeable or important difference between a letter before action from a decent firm of solicitors that you got six years ago from one you might get today... It may be on the margins that they are now attaching reports a bit earlier and are a bit more specific about periods, about what's wrong, but I do not think that the CPR has or indeed could make that much of a difference to the actual course of these cases. (Landlord lawyer) 
A landlord and a tenant lawyer commented on some tenant firms still leaping straight to proceedings rather than sending letters of claim:

They tend to issue proceedings and serve you with documentation of the claim, and basically they have nothing to lose by not complying with protocols because there isn't one, and they're legally aided. (Landlord lawyer)

Another landlord lawyer was more positive but still suggested a mixed picture, with too many tenant lawyers failing to properly specify the claim:

Some are good and they have improved, and they will do a proper letter of claim which will outline notice, but still very generally. Still, a lot of solicitors don't and they don't really set out their claim. (Landlord lawyer)

Equally, the remainder of our interviewees (landlords and tenants) were much more positive that a change in approach had occurred. In particular, they suggested that tenant lawyers are much less likely to proceed straight to issuing a claim. A tenant lawyer, who practised in the same city as this landlord lawyer, felt that he had tried to provide fuller letters of claim:

Before, we'd probably just give a brief outline of the case; we tend to now give full details of special damages, liability period and go a lot more in-depth for what we're actually seeking from the other side. Otherwise, we're just going to get a letter from the other side saying: you haven't given us enough detail for our client to investigate the claim... We want more details.' (Tenant lawyer)

Two landlord lawyers, based in the same city, also agreed that the amount of information provided with letters of claim had generally improved:

Different firms approach it in different ways but I think mostly, on the whole, you do get a good pack of information from the tenants' solicitors now. (Landlord lawyer)

Another landlord was positive but confined positive comments to a specialist group of tenant lawyers:

Major housing disrepair specialists seem to know what they're doing and they'll send a detailed letter before action... And others will give you as much as two lines: 'My claimant's property is in substantial disrepair.' Full stop. So, it varies, but tends to be better with a specialist group. (Landlord lawyer) 


\section{What do tenant representatives do differently?}

Pre- and post-Woolf tenant lawyers based their initial letter to landlords on their client's instructions and 'the documents they might bring in'. There was relatively little they could do to collect additional information beyond getting an expert's report land the draft protocol does not recommend that this is done routinely prior to sending a letter of claim). One question is whether tenant lawyers' basic approach to notification of claims has changed at all. Two suggested there had been changes:

There's more case establishment work... for instance, you would get a client come in, they will tell you, 'oh, I've lost $£ 2,000-£ 3,000$ worth of goods', we'll need to go over every one of those goods; when they were bought, if they have any proof. In relation to the disrepair, going over all the dates as to when they reported it, how they reported it, who they reported... a lot more detail in that respect and also in respect of inconvenience, how it has affected them. (Tenant lawyer)

This lawyer found that this work took about half an hour longer, but could still be done at the first client meeting with some follow-up work lcollecting receipts for special damages claims). Another tenant lawyer also suggested that the collection of detailed information on special damages had previously occurred at around the time of issuing proceedings, but now it occurred early in the claim:

We'd put [the client] on notice that we want that information, and often they don't have it at the first interview... So we send them away with a form to fill in, and say: 'Can you drop that back, together with a list as well.' (Tenant lawyer)

The responses of the tenant lawyer suggest there may have been some minor changes to the way that they gather instructions, but there was comparatively little that they could do to improve the information that they get for their claims. Any improvements that had occurred seemed, as a result, to be in terms of what information is relayed to landlords rather than what information is collected by tenants.

\section{Specific information to be provided}

Specific types of information that would be expected within the letter of claim are now looked at in more detail. The draft pre-action protocol suggests that an early notification letter should include (para.3.2):

- details of the defects, including any defects outstanding; 
- details of any notification previously given to the landlord of the need for repair;

- a request for disclosure of relevant documents; and

- proposals for the instruction of an expert.

Letters of claim should include further information (para.3.3):

- history of the defects;

- information as to any emergency work which has been carried out;

- the effect of a defect on a tenant;

- details of any special damages; and,

- details of costs incurred to date lthe pro forma letter of claim suggests attaching a detailed schedule of costs).

The pro forma letter of claim (Annexe B) suggests that the tenant ask the landlord to provide proposals for compensation or, in the alternative, the tenant can set out suggestions for general damages. Effectively then it leaves it up to the tenant representative whether they should make the first offer.

Some landlord respondents described the sorts of information that they sometimes received in good letters of claim: 'You get what information they would have to prepare their particular claim, I think is what it boils down to.' Thus they sometimes said they got a copy of the tenant's instruction sheet to the tenant representative, an expert report which fully described the alleged disrepair, witness statements and a schedule of special damages. Another landlord lawyer described what a good letter of claim contained, describing a copy letter that they had brought to the interview with them:

It's got a surveyors report, it's got [a] schedule... so you clearly know what the disrepair is, and what you're being asked to do... It's actually Part 36ed us. Well... we haven't even investigated it. So it's very premature, but... it does give you an idea of the amount or bracket of damages that you're going to be looking at. (Landlord lawyer)

Another landlord lawyer had some similar perspectives, showing how a clear, detailed letter of claim could help establish the tenant lawyers' competence and enable them to go to the housing department with a clear view of what was being alleged, whereas the opposite might breed cynicism or mistrust:

It specifies exactly what disrepair has been complained of and what the tenant is complaining of and not going on a sort of fishing expedition... itemising what defects there are in the property and that those defects have been notified and 
when and to whom, whether it's by phone, letter, have they kept copies, and really identify what the issue is right at the beginning because it's going to help us, because if we see that then you have a greater trust as a solicitor...you can really have a look at the case and assess it early on. (Landlord lawyer)

And then hopefully some of the good firms, they might even make a Part 36 offer right at the beginning. So, you know, they've done their homework basically and it's not just, 'yippee, here we go, here's another claim, this one has dragged on, we'll get costs for - yes,' because at the most cynical that's what happens.

Thus these responses suggest that there have been some improvements on the types of criteria that the draft pre-action protocol suggests should be covered in notifying claims. Comparatively few respondents averted to specific changes in tenant lawyers' approaches to describing the defects themselves. Of the tenant lawyers, three thought things had not changed very much, if at all, whereas one felt they had improved by 'taking and actually giving details about the disrepair and about the... level of compensation we'd expect'.

There was a stronger sense of improvement in the approach to disclosing special damages, with tenant lawyers being more willing to itemise special damages claims if they were able to. One tenant lawyer said:

In terms of special damages, we will, if we have a comprehensive list from the client... send that at the earliest possible stage. However... many of our clients will not be the most educated people and it can be difficult to get precise information as perhaps you would want to. (Tenant lawyer)

A landlord lawyer agreed: 'Well, they list the item, they list the value, which they never used to', but others indicated that the disclosure of details of special damages was not occurring voluntarily, and that tenant lawyers waited for a specific request for details of special damages. There may be two reasons for this. One would be to allow the client more time to remember all the special damages that they wanted to claim. The other was to allow flexibility in negotiation, particularly where special damages were not evidenced by receipts. Even so, there seems to be an approach that might prompt a rather wasteful chain of correspondence:

In the letter before action we don't go into details about specials at that stage. But if they respond to us they normally then say: 'Okay, you know, what are the specials?' And then we give them a list and any receipts. And what we're 
finding is that we're having to ask our clients much earlier on about what receipts they have, exactly what was destroyed. Whereas before we wouldn't actually do that until the stage of issuing proceedings. (Tenant lawyer)

There were occasions when tenant representatives did deal with general damages, such as when they made a Part 36 offer at the outset or provided a broad indication, 'We don't have to put a figure in... but we... say, “We think this is on a scale of...". However, landlord lawyers reported that tenants rarely made explicit what level of general damages they were seeking: 'They just say investigate and give us an offer, basically.' Another landlord reported tenant representatives adopting a very broad brush approach aimed at keeping the case out of the small claims procedure:

They use the 11,000 cut-off point... they just tend to say... we're looking for compensation for our client up to $£ 15,000$, and quite often when you get down to it you settle maybe at $£ 2,000$ to $£ 3,000$, so nowhere near the $£ 15,000$. (Landlord lawyer)

The requirements of the draft protocol (if implemented) may encourage some improvement here, requiring as it does details of the defects, including any outstanding defects and the history of the defects to be set out in the letter of claim as well as the effect of the defects on the tenants (particularly any personal injury that might be alleged) (para.3.3 and para.4.4).

It remains to be seen whether a general exhortation in the draft protocol to provide 'details of the defects' is sufficient to overcome tenant lawyer's reluctance to specify the alleged defects in a property or whether there are benefits in specifying in more detail what sorts of detail would be expected (for example, which rooms are affected, extent of defect etc.). This is an area which should be kept under review.

As shall be seen when settlements are considered later, there was a reluctance on behalf of tenant lawyers to specify damages claims too closely, if at all, and a particular reluctance to make first offers. Another area where tenant lawyers were sometimes reluctant to be specific was in relation to when the client had given prior notice to the landlord about alleged disrepair. Tenant lawyers based this decision on concerns about the accuracy of clients' instructions. Landlord lawyers saw this as claims building or a fishing expedition.

The time at which the tenant first notified the landlord of disrepair is most important. As shall be seen later, landlords are vulnerable on the issue of notice, especially where their record keeping is poor. Interviewees suggested 
that tenants' allegations of long periods of notice can be difficult to rebut: files can only show complaints that have definitely been made and recorded, whereas tenants can continue to allege that a complaint has been made, even where there are no records in support, on the basis that the landlord failed to record it. Conversely, tenant lawyers emphasised that tenants could have very poor recollections of when they made complaints. Even so, some landlord lawyers felt that some tenants had become more specific about notice:

Whilst some tenant lawyers are good, generally... they don't deal with notice and they still use very vague terminology, you know: 'Since the commencement of the tenancy there has been disrepair and the tenant has notified you of this." (Landlord lawyer)

A tenant lawyer explained the difficulties from a tenant's perspective:

It can be difficult with some clients to obtain... details as precise as you would like. It's not that we're being deliberately vague... it's simply that without the housing file and... people are not as good with dates... as lawyers would like them to be. (Tenant lawyer)

Another tenant lawyer said: 'We give a more detailed account of when the client reported it, how they reported it, who they reported it to.' A second said: 'I try not to give so many dates until I've actually got the file, you know,' and a third said he tried to only give a general picture of prior notification unless he had very concrete evidence form the client (such as a copy letter).

The picture emerging from these comments is of a significant wariness of notifying landlords of precise dates for prime notification. On one level this is because clients are unable to give accurate instructions on when they reported disrepair to the local authority. In some ways this is unsurprising: it may be difficult to recall when notification is made, particularly if the client holds no record and the prior notification took place a considerable time previously. Understandably, therefore, tenant representatives are keener to wait to see what the local authority records reveal about notice, if anything. Equally, it is understandable that the local authorities resent this approach. An approach which gives credence to a tenant's poor memory is also an approach that encourages sharp practice. It would be straightforward for a client to make no specific allegations of notice, for the lawyer to check their housing file and find no records in support of notice and the tenant then to remember that notice was given when they first moved into the property. 
One crucial issue will be the extent to which tenants will be prejudiced by early but inaccurate disclosure if they do specify in detail prior notification to the landlord, and it subsequently becomes apparent that that indication is inaccurate. The pre-action protocol says:

Letters of claim and the landlord's response are not intended to have the same status as a statement of case in court proceedings. Matters may come to light after the letter of claim has been sent, or after the landlord has responded, which could mean that the case of one or both parties is presented slightly differently than in the letters of claim or in the landlord's response. It would be inconsistent with the spirit of the protocol to 'take a point' on this in proceedings, provided that there was not obvious intention to mislead... in particular, points should not be taken regarding discrepancies relating to the general details of notice given in the early notification letter.

It is conceivable that landlords would seek to argue that the words presented slightly differently' mean that only very minor discrepancies between the letter of claim and the ultimate claim would be accepted without costs becoming an issue. Another issue is the extent to which a tenant specifying the period of notice would limit the landlord's duty of disclosure. It is conceivable that the landlord would confine the disclosure of documents to the period of notice alleged by the client. Indeed, one landlord lawyer volunteered that this was their approach. Where it is clear from the local authority's records that notice had occurred prior to the date alleged by the client in the letter of claim, this would obviously cause prejudice to the tenant. This will be returned to later in the chapter, when approaches to the disclosure of documents are looked at.

\section{The benefits of an expert report with the letter of claim}

One further point that is worth dealing with in more detail because it is incongruent with the draft protocol is the suggestion that tenants should generally instruct experts after the letter of claim land then generally as a single joint expert). It is clear that several landlords felt that the inclusion of an expert report at the stage of an initial letter of claim was actually helpful. It enabled them to see more clearly what disrepair was being alleged and, if the expert report was of sufficient quality, what it was expected the local authority should be doing to remedy disrepair. Several respondents commented on the fact that it was common for expert reports to be attached, often because there had already been Environmental Protection Act proceedings where an environmental health officer report had already been commissioned. The next chapter shows that there are some indications of a 
changing approach towards experts, at least for a minority of these respondents. Nevertheless, it is worth emphasising that the expert report provides a very useful early indication to landlords of the extent of the disrepair problem that they face.

\section{The landlord's response}

Under the published draft pre-action protocol, the landlord is expected within 21 days of the date of posting of an early notification letter - to reply, including all records or documents in any file relevant to the disrepair claim (including the tenancy file) and a response to the tenant's proposal for instructing an expert (para.3.5). If a letter of claim is sent, the landlord is expected to reply within 21 days of the date of posting with the same information, plus a response to the tenant's claim, although the unpublished revised draft protocol is believed to contain different proposals for timescales. The substance of any response is expected to include:

- whether liability is admitted, and if so, in respect of which defects;

- the reasons for disputing some or all of the defects;

- any allegations regarding lack of notice or access;

- a full schedule of intended works;

- a timetable for the works lincluding an anticipated start and completion date);

- any offer of compensation;

- any offer in respect of costs.

The phrasing of the last two bullet points is interesting. It does not seem to require an offer of compensation. If this is correct, the protocol does not put the onus on either tenant or landlord lawyers to make the first offer. As will be seen in the chapter on settlement, it may be helpful to require one or other party to make the first offer, as there is reluctance on both sides to do this. Similarly, there is reluctance on behalf of local authorities to make admissions. Again this is discussed in the chapter on settlement rather than here. It is worth considering, however, how landlords have adapted their process of responding to claims post-Woolf in the absence of any pre-action protocol. 
Landlords portrayed their approach to disrepair claims as seeking the quickest, most painless resolution of the claim. Thus it was typical for landlord lawyers to describe themselves as taking a 'commercial approach'.

To identify whether there is disrepair and to resolve it, and that doesn't mean doing everything, it means doing what's necessary, what do I do to make the case go away if that makes sense. (Landlord lawyer)

Some suggested this was a response conditioned by the authority's desire to get on with claims, rather than Woolf. Others suggested Woolf had acted as a catalyst for such change. One landlord had a much more proactive view of what they were attempting to do, which was about challenging, as well as settling, claims:

The surveyor's got to go out to one of our area housing officers, have an appointment with the housing officer, speak to them about the property, anything specific to it. It might be they've got a wild dog in the yard... it might be about previous, historical, you know, problems with the property, in terms of repairs... and then they do a trawl of the actual property file... you might have a nuisance tenant who's trying to claim... because we're about to evict them because they're a nuisance... That's quite a common thing. Or they've not paid their rent for months, you know, and they're miles behind on their rent. (Landlord lawyer)

\section{Speed of response}

As already seen in the chapter describing overall responses to the Woolf reforms, there is a perception that some, but not all, landlords have improved the speed of response to housing disrepair claims. It was much more difficult to get a concrete indication of how long they expected such steps to take. One landlord expected to acknowledge tenants' letters within 28 days and investigate within four months. Two operated a 90-day period to try and deal with the claim (seemingly based on the personal injury protocol). In that period they expected to investigate the claim, get the relevant papers and write with a settlement offer. Most landlords emphasised the amount of work involved in getting to this stage. One also suggested an approach which was geared towards as quick and painless a settlement as possible and indicated the amount of work that had to be done in arranging an inspection, getting a list of works specified, investigating housing files and then responding to a letter of claim:

We'll get the case opened, a letter will go off... to... a single joint expert... and get an inspection date arranged and then usually the in-house surveyor as well will go around to the property with the single joint expert, we'll get the 
specification prepared, we'll get that sent off to the solicitors, get a completion date, get the tenancy property files from the neighbourhood office. This is all very much within the first week; we'll ask for all the relevant information to come from the neighbourhood office... the files, details of works, details of the rent account. And then you'll look through that, and we've got an assessment form for getting requests to authorise settlement and authorise damages which we'll complete, we'll get typed up, giving details of notice, the defects complained of, looking obviously at their letter of claim as well... We will then assess and give it to the client and hopefully make a Part 36 offer. (Landlord lawyer)

As already discussed, some of the interviewees replied with great hostility to the suggestion that they should be able to respond to an early notification letter or a letter of claim within 21 days. One landlord lawyer suggested it would take months to get the relevant papers from their housing officers:

To be honest, it can take months simply because other factors get in the way, like further works need doing, they need to go back all the time... but I would say from once we receive the wad of paperwork from the disrepair team... there is no reason why... we couldn't go back to them, certainly within two months... there will have been cases where we have responded within a week or something. (Landlord lawyer)

One landlord lawyer had initially been able to get the process moving quite quickly but staffing problems had caused serious difficulties. Similar problems had arisen for another.

\section{Seeking the housing file}

Landlords hold various documents on the property and the tenancy. The housing file can be important for several reasons. It may provide evidence relevant to the issue of prior notification by the tenant of any disrepair. It may also provide information which helps the landlord challenge or limit the tenant's claim because the tenant has denied access for inspection or repair, because they have refused to move into temporary accommodation, or as evidence of rent arrears or other problems with the tenant which can be used against them. Often the file is the only objective evidence of the history of the property. This point was made by one landlord lawyer:

At the end of the day it comes down to periods of notice and so forth. The tenant might say anything and memories fail and, in fact, sometimes they'll have forgotten that there was a problem four years ago and it's the same problem they're complaining about now but from our point of view, in terms of what we 
accept as being evidence of disrepair and notice and so forth, we have to rely on our paperwork because frankly there usually is very little else... and in a sense that's their base as well. (Landlord lawyer)

The file can be both a positive resource (it allows concrete assertions based on objective evidence where documents are available on the file) or a negative resource (it permits assertions by either party which cannot be controverted if the file is silent on these points). A tenant lawyer provided an example scenario which was familiar to many of the interviewees, and showed how a file enabled positive assertions to be made on the basis of documents. His client had made specific allegations about a leaking roof which had been a problem for about eight months, as well as 'a little bit of damp in the hallway'. The client did not go into much detail about the damp. When the lawyer saw the housing file, he was able to ascertain that the damp problems were serious and longstanding:

She'd actually had major problems there for a number of years. And that was all detailed in the file, and one of the reasons that she'd forgotten about it all, was because her husband had dealt with all of the complaining and moaning, they were joint tenants, and then the husband had actually died... She said: ' just forgot, because my husband was dealing with it.'... And they'd never ever resolved the problem, they'd come in and out, in and out, in and out, and that was obvious from the file... That happens often. That the client... [has] said it's only a year, or two years, and then you get the file and you realise that they've been complaining far longer than that. (Tenant lawyer)

There are also examples where the absence of information left a party without the ability to rebut the case. This seemed particularly to affect landlords. A private practice landlord provided an example:

Clients would say we want to raise the defence of lack of access or the tenant has... refused to move into temporary accommodation, we've been trying to do this for years, that's why there's disrepair, but their documentation is really poor... you know, will it stand up in evidence? Therefore they'll settle. (Private practice lawyerl

A tenant lawyer also suggested that tenants' evidence would be supported in the absence of written contradiction:

The housing file doesn't really reveal an awful lot. The only useful information you tend to get is a repair which can establish notice, so that does give you some idea. I'm quite happy to do it on the basis of what my instructions are... sometimes it can be slightly difficult but generally I know that if a client says [something] you know, documents can't really disprove them. (Tenant lawyer) 
This was a point recognised more explicitly by a landlord lawyer. As with the private practice landlord lawyer, poor quality record keeping had led to the local authority having to accept whatever a tenant said about prior notice. This led them to downplay the significance of the file (in fact they tended to avoid sending the tenant lawyers the file, partly for this reason):

If you've not got any decent records, then what's the point in... denying something you can't in evidence... [we] take a practical approach, and we accept that it is almost impossible on a 25-page schedule of individual items, from our types of records, to prove al when it was reported, b) whether it was reported, cl was it ever done. If it was done, was it done properly? It's just food for prevarication and cost. So we kind of take the practical approach that we are deemed to have been on notice... Now that might change, because [our housing department] is now bringing in a new system for recording complaints. (Landlord lawyer)

Because files were typically either neutral or a win-win situation for tenant lawyers, landlord lawyers pointed to a broader, underlying frustration. The only objective evidence was in their possession and it was that which bolstered the tenant's case:

Sometimes you feel as though you are just opening the claim for them and that they haven't actually been given... sufficient details of the claim... that's part of litigation, you know, you accept that but it is I think very prejudicial often to the local authority, not always fair. (Landlord lawyer)

The housing file is important because it can establish objective evidence in its own right, but also because it can establish that the tenant's subjective account of disrepair is incontrovertible. For this reason, the draft pre-action protocol encourages the tenant to provide details of any notification previously given to the landlord of the need for the repair'. As in other aspects of the protocol, it does not indicate how precise such details should be. There are a number of scenarios which could cause problems. In particular, if a tenant provides instructions that disrepair was notified two years ago when, in fact, the notification took place prior to that (say five years previously), and the letter of claim is based on the two-year period, there will be a temptation for landlords not to disclose any evidence of notice prior to the two-year period. This is a real, not imagined, scenario:

I have had it used defensively... the authority will say it's not appropriate to disclose this information, or we're not going to send you information from an earlier period because it's not relevant to your pleaded claim. (Tenant lawyer) 
The pre-action protocol does not seem to preclude such an approach. Arguably, this is contrary to a 'cards on the table' approach to litigation. Whether this is perceived as a problem or not will depend on whether the purpose of resolving a disrepair claim is to deal with the tenant's subjective assessment of the claim or whether it is felt to be more appropriate to deal with the objective reality of the disrepair. This is an issue which resurfaces in considering whether or not experts should report solely on defects reported by the tenant, or more widely on all the defects that are apparent in the property (see below).

In implementing and reviewing the draft pre-action protocol for housing disrepair, greater attention may need to be given to the details which a tenant is expected to give about notice, what happens if the tenant's position on notice changes in the course of a case, and the relationship between the detailing of notice by the tenant and the landlord's resulting obligation to disclose the housing file.

It may be that the draft protocol could deal more clearly with contradictions between the tenant's claims about prior notification and the objective records of it. If the pre-action protocol were to specify precisely how much detail the tenant was to give in relation to prior notification, but also specify that the landlord was required to disclose any records relevant to prior notification relevant to the period alleged by the tenant but also relevant to any period prior to that where notification is apparent. It might also need to make explicit that landlords should not take points against a tenant changing their instructions where objective evidence supported the tenant's position. Equally, it might be sensible to emphasise that the tenant's first indication of prior notice would be the strongest evidentially in the absence of objective evidence. This might prevent tenants making vague allegations about prior notice, discovering that the file contained nothing on this, and then making much more specific and claim-enhancing allegations about prior notice. Another approach would be to permit the landlord not to disclose information relevant to prior notification until the tenant had made a suitably specific claim as regards notification.

Beyond these general points in relation to disclosure, it is also interesting to see whether the Woolf reforms have changed the approach of practitioners to the issue of disclosure. 


\section{The tenants' approach to disclosure}

Several respondents suggested that most of the better tenant lawyers have always requested the housing records anyway, given rights to request personal information under the Data Protection Act. However, one landlord lawyer challenged the perception that the Data Protection Act was sufficient:

Under the Data Protection Act, they're only entitled to personal information, so the only documentation they're going to get is things with the tenant's name and address on it. Now, that doesn't involve most of the records they're going to get under normal disclosure. (Landlord lawyer)

Several landlords suggested that tenant lawyers frequently did not request housing records, although some firms had begun to adapt their approach:

Some solicitors are aware of the draft pre-action protocol for housing disrepair and quote that and say, well, we're entitled to full disclosure of your file. (Landlord lawyer)

Some... firms... are now, on the back of the consultation paper, starting to send long, detailed lists... Which they should be doing under the pre-action protocol, and asking us to provide them with all the disclosure documentation. (Landlord lawyer)

Most of the tenant interviewees indicated that they had changed their approach. They were more likely to ask for the housing file and felt that the Woolf reforms had opened up the opportunity for early disclosure. Prior to the reforms, 'we wouldn't have got it, basically. And also, there was nothing there that allowed us to ask for the file.' Some landlords agreed that there had been changes: 'They don't take no for an answer very often.'

\section{Specificity of requests for disclosure}

Another issue is the specificity of the request made by the tenant for disclosure. The presumption lying behind the Woolf reforms is that disclosure should be targeted.

The aim of the early disclosure of documents by the landlord is not to encourage 'fishing expeditions' by the tenant, but to promote an early exchange of relevant information to help in clarifying or resolving issues in disputes. The tenant should assist by identifying the particular categories of documents which they consider relevant. (Draft Protocol, para.4.5) 
It was clear from the responses of both landlords and tenants that the current approach was to make a very general request for the 'housing file'. Tenants might request a copy of information that they are entitled to under the Data Protection Act, or a simple request for the complete housing file, or a request for the 'file and computer records'. As one landlord lawyer pointed out, tenant lawyers are unsure what records are likely to be available and helpful:

They won't know how to describe it and they'll have to be generalised in... Initially, they're not sure what they're after and they're not sure what they're going to get. (Landlord lawyer)

Another said:

Sometimes some firms use like a standard pro forma and... they'll say, we want $X Y Z$...In the letter of claim they'll sometimes list what they want specifically... Otherwise most of them have got a standard letter which is the Data Protection Act request... which means that you just have to send anything which has got the tenant's personal details on. (Landlord lawyer)

\section{Landlord's response to requests for documents}

As we have already seen, landlords resented very general requests for disclosure. As one private practice landlord lawyer pointed out, they feared that files enabled tenants to build claims:

We have generalised claims, and then: 'oh, lets have the whole file', and then suddenly we find... that their claim has expanded to fit in with whatever they find in the file. (Landlord lawyer)

Perhaps to counter this, but also to reduce costs, several landlords try to avoid giving disclosure:

We kind of, probably, if we're going to settle it, get away without doing it. (Landlord lawyer)

We won't send them generally anything, other than our surveyor's report. Which is limiting the whole legal process down to the bare bones... They've not got then to sit perusing through loads of records, because hopefully we're doing them a reasonable Part 36 offer, and they'll go away, and the costs should be very small. (Landlord lawyer) 
Others sought to force tenants into specific requests for disclosure:

We try and say, well, what documents do you actually want... Sometimes I think it's a sort of fishing expedition. It's very often that the tenant can't produce times and dates when they notified the association of problems or whatever, so that the tenant solicitors are relying on us to give them the information to present the case really. (Landlord lawyer)

Other interviewees (both landlords and tenants) indicated that landlords had changed their responses to disclosure requests. One landlord saw no point in resisting disclosure on the basis that he felt they were entitled to it anyway. Others, whilst resisting blanket requests for disclosure, pressured their housing departments or private clients:

We tend to deal with them a lot speedier than we used to... previously, we didn't put much pressure on the regional office to give us the information... but these days we do tend to give the regional office those instructions with strict deadlines... so we do try to put the pressure on those instructing us to give us the information so that we can actually deal with the claim. (Landlord lawyer)

I think landlord solicitors should have been doing it before, but immediately you get it you're wanting all the documents, you're wanting to claims assess. (Landlord lawyer)

Tenant lawyers had mixed experiences. One was positive: 'They are responding to Woolf, and they do actually send us the files.' Another indicated that landlords had been disclosing their file more readily but also that they were generally 'pretty slow'.

A further landlord lawyer also pointed to an approach which might be described as an ostrich taking its head out of the sand:

Before... we used to send out the letter of claim to the housing Department and not worry if nothing came back... [we just] waited for the summons to come in. (Landlord lawyer)

The tenant lawyer in this area said that actually it had not changed at all:

Now the situation is you send them out a 21-day, 28-day letter: they don't respond; we apply for legal aid and we issue; so in that respect the majority of our work hasn't really changed, because the main opponent doesn't react. (Tenant lawyer) 
This was put to the landlord lawyer. They blamed their housing department colleagues:

We obviously rely on the housing department, we have to rely on instructions to the housing department information and reply, so as many times we chase them up, if they don't provide it then the tenant's solicitor is in exactly in the same position they were before. (Landlord lawyer)

Another landlord lawyer pointed to a willingness to deal with disclosure more quickly, which was confounded by resourcing issues and other problems with tenants and experts:

Partly we had staffing problems... a backlog of cases ... we've been stretched. (Landlord lawyer)

\section{Summary}

There were marked differences of view about whether tenant lawyers' approach to notifying claims was suitably specific and detailed. Similarly, there were differences of view about any improvements in the way landlords responded to such claims. This suggests quite patchy improvements in this area. The pre-action protocol may go some way to redress these concerns, although in some senses its exhortations to provide detail are quite general. The potential for detailed, specific claims to limit disclosure may reduce the willingess of tenant lawyers to specify areas that they are not obliged to.

Clearly disclosure is an area where difficulties remain. Landlords resent responding to blanket requests for disclosure and several appear to resist disclosure, partly on that basis, but also as a way of saving costs. They would rather try and settle the case immediately than disclose the file. There were strategic advantages to them in settling cases pre-disclosure because they then did not risk strengthening tenants' claims, or even opening up new heads of claims. Tenants countered that approach with a view that they needed files because clients, for understandable reasons, could not remember precise details about prior notification.

These interviews suggest that the Woolf reforms have raised the level of requests for disclosure by tenant lawyers and the level of compliance with those requests. Those local authorities that seem more willing to, and able to, respond to requests for disclosure were also those authorities that had reorganised their housing disrepair teams into central, specialised 
departments. Interestingly, at least one of these had passed the job of preparing documents for disclosure to surveyors rather than their legal teams.

Whilst the desirability of confining disclosure to specific types of document and the periods of claim alleged by the tenant is self-evident, there are problems with this approach. One is that tenant lawyers are not generally in a position to specify in advance which documents they need. Tenants request the housing file, look at that and think about what might be missing. Whilst it may be possible to encourage a more proactive response from tenants, some respondents' remarks suggested a lack of knowledge sufficient to be able to do that job in a sensible way. Similarly, it is understandable that the granting of disclosure should be confined to the claim as specified in the client's letter of claim. Nevertheless, this may prejudice the client where there is objective evidence of more extensive disrepair or longer periods of prior notice, which is not disclosed because of the limits on the letter of claim. It may be that this is the price which has to be paid for a more efficient, targeted approach to disclosure. It will prejudice some tenants, however, and may discourage specific statements about prior notice with tenants claiming that prior notice may have been given up to the limitation period. If this were the case, the purpose of targeted disclosure would be defeated in any event.

It remains to be seen whether a general exhortation in the draft protocol to provide 'details of the defects' is sufficient to overcome tenant lawyer's reluctance to specify the alleged defects in a property, or whether there are benefits in specifying in more detail what sorts of detail would be expected (for example, which rooms are affected, extent of defect etc.). This is an area which should be kept under review. Similarly, in implementing and reviewing the draft pre-action protocol for housing disrepair, greater attention may need to be given to the details which a tenant is expected to give about notice, what happens if the tenants position on notice changes in the course of a case, and the relationship between the detailing of notice by the tenant and the landlord's resulting obligation to disclose the housing file.

It may be that the draft protocol could deal more clearly with contradictions between the tenant's claims about prior notification and the objective records of it. If the pre-action protocol were to specify precisely how much detail the tenant was to give in relation to prior notification, but also specify that the landlord was required to disclose any records relevant to prior notification, relevant to the period alleged by the tenant, but also relevant to any period prior to that where notification is apparent. It would also need to make explicit 
that landlords should not take points against the tenant where objective evidence supported the tenant's position. Equally, it might be sensible to emphasise that the tenant's first indication of prior notice would be the strongest evidentially in the absence of objective evidence. This might prevent tenants making very vague allegations about prior notice, discovering that the file contained nothing on this, and then making much more specific and claim-enhancing allegations about prior notice. Another approach would be to permit the landlord not to disclose information relevant to prior notification until the tenant had made a suitably specific claim as regards notification. 
Research Study 43 More Civil Justice? The impact of the Woolf reforms on pre-action behaviour 


\section{Chapter 4.5 Expert evidence}

One of the guiding principles of the Woolf reforms is that the use of the single joint expert should be encouraged (Draft Protocol, para.4.6(b)). Experts provide critical evidence in relation to housing disrepair claims. They identify disrepair and may be encouraged to identify how long that repair has been extant, how serious the disrepair is, and whether it is actionable or not. Similarly, they may be encouraged to indicate what should be done to remedy the disrepair. Expert reports provide a fundamental starting point for assessing what repair work must be carried out lor litigated as a specific performance issue) and what levels of disrepair compensation should be.

The draft protocol suggests that an early notification or a letter of claim should contain proposals to jointly instruct a single joint expert to inspect and provide a report on the property. Of course, pre-protocol, the potential for single joint experts was well known - given the personal injury and other protocols. One interesting issue, therefore, is the extent to which housing practitioners have already begun to instruct single joint experts.

\section{Single joint experts?}

It was clear that the preferred approach of most landlords and several tenants was for the tenant to instruct an expert and for the landlord to use either their own independent expert ${ }^{50}$ or, more often, an in-house surveyor. In this sense, the Woolf reforms have not prompted a change. There are a number of reasons for the general resistance to single joint experts. Several landlord lawyers said that tenants rarely suggested single joint experts. Sometimes this would be because the tenants had already instructed an expert, possibly due to prior Environmental Protection Act proceedings in the magistrates' court. Even where tenant lawyers suggested a single joint expert, several landlords indicated that they would resist those suggestions. Similarly, some local authorities indicated that whilst they supported the single joint expert approach, they would in any event send round their in-house surveyor to have a joint meeting with the 'single' expert. This, in effect, meant that the landlords had two bites at the expert cherry. 


\section{Reasons against joint experts}

Landlord representatives were keen to explain their resistance to single experts. It is clear that local authorities hated paying for outside experts when they had their own surveyors. Partly, however, it is about trust; for landlords, external experts raise the potential for arbitrariness. The desire for landlords to retain control over the repair process is also important to them. It was also suggested that single experts were much more geared to trial situations (where claims had to be adjudicated) rather than the majority of cases (where cases had to be negotiated):

You don't want a joint expert because... we might not agree with him, the claimant might not agree with him... I think the whole balance of the expert problem, is weighted in favour of the trial... the court rules obviously have to provide a process all the way to trial but there's a risk... that the very steps are made too onerous or complicated for all those cases which will settle, which is the vast, vast majority. There would be a problem in my view with having a joint expert at trial anyway because I think both parties could end up being unhappy with what he or she said... I think the whole expert issue, certainly from the work we do, is much exaggerated. (Landlord lawyer)

There were other issues behind this concern. Local authorities would use their in-house surveyor anyway, regardless of whether a single expert was instructed or not. They pointed out that local authorities usually lost disrepair cases anyway, and so costs issues were their concern: they paid the costs, not the tenant, in the end. Furthermore, they felt it was necessary to have an inhouse person to schedule and order the work, as well as to check it on completion:

It's not just us being averse to having outside people who are going to produce reports... there is absolutely no benefit to us in having a joint expert, it doesn't save us anything because... there is some liability a lot of the time and therefore we're going to have to pay for the expert anyway... somebody from the council, whoever it is, has to go to that property to order the work... An outside expert... has no clout or no position with our contractors to get them done... It always involves the landlord/owner to... check that it has been done and paid for... So the actual inspection costs, and going back costs, and drafting a schedule of work which may become an expert's report in the fullness of time, that's work that has to be done by us anyway. (Landlord lawyer)

This landlord lawyer was probed on this. His arguments about cost were also clearly arguments about control. Whilst it might be thought that a single joint expert would be capable of drafting schedules of work, the local authority wanted to be able to schedule work in a way that was as cheap as possible. 
Tenants would say that this risked poor quality or 'patch' repairs. The landlord also suggested that there would be bureaucratic barriers to giving an independent expert such a pivotal role:

It would be quite unacceptable for an outside person to be able to instruct the people that we have to pay. So that's just not on; [for the expert to]... say: 'hello, I'm going to instruct your contractors to do $X, Y$ and $Z, I$ 'm a joint expert, you know, where is your computer, where are your forms, where is your headed paper?' (Landlord lawyer)

Other landlords made similar points:

[Independent experts] haven't got the internal knowledge of development programs, or program works, or all the intricacies or the multitude of problems with a local authority... Now they could be instructed in that quite clearly, but even then... there's a practical problem in them actually scheduling the works. (Landlord lawyer)

Another said:

Well, they wouldn't schedule it, would they?... Some other person within my department would have to then convert that into a language that's understood by our repair contractor. (Landlord lawyer)

Another point was that their in-house people might already be involved in a complaint before the case looks ready for any expert, work may have been scheduled or commenced, and a single joint expert on top of that process would cause them difficulties:

We just get on and get done what we think's necessary, and then if that suddenly does progress and they come up with a Scott schedule and... they've brought in a single or joint expert, we've already gone the road doing a piece of work and scheduling work, which just makes it messy. (Landlord lawyer)

They also made clear that the local authority had much broader resource concerns in mind, which emphasised the need for them to retain control. A problem accepted and remedied in one property might set a precedent affecting large numbers of other properties.

We've probably got another 1,500 properties in the same condition so... perhaps for the wrong reason... we want to try and hang onto control as long as we possibly can. (Landlord lawyer)

Only one local authority thought it was possible to work with outside experts and save costs. There was some acknowledgement that there were problems with in-house experts, particularly with the lack of independence and level of 
qualification of in-house surveyors. Some local authorities tended to push these to the back of their minds on the basis that cases would never go to trial. Some sought to address the problems more directly, either by instructing outside experts in cases they felt were bound for litigation, or by trying to beef up the expertise in their in-house teams. Thus, even though Woolf may not have increased dramatically the use of single joint experts, there was an indication that it may have improved the standards and approach of in-house experts.

It was not just the landlords who felt that having two experts was useful. In a strong echo of the landlord comments, one tenant lawyer said that an inhouse surveyor who accepted that work needed doing was more persuasive than an independent expert:

If they have an in-house person [who] say[s] there is disrepair here, they are likely to take notice of that... If there is a single expert who said there's something wrong with this place, and was nothing to do with the council, they find it harder to accept psychologically. (Tenant lawyer)

If this is correct, the use of two experts could promote speedier settlement and might reduce costs, because both parties are likely to be happier with the outcome of an early experts' meeting than a single joint expert's report. Most respondents indicated that after joint inspections between the tenant expert and the landlord's surveyor, disrepair was usually agreed ('it's rare to have something which one says is disrepair and one isn't'). As both tenants and landlords pointed out, the landlords usually bear the cost of the independent expert, hence, even if there is extra cost, it is borne by them in any event. Some tenant lawyers also reported that it would be inconceivable for landlords to instruct the experts that tenants had used, and vice versa.

These responses suggest trenchant opposition to the use of single joint experts, particularly but not exclusively amongst landlords. Nevertheless, some did try to use joint experts. One local authority and one housing association landlord had some success in persuading tenant firms to use single joint experts:

In [London] we have had much more success in insisting on single joint experts and arguing that... you are obliged to consider it... so certainly local firms have almost changed their practice, because in the past they would just run off and get their own friendly expert who often would be an environmental health specialist and not a surveyor. (Landlord lawyer) 
Even some sceptical landlords had occasionally used single joint experts, for example, for personal injury aspects of a claim, and areas of disrepair which needed more specialist knowledge than ordinary surveyors would have (e.g. design defects were alleged, or heating engineers were needed).

\section{Process of instruction for single joint experts}

Where respondents had experience of instructing single joint experts, they were asked to explain how they had done it. In particular, they were asked to discuss how the expert was chosen, how they were instructed, how supplementary or amended reports were dealt with, and how issues of costs were handled.

The draft pre-action protocol pro forma letter of early notification provides simply for the inclusion of a single expert's name and address with a copy of their CV and a draft letter of instruction. It is then for the landlord to object (Annex A). A number of respondents had developed their own lists of acceptable experts whom they expected opponents to choose from. Sometimes landlord lawyers produced a list and sometimes tenants, although in some areas there were difficulties for landlords in disputing particular experts ('it's a bit futile disputing experts because we all know it's going to be one of three people, generally').

Respondents' approaches to drafting instructions differed. One landlord lawyer said they usually did separate instructions but were hoping to develop standard agreed instructions to save costs. Another landlord lawyer said: 'On the whole we ask that there be a joint letter of instruction, and on the whole that has worked.' They also pointed out that tenant lawyers would object to experts reporting on issues which the landlord would want reports to cover. This led to a pointless argument and separate instructions:

We always want the surveyor to comment on any tenant waste or... condensation not due to... water penetration, that type of issue. Some firms have taken objection to that, they feel that the surveyor should only comment on the landlord's repairing obligations and not comment on the issue of tenant waste, which seems absurd... So they write a letter saying, 'we feel you should only comment on the landlord's obligations,' and we write and say, 'no, no, we think you should also comment on any tenant waste that you find...'. And he'll comment on it and just include both letters in there, in his report. (Landlord (awyer) 
One tenant lawyer described a similar process. If there was a disagreement over instructions, they recognised they would simply have to 'grin and bear it'. Similarly, with supplementary questions on reports, the usual practice was for parties to write to the expert direct, raising any further questions they wanted answered, and copying that letter to their opponent, rather than seeking to agree these questions in advance.

Where single joint experts were instructed, costs did not cause practitioners any real problems. Costs appeared to be agreed initially being paid on a halffor-half basis, with all parties assuming that eventually the landlord would repay the tenant lawyer when the case was settled.

On the whole, there have not been dramatic moves towards single joint experts, although some (notably the private practitioners representing housing associations in this sample) have begun to use single joint experts. Some of the tenant lawyers also were trying to adopt this approach but found that, even where a single joint expert was agreed, the local authority would in any event use in-house experts either to attend inspections and negotiate with the single joint expert or to comment on expert reports. In spite of only modest changes being found in respect of the use of single joint experts, there were other changes in relation to expert evidence, which were attributed in part to the Woolf reforms.

\section{Changes in the quality of reports}

Landlords had four interrelated criticisms of expert reports:

- They were not specific enough in terms of describing the repair and whether the landlord was liable for it (e.g. under section 11).

- They tended to assert as fact the tenants' representations about a property during an inspection.

- They failed to include 'waste' (damage that the tenant had caused).

- They were obviously biased towards getting the absolute maximum for tenants. 
Encouragingly, several landlord respondents felt that the quality of expert reports had improved as a result of the Woolf reforms. One landlord lawyer said that:

I think experts have realised that they might actually have to go to court and be objective about this rather than just batting for one side or the other... [Previously] they were vague... they wouldn't identify which defects were which and they just asked for the moon and the stars and they were based upon what the tenant told them. So the slant of the report was very critical and yet, when you began to look at it... they are not within the landlord's repair obligation on any analysis... I think reports are... more accurate... but I wouldn't want you to get the impression that experts' reports have improved dramatically because they're still not brilliant. (Landlord lawyer)

Another landlord lawyer agreed, suggesting that experts were much more conscious of their duty to the court. Perhaps a more important reason was that they wanted to be perceived as independent and reliable if there was any move towards a controlled list of single experts:

These private surveyors know that unless they are seen to be independent, they're not going to be on the list for doing the joint expert. And I think that's why they've moderated, as well as their obligation to the court. (Landlord lawyerl

Thus one of the motivations behind improved objectivity in expert reports is an assumption that there will be a controlled list of acceptable, single joint experts from which the parties can choose. This suggestion hails from Lord Woolf's final report but it has not been carried forward into the draft preaction protocol.

Nevertheless, it was common for landlord lawyers to perceive an improvement. Another landlord lawyer described a stronger sense amongst experts that their obligations are to the court and not to the party instructing them. One landlord lawyer suggested the improvement might be more of a question of improved form, rather than substance:

They have to put certain sort[s] of statements in there that they've complied with their obligations to the court. Previously they never did that. [Whether they are] thinking about their obligation to the court more, I'm not convinced that they are, but at least it's forcing them to think about that more than they would have in the past. (Landlord lawyer) 


\section{Changes in the identity of experts}

Some respondents also pointed out changes in the identity of experts. Several suggested that the choice between an environmental health officer and a building surveyor was made more carefully now l'using the right expert for the right job'), although there remained historic problems lone landlord lawyer said, 'they'll always try and choose experts who'll be tenant biased'). Similarly, a landlord firm reported a tenants firm having ceased to use internal Environmental Health Officers, who were also fee-earners in their firms, to provide reports ('they weren't independent and they didn't have any objectivity, because often they were actually bringing the cases as the feeearner as well as being the expert'). Again, this was put down to the threat of a list of suitable, independent experts; a threat that has abated.

Similarly, some respondents reported a contraction in the number of experts who were available to do the work. This had slowed down the process of instructing experts, who are far too busy because there's only a handful of them:

\section{Joint inspections}

Whilst single joint experts were often rejected by respondents, many pointed to a change in the incidence, and timing of, joint inspections. That is, they said joint inspections occurred in more cases and they occurred earlier. All the indications we received were that meetings between experts were generally without the presence of lawyers. These inspections were often seen as crucial to paving the way to an early settlement. One tenant lawyer said:

We'll always try and make the initial inspection a joint inspection... it has made a dialogue in terms of negotiation with the authority a lot easier and, in terms of them admitting liability... they are now willing as a matter of routine to have a joint inspection and that has made a lot of difference... that is the key change as far as I'm concerned with Woolf... their behaviour has made for an earlier dialogue between the two parties in terms of agreeing areas of liability. (Tenant lawyer)

Another tenant lawyer agreed, pointing out, 'there's a good chance that we'd actually get a meeting together before any proceedings are issued in order to draw up the joint schedule, and things like that'. Many landlords also agreed that this was a strong and important change. 


\section{Summary}

Resistance to single joint experts is strong, but not uniform. Some practitioners have shifted towards greater use of single joint experts. Landlord local authorities, in particular, prefer to use in-house surveyors to negotiate with the tenants' own experts. This provides them with an expert they can trust, as well as enabling them to exert greater control over the resolution of the claim and, in particular, the scheduling of work to be carried out to end the disrepair. It was suggested by both landlords and tenants that this approach allowed both parties to retain a degree of control over the negotiation of a settlement which would not be there if a single joint expert simply presented a report and expected the parties to accept it.

It seems likely that even where tenants and landlords are single joint experts, there is a considerable likelihood that local authorities and others with inhouse surveyors will continue to use that expertise either directly or indirectly in the resolution of housing claims. If that is so, there may be little cost saving in using single joint experts. Similarly, tenants may be placed at a disadvantage by single joint experts because landlords would be likely to retain partisan expertise in any event to scrutinise the expert's report, whereas tenants would not. It should also be remembered that there are benefits to the landlord if a tenant instructs an expert early in the claim. It means that they have a clear indication from the outset of what precise levels of disrepair were being alleged; they could then establish an idea of the likely size of the claim. As will be seen in the next chapter, this is an important factor in landlord lawyers' minds in seeking to gain authority to settle housing disrepair cases.

What remains to be seen is whether the draft protocol will alter the current approach to experts and what the implications of that will be. Respondents' views generally suggested that there is the potential for joint experts to inhibit settlement, increase the transaction costs for landlords carrying out repairs, and prejudice the interests of tenants who have to deal with a neutral joint expert and a partisan landlord expert. The fears of housing practitioners in these respects may prove unfounded. Conversely, a realistic threat that the court may make an order appointing a single expert should the case progress to litigation may encourage a higher degree of objectivity from experts keen to be appointable as single experts in the future. As a result, the role of experts in housing disrepair is an area which should be kept under review as experience of the reforms develops. 
In spite of these pessimistic responses to a particular aspect of the Woolf reforms, respondents did indicate some other improvements in the way that expert evidence was now handled. In particular, several respondents perceived an improvement in the quality and objectivity of expert reports as well as a shift towards a narrower, but more independent and appropriately qualified, cohort of experts. This latter shift was not entirely unproblematic however: it could lead to greater delays and higher costs for expert evidence. Nevertheless, the Woolf reforms do appear to have led to some improvements in expert evidence. 


\section{Chapter 4.6 Settlement}

Perhaps the acid test of the Woolf reforms is whether or not settlement has been made easier, quicker and cheaper whilst also encouraging a 'litigation as a last resort' culture. As we have seen, the Practice Direction on protocols treats the avoidance of litigation as an objective, but the draft pre-action protocol on housing disrepair cases is perhaps more tentative. The landlord's response to a tenant's letter of claim should include 'any offer of compensation', (para. 3.5; our emphasis added). Presumably this means that where the landlord does not have an offer to make, then that is acceptable under the protocol. Similarly, the guidance notes to the protocol state:

Although not specified in the protocol, parties and their legal representatives are encouraged to enter into discussions and/or negotiations before starting proceedings. Parties should remember that the courts increasingly take a view that litigation should be a last resort and that claims should not be used too early when a settlement is still likely. (Para.4.1)

Nevertheless, a large number of the respondents to this research indicated at least some change in approaches to negotiation and settlement of housing disrepair claims. They felt that it was now easier to negotiate settlements in relation to disrepair claims because of Woolf. Most of these were quite strongly positive, with one describing it as a 'sea change'. Others were more restrained:

There is a tendency to try and settle cases at the beginning... so definitely I would say that... it is easier to settle cases... but... litigation is litigation, you still have huge disputes over quantum and it's never going to be ideal. (Landlord lawyer)

Only one lawyer la tenant lawyer) was of the view that settlement behaviour had not really changed at all. A common refrain was that Woolf 'concentrates your mind to try and settle it earlier', although some attributed the change to commercial factors, changes in small claims limits, and the Legal Services Commission, rather than Woolf reforms on pre-action:

I think the change in the valuation in the small claims court [is important]... If we get the work done quickly... take out their specific performance claim, then the damages have to be above $£ 5,000 \ldots$ then it knocks out their legal aid so they tend to settle more quickly than if they think the value of the claim is below $£ 5,000$ which often it is. (Landlord lawyer) 
This landlord lawyer was also insisting that tenant lawyers confirm that they've reported Part 36 offers to the Legal Services Commission and was writing to the Legal Services Commission in the hope that this would add to the pressure to settle.

As well as a general consensus that settlement was quicker and easier, several respondents reported that the number of cases settling pre-action had increased. Even when proceedings were issued, most respondents felt that settlement was generally occurring more quickly compared with the general picture pre-Woolf, where settlement would typically only take place after the exchange of witness statements or even at the doors of the court. It is worth exploring what the parties' attitudes to settlement were.

\section{Attitude to settlement and the economics of settlement}

Landlord lawyers were keen to emphasise that commercial realities meant they were always looking to settle. They were of the view that disrepair claims generally led to some compensation payment, so it was better to agree compensation early and reduce costs:

At the end of the day it's more likely that someone will get something out of the claim, it may be a nominal amount; as far as we're concerned, commercially it makes sense to settle it as quickly as possible... cost sometimes will outweigh the amount of compensation that you pay and so therefore you try and settle it as quickly as possible. (Landlord lawyer)

Another landlord lawyer described a process of pragmatic horse trading, based on the presumption that they were doomed on costs:

They might say, 'my client's been complaining for three years, about dampness'. And... our surveyor... will probably say, 'well, yeah, it's been there for some considerable time'. And we'll say, 'well all right, we'll give you a year and a half'... We won't get involved in broad arguments about each and every action. 'Cause you know that if you go to court and lose on two or three actions out of a whole schedule, you're going to go down for the costs. (Landlord lawyer)

It was common for landlords, and especially private practice lawyers, to emphasise their desire to sort out cases and avoid racking up costs:

They're always concerned about their legal budgets, they hate paying legal fees... whether it's to us or to the other side, but they simply hate paying legal fees to a tenant's solicitors. So if they can pay a tenant's solicitors $£ 1,000$ rather than $£ 5,000$ they're extremely happy... If they can pay us less they're 
happy too... The savings per case... taking our costs and the other side's costs, you might be looking at $£ 6,000$ or $£ 7,000 \ldots$ it's a big deal to them. (Private practice landlord lawyer)

Another landlord pointed to the economics of a settlement culture leading to a kind of blunt justice: more cases got compensation land more of these would be without merit) but actual damage settlements, on average, decreased:

You've got less damages and costs being paid but actually more cases, or a greater percentage of cases, having damages and costs paid on them. (Landlord lawyer)

This suggests that the economics of disrepair cases have encouraged quicker settlements, lower average damage payments, but more successful claims (as a proportion of claims made). This landlord lawyer backed up his claims with management statistics. Because the number of claims made had dropped, landlords sometimes perceived a drop in legal costs and a drop in compensation payments. The latter could be due, as one tenant lawyer suggested, to a reduction in the length of time a tenant has had to suffer disrepair and therefore lower general damage claims. But it could also be due to a number of other factors. One tenant lawyer suggested that clients were less aggrieved where local authorities dealt with disrepair and settled cases quickly. This would reduce the tendency of tenants to dig their heels in when it came to compensation. Similarly, Funding Code issues and, in particular, the Legal Services Commission's greater emphasis on cost-benefit analysis, may be prompting tenant representatives to settle for lower amounts of compensation. Some tenant lawyers were also conscious of the concept of proportionality, and that they had to consider whether it was worth rejecting a settlement given the extra work that would be generated as a result; work which would not necessarily be claimable.

\section{Other factors affecting settlement}

There were a number of other factors beyond economics that interviewees suggested had contributed to making settlement either easier or quicker. Thus, a tenant lawyer suggested that landlord lawyers who took the lead in suggesting a timescale within which a claim will be investigated and negotiated were more likely to meet with a positive response. Landlords had to make time for settlement but they also had to mean it. Tenant lawyers quickly picked up on landlord lawyers who asked for extensions of time to reply to letters of claim but then did nothing. 
Another factor giving rise to easier and quicker settlement was a greater willingness on the part of landlords to schedule repairs quickly and to get those repairs done. Several respondents, landlords and tenants, pointed out that it was essential for there to be agreed timescales within which the work would be done, and preferably for the work itself to be completed. Some landlord lawyers emphasised the need to have works completed and inspected prior to settlement of compensation if an agreement was to be robust and long lasting:

[A] date for a joint post-inspection. That's important... That is our mechanism for stopping them keeping coming back once we've resolved it. In other words, we used to get the works done, and then they'd come and say, 'well, it's not been done properly.' (Landlord lawyer)

A number of landlord lawyers claimed to have changed their approach to inspection and repair, pressurising their own clients to sort out the claim, rather than sitting back and waiting for proceedings to be issued. This was partly a matter of reducing legal costs, but it was also about reducing the extent to which claims would go wrong:

[I] put pressure on those instructing us to get round and inspect and get the works done before they can sue us... If they're asking for compensation... we've probably done the work so the judge will be a bit more sympathetic to the housing association. (Landlord lawyer)

Landlord claims were not simply self-serving. Tenants recognised the reality of this change, describing a complete reversal from the process that used to happen under disrepair claims pre-Woolf. Cases had to be issued, and go to trial or be settled by consent with a Tomlin order, which would specify the works to be completed within a particular time frame before compensation would be paid. Now, however, repairs and settlements occurred pre-action:

Whereas now, the work's are being done, probably within about two or three months of us writing the letter before action... negotiations in relation to quantum are going on whilst the works are being completed. Whereas before it was completely the other way round 'cause you'd get your quantum sorted out at trial, but ... you'd still have to get your order for specific performance... In terms of compensation, we don't actually work out the compensation until the works have actually been completed and everything's hunky-dory now. (Tenant lawyer)

There are other factors that also seem to aid settlement. Better and clearer information in the letter of claim enabled landlord representatives to 'get a fairly good idea of what sort of size claim it is'. Similarly, for tenant lawyers, 
the fact that landlords now 'actually send the file' enabled sensible settlement discussions to proceed, as did the fact that landlords now tended to get surveyors' reports more quickly. Similarly, as noted in the chapter on housing experts, the increasing tendency of local authorities to hold joint inspections in relation to disrepair claims had greatly improved the opportunities for early dialogue between the two parties. Making early offers and simply dealing with correspondence rather than engaging in a process whereby correspondence was ignored, chased, ignored and chased again. These were all mentioned by tenants as improvements that had aided settlement.

Part 36 offers were repeatedly mentioned as a positive factor in promoting settlement (see below). Similarly, there was a feeling that the Woolf reforms had replaced a system of resistance played out against a very flexible procedural backdrop with a more sensible pragmatism. It was no longer the parties, but the courts, that controlled the fast track timetable and dictated the pace:

It has changed the culture... In previous litigation you were sort of more aggressive, that aggressiveness is now dying as you become more amenable... because you're not dictating the pace, the other side is not dictating the pace, nobody is trying to take procedural advantage of the other and... Now it's the court dictating the time and if you want anything you have to go back to the court so you're not taking much advantage over the other one procedurally. (Landlord lawyer)

Another landlord lawyer related a willingness to settle to the court management but in a less edifying light. Cases were settled to avoid the unpredictability of the courts:

I think the main fear of most lawyers, if they're going to litigate, is... a case management conference... the fear of the court managing the case... I think that's the bottom line... It just makes people focus on what they're doing. (Landlord lawyer)

Some interviewees also referred to more underlying, or cultural, changes of approach and emphasis, which had been brought about as a result of Woolf. Thus a landlord lawyer suggested, 'it takes a different kind of lawyer to sit down and actually try and sort things out'. And a tenant lawyer talked about a 'sea change' in attitude, a shift from stand-off to engagement:

I think that people's attitudes... landlords' attitudes have changed a lot... preWoolf we wouldn't get anything from the local authorities at all... It really has been a sea change... you could actually enter into a dialogue with the other side, whereas before you couldn't. (Tenant lawyer) 
Another landlord lawyer also pointed towards engagement in the substance of the dispute rather than searching for procedural delaying tactics: 'It's made certain solicitors stop and think, and... talk. Trying to resolve.' Although another tenant lawyer was cautious about attributing this effect to Woolf, he did say:

The facilities were there pre-Woolf to do all these things, it's just that they didn't for various reasons, but I do think the actual emphasis in Woolf has concentrated their minds on making the offers as well as just the improvements in the efficiency of the local authorities. (Tenant lawyer)

This theme of cultural change, of stopping to think and engage, was a common one emerging in most, but not all, interviews. It suggested a broader shift in the skills and outlook of housing lawyers:

Woolf has basically turned a lot of litigators into claims handlers, you're a claims handler... like... working in an insurance company... A lot of the claims that maybe we wouldn't have settled now you would just... get rid of... limit the cost... Looking optimistically, a culture of trying to resolve cases without getting into [the] petty sort of battles and needless applications that are brought. (Landlord lawyer)

This latter comment suggests an interesting paradox. Lawyers perceived the sense in the Woolf reforms and the benefits to their clients, and indeed themselves, in dealing with the substance of disrepair claims, rather than the procedures by which such claims were litigated. Equally, there is a sense in which the work has been downgraded to that of a 'claims handler', with the art of litigation and, in particular, the art of defence, being diminished in the lawyer's repertoire.

A final aspect leading to quicker settlement was, according to some landlord and tenant respondents, the concept of proportionality. It is surprising that this was mentioned given the general perception amongst landlords that costs were significantly disproportionate to damages even post-Woolf (see above). Even so, a landlord lawyer felt that the concept of proportionality had reduced a willingness of tenants to push cases further in an attempt to get more compensation. As has been noted at other points in this report, this may have a downward impact on damages:

[Tenant] solicitors have really got to be conscious of the amount of work and effort that they're putting into a matter which is, at the end of the day, going to have a relatively small damages payment. (Landlord lawyer) 
Another landlord lawyer agreed:

Even though... the costs are out of proportion to the compensation obtained... you might get a few solicitors' firms that think, oh well, test of proportionality, we better try and settle it rather than let it drag on for years. (Landlord lawyer)

\section{Admissions}

One of the ways in which landlords appear not to have changed their behaviour was in making admissions of liability. A landlord's response to a tenant's letter of claim is, under the draft pre-action protocol, expected to include whether liability is admitted; if so, which defects are admitted and, where liability is disputed, why liability is disputed (para.3.5). Our tenant and landlord interviews suggest that landlords tended to make offers on a without-prejudice basis rather than any admissions of liability. Typically, landlord lawyers said, 'we will often make Part 36 offers but not necessarily with admissions for liability'. Another landlord lawyer described a greater willingness to engage with tenant representatives, discuss disrepair and discuss what was to be done about it. Whilst this increased the amount of information flowing between the parties, actual admissions were not forthcoming. As one landlord lawyer implied, the process is to settle rather than to admit:

I think there has been a change in culture in that we're more prepared to admit if there's been a problem... I would say that we were pretty up-front really because we don't want to get involved in legal action, especially if the tenants are legally aided... we acknowledge there's been a problem, we'll try and do the work as soon as possible and we'll hand you over compensation.

Interviewer: DO YOU MAKE FORMAL ADMISSIONS OF LIABILITY, OR IS IT MORE WITHOUT PREJUDICE?

Yeah, without prejudice. I just think it's in the lawyer's nature not to make a complete admission. (Landlord lawyer)

\section{The process of making offers}

A key issue relevant to settlement is when the first offer is made. Landlord and tenant lawyers referred to reluctance on the part of tenants' representatives to make a first offer. This left landlord lawyers with less information to evaluate the claim and (in their eyes) unable to advise their client as to the costs and benefits of defending the claim: 
I used to ask tenants' solicitors, 'let me know what you think the claim is worth', and they'll say 'no, we're not going to tell you that, you make an offer and we'll tell you if it's acceptable or not,' so it's like playing a guessing game. (Landlord lawyer)

A tenant lawyer pointed out one reason why tenant lawyers would be reluctant to make a first offer:

We're rarely in a position at that initial stage to make a realistic Part 36 offer without having seen what the housing file says in terms of repairs that have been done, notification and all the rest of it... it's not usually possible to make... not wise to make an offer solely on the client's verbal instructions as it were. (Tenant lawyer)

Another tenant lawyer agreed. She explained her reluctance to make a first offer:

Pre-Woolf... I was always trained to say, 'don't make the first offer'... PostWoolf, in a sense that has changed, because we do have to think about it, and it is more sensible actually to make an offer, but you don't want to go too low... I haven't really worked out what course [to take]... to tell you the truth. We tend to do it on a case-by-case basis, rather than saying, right... I probably should be [ready] at this stage to make a Part 36 offer'. (Tenant lawyer)

Landlords tried to get tenants to make the first offer, 'we always want them to... nail their colours to the mast', and several landlord lawyers pointed out that there might be benefits to a tenant lawyer in making the first offer, in that the landlord representatives then had a starting figure against which they could gauge the costs and benefits of proceeding or settling. Nevertheless, landlords found that they often had to give in and make a first offer:

My approach to things usually is... to say... well, what sort of compensation are you looking for?... But what you usually find is that then they bounce it back to you and say, 'well, what are you prepared to give us?'... If it gets to the point where, you know, it's just an exchange of correspondence and we're not getting anywhere, then l'll take a view according to the case law and my lawyer's training and experience as to what I think it's worth and make a Part 36 offer to settle. (Landlord lawyer)

One problem was that tenants were not willing to make an offer before receiving disclosure. It was clear that landlord representatives also relied on the housing file in assessing their first offer:

We would work from the file... see what disrepair there was, what dates it was reported from, what repairs were carried out and when. And then we would try to assess what we think the claim is, using the very generalised sort of 
allegations made by the tenant. And then immediately at that point write to the client saying: 'This is what we think it's worth. This is the cost of... defending. Do you want to make an offer?' (Landlord lawyer)

Landlords said it was typically them who made the first offer and it may be in their interests to do so as a way of minimising costs if, as these interviews suggested, early offers led to early settlements. Whilst they did not feel that their making the first offer was a change in practice, they did feel they were making offers more quickly now. Equally, some tenants clearly did make the first offer, sometimes with the letter of claim, as landlord lawyers acknowledged:

Some... do really good letters of claim... actually saying... what they think the quantum is, although usually that has been inflated slightly. (Landlord lawyer)

Another landlord lawyer said:

Certain firms... make an initial Part 36 offer which I think is a very good thing and something to be encouraged... [I]t would be very helpful for defendants if they knew this is the range of damages that are being sought... and it's not going to then just sort of turn into fishing expeditions. (Landlord lawyer)

\section{Part 36 offers}

Pre-Woolf it was possible for tenants or landlords to make Calderbank offers, but the creation of Part 36 offers provided a renewed focus on claimant offers backed up by the potential for interest and indemnity costs. It also emphasised the facility for landlords to make offers without having to make payments into court. Some of our respondents, as already noted, pointed to the existence of Part 36 offers as a beneficial element speeding settlement. One issue that was explored in the interviews was the extent to which parties were using Part 36 offers. There was a general feeling that both landlords and tenants were using Part 36 offers and also that the likelihood of both sides making an offer had increased, because Part 36 focused practitioners' minds onto opportunities for offer making. Just occasionally, it was suggested that the use of Part 36 offers was confined to better, more specialist, firms, but most of the interviewees said that either they or their opponents were using Part 36 offers. Some felt that the fact that one party made a Part 36 offer was more likely to encourage the other party to make a Part 36 offer. There was also a feeling amongst some practitioners that the use of Part 36 offers had had a cultural effect rather than a substantive effect. Thus, this tenant lawyer suggested that: 
The benefits of a Part 36 offer for a claimant aren't particularly great, so I don't particularly think it would cause them to go, 'oh a Part 36 offer',... I don't think it's a major sort of threat unlike if they made one.

Nevertheless, that lawyer said that he used Part 36 offers routinely. Certainly for landlords, the suggestion is that Part 36 has not dramatically increased their leverage. As one tenant lawyer said, use of Part 36 had coincided with a greater likelihood of making settlement offers:

There is a cultural thing that has made Part 36 offers larger in defendants' minds. Again it's difficult to disentangle general greater efficiency... [Before] they wouldn't pay in or even think about any sort of settlement until they'd sent their brief to counsel a couple of days before trial. (Tenant lawyer)

This change was even more apparent for tenants:

I mentioned earlier about claimants being a bit hedgy about telling you what they want. I think it has had this effect that they now say: 'Right, we'll make the Part 36 offer. We'll actually force the slow council into some sort of proven response'... It has had perhaps not the effect that was intended in terms of the cost section but it has allowed claimants to make an offer which has some... procedural basis, so there's something in an envelope on the judge's chair which he just produces or which he looks at... So, yes, I think it has had an effect because you do get claimants making Part 36 offers, that is quite common and I think that's a good thing. (Landlord lawyer)

It is interesting to note that several of these responses have emphasised the peripheral nature of costs and interest sanctions, although some did feel that the cost sanctions were a benefit.

Some comments were made on the content of Part 36 offers. One landlord lawyer complained about the inadequate content of Part 36 offers from tenant lawyers:

When we make Part 36 offers we set out completely the basis on which we say we're liable... There have been lots of cases I think, on Part 36 in particular, where if we say it's not acceptable, we want you to come back under the rules and set out... the basis on which they are rejecting it, what their case is, what you say the offer should be... If you don't do that you can start getting into the realms of indemnity costs orders and things... We're trying to use the rules sort of in that way to force people to set out their stall almost on what their claim is and... what they want and what they are prepared to settle on... they will never do that, they will always just leave it to the landlord solicitors to come up with a figure. (Landlord lawyer) 
Whilst there was some sympathy for the need for more detailed explanations of the basis for offers (or rejections of offers) amongst other landlord lawyers, most other respondents concentrated on the amount being offered as part of a Part 36 offer. As this landlord lawyer said:

Now the most important thing in that Part 36 offer will be the figure, and if the figure is off beam then it doesn't matter whether they complied with 361 (c), whatever it is... whether the notice is defective or whether we never made a payment in... It is often the case that when you get to the stage of making an offer, the other side are talking to you and saying, 'well, we want... you're offering six, what about seven?', and that the formula of Part 36 offers is not important... It's a good framework but it can be regarded as a strait-jacket, an unnecessary strait-jacket which you have to follow and for practical practitioners, once you get to the stage of being able to make an offer, the Part 36 process probably doesn't make much of a difference. (Landlord lawyer).

\section{Mediation}

None of the respondents reported using mediation in settling housing disrepair claims. One landlord lawyer expressed an interest in using it, on the basis that it would be cheaper and less adversarial. Another was interested in housing officers 'mediating' directly with clients before lawyers were instructed. They were also interested in putting arbitration clauses into tenancy agreements serviced by a bespoke arbitration scheme like the one in Southwark. Equally, arbitration schemes might operate to exclude or minimise the role of lawyers for legal aid reasons.

Generally, parties showed little or no inclination to mediate. They suggested that the nature of the dispute meant that negotiation was normally adequate, and if it was not then mediation would not help; differences had to be adjudicated at trial:

To be honest, from most of the cases, I think there is some negotiation between the parties and for the cases that will go to court... either there is some radical difference between the parties as to what the defect is or how it's caused or how to resolve it or, more commonly, they will want $£ 20,000$ on analysis we think they're only ever going to get $£ 12,000$, and that financially it is worth us going to court. (Landlord lawyer)

Housing disrepair cases are expert evidence- dependent things, liability really is settled most of the time. Obviously there are other issues, interpretation of tenancy agreements, etc., and most of the time it's simply a question of what the experts say, and once you're over that it's a question of offers of settlement under Part 36, and mediation hasn't been pushed by the court or by the opponents or by us. (Tenant lawyer) 
Some suggested that tenant representatives never take up offers of mediation or that landlords failed to suggest it. Others said simply that it was not a requirement for housing matters or that the absence of a local mediation scheme precluded it.

\section{Costs and settlement}

Landlords sometimes took a somewhat fatalistic attitude to costs:

They get their costs anyway because, if you're liable for one defect, you're liable for one defect, and if you can knock them out on the other 29, good, but I'm afraid that the essential crux is that you're still liable, and trying to sort of reduce the costs accordingly is always a bit artificial. (Landlord lawyer)

Several landlords suggested costs disputes dragged out claims for long periods of time, when the essential subject matter of the dispute had been resolved. Often settlement had occurred with costs to be agreed or assessed, with only one landlord claiming to go for settlements which included damages and costs. Several landlords criticised tenant lawyers who 'might go a bit high but they usually tend to settle it'. Tenant lawyers were also criticised for 'quoting ridiculous amounts, especially if it's pre-issue and nothing has been contested'. Generally costs were settled and few had carried out threats for cost assessment.

\section{Small claims and costs}

Several landlords pointed to uncertainties about whether a case was a small claim case or not as giving rise to significant disputes on whether costs were payable. This landlord was typical:

A huge headache, I would say, on costs pre-action... we would still argue that often they may not be entitled to costs, especially if they were to issue proceedings, it would probably be dealt with as a small claim, there are many cases that fall into that category and then you get obviously into the arguments of: 'We believe that the costs of the works are over 11,000 , all the damages agreed are over 11,000 .' If the works have been completed you're then arguing... this would fall under a small claim, the damages are going to be under $€ 5,000$, all works have been completed, you know, this could have been dealt with without use of lawyers. It's still a huge difficulty but we... are still finding we will pay costs. (Landlord lawyer) 
It was clear that a number of landlords found themselves arguing about costs on cases that they regarded as being small claims cases. It seemed likely also that some of these cases were cases that would have been fast track cases but, as a result of negotiation between the tenant lawyer and the landlord, some repairs had been carried out. Only at that stage would the case be a small claim case. Nevertheless, landlords are seeking to treat those cases as small claims and not pay costs. Even so, it was clear that landlords often seemed to find themselves paying some costs.

\section{Summary}

There was a clear and strong feeling amongst the majority of respondents that settlement was quicker. A large number of respondents pointed out that there were more settlements pre-action than previously. There are a number of factors contributing to a stronger settlement culture. Attitude to settlement had changed; this may be partly attributed to Woolf but also to greater realism amongst local authorities. Similarly, better resources for housing repairs may have enabled local authorities to conduct more repairs and therefore settle more cases quickly.

The way the parties approached claims also made a difference to settlement. Making time for settlement and using that time productively was important. Similarly, ensuring that repairs were scheduled and carried out was a crucial factor for some parties in reaching settlements. Better letters of claim, quicker disclosure of relevant housing documentation and approaches to experts also improved settlement. Heightened use of offers and Part 36 in particular also seemed to contribute to the settlement culture. There may also be other factors, such as parties' reluctance to have proceedings issue and then enter into the fast track, where time pressures would mean much more work having to be carried out quickly with possibly detrimental results.

There were also areas in which settlement behaviour might improve. Admissions were rare. It may be that this is not a problem if parties are exchanging without-prejudice details about what repairs will be carried out and when. The content of offers may also be lacking. For some practitioners this caused a problem. Lack of detail in offers made it difficult for a party to evaluate the basis of, in particular, the tenant's case. Cost issues also posed difficulties, particularly with regard to small claims. 
Research Study 43 More Civil Justice? The impact of the Woolf reforms on pre-action behaviour 


\section{Chapter 4.7 Housing disrepair work: do the reforms meet their aims?}

Broadly speaking, the Woolf reforms have been positively received by the housing practitioners interviewed for this research. The positive responses were also laced with some caution. In particular, there was a feeling that the Woolf reforms had not been adopted uniformly throughout the profession, with a particular concern focusing on less specialised solicitors and those with inexperienced or unqualified staff dealing with housing complaints. There was also a strong sense that larger forces, especially resourcing issues in local authorities, lay behind the success or failure of an approach, which puts a premium on the quick investigation and resolution of claims.

It is important to keep in mind, when considering the potential impact of the Woolf reforms on housing disrepair litigation, the specific context for housing litigation. There is, certainly from the perspective of landlord lawyers, a degree of scepticism of tenants and their lawyers, which could lead to quite serious levels of hostility and adversarialism. Equally, however, the fact that both tenant lawyers and landlord lawyers are under a degree of pressure to ensure that cases are handled as cheaply as possible leither from the local authorities or from the Legal Services Commission) may mean that there is a reasonably strong incentive to settle cases quickly, which is independent of the Woolf reforms. Other aspects of managerial change have all added to a framework which emphasises pragmatism and settlement over adversarialism.

There are some other interesting aspects to the environment in which housing disrepair cases arise. Pragmatism and pressure towards settlement may be reducing the compensation payments to tenants, thus reducing the overall cost of the housing disrepair litigation process to landlords. There are also interesting indications of conditional fee agreements beginning to have a role in housing disrepair litigation, although only a very minor role. The vast majority of litigation is legally aided. 


\section{The impact on structure and management}

Our interviewees did not report dramatic changes to management or structure of their organisations (be they private practice or in-house lawyers). Greater emphasis on procedures and systems appeared to relate more to external forces, such as legal aid franchising or efficiency drives in client organisations. One interesting question that interviewees' responses posed, but did not answer, was whether the skills demanded of practitioners postWoolf are met by their current staffing structures. In particular, there was a reasonably strong suggestion that Woolf led to routinisation of some aspects of practice (particularly basic procedural steps) which might sensibly be dealt with by non-qualified staff; whereas the general emphasis on speed and early settlement put a premium on expertise and experience lpossibly requiring qualified staff). Nevertheless, it was clear that interviewees had not generally reorganised their staffing patterns to adapt to Woolf. Rather, they sought to manage the work with the existing balance of staff. Where firms had sought to employ paralegals in large numbers, their opponents felt that the staff did not have the necessary knowledge or flexibility to handle cases in the spirit of Woolf.

\section{Costs: reasonable, predictable and proportionate?}

The impact of the Woolf reforms on the costs of housing disrepair claims was usually reported to be positive. As one would expect, tenant lawyers reported that the cost of disrepair claims had dropped. This view was supported by enough landlord representatives to suggest that the change was real rather than imaginary. Our data on personal injury cases suggests, however, that practitioner views on costs have to be treated with caution as their views may be different from the reality. Nevertheless, landlord lawyers remained concerned about the disproportionate level of costs to damages.

No respondents felt that costs had become more predictable post-Woolf. This unpredictability and lack of proportionality could be argued as a reason for or against the introduction of fixed costs. If fixed were costs to be proceeded with, this area would require further research.

\section{Changes in information and culture}

The perceived shift towards quicker and cheaper resolution of disputes was matched by a perceived improvement in the way information was provided and the way that the parties engaged in resolving housing claims. This is partly 
attributable to a change of attitude amongst local authorities, but also to the parties recognising that procedural reforms meant that there was less opportunity for engaging in adversarial use of procedure. Thus, in many ways, the most impressive aspect of the reforms is that they do appear to have influenced practitioners towards a significant change in culture. This change is not, as we have repeatedly emphasised, uniform. There are those who continue to ignore claims and force tenants into making applications. Nevertheless, the overall improvement, at least for the majority of our respondents, is significant.

\section{Problems with the courts}

A common concern was that there was an unwillingness or inability amongst some courts to implement Woolf reforms. This was mainly through lack of resources but also through some judicial resistance. Some courts were unable to list applications quickly enough for procedural timetables to have much bite. Nor was it apparent that courts were sanctioning pre-action misbehaviour in the courts that these practitioners dealt with.

\section{Notification of claims}

There were marked differences of view about whether the tenant lawyers approach to notifying claims was suitably specific and detailed. Similarly, there were differences of view about any improvements in the way landlords responded to such claims. This suggests quite patchy improvements in this area. The pre-action protocol may go some way to redress these concerns, although in some senses its exhortations to provide detail are quite general. The potential for detailed, specific claims to limit disclosure may reduce the willingness of tenant lawyers to specify areas that they are not obliged to.

\section{Disclosure}

Difficulties remain with disclosure. Landlords resent responding to blanket requests for disclosure and several appear to resist disclosure, partly on that basis but also as a way of saving costs. They would rather try and settle the case immediately than disclose the file. There were strategic advantages to them in settling cases pre-disclosure because they then did not risk strengthening tenants' claims, or even opening up new heads of claims. Tenants countered that approach with a view that they needed files because clients, for understandable reasons, could not remember precise details 
about prior notification. Nevertheless, these interviews suggest that the Woolf reforms have raised the level of requests for disclosure by tenant lawyers and the level of compliance with those requests. Those local authorities that seem more willing, and able, to respond to requests for disclosure, were also those authorities which had reorganised their housing disrepair teams into central, specialised departments. Interestingly, at least one of these had passed the job of preparing documents for disclosure to surveyors rather than their legal teams.

Whilst the desirability of confining disclosure to specific types of document and the periods of claim alleged by the tenant is self-evident, there are problems with this approach. One is that tenant lawyers are not generally in a position to specify in advance which documents they need. Tenants request the housing file, look at it, and think about what might be missing. Whilst it may be possible to encourage a more proactive response from tenants, some respondents suggested a lack of knowledge sufficient to be able to do that job in a sensible way. It is understandable that the granting of disclosure should be confined to the claim as specified in the client's letter of claim. Nevertheless, this may prejudice the client where there is objective evidence of more extensive disrepair or longer periods of prior notice that is not disclosed because of the limits on the letter of claim. It may be that this is the price which has to be paid for a more efficient, targeted approach to disclosure. It will prejudice some tenants, however, and may discourage specific statements about prior notice with tenants claiming prior notice may have been given up to the limitation period. If this were the case, the purpose of targeted disclosure would be defeated in any event.

\section{Single joint expert}

Resistance to single joint experts is strong, but not uniform. Some practitioners have shifted towards greater use of single joint experts. Landlord local authorities, in particular, prefer to use in-house surveyors to negotiate with the tenants' own experts. This provides them with an expert they can trust, as well as enabling them to exert greater control over the resolution of the claim and, in particular, the scheduling of work to be carried out to end the disrepair. It was suggested by both landlords and tenants that this approach allowed both parties to retain a degree of control over the negotiation of a settlement which would not be there if a single joint expert simply presented a report and expected the parties to accept it. It seems likely that even where single joint experts are used by tenants and landlords, local authorities will continue to use in-house expertise either directly or indirectly 
in the resolution of housing claims. If that is so, there may be little cost saving in using single joint experts. Similarly, tenants may be placed at a disadvantage because landlords would be likely to retain partisan expertise in any event to scrutinise the report of a single joint expert, whereas tenants would not.

It should also be remembered that there are benefits to the landlord if a tenant instructs an expert early in the claim. It means that they have a clear indication from the outset of what precise levels of disrepair are being alleged; they could then establish an idea of the likely size of the claim. These views all call into question the efficacy of single joint experts for housing disrepair claims.

Conversely, there was clear evidence of other improvements in the way that expert evidence was now being handled. In particular, several respondents perceived an improvement in the quality and objectivity of expert reports as well as a shift towards a narrower, but more independent and appropriately qualified, cohort of experts. This latter shift was not entirely unproblematic however: it could lead to greater delays and higher costs for expert evidence. Nevertheless, the Woolf reforms do appear to have led to some improvements in expert evidence.

\section{Speed}

There was a clear and strong feeling amongst the majority of respondents that settlement was quicker. A large number of respondents pointed out that there were more settlements pre-action than previously. There are a number of factors contributing to a stronger settlement culture. Attitude to settlement had changed; and this may be partly attributed to Woolf but also to greater realism amongst local authorities. Similarly, better resources for housing repairs may have enabled local authorities to conduct more repairs and therefore settle more cases quickly. The way the parties approached claims also made a difference to settlement. 'Making time for settlement and meaning it' was important. Similarly, ensuring that repairs were scheduled and carried out was a crucial factor for some parties in reaching settlements. Better letters of claim, quicker disclosure of relevant housing documentation and approaches to experts also improved settlement. Heightened use of offers and Part 36 in particular also seemed to contribute to settlement culture. There may also be other factors, such as parties' reluctance to have 
proceedings issue and then enter into the fast track. Settling early meant that time and workload pressures, as well as greater unpredictability in terms of outcome, could be avoided.

There were also areas in which settlement behaviour might improve. Admissions were rare. It may be that this is not a problem if parties are exchanging without-prejudice details about what repairs will be carried out and when. The content of offers may also be lacking. For some practitioners this caused a problem. Lack of detail in offers made it difficult for a party to evaluate the basis of, in particular, the tenant's case. Cost issues also posed difficulties, particularly with regard to small claims.

\section{Problems with the draft protocol}

Unlike personal injury and clinical negligence, there is no experience of using an approved protocol. The draft protocol has not yet been published, and so the research can not comment on the content of that. On the assumption that the draft protocol operates, broadly speaking, along similar lines to the version published for consultation, it may be worth pointing to areas which are most likely to give rise to problems. It should be emphasised that the aim here was not to prejudge the draft protocol, but to highlight areas where particular vigilance may need to be maintained.

According to the respondents, personal injury elements to disrepair cases are becoming increasingly common. The draft protocol suggests that the disrepair protocol will apply to all civil claims which include a claim for a disrepair, but not counterclaims or set-offs' (p.13). That includes disrepair cases with a claim for personal injuries (p.15). confusingly, it also states that: 'If there is a personal injury case which is serious enough to be dealt with separately, on behalf of any claimant, the personal injury protocol should be followed, as appropriate, with necessary modifications.'

This is an area where it may be sensible for clearer definition in the pre-action protocol. Whether a personal injury case is 'serious enough to be dealt with separately' is likely to be subjectively interpreted. Nor is it clear what 'necessary modifications' should be made to the personal injury protocol in such circumstances. Further consideration may need to be given to the overlap between disrepair and personal injury protocols. 
The draft protocol relies on a general exhortation to provide 'details of the defects' in describing what a tenant lawyer should specify in a letter of claim. Whether this is sufficient to overcome tenant lawyers' reluctance to specify the alleged defects in a property or whether there are benefits in specifying in more detail what sorts of detail would be expected (for example, which rooms are affected, extent of defect etc.) is an area which should be kept under review.

Similarly, in implementing and reviewing the draft pre-action protocol for housing disrepair, greater attention may need be given to the details which a tenant is expected to give about notice, what happens if the tenants' position on notice changes in the course of a case, and the relationship between the detailing of notice by the tenant and the landlord's resulting obligation to disclose the housing file.

It may be that the draft protocol could deal more clearly with contradictions between the tenant's claims about prior notification and the objective records of it. If the pre-action protocol were to specify precisely how much detail the tenant was to give in relation to prior notification, but also specify that the landlord was required to disclose any records relevant to prior notification relevant to the period alleged by the tenant, but also relevant to any period prior to that where notification is apparent. If the protocol does not specify this, tenants will be prejudiced by non-disclosure of objective and relevant evidence. It might also need to make explicit that landlords should not take points against the tenant who changes their instructions where objective evidence supported the tenant's position. Equally, it might be sensible to emphasise that the tenant's first indication of prior notice would be the strongest evidentially in the absence of objective evidence. This might prevent tenants making very vague allegations about prior notice, discovering that the file contained nothing on this, and then making much more specific and claim enhancing allegations about prior notice. Another approach would be to permit the landlord not to disclose information relevant to prior notification until the tenant had made a suitably specific claim as regards notification.

One final point on the draft protocol is whether it will alter the current approach to experts and what the implications of that will be. Respondents' views generally suggested that there is the potential for joint experts to inhibit settlement, increase the transaction costs for landlords carrying out repairs and prejudice the interests of tenants who have to deal with a neutral joint expert and a partisan landlord expert. It may be that the fears of housing practitioners in these respects may prove unfounded. Conversely, a realistic 
threat that the court may make an order appointing a single expert should the case progress to litigation may encourage a higher degree of objectivity from experts keen to be appointable as single experts in the future. As a result, the role of experts in housing disrepair is an area which should be kept under review as experience of the reforms develops.

\section{Overall}

Given the limited number of interviews that could be conducted for this research, it is difficult to generalise about the impact of the Woolf reforms across all housing cases. That would require a fuller study and other methods, such as file review. Nevertheless, there is enough evidence to suggest that the Woolf reforms have had a significant, if uneven, impact on housing disrepair litigation. It would be interesting to continue to monitor progress once the housing disrepair protocol is implemented. In the medium term, other factors may have an impact, such as the Law Commission's review of housing law and general changes in local government resourcing of housing repair.

There is also evidence of problems to be addressed. Some firms and landlords appear to flout the spirit of Woolf, either wilfully or through lack of knowledge of Woolf and/or housing law. There is also variability in practice. The pilot study suggested three types of landlord: adversaries, resolvers, and failures. In fact, none of the interviewees for this study appeared to fall neatly into any of these categories. Rather different parts of their strategy evidenced each of these three approaches to disrepair cases. Thus at least two landlord authorities had adopted their strategies akin to resolvers, but found that lack of resources pushed them towards being failures. Others had some strategies which were adversarial le.g. placed particular emphasis on questioning the 'morally dubious' nature of tenants claim) whilst simultaneously looking to settle cases quickly. An interesting example of a mixed adversarial/resolver strategy was the tendency for some local authorities to try and settle a claim rather than disclose their housing file. This they did partly because it was cheaper and quicker, but also because it prevented tenants building their claim. Similarly, private practice landlord lawyers were much more active in using Woolf adversarially to try and limit disclosure but also in encouraging tenant lawyers to specify their claims and allow a pre-action period of grace for investigation and negotiation. Settlement may be an adversarial as well as cooperative strategy, depending on the amount of information that has been exchanged and the relative bargaining strategy. This acts as a reminder that 
the Woolf reforms may have complex and under-explored effects on the process and outcomes of disputes. Although the picture is broadly positive, it is also complex. 
Research Study 43 More Civil Justice? The impact of the Woolf reforms on pre-action behaviour 
Section 5. Conclusion 
Research Study 43 More Civil Justice? The impact of the Woolf reforms on pre-action behaviour 


\section{Chapter 5.1 Conclusion: areas for review}

The Woolf reforms have taken one step. I hate to think that the ultimate conclusion will be: 'Well, we've gone so far, let's leave it now.'... It will be great for dialogue to continue for improvement in the rules. (Insurer)

There is much that is positive in the reforms. The culture has become less adversarial, better information is now exchanged before litigation starts and settlement is now more focused on the substantive issues in the case. Nevertheless the reforms are best seen as part of a continuing process to improve the landscape of civil litigation. Here we highlight areas that would benefit from further review and consideration. Our aim is to pinpoint problems rather than prescribe solutions. The pre-action protocols were produced through dialogue between opposing interest groups. This has proved an effective means of improving litigation culture, and it seems appropriate that such dialogue should continue.

\section{Reviewing Part 36: penalties attached to claimant offers}

There was considerable support for the idea that claimants should be able to make formal offers that carried recognised sanctions if wrongly rejected. However, claimant solicitors had little experience of penalties being imposed, and doubted if the penalties were effective.

The penalties are presently set out in Rule 36.21. The first criticism made of this rule was that it applied only to cases that go to trial. There are no penalties in the great majority of settled cases. Secondly, the interest provisions were thought to bite only on early offers in large cases. Interest payments add little to the bulk of claims worth less than $€ 3,000$. Nor are they effective in the immediate run-up to trial, even in large cases. While defendants possess a major weapon in the form of a payment into court, claimants are unable to apply commensurate pressure. Although claimant solicitors liked the idea that Rule 36.21 includes a cost penalty, there is considerable confusion about what it might mean to receive indemnity costs under Rule 36.21(3) for cases fought under a CFA or collective CFA.

There is a case for reviewing the penalties contained within Rule 36.21, to make them more appropriate to a wider variety of cases. Claimant solicitors expressed strong support for a cost penalty lusually based on a specified 
uplift to existing costs). However, the Civil Justice Council should consider whether, as a matter of principle, sanctions should be applied for the benefit of the claimant or their solicitor (or both).

\section{Approving new protocols}

There was considerable support for the three main protocols: dealing with personal injury; clinical disputes; and housing disrepair. They were felt to be easy to adapt to a range of cases. A general protocol is currently under consideration, which it is hoped will cater for areas not presently covered.

There was little support for a further proliferation of protocols. Most of those involved with personal injury claims feared that more protocols, to cover specific aspects of personal injury work, would add unnecessary technicalities. The low awareness of the MASS protocol suggests that solicitors have only a limited capacity to absorb new protocol requirements. Under the Protocol Practice Direction, protocols require the approval of the Head of Civil Justice (para. 1.1). The Head of Civil Justice should approve new protocols only if there is a clearly demonstrated need for them.

\section{The Personal Injury Pre-Action Protocol}

The following proposals are aimed at the Personal Injury Pre-Action Protocol working party as part of the next review of the protocol.

\section{Early notification}

The protocol suggests that, in some circumstances, the claimant solicitor may wish to provide an insurer with an 'early notification' that a letter of claim would be submitted in due course. There were considerable differences in how solicitors used this provision: one firm sent an early notification in almost every case, while others never sent them at all. For their part, insurers saw little point in early notifications unless the letter of claim would be delayed to such an extent that it would arrive over a year after the accident. Given the variety of practice, and the (sometimes unnecessary) cost of sending an early notification letter, it would be useful to provide claimant solicitors with clearer guidance about when early notifications should be used. 


\section{Quantum information in the letter of claim}

At the time of the letter of claim, insurers and claimant solicitors have opposite concerns. Insurers' first priority is to put a valuation on the case, both for the purposes of their own reserves and to decide how the case should be investigated. Claimant solicitors, on the other hand, are much more worried about liability, and often postpone valuations until after the medical report has been received. Insurers were particularly critical of the level of information given in letters of claim about the injury and special damages. The file survey confirmed that many letters contained significant omissions. One quarter of letters failed to indicate the nature of the injury, two-thirds failed to provide any indication of the amount of lost earnings, while threequarters failed to specify any other expenses incurred. There is a need to promote greater understanding among claimant solicitors about the reliance insurers place on financial information at this stage of the case.

\section{CRU information}

Letters of claim rarely meet protocol requirements to provide information used by the compensation recovery unit. Although the protocol requires letters of claim in road traffic cases to provide the name and address of the treating hospital, very few do. We found no road traffic letters that contained the claimant's hospital reference number. The requirements appear unrealistic. The protocol working party should review the provisions. It should consider what information claimant solicitors need to provide for CRU purposes and at what stage it is reasonable to expect them to pass it to insurers.

The insurer's response: penalties for failing to meet the timetable

The protocol states that insurers must provide a response within three months of the acknowledgement (or around 112 days from the letter of claim) stating whether liability is denied and, if so, giving reasons. The file survey showed that, overall, the deadline was exceeded in around one third of cases. Claimant solicitors complained that the number of late responses was too high. Although they were often sympathetic to special cases, they felt that many late responses resulted from understaffing by insurers. Claimant solicitors' main criticism of the protocol was that it contained too few sanctions to enforce compliance. Although in theory they could react to a later 
response by issuing proceedings, this was usually not a practical possibility because of the need to get an expert's report. It would be useful to review the consequences for defendants if they fail to meet the three-month deadline.

Many claimant solicitors suggested that the most appropriate form of penalty would be a cost penalty. There is logic to this, as it is reasonable for claimant solicitors to delay a full investigation of liability until they have received the insurers' response. If, however, no response is forthcoming, claimant solicitors need to incur the additional costs of investigating liability by, for example, taking witness statements. In Callery v. Gray, Lord Woolf indicated that claimant solicitors might take steps towards imposing informal cost sanctions by agreeing a 'two-stage' success fee with their clients. He gave, as an example, a case in which the uplift might be agreed at 100 per cent, subject to a reduction to 5 per cent should the claim settle before the end of the protocol period. This would give the insurer a direct cost incentive to meet the protocol deadlines. It would, as Lord Woolf put it, encourage rigorous consideration of the merits of the claim during the protocol period and therefore accord with the intent of the CPR ${ }^{51}$ Furthermore, if a system of fixed fees were to be introduced, such a system might strive for the same effect by establishing one fee if liability was admitted during the protocol period and a higher fee if it was not admitted.

If such as system is to develop leither through privately agreed 'two-tier' success fees or through fixed fees), the protocol needs to be very clear about what insurers are required to do, by when, in order to obtain the 'cost reduction'. There is an ambiguity within Lord Woolf's suggestion, in that he talks of a claim being 'settled before the end of the protocol period'. However, as already seen, the protocol deadlines run out after the insurer's response. There is no timetable for the claimant solicitor to submit a medical report, and no set time thereafter for offers to be exchanged. One possibility would be to extend the timetable to cover these events. Another would be to accept that success fees protect largely against the risk of losing on liability. The key issue is not, therefore, whether insurers make an offer at any particular stage, but whether they admit liability within the timetabled period. If this approach is taken, the working party will need to consider whether there should be any provision to extend the three-month response period by (say) a further two months, if the insurer writes in good time showing good cause. 


\section{Defining an admission}

Insurers are now more likely to make outright admissions of liability and less likely simply to indicate a willingness to negotiate. However, most insurers were still cautious about applying words such as 'admit' or 'accept' to liability. Over half of protocol responses involve some form of equivocation, such as 'liability is not in issue', or 'liability is not in dispute'. While many claimant solicitors accepted these, others pointed out that they might not be legally binding. Clients would be prejudiced if their solicitors failed to investigate liability only to find that liability was later denied.

The protocol should provide guidance (and sample letters) on what amounts to an admission. Claimant solicitors need to feel secure that they are not prejudicing their clients by ending their investigations into liability. Conversely, the working group needs to consider in what circumstances, and how, an insurer can keep some options open if the medical report includes surprises: either that the injuries were much more serious than first thought, or that they were not wholly caused by the accident.

If there is to be a development of two-tier success fees (or fixed fees) that pay less in the event of a protocol admission, it requires a clear and exact definition of what amounts to an admission.

\section{Agreeing medical experts}

A major problem with the protocol procedure is that it has slowed the process of obtaining medical reports. Instead of instructing a doctor soon after the first meeting, claimant solicitors must now contact the other side and wait for an acknowledgement. Defendants then have a further 14 days to agree to names. The median time taken to issue instructions has increased from just over two months to well over three months. This, coupled with increasing delays in writing reports, means that, post-Woolf, half of first medical reports took over six months to obtain. As responses on liability are produced more quickly, there is an increasing problem of 'dead time' after liability has been accepted, while the parties wait for medical evidence. In half of cases, over four months is spent in dead time of this sort.

It is questionable whether the benefits derived from the process of submitting and agreeing names justify the delay involved. Our own view is that, initially, the procedure was advantageous, as part of a cultural shift towards less partisan experts. However, its benefits are diminishing as time goes on. On a practical level, insurers rarely have access to the information 
they would need to make reasoned decisions about which experts could agree. Given that claimants can ask for amendments without the defendant's knowledge and suppress reports they disagree with, the procedure has only a limited effect in ensuring unbiased reports. Alternatives might include a central list of unacceptable experts, or a certificate from a claimant solicitor when a report is disclosed, to say that they had not sought any undisclosed amendments or were not holding undisclosed reports. In the absence of such a certificate, defendants could have the right to obtain their own report.

\section{GP records}

Insurers complained that too many medical experts wrote reports without access to GP records. Our survey found that around one-quarter of reports were written without such access. A review of the protocol might also consider whether the absence of GP notes should trigger any particular sanction (such as giving defendants the right to obtain their own evidence if they wish).

\section{The Clinical Disputes Protocol}

Broadly speaking, the Clinical Disputes Protocol is working effectively as a framework for the early exchange of information and to facilitate settlement. The protocol is subject to ongoing review by the Clinical Disputes Forum. Here we highlight areas that would benefit from further review, based upon the interviews conducted.

\section{Medical records}

For the most part the arrangements for release of medical records work well and the timetable is appropriate. However, the Clinical Disputes Forum should consider whether the claimant's solicitor ought to inform the healthcare provider at the request-for-records stage whether land if so where) the claimant has received additional treatment. Consideration should also be given to a procedure by which requests for records could be fast tracked in appropriate circumstances.

\section{The letter of claim}

The protocol does not specifically require the letter of claim to contain details of the claimant's case on causation. It refers more generally to 'allegations of negligence," and it appears that claimant solicitors are taking this to mean 
allegations of breach of duty only, making it more difficult for the healthcare provider to respond fully. A review of the protocol might consider whether it is possible to emphasise the importance of setting out the claimant's case on causation.

At present the letter of claim template in the protocol lists schedules of loss and supporting evidence as possible enclosures. Fuller information is more likely to lead to an early compromise, particularly in low value claims. Consideration should be given to issuing further guidance to claimant solicitors as to when such enclosures should be supplied with the letter of claim.

\section{The letter of response}

Whilst it is clear that there are difficulties involved in meeting the time limit for a letter of response, the system for seeking and granting extensions of time in appropriate circumstances appears to work well. For this reason, we would suggest that the Clinical Disputes Forum does not seek to make any changes to this timetable.

\section{Expert evidence}

This aspect of the reforms is not directly referable to pre-action behaviour, but practitioners were keen to mention their experiences in relation to instructions to joint experts (primarily on quantum) and meetings of experts. There remain difficulties concerning the mechanism for agreeing instructions to joint experts, obtaining further information from them, and their attendance at conferences. At this time, the Clinical Disputes Forum is consulting with its members on a series of guidelines for instructing single joint experts in situations where the parties had agreed, or the court ordered, that a single joint expert should be instructed. We welcome this initiative and would ask that the Clinical Disputes Forum consider the issues raised here when finalising the guidelines and consider whether further specific guidance to experts is required in these circumstances. Furthermore, where experts are not jointly instructed, consideration should be given to amending Rule 35 to state the time limit by which an expert should respond to written questions from the other party. 


\section{Housing Disrepair Pre-Action Protocol}

The Housing Disrepair Protocol is not yet a settled or public document. The Housing Disrepair Protocol Working Group (HDPWG), supported by the Law Society, has produced a draft pre-action protocol which has been consulted on (HDPWG 2001). The final version has been settled by the Working Group and awaits the agreement of Lord Justice May to proceed to being a preaction protocol. This latest version has not been published, let alone implemented. Thus it is impossible to provide a concrete evaluation of the impact the protocol will have on practice. It is possible to indicate areas where the protocol (as set out in the published consultation draft) may benefit from further thought before it is agreed by Lord Justice May, or as part of a broader process of review once the protocol is implemented.

\section{Overlap with the personal injury protocol}

According to the respondents, personal injury elements to disrepair cases are becoming increasingly common. The draft protocol suggests that the disrepair protocol will apply to all civil claims which include a claim for a disrepair, but not counterclaims or set-offs' (HDPWG 2001, p.13). That includes disrepair cases with a claim for personal injuries (p.15). confusingly, it also states that if there is a personal injury case which is serious enough to be dealt with separately, on behalf of any claimant, the personal injury protocol should be followed, as appropriate, with necessary modifications.' This is an area where it may be sensible to have a stronger definition in the pre-action protocol. Whether a personal injury case is 'serious enough to be dealt with separately' is likely to be subjectively interpreted. Nor is it clear what 'necessary modifications' should be made to the personal injury protocol in such circumstances. Further consideration may need to be given to the overlap between disrepair and personal injury protocols.

\section{Detailing Disrepair}

The draft contains a general exhortation to provide 'details of the defects' in the letter of claim. We are not convinced that this will always be sufficient to overcome tenant lawyers' reluctance to specify the alleged defects. There may be benefits in specifying in more detail what sorts of detail about defects should be expected of a claimant lawyer making a claim (for example, which rooms are affected, extent of the defect etc.) This is an area which should be kept under review. 


\section{Detailing notice and disclosure of housing records}

In implementing and reviewing the protocol, greater attention needs to be given to how information is exchanged about the notice the tenant has given to the landlord that a disrepair exists. It would be useful if the protocol specified more clearly what details a tenant should give about notice, and what happens if the tenant's position on notice changes during the course of a case.

Further thought also needs to be given to how the tenants' allegations of notice affect the landlord's obligation to disclose the housing file.

It is recommended that the protocol should specify that once details have been given, the landlord is obliged to disclose all records relevant to notice, whether the records arose before, at the same time or after the date alleged by the tenant.

If the protocol does not specify this, tenants might be prejudiced by nondisclosure of objective and relevant evidence. The protocol might also need to make explicit that landlords should not take points against tenants who change their instructions where objective evidence supports their position.

It might be sensible, however, to emphasise that the tenant's first indication of prior notice would be the strongest evidentially in the absence of objective evidence. This might prevent tenants from making vague allegations about prior notice, discovering that the file contained nothing on this, and then making much more specific and claim enhancing allegations about prior notice. Another approach would be to permit the landlord not to disclose information relevant to prior notification until the tenant had made a suitably specific claim as regards notification.

\section{The vexed question of experts}

One final point concerning the draft protocol is whether it will alter the current approach to experts and what the implications of that will be. Respondents' views generally suggested that there is the potential for joint experts to inhibit settlement, increase the transaction costs for landlords carrying out repairs, and prejudice the interests of tenants who have to deal with a neutral joint expert and a partisan landlord expert. Equally, the fears of housing practitioners in these respects may prove unfounded. Conversely, a 
realistic threat that the court may make an order appointing a single expert should the case progress to litigation may encourage a higher degree of objectivity from experts keen to be appointable as single experts in the future.

As a result, the role of experts in housing disrepair is an area which should be kept under review as experience of the reforms develops.

\section{Costs}

\section{Further research}

No evidence was found that the costs paid to claimant solicitors to negotiate a personal injury settlement had reduced. Instead, the evidence provided by insurers pointed to a substantial increase in such costs since 1999. Our own small survey carried out for this study suggested that costs had risen at above the rate of inflation. The Civil Justice Council should commission a further study of personal injury costs, looking in more depth at data gathered from a wider range of insurers. It should include issued cases as well as cases settled in-house before issue.

In clinical negligence cases, interviewees suggested that the protocol has succeeded in contributing to a reduction in pre-issue costs, particularly since procedures for the release of medical records have removed the need for applications for pre-action disclosure. However, costs savings in this regard may be set off against the need for greater front-loading by defendants. Interviewees cited examples of cost-generating administration, such as the need to prepare interim costs schedules. Further research into clinical negligence claims would serve to clarify whether costs savings are actually being made and to examine the use to which interim costs schedules are put.

Unlike personal injury cases, the evidence suggested that, overall, housing disrepair cases had reduced in cost, although there was also felt to be some front-loading which reduced the impact of early settlements on costs. However, these views on costs have not been objectively verified and there remained a significant level of concern amongst landlords that costs were still disproportionate to damages. We recommend that detailed research based in part on landlord and claimant lawyer case files and other records be undertaken to evaluate more objectively the position on costs of disrepair cases. 


\section{Fixed fees in personal injury claims}

Claimant solicitors, defendant solicitors and insurers were agreed that too much time, effort and resources are now taken up with disputes over costs. The use of cost negotiators has increased over the last two years, so as to become another 'cottage industry' in the claims-handling process. Recently, the problem has been exacerbated by the introduction of recoverable success fees and insurance premiums in CFA cases. Insurers complained that without a fixed fee regime, the Woolf proposals had been only partially implemented. Given that large numbers of small personal injury claims are being brought in an increasingly standardised way, personal injury work appears to be an appropriate area for fixed fees.

The initiative by Lord Phillips and the Civil Justice Council to establish a committee to consider fixed fees for personal injury cases in more detail is welcomed. ${ }^{52}$ Findings for this study suggest that it should be possible to introduce a fixed fee regime, at least for small fast track personal injury cases, that would provide claimant solicitors with appropriate remuneration without the current level of disputes over costs.

\section{Fixed fees in clinical negligence claims}

Fixed fees would not be appropriate for clinical negligence claims, which involve a highly individuated approach to cases, and where the amount of work required differs substantially from case to case.

\section{Fixed fees in housing disrepair claims}

It is still too early to state whether fixed fees are an appropriate way forward for housing disrepair claims. Further research loutlined abovel would be needed to assess the viability of any system of fixed costs in the context of housing disrepair work. 
Research Study 43 More Civil Justice? The impact of the Woolf reforms on pre-action behaviour 
Bibliography and Appendices 
Research Study 43 More Civil Justice? The impact of the Woolf reforms on pre-action behaviour 


\section{Bibliography}

Armstrong N. and Peysner J. (1996): Costs in Personal Injury Litigation. (Report to the Association of Personal Injury Lawyers, Nottingham.)

Blundell H. (1998): 'Pre-action Protocols - A Balanced Discussion', JPIL SR $110-18$.

Burne S. (2001): 'Pre-action Protocols under the CPR', Legal Action, October 2000, pp.6-8.

Cane, Peter (1999): Atiyah's Accidents, Compensation and the Law, sixth edition, (Butterworths, London).

CEDR (2000): The CEDR Civil Justice Audit, (CEDR, London).

Clinical Disputes Forum, (forthcoming): Pre-action Protocol for the Resolution of Clinical Disputes. Feedback survey.

Crook T., Hennebury J. and Hughes J. (2001): Repair and Maintenance by Private Landlords, (DETR, London).

Dangoor M. (2001): 'The Pre-action Protocol for the Resolution of Clinical Disputes. "Is the Prescription Good Medicine?"', Clinical Risk 7, 3-9.

Department of Health (2001): NHS Complaints Procedure - National Evaluation (London).

Department of Health (2000): An Organisation with a Memory. Report of an expert group on learning from adverse events in the NHS chaired by the Chief Medical Officer. (HMSO, London).

Department of Health (2001): Building a Safer NHS for Patients. (London).

Department of Health (2001): Clinical Negligence: What are the Issues and Options for Reform? (London).

Department of Health (2001): Reforming the NHS Complaints Procedure - a listening document. (London) 
Dingwall et al (2000): 'Firm Handling: The Litigation Strategies of Defence Lawyers in Personal Injury Cases', 20 Legal Studies 1.

Dugdale A.M. (2000): 'Negligence' in Clerk and Lindsell on Torts, 18th Edition, (Sweet and Maxwell, London).

Fennell S. (1994): The Funding of Personal Injury Litigation (University of Sheffield, Sheffield).

Galanter M. (1974): 'Why the Haves Come out Ahead: Speculations on the Limits of Legal Change', 9 Law and Society Review 347.

Galanter M. (1984): 'Words of Deals: Using Negotiation to Teach about Legal Process', 34 Journal of Legal Education 268.

Gibb, Frances (2000): 'Verdict on the Woolf Shake-up: It's a Qualified Success', The Times, 2 May 2000.

Genn H. (1987): Hard Bargaining: Out of Court Settlement in Personal Injury Actions, (Clarendon Press, Oxford).

Genn H (1998): The Central London County Court Pilot Mediation Scheme: Evaluation Report, Research Series 5/98 (Lord Chancellor's Department, London).

Goriely T. (1998): 'The New Pre-action Protocol for Personal Injury Claims', New Law Journal 6861, pp.1547-8.

Goriely et al (1998): Costing Fast Track Procedures Through Hypothetical Studies (Lord Chancellor's Department, London).

Harris D. et al (1984): Compensation and Support for Illness and Injury, (Clarendon Press, Oxford).

Housing Disrepair Protocol Working Group (2001), Draft Pre-Action Protocol for Housing Disrepair Cases, (Law Society, London).

Law Commission (2001): Reform of Housing Law: A Scoping Paper, (Law Commission, London)

LCD (1998): Evaluation of the Personal Injury Protocol Pilot, (Lord Chancellor's Department, London). 
LCD (2001): Emerging Findings. An Early Evaluation of the Civil Justice Reforms, (Lord Chancellor's Department, London).

LGA (1997): Circular 303/97: Housing Disrepair Litigation, 16 October 1997.

Legal Services Commission (2001): The Funding Code, (LSC, London).

Mears M. (2000): The Times, 7 November 2000, and the letter column on 14 November 2000.

Mulcahy et al (2000): Mediating Medical Negligence Claims: An Option for the Future? (University of London, London).

Mulcahy et al (1999): Cause for Complaint? An Evaluation of the Effectiveness of the NHS Complaints Procedure, (Public Law Project, London).

Ormandy D., Burridge R. and Battersby S. (1995): The Use of Section 82 of the Environmental Protection Act 1990 Against Local Authorities and Housing Associations, (DETR, London).

Peysner J. (2001): 'Mapping the New Litigation Landscape' in (ed.) J. Peysner, Civil Litigation Handbook, (Law Society, London).

Peysner et al (1998): Report of the Fast Track Simulation Project, (Lord Chancellor's Department, London).

Pleasence, Pascoe (1998): Report of the Case Profiling Study: Personal Injury Litigation in Practice, (Legal Aid Board Research Unit, London).

Pleasence P., Maclean S. and Morley A. (1996): Profiling Civil Litigation: the Case for Research, (Legal Aid Board Research Unit, London).

Ross H.L. (1980): Settled Out of Court, (Aldine, Chicago).

Sherr A. and Goriely T. (1997): Outcome Measures in Housing Work, unpublished report to the Legal Aid Board, London.

Tomkins, Nigel (2001): 'Early Settlement and the Protocols' in (ed.) J. Peysner, Civil Litigation Handbook, (Law Society, London).

Taylor, Christopher (2001): 'Distilling the Spirit of Woolf', New Law Journal, July 13, 1035-6. 
Woolf H. (1996): Access to Justice - Final Report to the Lord Chancellor on the Civil Justice System in England and Wales, (HMSO, London).

Yarrow, Stella (1997): The Price of Success, (Policy Studies Institute, London).

Yarrow, Stella (2000): Just Rewards? The Outcome of Conditional Fee Cases: Summary, (University of Westminster, London).

Yarrow, Stella, and Abrams, Pamela (2001): Nothing to lose? Clients' Experiences of Using Conditional Fees, (University of Westminster, London) 


\section{Appendix 1 Personal injury: methodology}

The personal injury element of the study was based on 30 face-to-face interviews: 18 with claimant solicitors (in 17 firms); eight with insurers (in five companies); and four with defendant solicitors (in four separate firms). These interviews were supplemented with data collected from 310 claimant solicitor files - of which 158 had been closed before the introduction of the reforms and 152 had been opened after the reforms. We also spoke to seven solicitors over the telephone.

\section{Selecting interviewees: claimant firms}

The research was designed to include a cross-section of large, medium-sized and small firms handling personal injury work on behalf of claimants. However, there are no easy ways to define firm size, which may depend on turnover, case-starts, the numbers of partners, the number of solicitors or the number of fee-earners.

After some discussion,we defined large firms as those listed in Chambers and Partners as leading firms, or those in the top two tiers of highly regarded firms for claimant personal injury work. These were all specialist firms with considerable reputations in the field.

We defined medium-sized personal injury firms as firms employing 16 or more solicitors in a single branch, of which at least one is a member of the personal injury panel (but which are not large firms, as defined above). We decided to look at the number of solicitors, on the grounds that this information is readily available from the solicitors-online database, and is a more accurate indicator of size than the number of partners. Although, ideally, we would have liked to look at the number of solicitors doing personal injury work, it did not prove feasible to obtain this information prior to recruiting firms. Many firms with large departments enrol only one or two solicitors onto the Law Society panel.

This left small firms. During the pilot, we identified all the firms that said they did personal injury work in one north and one south London suburb. This produced a total of 13 firms, of whom only two were on the Law Society panel. However, telephone calls revealed that most of the firms not on the panel no longer did personal injury work and that no non-panel firm had conducted ten 
or more case since May 1999. It was therefore decided to confine the study to firms with at least one solicitor on the personal injury panel. Small firms were therefore defined as firms with at least one member on the personal injury panel, but which were not medium-sized or large firms.

The original intention was to visit 18 firms: seven large; six medium-sized and five small. However, as discussed below, the requests for files put a considerable burden on medium-sized firms. Out of 21 medium firms contacted, only four were able to participate. We therefore revised the methodology. We conducted face-to-face interviews in seven large firms, four medium-sized firms and five small ones. In one medium-sized firm, we spoke to two people. In order to ensure that the sample was not biased, seven solicitors in the medium-sized firms who had originally refused to participate were re-contacted. They all proved willing to talk over the telephone, so we carried out a shorter version of the interview in this way. As discussed in the report, the views expressed by telephone were broadly similar to those given face to face.

The typologies of firm size should be treated with care. For example, one 'small firm' in the study employed paralegal staff to conduct large numbers of small cases in a highly routinised way, while one 'large' firm had developed its reputation though handling a few major claims through a small team of highly specialist solicitors. Although we do refer to large, medium-sized and small firms in the way defined above, we also categorise firms in other ways (e.g. 'standardised', or 'bespoke' firms) where this is relevant to the analysis.

Locations were chosen to reflect a variety of large cities and smaller towns in both the South and north of the country. Out of 18 interviews, nine were in London, three were elsewhere in the south of England and five were in northern cities.

\section{Selecting defendant representatives}

We held meetings with the Association of British Insurers (ABI) and Lloyd's to explore the way the industry is structured after the many recent mergers. Lists provided by the $A B I$ suggested that the market was dominated by some eight 'giant' firms operating across sectors land so covering employers and public liability as well as motor insurance). Unsurprisingly, it was these eight or so firms that most frequently cropped up in our discussions with claimant solicitors and in the file reviews. The giants are supplemented by 30 to 40 smaller $A B I$ firms, many of whom specialise in one area of work. The 
Lloyd's market is less important in purely numerical terms, but its network of syndicates has a different structure and ethos, and forms a distinct industry sector. It more often uses loss adjusters to handle claims.

We discussed how to use our eight interviews to obtain a wide range of views. We decided to conduct six interviews with staff working in three 'giant' insurance companies. In each company we spoke to a manager with an overview of the reforms (and in one case interviewed two managers together). We also talked to a claims-handler in the same company with day-to-day experience of fast-track claims. We then interviewed a claims manager from a smaller $A B I$ member firm, and a loss-adjuster with considerable experience of working for both $\mathrm{ABI}$ members and several Lloyd's syndicates.

The companies were selected from lists provided by the ABI and Lloyds. The $A B I$ also very kindly wrote letters of introduction to a range of firms. We then contacted firms directly to ask them to nominate suitable individuals. All the firms contacted were happy to cooperate.

Finally, we spoke to four solicitors experienced in handling defendant claims, two in London and two in northern cities. They were selected from firms recommended by Chambers and Partners for defendant personal injury work.

\section{Interviews}

Interviews were based on a topic guide agreed with the Law Society and Civil Justice Council. Face-to-face interviews took between one hour and one hour 30 minutes to complete. Telephone interviews took between 10 minutes and 30 minutes. All interviews were tape-recorded and transcribed.

\section{File reviews}

The claimant firms approached for interviews were also asked to provide a sample of concluded 'pre-Woolf' and 'post-Woolf' cases. We defined preWoolf cases as those finished before January 1999, and post-Woolf cases as those started after 1 May 1999. We avoided 'transitional cases' that spanned the introductory period, as these could not be used to evaluate whether a change had occurred.

The first firm was visited 20 months after Woolf implementation; the final firm was visited 28 months after implementation. By evaluating the reforms so soon, we were confining ourselves to small, relatively quickly resolved cases. 
Although no damages limit was imposed on post-Woolf cases, damages in these cases tended to be low: in all but five cases, damages were less than $£ 15,000$. We therefore asked firms to concentrate on pre-Woolf cases with damages under $€ 15,000$. In fact, all but three pre-Woolf cases in the sample had damages of less than $€ 15,000$.

One large firm had a sophisticated database, that allowed us to look at the rate at which cases were finishing. Out of 5,700 cases opened between 1 May and 31 December, 35 per cent had finished by 31 January 2001. The equivalent figures for pre-Woolf (cases started May 1997 to December 1997 and finished by 31 January 1999) was 30 per cent. This suggests that cases may be completing more quickly than before, but that the difference is small. Our sample was confined to the quickest one third or so of cases.

Research conducted in 2001 cannot provide a definitive answer to whether, in overall terms, cases are concluded more quickly or cheaply. However, file reviews could yield some relevant data about the time and cost taken by smaller cases. They also provided much other information about how cases are conducted and served as an important 'reality check' on what respondents said.

\section{Numbers of files}

The number of files requested depended on the size of the firm.

- Large firms were asked to provide 25 pre- and 25 post- Woolf files, with the aim of completing 20 reviews in each sample per firm.

- Medium firms were asked for 15 pre- and 15 post-Woolf files, with the aim of completing 10 reviews in each sample per firm.

- Small firms were asked for 10 pre- and 10 post-Woolf files. However, we accepted that many would not be able to provide this number. The aim was simply to complete as many as possible.

Although we offered to pay retrieval costs, firms experienced considerable difficulties in providing the number of files requested, with the greatest difficulties experienced by the medium-sized firms. Two firms lone large, one medium-sized) were happy to talk to us but were unable to provide any files. Another large firm later provided nine files without an interview, but we were unable to provide a substitute for the medium-sized firm. The file sample is therefore based on 16 firms. 
Table Ap1.1 shows that, in practice, the sample was dominated by large firms which supplied 72 per cent of all files in the sample. Many other firms approached simply did not have enough files to meet our requests. In the absence of national data, it is difficult to know how far this reflects the actual distribution of cases.

Table Ap1.1 Number of cases in sample from each firm visited

\begin{tabular}{|c|c|c|c|}
\hline & $\begin{array}{c}\text { Pre-Woolf } \\
\text { No. }\end{array}$ & $\begin{array}{c}\text { Post-Woolf } \\
\text { No. }\end{array}$ & $\begin{array}{l}\text { Total } \\
\text { No. }\end{array}$ \\
\hline Large firm 1 & 9 & 11 & 20 \\
\hline Large firm 2 & 20 & 24 & 44 \\
\hline Large firm 3 & 12 & 2 & 14 \\
\hline Large firm 4 & 13 & 15 & 28 \\
\hline Large firm 5 & 22 & 23 & 45 \\
\hline Large firm 6 & 16 & 11 & 27 \\
\hline Large firm 7 & 14 & 21 & 35 \\
\hline Large firm 8 (no interview) & 7 & 2 & 9 \\
\hline All large firms & 113 & 109 & 222 \\
\hline Medium firm 1 & 7 & 10 & 17 \\
\hline Medium firm 2 & 9 & 2 & 11 \\
\hline Medium firm 3 & 4 & 2 & 6 \\
\hline All medium firm & 20 & 14 & 34 \\
\hline Small firm 1 & 1 & 3 & 4 \\
\hline Small firm 2 & 8 & 10 & 18 \\
\hline Small firm 3 & 6 & 3 & 9 \\
\hline Small firm 4 & 3 & 2 & 5 \\
\hline Small firm 5 & 7 & 11 & 18 \\
\hline All small firms & 25 & 29 & 54 \\
\hline Total & 158 & 152 & 310 \\
\hline
\end{tabular}

Although firms were asked to provide equal numbers of pre- and post- Woolf files, this was not always feasible in practice. We therefore applied a weighting factor to the pre-Woolf files, which weighted them to the number of post-Woolf files supplied by the same firm.

Data collection was conducted by the authors of the report working with two research assistants. Copies of the data collection form and interview schedules are available from the Law Society upon request. 
Research Study 43 More Civil Justice? The impact of the Woolf reforms on pre-action behaviour 


\section{Appendix 2 Clincial negligence: methodology}

The research consisted of 12 semi-structured interviews with claimant and defendant solicitors and representatives within trusts. During the pilot phase of the study, two interviews with claimant solicitors were conducted and a number of meetings were held with other interested parties:

- FOIL (Forum of Insurance Lawyers);

- AVMA (Action for Victims of Medical Accidents);

- APIL (Association of Personal Injury Lawyers);

- Suzanne Burn of the Clinical Disputes Forum;

- Steve Walker, Chief Executive of the NHSLA (National Health Service Litigation Authority);

- Margaret Dangoor, Executive Director of ALARM (Association of Litigation and Risk Managers).

The purpose of this phase was to obtain background information on the protocol and to canvass views on the intended methods and the selection of participants. This process was also used to further refine the topic guides to be used for the interviews.

\section{Selecting claimant solicitors}

Claimant solicitors were selected from a list of those holding Legal Services Commission clinical negligence franchises supplied by the Legal Services Research Centre. The two firms chosen from this list for the pilot phase were both based in London. Chambers and Partners was used to verify that a significant proportion of their work comprised clinical negligence claims.

For the remaining interviews, given the large number of firms on the list, firms were chosen at random. Some firms were eliminated as they were already taking part in the personal injury part of the project. Others were outside the geographical locations chosen in the original methodology, namely London and northern cities. Having obtained a list, the firms were contacted to verify that they did in fact undertake clinical negligence work. 
The list was further condensed as many firms indicated that they no longer did so. Finally, four firms in London and three in the north were approached. Four of these firms agreed to take part in interviews.

The comments of a seventh claimant solicitor who was interviewed for the personal injury part of the study but undertook a significant amount of clinical negligence work and so had relevant experience, were also included. Generally, respondents tend to reflect the experience of those in smaller and medium-sized firms. Some of the firms had more than one branch office. The firms varied in the proportion of personal injury and clinical negligence work they undertook; in one firm, clinical negligence was 75 per cent of the firm's work whilst, in another, this figure was put at between 5 per cent and 10 per cent. As a result, the amount of work in these areas had an impact on the size of the team.

\section{Selecting defendant solicitors}

There are currently 15 firms of solicitors on the NHSLA clinical negligence panel. The NHSLA was consulted on variables to take into account when selecting the sample of defendant firms to participate in the research. In the light of this, three firms were selected from the panel; one based in London, one in the south and one in the north. All three firms agreed to take part in the research. These firms tended to be larger than the claimant firms in the study.

All the solicitors interviewed, both claimant and defendant, were at partner level and had significant experience of clinical negligence litigation both prior to and following the introduction of the reforms. One of the interviews was conducted with a personal injury partner present and another with an assistant solicitor present so that their views could be added to the issues explored in interview.

\section{Selecting representatives within trusts}

The interviewees within trusts were selected from a database of members of ALARM. Initially, acute trusts were selected from the database, on the basis that these trusts would have the greatest throughput of claims and interviewees would therefore have the most experience of the reforms. Three trusts were selected from the list of acute trusts. One was located in London, one in the north and the third in the south. In one trust, two members of the 
legal claims team were interviewed at the same time. Interviewees had different titles but, for the sake of uniformity and confidentiality, they will be referred to as 'claims managers' throughout the report. 
Research Study 43 More Civil Justice? The impact of the Woolf reforms on pre-action behaviour 


\section{Appendix 3 Housing disrepair: methodology}

Twelve semi-structured interviews were conducted with housing practitioners. Two interviews with experienced housing solicitors with expertise in disrepair cases were conducted for the pilot stage of the research: one private practice solicitor with a predominantly tenant-based practice funded under a legal aid contract, and one solicitor in a local authority legal team specialising in housing and disrepair matters. Further meetings and discussions were held with representatives from HLPA, the LGA and others with knowledge of housing disrepair litigation as part of the pilot process.

Of principal interest to the pilot stage of the research, beyond refining the interview schedules, was the nature of the sample to be selected for interview. It became clear that the greatest source of diversity in housing litigation was likely to be found amongst landlords. Tenant lawyers carrying out sufficient work to be sensible targets for interviews were likely to be a more homogenous group, having a degree of standardisation of approach required by the Legal Service Commission's approach to franchising and its funding code. In contrast, landlord work splits into two main types:

- work handled in-house lespecially by local authorities, but some housing associations); and,

- work handled by private practice lusually for social and private landlords).

It was suggested by those we consulted that the approaches of in-house and private practices may differ significantly. A further distinction, which was also emphasised, was the difference in approach of local authorities. Three types emerged in discussions:

- 'Resolvers'. These local authorities have sought to integrate disrepair litigation with management of housing complaints more generally to resolve complaints appropriately and cost effectively. For these local authorities, disrepair complaints are seen as an inevitable part of running a housing law service. 
- 'Adversaries'. These local authorities perceive complaints as solicitor driven and are reported as taking a robust, adversarial line to the handling of pre-action and litigation steps. Some informants described these authorities as ideologically driven.

- 'Failures'. The researchers found these local authorities to be disorganised in their handling of complaints and ill-equipped to respond appropriately to disrepair litigation.

Each of these three types would be likely to approach the Woolf reforms in different ways. Similarly, some organised local authorities have developed the way that work is handled in the early stages to emphasise a professional, nonlegal response by surveyors and environmental health officers which is then passed on to legal departments only in the event of litigation being likely. This meant that pre-action behaviour in some local authorities would be better understood if it included the perspective of the surveyor/environmental health disrepair teams. As a result, a non-lawyer disrepair team manager was included in the interviews.

The interviews conducted sought to reflect the variety of type of landlord for the research. Pilot work suggested that the landlord sector was considerably more diverse than the tenant lawyer sector. This study is exploratory; it examines the range of approaches to disrepair litigation rather than definitively measuring the performance of the entire market. It does not seek to weigh, in any quantitative sense, the views of tenant advisers against the views of landlord representatives. Hence the research did not need equal numbers of tenant and landlord representatives. It was agreed four tenant representatives and eight landlord representatives would be interviewed. This captures a greater range of landlord views.

\section{Selecting landlord representatives}

A range of landlord types were selected: social landlords, local authority landlords, and private practitioners doing work for social and private landlords. Interviews were arranged with a staff members who had the most direct, day-to-day experience of conducting disrepair litigation pre-Woolf and post-Woolf, rather than simply seeking to speak to the head of the relevant department. 
Five interviews took place with in-house lawyers from local authorities. One of these interviews was also attended by a non-lawyer member of the housing disrepair team. A further interview was held with an in-house lawyer from a housing association. Two private practitioners doing landlord work were chosen from the Chambers directory. Given the exploratory nature of the study, it was important to select practitioners from the larger firms to ensure sufficient experience of such work. The National Housing Federation was able to help identify housing associations that handle their disrepair work entirely in-house, and one of those associations was selected for interview.

\section{Selecting tenant representatives}

Four tenant representatives were selected for interview on the basis of their holding LSC contacts in housing. Prior to arranging the interviews, the firms confirmed that they were currently completing in excess of 20 disrepair cases per annum, which ensured that they had a significant experience base on which to provide views on Woolf and housing disrepair. Interviews were arranged with fee-earners who had the most direct, day-to-day experience of conducting disrepair litigation, and it was confirmed that they also had experience of conducting such cases pre-Woolf, rather than simply seeking to speak to the head of the relevant department. The interviews were conducted in a range of geographic locations to mirror as far as possible the locations chosen for landlord representatives. One of these tenant interviewees worked at a law centre.

\section{Location of interviewees}

Local authorities were selected primarily on geographical grounds. Legal aid data and LGA data was used to ascertain which areas of the country had large amounts of disrepair claims and then selected local authorities in those areas of the country. Half the tenant and landlord interviews were in London and the remainder in the north and the Midlands. There was a degree of match between the landlords interviewed and the tenants interviewed, with a number of the tenant organisations taking cases against one or more of the landlord organisations in our sample. This enabled some reality-checking of any self-serving responses to interview questions. 


\section{Level of interviewee and nature of their work}

We spoke to a range of qualified and non-qualified staff as well as partners and non-partners amongst the solicitors. Interviewees had widely varying volumes of disrepair work. Two landlord authorities had about 170-200 active disrepair cases, whereas another had 700 to 800 disrepair cases on their caseload. Another estimated that each of the five fee-earners carried about 100 current cases. The two other in-house lawyers lone a local authority and the other a housing association) claimed only to have very low numbers of disrepair claims a year (less than 12).

None of the private practice firms provided precise estimates of the numbers of cases with which they dealt, but it was clear that volumes were large for three of these firms. The law centre interviewee said that he handled relatively small numbers of disrepair claims each year.

Copies of the interview schedules are available from the Law Society on request. 


\section{Footnotes}

1 From Professor John Peysner and Professor Mary Seneviratne, of Nottingham Law School.

2 See Housing Disrepair Protocol Working Group (HDPWG) (January 2001).

3 Legal Aid Board Annual Report 1999/00, p. 39.

4 See Moorhead and Harding (2002), Access or Quality? Tolerance Work under Civil Contracts (LSC, forthcoming).

5 See LCD (2001) for further surveys. Surveys had also been conducted by Eversheds, Wragge and $\mathrm{Co}$, and Lovells.

6 A postal questionnaire was sent out in July 1999 to 110 NHS trust members of ALARM (Association of Litigation and Risk Management).

7 A telephone questionnaire with 25 claims managers was carried out in May 2000 : Dangoor (2001).

8 See, for example, Genn (1987, p.10-12) and Galanter (1974 and 1984). A more recent example is provided by Peysner (2001).

9 Pleasence et al (1996) provide a useful summary of work in this area. Important studies on funding and costs include Fennell (1994) and Armstrong and Peysner (1996). Yarrow (1997 and 2000) has tracked the early development of conditional fees for personal injury litigation.

10 See Pleasence 1998, p.67

11 For a further discussion of how claims management companies operate, see Peysner (2001, p.21).

12 For example, in early 2001, as part of the pilot, we identified all firms in two London suburbs listed on Solicitors Online as undertaking personal injury work. Telephone calls, however, revealed that only two out of 13 firms had conducted 10 or more cases since May 1999.

13 [2001] 3 All ER 833.

14 In order to compare like with like, the analysis was confined to cases with minor or moderate injury obtaining less than $€ 7,000$ in damages and lasting for less than two years. This gives a base of 98 pre-Woolf cases and 127 post-Woolf cases.

15 On a Mann-Whitney U test, $\mathrm{p}=0.001$.

16 The sample contained 62 post-Woolf RTA cases and 69 post-Woolf accidents at work. The difference is statistically significant. 
17 This is acknowledged in the pre-action protocol itself, which specifies that the letter of claim should be sent 'before issues of quantum are addressed in detail,' (para. 3.1). Under para. 2.7, the letter of claim should emphasise the importance of passing the letter of claim to the insurer and the possibility that the insurance cover might be affected.

19 See Chapter 2.1, for an explanation.

20 See, for example, Dugdale (2000) pp.274-5 and 408; Cane (1999) pp.6 and 77; and Genn (1987) p.4.

21 This study was limited to 'ordinary' cases with costs of less than $€ 5,000$. Harris et al. (1984) found that 3 per cent went to trial. It is safe to estimate the 'true' figure at substantially under 5 per cent.

[2001] EWCA Civ 511.

23 On a Mann-Whitney $U$ test, $p=0.035$.

24 The table suggests that non-notified changes may be less common than they were before the reforms, but the numbers are too small for this to be said with conviction.

25 On a Mann-Whitney U test, $\mathrm{p}=0.001$.

26 On a Mann-Whitney $U$ test, $p=0.001$

27 The difference is significant. On a Mann-Whitney $U$ test, $p=<0.001$.

28 Genn (1987) stressed that the threat alone may not be enough. The claimant would need to be prepared to act on the threat. (p.133)

29 The difference is significant only at the 90 per cent level $(p=0.096)$. This suggests that the number of offers has risen, but the finding does not meet normal standards of proof.

30 For a discussion and definition of 'standard fast track' claims, see Chapter 2.1.

31 $\mathrm{p}=0.008$. For a discussion of standard fast track cases, see Chapter 2.1

32 On a Mann-Whitney U test, $\mathrm{p}=0.002$.

33 For a discussion of standard fast track cases, see Chapter 2.1. This analysis is based on 72 pre-Woolf cases and 112 post-Woolf cases. The mean number of communications was 15 pre-Woolf and 17 post-Woolf.

34 On a Pearsons Chi-Square, $p=<0.001$

35 Again, the difference in the proportion of files containing such a threat is significant: $p=0.012$.

36 By focusing on when the claimant received their damages, we removed the delays engendered solely by cost disputes. 
37 From July 1999 to July 2001, the Retail Price Index increased by an average of only 4.1 per cent per year.

When one excludes the $€ 1,815$ paid in success fees across the three cases, the mean decreases to $£ 1,746$. The average increase remains at around 11 per cent.

$39=0.47$ and is significant at the 99 per cent level.

40 We started with the same scale, but added a 'very minor' category of full recovery within three months, which reflected the nature of our sample. In presenting the findings in Table 2.8.2 we have combined the two moderate categories (full recovery within three years, and moderate with persistent problems) to reflect the relatively small number of moderate injuries within the survey. Severe and fatal injuries have been omitted from our definition of a standard fast track case.

41 Claims still outstanding were found to be on average 8.3 years old, with 22 per cent over 10 years old. Some of the claims would have been claims dealt with under the Existing Liabilities Scheme (claims closed since 1 April 1995 for events occurring before that date). The report states that the database does not include reliable information about when claims were actually made or when they were settled. The report therefore estimates the average time from claim to settlement (see Appendix 1 of the Report). See also the NHSLA Report and Accounts 2001 for further statistics on the cost and incidence of claims. Claims managed by the Authority under the CNST rose from 2,411 as at 31 March 2000, to 4,115 as at 31 March 2001.

42 Bolam v. Friern Hospital Management Committee [1957] 1WLR 582

43 Peet v. Mid Kent Healthcare Trust (Court of Appeal, 5.11.01).

44 Housing Disrepair Protocol Working Group (HDPWG), January 2001.

45 Lord Woolf commented: 'Now that I've indicated my views I very much hope that landlords will accept my approach.' (Para. 72)

46 The DETR (Department for Transport, the Environment and the Regions) was reorganised following the 1997 general election into the DLTR (Department for Transport, Local Government and the Regions).

47 Source: Legal Services Commission, personal communication.

48 Legal help and green form claims in 2000 were actually 2 per cent higher than in 1999. The increase in legal help is probably due to a bulge in green form claims as firms switched from green form to legal help contracts.

49 Five of the working group members generally represented tenants, three generally represented landlords, and five were from other organisations such as the Law Society, Legal Services Commission and government departments. Some landlords used outside experts with the facility to call on in-house people for assistance and for ordering any repairs to be done. Another landlord targeted outside experts at cases he thought would litigate: 'I just have to use my, sort of, lawyers' instinct, and if I think it is probably going to go to litigation then I will get an external person rather than use in-house, definitely, yes.' 
Research Study 43 More Civil Justice? The impact of the Woolf reforms on pre-action behaviour

51 [2001] 3 All ER, p. 856.

52 See the Law Society's Gazette, [2001], 7 December. 


\section{View the SRU Publications List a}

\section{www.research.lawsociety.org.uk}

- Trends in the Solicitors' Profession: The Annual Statistical Report 2000 - Summary

- Fact Sheets: The Solicitors' Profession in England and Wales

- Private Practice Solicitors: Salaries 2000 - Data Tables

- Research Study Series: Executive Summaries

- Solicitors' Firms: Business Survey 2001 Findings and Panel Study 1999

- SRU Publications List and Order Form

- Research Links

\section{Strategic Research Unit}

The Law Society

113 Chancery Lane

London WC2A 1PL

Enquiry Line: 02073205623

Fax: 02073165642

\section{EnquiriesSRUalawsociety.org.uk}

